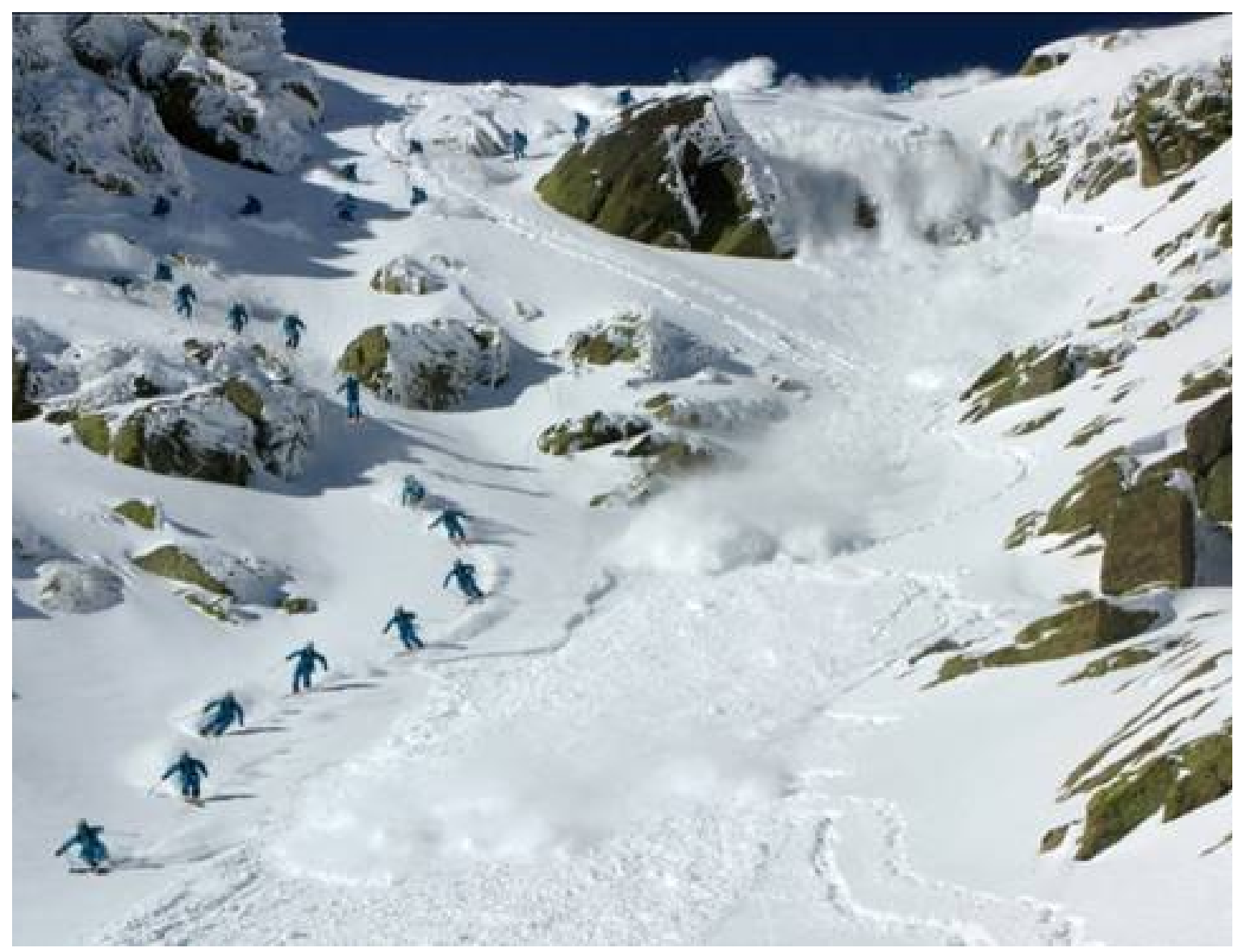

\title{
Guía PARA LA OBSERVACIÓN NiVOMETEOROLÓGICA
}

\section{AGENCIA ESTATAL DE METEOROLOGÍA}

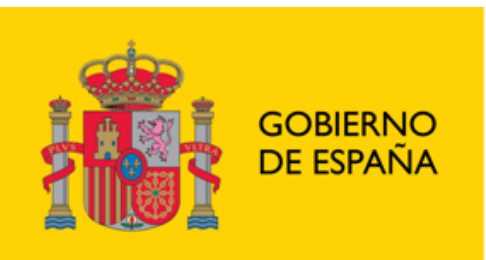

DEAGRICULTURA,ALIMENTACIÓN Y MEDIO AMBIENTE

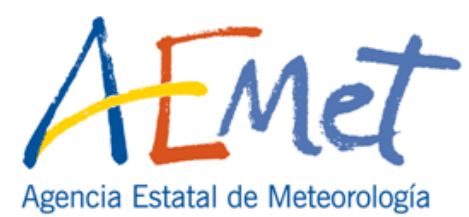




\section{Guía para la Observación Nivometeorológica}

Autores: Gerardo Sanz, Javier Rodríguez, Ramón Pascual, Luis Pantoja, Juan Antonio Fernández-Cañadas, Esther Miquel, José Antonio García-Cabarga.

Fecha: febrero de 2013

Nota: esta guía trata de recoger los procedimientos de observación más actuales, incorporando las novedades, para las que a menudo la documentación está dispersa. Debido a los continuos avances en las técnicas de observación del manto nivoso, sin dar tiempo a veces a que se adopten verdaderos estándares, las actualizaciones no siempre son un proceso inmediato. Por ello, es posible que alguno de los métodos sea diferente a lo establecido en otros documentos, y son bienvenidos los comentarios sobre la forma de hacer las observaciones o sobre novedades que vayan apareciendo. Así, esta primera versión podrá ser actualizada conforme vaya siendo necesario.

\section{Agradecimientos:}

Los autores agradecen las aportaciones recibidas para la elaboración del documento, y reconocen el esfuerzo de todos aquellos que se dedican en la Agencia Estatal de Meteorología a los temas de la nieve y la montaña. Personas como Manolo Abad, que aportaron sus opiniones y sugerencias de redacción, y otros como Samuel Buisán, José Manuel López, Paco Espejo, María Palomo, Amadeo Uriel, Javier Ferraz y José Luis Jiménez, así como los trabajadores de las unidades de predicción, y todos los demás que contribuyen o han contribuido al desarrollo y mantenimiento de las actividades nivometeorológicas, y que es imposible citar en su totalidad.

También, sobre todo, AEMET quiere agradecer el esfuerzo de los colaboradores de las redes de observación en alta montaña, a quienes va especialmente dedicada esta guía.

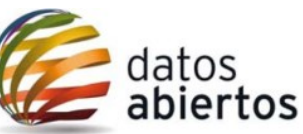

Aviso Legal: los contenidos de esta publicación podrán ser reutilizados, citando la fuente y la fecha, en su caso, de la última actualización

\section{Edita:}

(C) Ministerio de Agricultura, Alimentación y Medio Ambiente Agencia Estatal de Meteorología Madrid, 2013

Catálogo de Publicaciones de la Administración General del Estado: https://cpage.mpr.gob.es

NIPO: 281-13-006-4

https://doi.org/10.31978/281-13-006-4

Agencia Estatal de Meteorología (AEMET)

C/ Leonardo Prieto Castro, 8

28040 Madrid

http://www.aemet.es/

@Aemet_Esp

https://www.facebook.com/AgenciaEstataldeMeteorologia 


\section{Prólogo}

La observación nivometeorológica es uno de los tres pilares que soportan las actividades de diagnóstico y predicción del estado del manto nivoso, probablemente el más importante. Observación tanto de variables específicas del manto nivoso como de las condiciones meteorológicas, que gobiernan la evolución de la nieve en el interior del manto.

La Agencia Estatal de Meteorología mantiene una red de observatorios en zonas con manto nivoso estacional, equipados con material especial, y atendidos en su mayor parte por personas del ámbito de la montaña y la nieve, que cooperan con su esfuerzo diario. Es fundamentalmente para ellos, para los colaboradores de la alta montaña, para quienes se ha elaborado esta primera Guía para la Observación Nivometeorológica de AEMET. Su fin es hacer que el esfuerzo dedicado a la observación sea lo más productivo posible.

La guía es una compilación de los métodos para la recogida y transmisión de datos de observación nivológicos y meteorológicos. En los últimos años se ha asentado el uso de referencias renovadas, como la tabla para catalogar el tamaño de los aludes, con cinco niveles en lugar de los cuatro que se manejaban anteriormente. También, algunas técnicas se han ido modificando, cambiando la forma en que se puntúan o interpretan. Todo ello se ha incorporado a la guía junto con el resto de procedimientos tradicionales de la observación nivometeorológica.

El contenido sigue, durante los tres primeros capítulos, el mismo orden en el que se suelen hacer las cosas en la práctica cuando se elabora un parte NIVOMET, detallando el proceso completo. Comienza por la valoración del 'tiempo presente' y el 'tiempo pasado'. A continuación la toma de medidas, tanto de las variables meteorológicas como de las propias del manto nivoso. Por último, el cifrado del parte mediante el uso de la clave. En los capítulos siguientes se documentan los procedimientos para el resto de observaciones del estado del manto nivoso que se realizan en AEMET: sondeo por golpeo, perfil estratigráfico y tests de estabilidad. En los apéndices, se incluyen ejemplos de impresos para la toma de datos. 
ÍNDICE

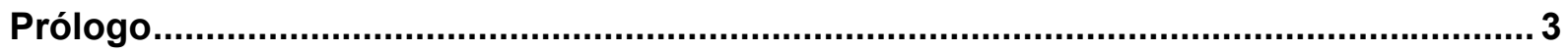

0 Observación meteorológica y nivológica en la estación ........................................... 7

El horario de las observaciones: las horas UTC .................................................... 7

1 Observaciones previas: antes de llegar al jardín meteorológico. Los meteoros..... 7

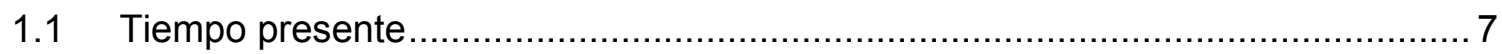

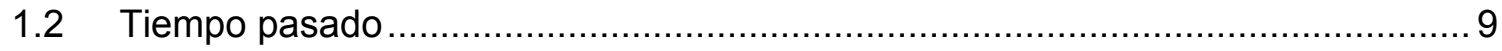

1.2.1 Estimación de meteoros pasados................................................... 9

1.2.2 Altitud máxima del límite lluvia-nieve (cota máxima de lluvia)................ 10

1.3 Viento: medida o estimación ( $1^{\text {a }}$ observación de ventiscas en altitud)................. 11

1.3.1 Efectos del viento sobre el manto nivoso .......................................... 12

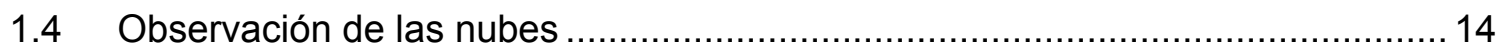

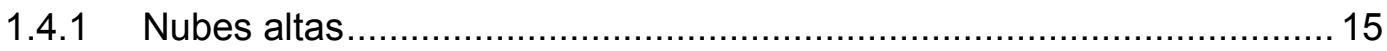

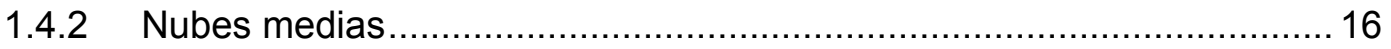

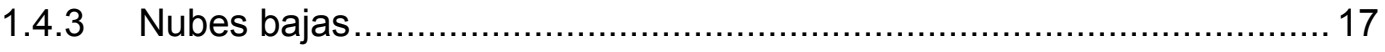

2 Observaciones en el jardín meteorológico ........................................................... 18

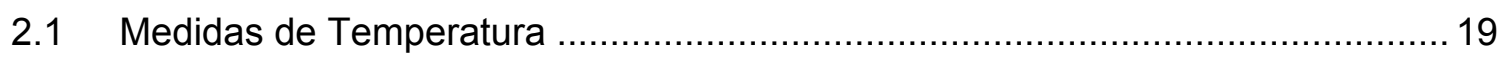

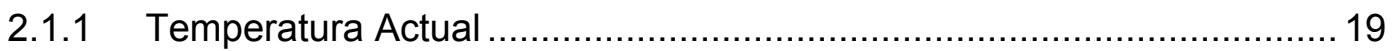

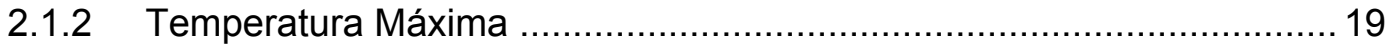

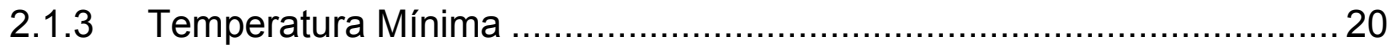

2.1.4 Mantenimiento de los termómetros ...................................................... 20

2.1.5 Medidas con el termómetro Six-Bellani ............................................... 21

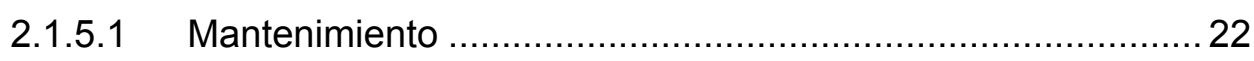

2.1.6 Medidas con el termohigrógrafo …................................................. 22

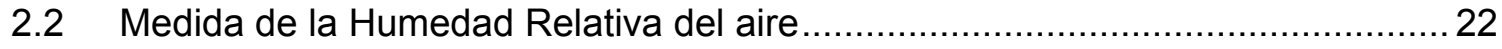

2.2.1 Cambio de la banda de papel del Termohigrógrafo ............................. 23

2.2.1.1 Mantenimiento ........................................................... 23

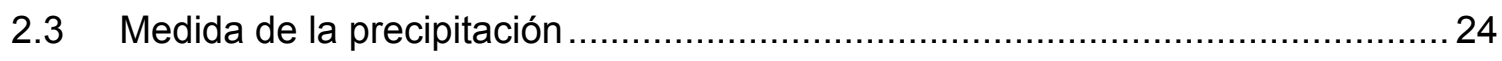

2.3.1 Coherencia con la estimación del tiempo pasado ................................ 25

2.4 Medida del espesor total de nieve y del espesor de nieve reciente .................... 26

2.4.1 Espesor total del manto nivoso...................................................... 26

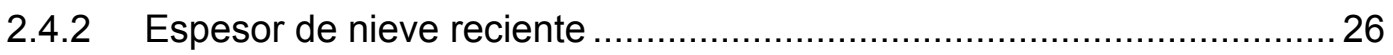

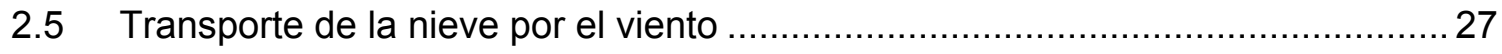

3 Observaciones fuera del jardín meteorológico .................................................... 28

3.1 Medidas del estado del manto nivoso en la zona del observatorio ..................... 28

3.1.1 Estado de la nieve en superficie ................................................... 28

3.1.2 Hundimiento del primer tubo de la sonda de golpeo ............................. 30

3.2 Temperatura de la superficie de la nieve......................................................... 30 


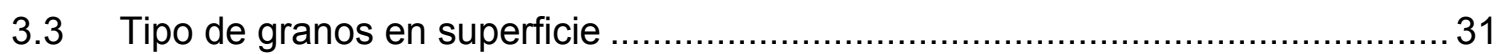

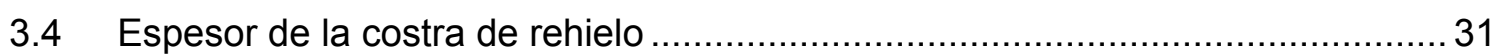

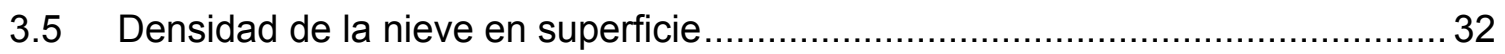

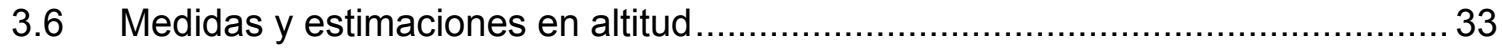

3.6.1 Viento, espesor total y espesor de nieve reciente en altitud ................. 33

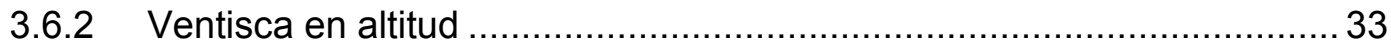

3.7 Observación de aludes y estimación del nivel de peligro local............................. 34

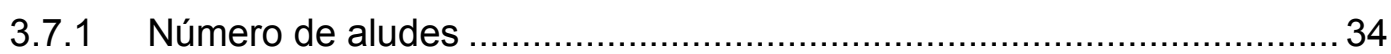

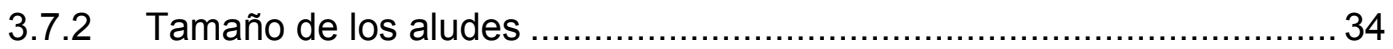

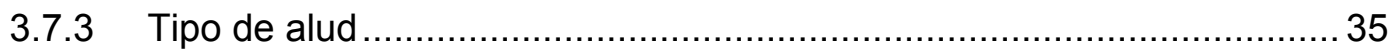

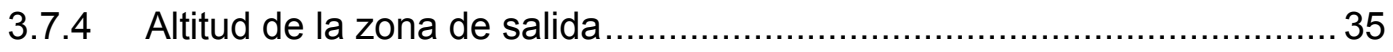

3.7.5 Orientación de la zona de salida ........................................................ 35

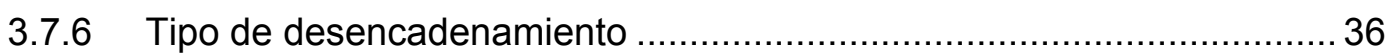

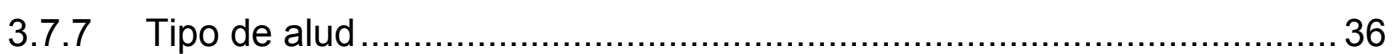

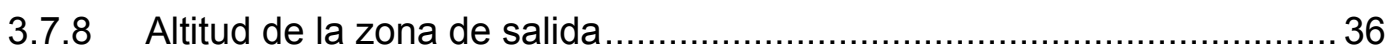

3.7.9 Exposición de la zona de salida ........................................................ 36

3.7.10 Estimación del nivel de peligro local..................................................... 36

3.8 CIFRADO DE LAS OBSERVACIONES. LA CLAVE NIVOMET ......................... 41

3.8.1 Secciones, grupos y cifrado de las observaciones............................... 41

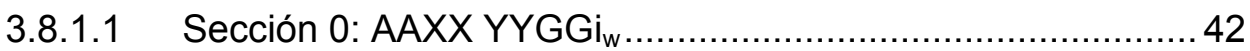

3.8.1.2 Sección 1: Iliii $i_{R} i_{x} h / /$ Nddff 1SnTTT 29UUU $7 w w W_{1} W_{2}$

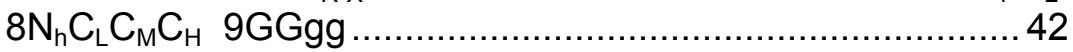

3.8.1.3 Sección 3: $333\left(1 \mathrm{~S}_{n} \mathrm{~T}_{x} \mathrm{~T}_{x} \mathrm{~T}_{x} 2 \mathrm{~S}_{n} \mathrm{~T}_{n} \mathrm{~T}_{n} \mathrm{~T}_{n}\right)$ 4/sss $\left(7 \mathrm{R}_{24} \mathrm{R}_{24} \mathrm{R}_{24} \mathrm{R}_{24}\right)$ $907 t t$ 931s's' ................................................................ 48

3.8.1.4 Sección 5: $555 \quad 7 \mathrm{I}_{z} Z_{x} Z_{x} Z_{x} \quad 8 I_{t} d_{t} q_{t} q_{t} \quad 1 S_{n} T_{s} T_{s} T_{s} \quad E_{n}^{\prime} P_{s} P_{s} N_{v} C_{n}$ $L^{\prime}{ }_{1} L^{\prime}{ }_{2} L^{\prime}{ }_{3} L^{\prime} L^{\prime}{ }^{\prime} \quad L_{6} L_{7} L_{8} L_{9} L_{5} \quad$ (2ddff $\quad$ ssss's') $\left(4 F_{1} F_{2} e_{c} e_{c}\right)$ $\left(5 I M_{v} M_{v} M_{v}\right)$ 50

4 Observaciones del manto nivoso en terreno representativo cercano a la estación: sondeo por golpeo y perfil estratigráfico, test de estabilidad ................................. 58

4.1 Sondeo por golpeo y perfil estratigráfico del manto nivoso ................................. 58

4.1.1 Criterios de elección del emplazamiento .........................................5 58

4.1.2 Datos topográficos, meteorológicos y temporales..............................59

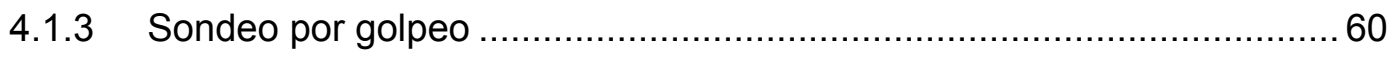

4.1.3.1 Sondeo previo del espesor total del manto con la sonda fina 60

4.1.3.2 Ubicación de los observadores............................................... 60

4.1.3.3 Sonda de golpeo y hoja de anotación para medidas de resistencia ...................................................................... 60

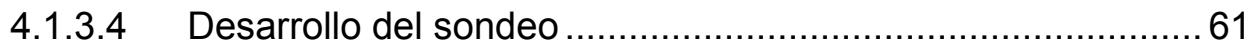

4.1.4 Perfil estratigráfico o cata de nieve.................................................. 66

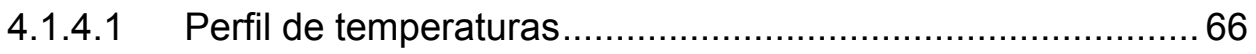


4.1.4.2 Análisis de las capas del manto nivoso ..............................67 67

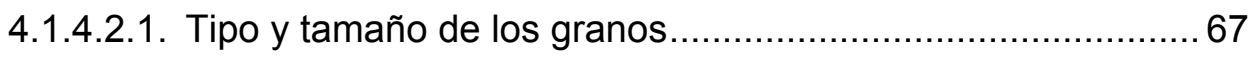

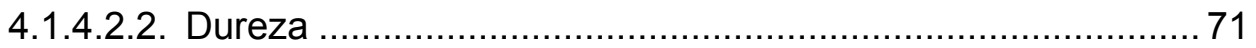

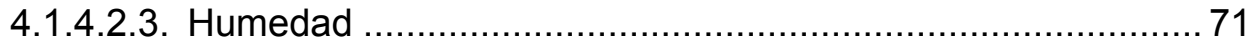

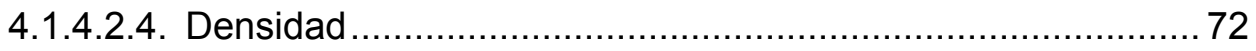

4.1.4.2.5. Evolución de la nieve en el manto nivoso ............................. 72

4.1.4.3 Cálculos y elaboración del informe del sondeo ...................75

4.1.4.3.1. Cálculos y gráfica de resistencia ..................................... 75

4.1.4.3.2. Gráfica de temperaturas ................................................ 77

4.1.4.3.3. Tabla del perfil estratigráfico .......................................... 77

4.1.4.3.4. Análisis e informe ........................................................ 78

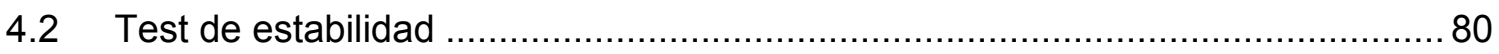

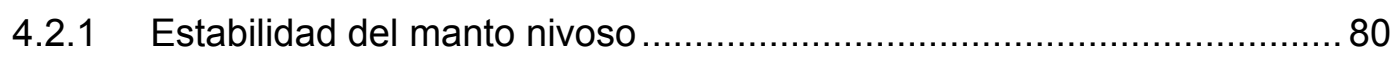

4.2.2 Elección del emplazamiento y principios básicos de los tests................ 81

4.2.2.1 Calidad de la superficie de ruptura .................................... 82

4.2.2.2 Cifrado del resultado de los test de estabilidad ................... 83

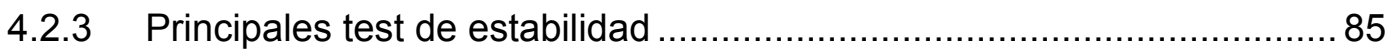

4.2.3.1 Test de la Pala -test Noruego o de Faarlund- (ST) ............... 86

4.2.3.2 Test de Compresión (CT) ............................................ 88

4.2.3.3 Test de la Columna Extendida (ECT) ............................. 90

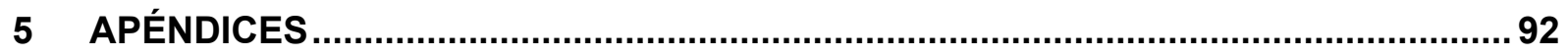

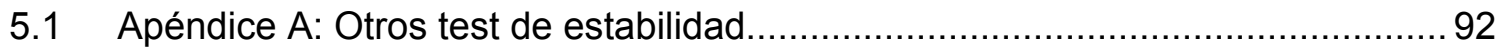

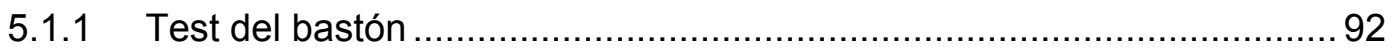

5.1.2 Test de la pala inclinada (Shovel Tilt Test) ....................................... 92

5.1.3 Tests de la pendiente con esquís ................................................... 92

5.1.4 Test Rutschblock o del bloque deslizante (RB) ............................... 93

5.1.5 Test de Stuffblock o del peso (SB) ................................................. 95

5.1.6 Test de la cuña deslizante (Rutschkiel test) ...................................... 96

5.1.7 Test de la propagación de la sierra (PST) ..................................... 97

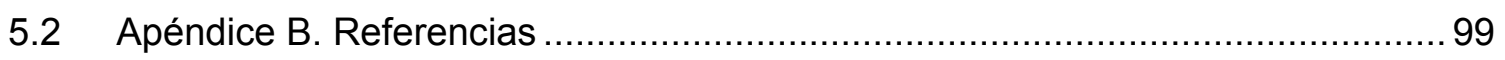

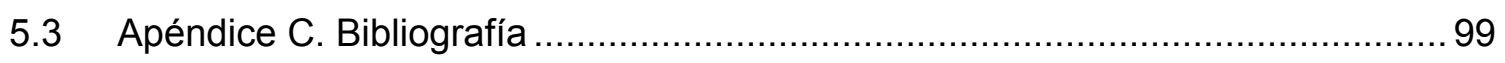

5.4 Apéndice D: Impresos para toma de datos. ............................................... 101

5.4.1 Hoja de toma de datos para test de estabilidad ................................ 101

5.4.2 Hoja de toma de datos para perfil estratigráfico ................................. 102

5.4.3 Hoja de toma de datos para sondeo por golpeo................................. 103

5.4.4 Hoja para gráfico de sondeo y perfil estratigráfico .............................. 104

5.5 Apéndice E: Síntesis de la clave NIVOMET .................................................. 104 


\section{Observación meteorológica y nivológica en la estación}

Un observatorio meteorológico es el lugar destinado a realizar observaciones. Para ello, dispone de instrumental específico que varía según las diferentes variables que se midan. El observatorio más básico únicamente consta de un pluviómetro con el que se obtiene el valor de la precipitación.

A la precipitación, y sin necesidad de más instrumental, se puede añadir el "tiempo presente" y el "tiempo pasado". Bajo la denominación "tiempo presente" se incluyen todos los fenómenos meteorológicos que apreciamos en el momento de la observación como la nubosidad, la visibilidad, los meteoros (lluvia, nieve, granizo, escarcha,..). El "tiempo pasado" se refiere a los fenómenos ocurridos desde la última observación.

Muchos observatorios disponen también de termómetros de máxima y de mínima, con los que podemos medir las temperaturas extremas en periodos de 12 o 24 horas, y otros tienen también el par "termómetro seco" y "termómetro húmedo", que nos permite medir la temperatura en el momento de la observación y calcular la humedad del aire a partir de la diferencia entre las temperaturas indicadas por ambos termómetros. La humedad también puede medirse directamente mediante un higrómetro.

El viento es otra variable a registrar y su velocidad se mide con el anemómetro. En caso de no disponer de él, se puede estimar según los efectos que provoca. En observatorios más completos también se miden las horas de sol, la radiación solar, las temperaturas de subsuelo a diferentes niveles de profundidad, la evaporación y otras variables más.

En el caso que nos ocupa, a las observaciones meteorológicas añadiremos las observaciones nivológicas, con las que obtendremos información del estado y las características del manto nivoso.

\section{EI horario de las observaciones: las horas UTC}

Las observaciones meteorológicas se realizan en todo el mundo respecto de un horario estándar. Para ello, por convención se usa un reloj de 24 horas basado en el meridiano de longitud $0^{\circ}$. A este horario se le denomina 'Tiempo Universal Coordinado', o UTC por sus siglas en inglés, y con él la hora es la misma en todos los puntos del planeta. En ocasiones, por persistir la costumbre del uso del alfabeto radiofónico, a las horas UTC se las llama "horas Z" u "horas Zulú".

En la España peninsular y en Baleares, las horas UTC son una hora menos que la hora local en invierno y dos horas menos que la hora local en verano. Así, las 08 UTC son las 09 horas locales en invierno y las 10 horas locales en verano.

\section{Observaciones previas: antes de llegar al jardín meteorológico. Los meteoros.}

\subsection{Tiempo presente}

Es la descripción de los meteoros que tienen lugar en el momento de la observación, entendiendo como tal los diez minutos previos a la hora del parte. Es decir, en una observación que realicemos para el parte NIVOMET de las 08Z, son los meteoros que observemos que están presentes entre las $07.50 Z$ y las $08 Z$.

Para los meteorólogos, un meteoro es un fenómeno, distinto de una nube, que sucede en el seno de la atmósfera o sobre la superficie terrestre. En la observación nivometeorológica se tienen en cuenta los siguientes meteoros: 
Niebla: es la suspensión en la atmósfera de gotas muy pequeñas de agua que reducen la visibilidad horizontal a menos de un kilómetro (gotitas casi microscópicas que flotan en el aire). Debemos distinguir el meteoro niebla de aquello que la provoca, que será en general una nube tipo estrato o similar, pegada al terreno. Las nubes no son meteoros y tienen su propio grupo de cifrado.

La visibilidad es la menor distancia a la cual se dejan de identificar a simple vista, cuando hay suficiente luz ambiental, puntos fijos del paisaje: casas, árboles, picos, etc. En caso de ausencia de luz la visibilidad es aquella que habría si hubiese suficiente luz ambiental. En general se habla de buena visibilidad cuando ésta es mayor de diez kilómetros, y de visibilidad regular, de neblina, de bruma o de calima, cuando está entre uno y diez kilómetros.

Es bastante habitual que la visibilidad sea distinta según la dirección en la que se mire. Cuando esto sucede se toma como valor de la visibilidad la distancia más corta. Por ejemplo: se distinguen los objetos del paisaje hasta $15 \mathrm{Km}$ en todas las direcciones salvo hacia el Este, que sólo se distingue hasta $8 \mathrm{Km}$; en este caso la visibilidad es de $8 \mathrm{Km}$. Para facilitar la estimación, es útil hacer una relación de elementos del paisaje y un mapa de referencias de visibilidad por sectores centrados en el punto de observación.

La visibilidad puede reducirse por causas distintas de la niebla, frecuentemente por estar lloviendo o nevando. En ese caso, el meteoro a cifrar será la lluvia o la nieve, no la niebla.

Si ha habido precipitación podremos distinguir la intensidad de ésta diferenciando entre débil, moderada o fuerte (ver la explicación en el apartado 2.3, de medida de la precipitación). También podemos diferenciar su carácter (intermitente o continua). Cuando la precipitación se caracteriza por comenzar y terminar bruscamente y dura poco tiempo (menos de 10 minutos) hablamos de chubascos, que pueden ser de lluvia, nieve o granizo, y son producidos por nubes de desarrollo vertical como grandes cumulus o cumulonimbus.

Cuando la temperatura es mayor de $0{ }^{\circ} \mathrm{C}$ la precipitación suele caer en forma de gotas de agua líquida, esto es la Iluvia. Con temperaturas bajo cero tendremos en general nieve, aunque a veces puede llegar a nevar con temperaturas positivas de hasta 4 ó $5^{\circ} \mathrm{C}$ y también puede ocurrir que precipite agua líquida con temperatura menor de $0{ }^{\circ} \mathrm{C}$ (Iluvia engelante), en este último caso, la lluvia en contacto con el suelo se congela y se forma hielo liso (engelamiento).

La llovizna se diferencia de la lluvia en que el tamaño de las gotas es más pequeño, (diámetro menor de $0,5 \mathrm{~mm}$ ). Suele caer suavemente, nunca en forma de chubasco, en días de niebla o de nubosidad muy baja (stratus) y reduce mucho la visibilidad.

La nieve es una precipitación sólida formada por cristales hexagonales en forma de estrella, agujas, plaquetas o columnas. Que tenga una forma u otra depende fundamentalmente de la temperatura. Cuando aparece mezclada con agua lo llamaremos aguanieve.

La nieve granulada la forman partículas de hielo blanco y opaco que se pueden aplastar con los dedos, de formas redondeadas con el aspecto de bolas de poliespan. Su diámetro puede alcanzar los $5 \mathrm{~mm}$.

La cellisca es una precipitación de partículas de hielo traslúcido y esférico, de diámetro inferior a 5 $\mathrm{mm}$. Constituyen un estado intermedio entre la nieve granulada y el granizo. Se diferencia de la nieve granulada en que ésta es blanca y algo rugosa, mientras la cellisca es lisa y traslúcida, y del granizo por su menor tamaño.

El granizo es un grano de hielo, normalmente transparente, cuyo diámetro varía desde los 5 hasta los $50 \mathrm{~mm}$ (cuando los gránulos son grandes se suele denominar pedrisco). Se produce siempre en forma de chubascos, habitualmente durante fuertes tormentas y en los meses más cálidos. 
La tormenta se cifra cuando se oye algún trueno en el lugar de observación. Las tormentas suelen ir acompañadas de precipitación en forma de chubasco de lluvia y/o granizo, a veces también de nieve. Las únicas nubes capaces de generar tormentas son los cumulonimbus. El trueno es la consecuencia acústica del rayo, que, a su vez, no es sino una descarga eléctrica brusca en el seno de la atmósfera. La descarga puede producirse entre la nube y la tierra, entre dos niveles diferentes dentro de una misma nube o entre dos nubes distintas.

Veamos ahora meteoros o fenómenos que no proceden de las nubes sino que se depositan sobre los objetos de la superficie.

Si la noche anterior fue fría, con el viento flojo o en calma y el cielo permaneció despejado es muy posible que encontremos escarcha en superficie. Sobre el manto nivoso la escarcha adquiere forma de pluma y alcanza un tamaño mayor que sobre superficies no nevadas llegando a dimensiones de varios centímetros. En zonas de umbría puede permanecer sobre el manto nivoso y podremos identificarla.

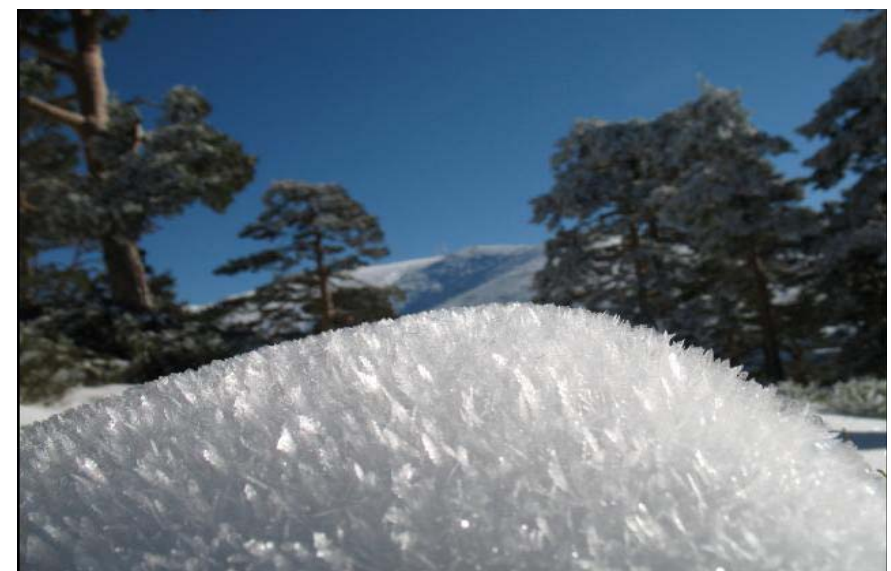

Fig. 1 Escarcha sobre el manto nivoso.

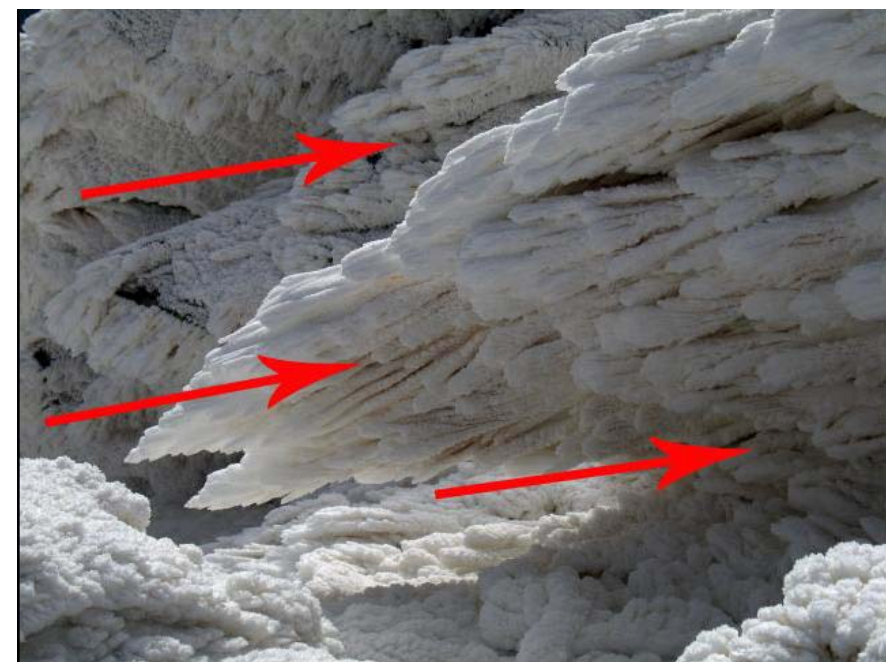

Fig. 2 Cencellada.

Otro tipo de depósito es la cencellada. Aparece con niebla y temperaturas menores de $0{ }^{\circ} \mathrm{C}$, cuando debido a la congelación de las gotitas de agua contenidas en la niebla se forma un depósito frágil de finas agujas de hielo (cencellada blanda). Si además tenemos viento moderado o fuerte, entonces la cencellada (cencellada blanca) adquiere forma de láminas de hielo blanco y se adhiere a superficies como las ramas de los árboles, las rocas o los cables, siempre a barlovento del viento dominante, pudiendo alcanzar un tamaño importante, de varios centímetros.

\subsection{Tiempo pasado}

\subsubsection{Estimación de meteoros pasados}

Junto con las estimaciones del momento de la observación, es necesario aportar también información de cómo ha sido el tiempo en las horas precedentes, desde la última observación, en general en el caso de la montaña las últimas 24 horas. Por ello, en la medida de lo posible, debemos fijarnos en si se da alguno de los meteoros concretos que se tienen en cuenta en la observación nivometeorológica: ventisca, niebla, precipitaciones, y tormenta. 


\subsubsection{Altitud máxima del límite lluvia-nieve (cota máxima de lluvia)}

Debido a la variación de la temperatura con la altitud, la precipitación puede tener forma de lluvia en unos niveles y forma de nieve en otros más altos. Importa entonces poder estimar con la mejor aproximación posible la altitud del límite lluvia-nieve. El límite lluvia-nieve es la altitud máxima en la que podemos apreciar señales de que la precipitación no fue en forma de nieve en su totalidad, o dicho de otra forma, la altitud máxima a la que ascendió la lluvia.

La precipitación de nieve deja una señal muy evidente blanqueando el terreno o aumentando el espesor del manto existente. La lluvia, en ocasiones, no nos ofrece señales tan claras, pero sí podemos observar si ha disminuido el espesor del manto de nieve y la presencia de surcos de percolación, que son una especie de pequeños canales que forma la escorrentía del agua líquida en el manto nivoso.

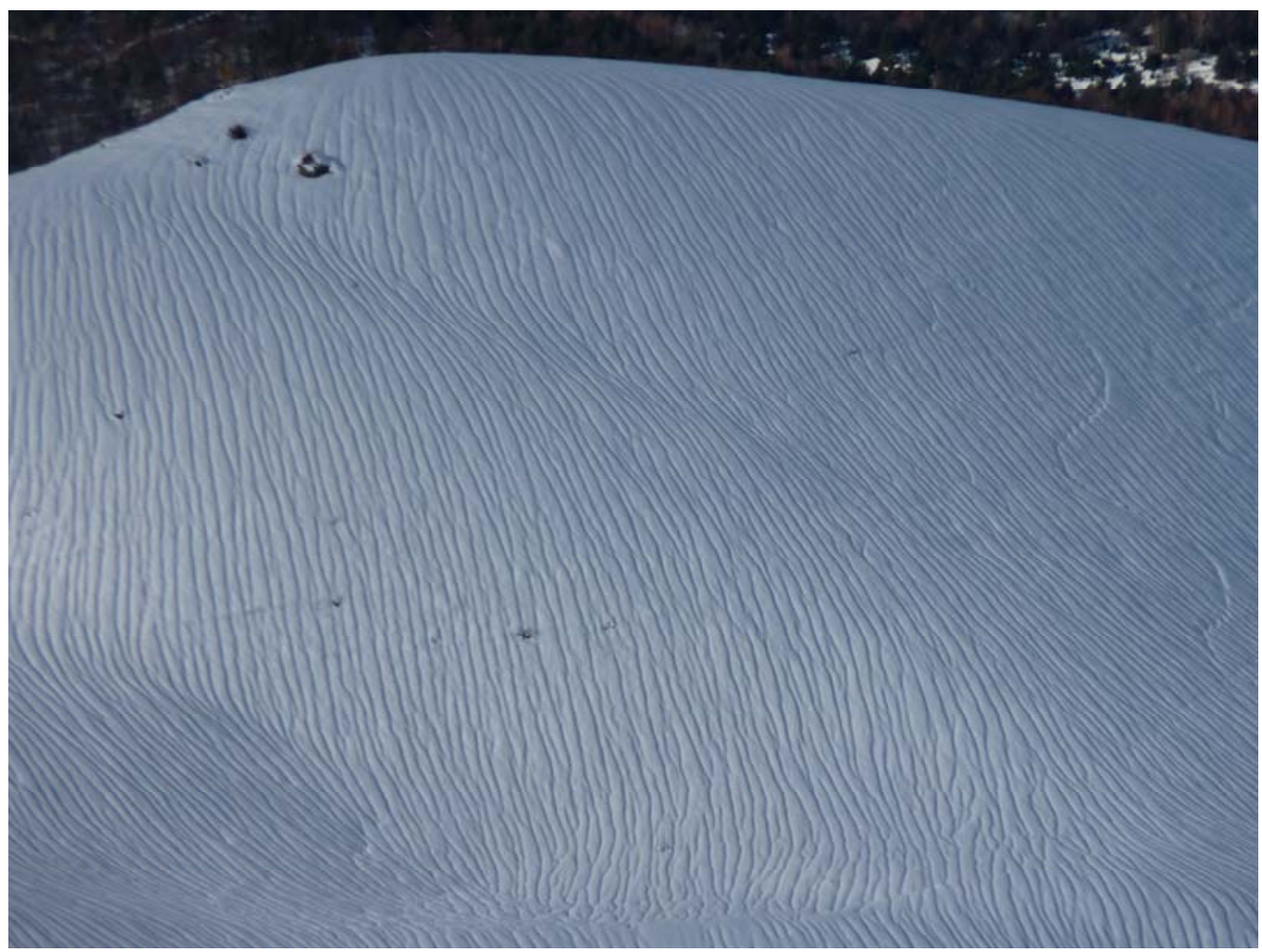

Fig. 3 Surcos de percolación en Panticosa, tras lluvias copiosas

Para la estimación de las condiciones en las que se encuentra el manto nivoso es muy importante conocer si sobre él ha llovido. Si se sabe, por haberlo observado o por tener una referencia fiable, se cifrará la máxima altura a la que ha llegado a producirse precipitación en forma líquida, la máxima altitud que ha alcanzado la cota de nieve.

Si únicamente se conoce lo que ha sucedido en el observatorio, la referencia será la propia altitud de éste. En caso de que en el observatorio únicamente haya nevado, sin llover en ningún momento, la altitud máxima del límite lluvia-nieve estará 'por debajo' de la altitud del observatorio. En caso de que en el observatorio haya llovido (haya nevado o no) en algún momento en las últimas 24 horas, la altitud máxima del límite lluvia-nieve estará 'por encima' de la altitud del observatorio. 


\subsection{Viento: medida o estimación ( $1^{\text {a }}$ observación de ventiscas en altitud)}

El viento queda definido por su dirección y por su velocidad o fuerza. La dirección es aquélla de donde viene el viento. Se expresa en grados con relación al norte geográfico o en "lenguaje claro". Por ejemplo: $90^{\circ}$ equivale a Este $(\mathrm{E}), 360^{\circ}$ o lo que es lo mismo $0^{\circ}$ equivale a Norte $(\mathrm{N})$.

La dirección del viento se determina con la veleta; es la dirección hacia donde apunta la flecha. Si la veleta señala el norte, tendremos un viento de componente norte. A falta de veleta las ramas de los árboles, una bandera o un penacho de humo nos muestran la dirección del viento.

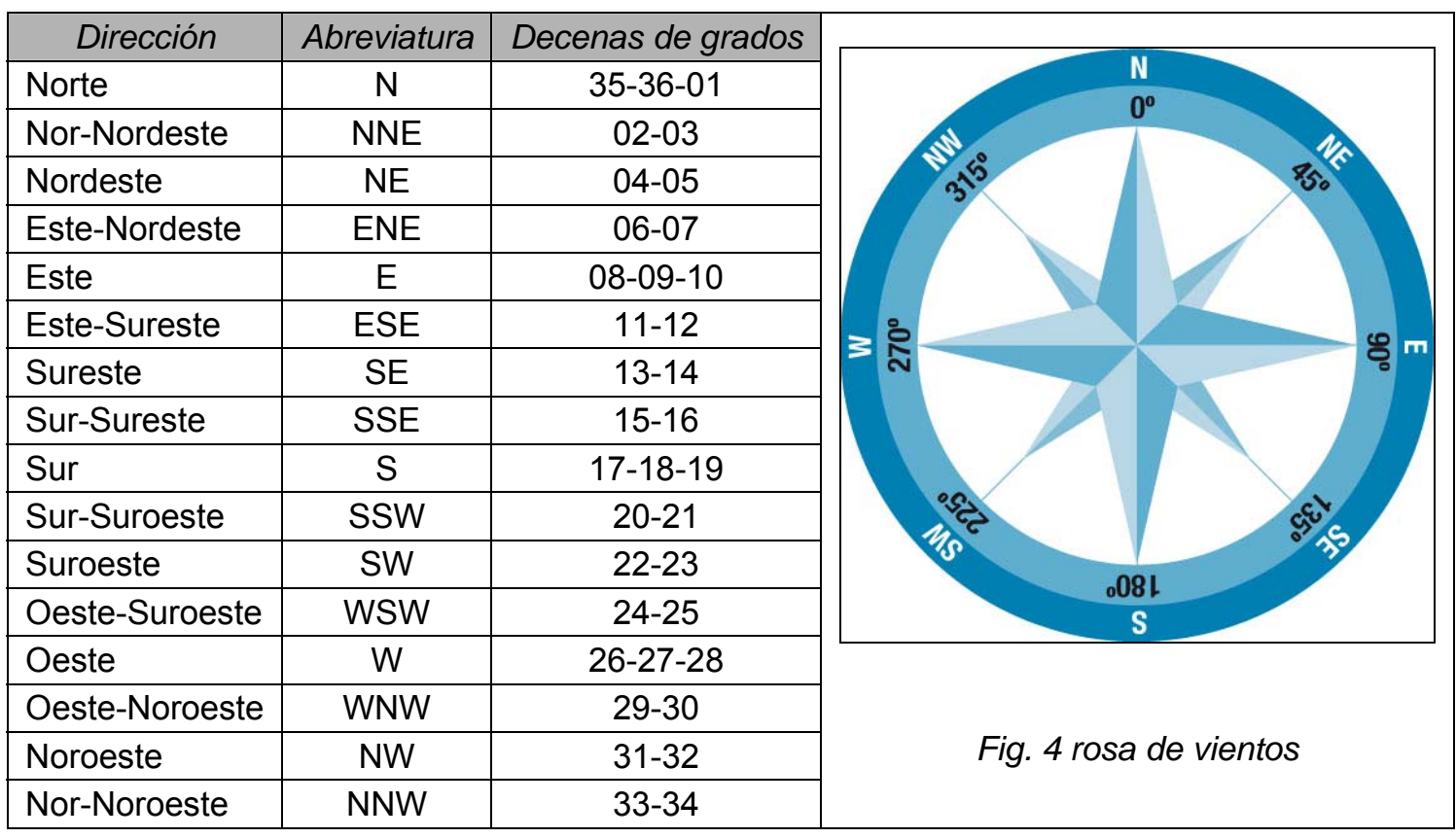

La velocidad o fuerza del viento se expresa en nudos $(k t)$, metros por segundo $(\mathrm{m} / \mathrm{s})$ o kilómetros por hora $(\mathrm{Km} / \mathrm{h})$, la equivalencia aproximada entre estas unidades es la siguiente:

$$
1 \mathrm{kt} \cong 0,5 \mathrm{~m} / \mathrm{s} \cong 2 \mathrm{Km} / \mathrm{h}
$$

La velocidad del viento se mide con el anemómetro, pero si el observatorio no dispone de él, se puede estimar mediante los siguientes criterios:

\begin{tabular}{|c|l|}
\hline $\begin{array}{c}\text { Cifrado } \\
(\mathrm{m} / \mathrm{s})\end{array}$ & \multicolumn{1}{c|}{ Descripción } \\
\hline 00 & Calma, no hay viento, el humo se eleva verticalmente \\
\hline 02 & Las banderas y las hojas de los árboles se mueven \\
\hline 07 & Las banderas ondean y, las ramas más finas se mueven \\
\hline 14 & Las ramas gruesas se agitan, los hilos telefónicos silban, el uso del paraguas se hace difícil \\
\hline 20 & Cuesta andar contra el viento, el viento rompe las ramas más débiles \\
\hline 30 & Temporal, daños importantes \\
\hline
\end{tabular}

En la montaña, tanto la dirección como la velocidad del viento se ven muy influenciadas por la topografía. La forma y disposición de crestas y valles de los montes hacen que pueda soplar el viento con dirección y velocidad muy diferentes a los de la corriente general.

Cuando se dispone de anemómetro, en la observación NIVOMET la fuerza del viento se cifra en metros por segundo $(\mathrm{m} / \mathrm{s})$. 


\subsubsection{Efectos del viento sobre el manto nivoso}

Los efectos del viento sobre el manto nivoso se pueden manifestar durante y después de las nevadas. Un viento suficientemente fuerte puede arrancar los granos de la superficie del manto nivoso y transportarlos a una cierta altura dando lugar a la ventisca. La ventisca puede darse en nuestra zona de observación (ventisca en la estación) reduciendo, en ocasiones muy notablemente, la visibilidad, y provocando acumulaciones de nieve (ventisqueros), principalmente a sotavento del relieve. Por ejemplo, con viento dominante de componente norte (ventisca del norte) encontraríamos acumulaciones de nieve principalmente en orientaciones sur.

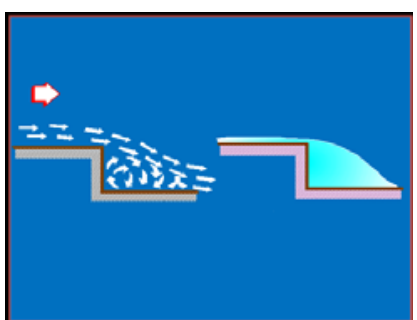

Fig. 5 Formación de ventisquero a sotavento.

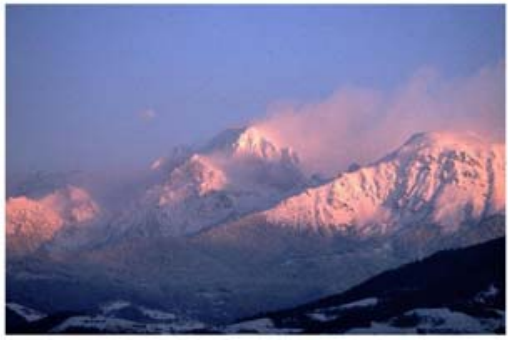

Fig. 6 Ventisca en altitud

Puede ocurrir que no tengamos ventisca en nuestra estación, pero que sí la observemos sobre las cumbres de las montañas cercanas (ventisca en altitud). Ésta es fácilmente reconocible porque da a las zonas más altas el aspecto de "montaña humeante". La dirección en la que se mueve la nieve que forma la ventisca es la misma que la dirección con la que sopla el viento dominante.

Podemos observar también los efectos que el viento provoca en la formación de cornisas, dunas, sastrugis y placas de viento.

Las dunas son acumulaciones de nieve de formas suaves, regulares y uniformes. La rampa suave y ascendente de la duna (zona de erosión), nos indica la dirección de donde viene el viento (barlovento), y el escalón más brusco es la zona de acumulación (sotavento).

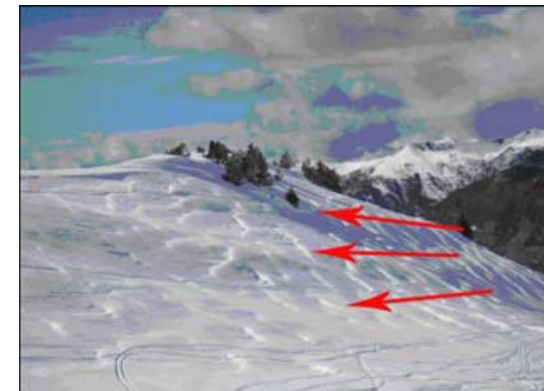

Fig. 7 Dunas

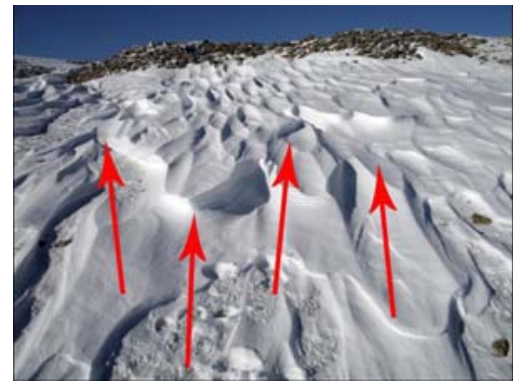

Los sastrugis son formas angulosas e irregulares a modo de capas, producidas por fenómenos de erosión del manto nivoso debidas al viento. En este caso y a diferencia de las dunas, la parte abrupta corresponde a la zona expuesta al viento, es decir a barlovento, y la parte uniforme a la zona de sotavento. En ocasiones esta erosión llega a producir formaciones huecas e incómodas para andar por ellas, que se fracturan a nuestro paso.

Fig. 8 Sastrugis

Las cornisas son acumulaciones de nieve, a veces de gran tamaño, que se forman sobre las crestas de las montañas. Las partículas de nieve son transportadas pendiente arriba, en la dirección del viento dominante y se fijan entre sí en la cumbre, formando acumulaciones extraplomadas en la vertiente opuesta. Como en el caso de las dunas y los ventisqueros, se produce erosión a barlovento y acumulación a sotavento.

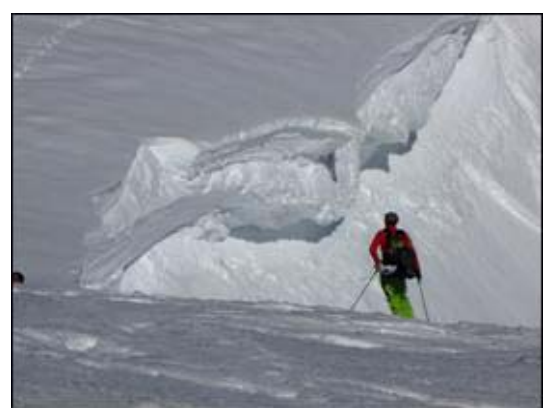

Fig. 9 Cornisa 
A sotavento de una cornisa, donde se ha producido acumulación de la nieve transportada por el viento, es muy fácil que encontremos placas de viento.

El viento hace que las partículas de nieve transportadas, al chocar entre ellas y quedar depositadas en su nuevo emplazamiento, se suelden entre sí, formando un conjunto rígido pero poco plástico, frágil y capaz de propagar fracturas, de una manera similar a como lo hace el vidrio. A la cohesión que presenta la nieve en estos casos se le llama cohesión de sinterización y, es típica de los cristales de nieve del tipo 'granos finos'. Los tipos de cristales de nieve, su cohesión y su evolución en el interior del manto se detallan más adelante, en el punto de la evolución de la nieve en el manto nivoso.

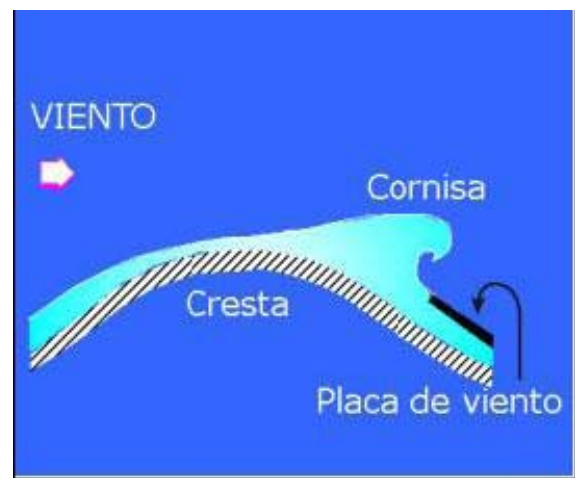

Fig. 10 Formación de placas de viento a sotavento de una cornisa

Para que se formen placas de viento no es necesario que éste sea muy fuerte. Con vientos moderados o incluso débiles, los cristales de nieve reciente ven favorecida su cohesión por sinterización y dan lugar a placas denominadas 'friables', desmenuzables. Vientos moderados y fuertes rompen más los granos de nieve, quedando básicamente 'granos finos' que al ser más pequeños se cohesionan en bloques más compactos, dando lugar a placas 'duras'. Cuando el viento es muy fuerte, su eficacia para formar placas disminuye, ya que la nieve se levanta lejos del suelo en remolinos turbulentos y tiende a sublimarse directamente en el aire ambiente.

En el caso de las placas friables la cohesión por sinterización es débil. El flujo del alud se vuelve pulverulento (de ahí el término friable). Por ello los aludes de placa friable a menudo se encuadran entre los de nieve reciente pese a que se inicien con fracturas lineales. La nieve en las placas friables es más bien blanda, hundiéndose en ella fácilmente un bastón de esquí, poco densa (menos de 200 $\mathrm{Kg} / \mathrm{m}^{3}$ ), y poco resistente a la penetración y a la cizalladura. Es agradable de esquiar ya que la nieve está poco apelmazada y parece nieve polvo, pero puede ser peligrosa por la posibilidad de existencia de estructuras de placa (una placa sobre una capa de débil cohesión). Una nieve con estas características puede originarse asimismo por metamorfosis de gradiente débil después de la precipitación, y también en nevadas de gran intensidad, en las que son muy numerosos los contactos entre los granos de nieve, favoreciéndose así una cohesión parcial de sinterización.

En el caso de las placas duras la cohesión es mayor. Están formadas muy mayoritariamente por granos finos y son compactas. Su densidad es bastante elevada, de 2 a 4 veces mayor que la de la nieve no venteada, entre 200 y $400 \mathrm{Kg} / \mathrm{m}^{3}$. Se forman la mayoría de las veces bajo la acción del viento moderado o fuerte.

Las placas se localizan con dificultad, sobre todo si una capa de nieve reciente las cubre. En ocasiones las placas duras se pueden distinguir del resto de la nieve que las rodea por el aspecto mate de su superficie, su color lechoso, y el hecho de que el esquí desliza mal sobre la nieve dejando tan sólo una débil huella.

Podemos esperar que se formen placas de viento cuando se ha producido una nevada fría, seca y con presencia de viento, o después de una ventisca acompañada o no de precipitación de nieve. Igualmente, cuando observemos cornisas, sastrugis o dunas, debemos esperar la presencia de placas de viento. 


\subsection{Observación de las nubes}

Cuando el vapor de agua (no visible) que contiene la atmósfera, se transforma en gotitas (condensación) o se congela (sublimación), se hace visible formando una nube. Por lo tanto una nube es un conjunto de gotitas de agua y/o cristales de hielo que se hacen visibles y permanecen suspendidos en el aire. La saturación se puede producir bien porque aumente la cantidad de vapor de agua o bien porque descienda la temperatura. La cantidad de vapor de agua que puede contener una masa de aire sin alcanzar la saturación depende de la temperatura, cuanto mayor sea ésta, más vapor de agua puede contener una masa de aire sin saturarse.

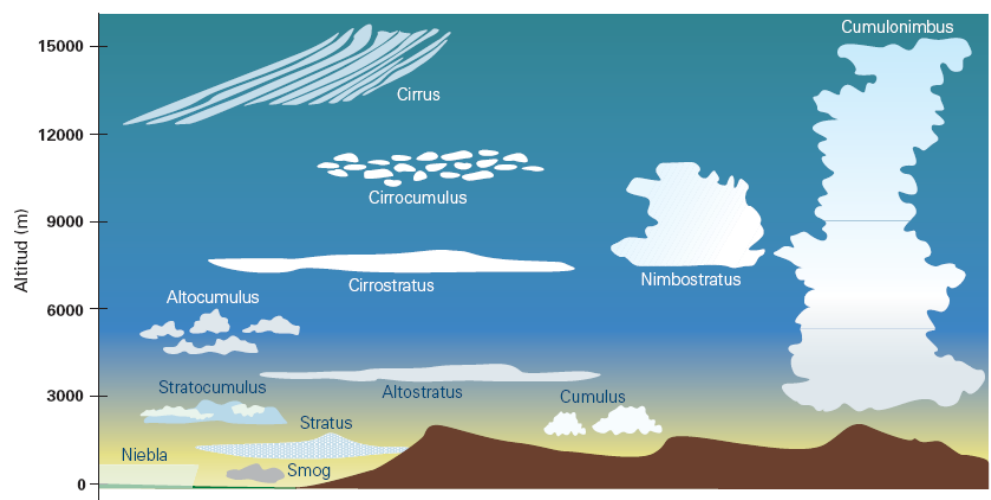

Fig. 11 Los diferentes géneros de nubes

Para medir la cantidad de nubosidad de un género de nubes lo que hacemos es estimar la superficie visual del cielo oculto por dichas nubes. Para ello, dividimos el cielo en ocho sectores $u$ octas y evaluamos el número de sectores que podrían estar ocupados por las nubes si las agrupásemos todas en un bloque.

La nubosidad total se refiere al conjunto de todas las nubes que vemos en el cielo, sin hacer distinción entre los diferentes géneros. La mayoría de las veces no coincidirá con la suma de las nubosidades de los diferentes géneros. Por ejemplo podemos tener $6 / 8$ de Cirrus y $4 / 8$ de altocumulus, siendo la nubosidad total de $6 / 8$ al estar los altocumulus situados por debajo de los cirrus y apreciarse continuidad en la capa superior.

Un dato importante referente a la nubosidad es la altura sobre el terreno de las nubes más bajas por encima de la estación. Se trata de localizar las nubes más bajas y tomando como referencia los montes cercanos estimar la altura a la que se encuentran con respecto a la altitud del observatorio.

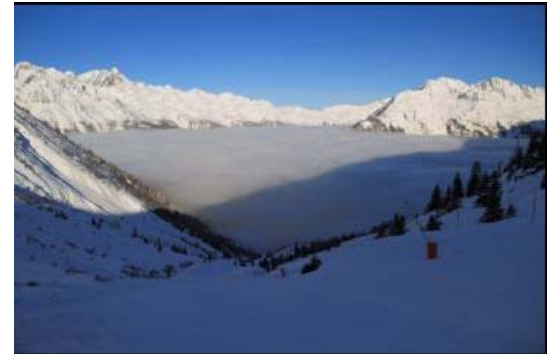

Fig. 12 Stratus (St) formando un mar de nubes en el valle
También se debe realizar y cifrar la observación de nubes en el valle. Es relativamente habitual que en observatorios de montaña encontremos nubes cuyas cimas estén por debajo del observatorio. Estas nubes suelen ser stratus, y podemos estimar su altitud (en este caso no será altura) a partir del conocimiento de la orografía del lugar o estimando la diferencia de cota respecto de la altitud del observatorio. Pueden aparecer de manera aislada o bien pueden formar un mar de nubes ocultando los valles de manera parcial o total.

Existen diez géneros de nubes que permiten otras subdivisiones en especies y variedades. Estos diez géneros los podemos repartir, según la altura de la base, en 3 pisos de nubes. Nubes altas, nubes medias y nubes bajas. 


\subsubsection{Nubes altas}

Sus bases están situadas a más de $7 \mathrm{Km}$ de altura, pudiendo llegar hasta los $14 \mathrm{Km}$. No originan precipitación. Pueden ser de tres géneros:

\section{Cirrus (Ci)}

Tienen forma de filamentos blancos y delicados, con aspecto fibroso o con brillo sedoso. Suelen ser delgadas. Pueden constituir bancos densos.

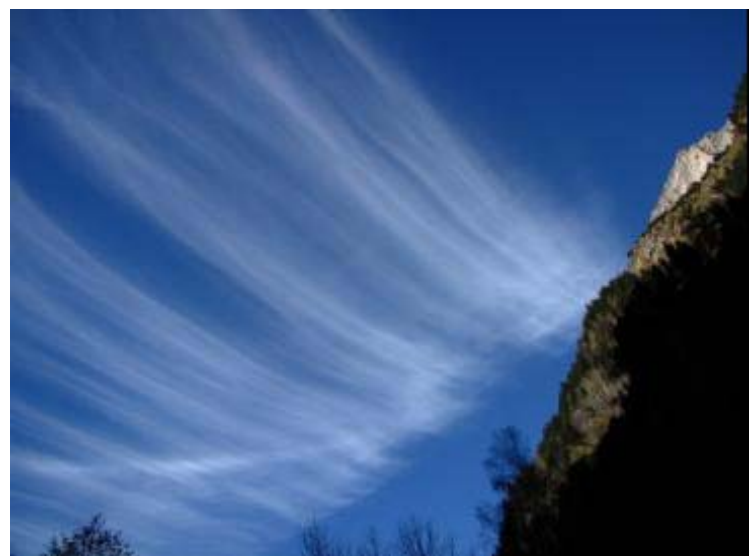

Fig. 13 Cirrus (Ci)

\section{Cirrocumulus (Cc)}

Banco, manto o capa de nubes blancas, compuestas de elementos muy pequeños en forma de glóbulos, y dispuestos más o menos regularmente; la mayoría de los elementos tienen un diámetro aparente inferior a un grado (diámetro menor que el meñique con el brazo extendido).

\section{Cirrostratus (Cs)}

Velo nuboso transparente y blanquecino de aspecto fibroso o liso, que cubre total o parcialmente el cielo y suele producir fenómenos de halo alrededor del Sol o la Luna.

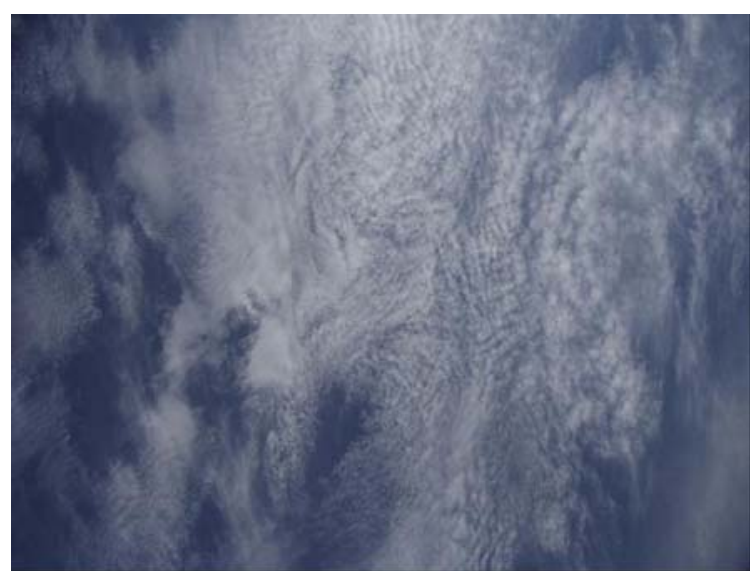

Fig. 14 Cirrocumulus (Cc)

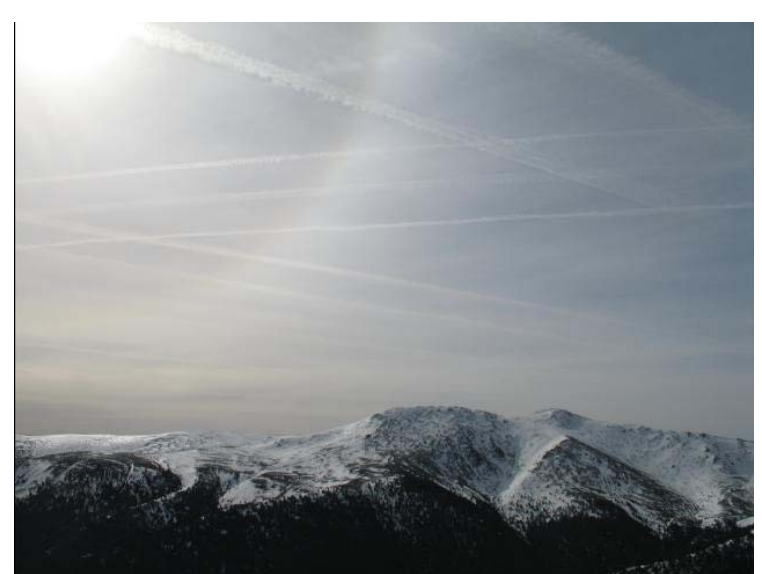

Fig. 15 Cirrostratus (Cs) 


\subsubsection{Nubes medias}

Sus bases se encuentran entre los 3 y los $7 \mathrm{Km}$ de altura. Algunas de ellas producen precipitaciones. Pueden ser de tres géneros:

\section{Altostratus (As)}

Capa nubosa grisácea o azulada, de aspecto uniforme, que cubre total o parcialmente el cielo y que presenta partes suficientemente delgadas para dejar ver el Sol, al menos vagamente, como a través de un vidrio deslustrado, pero no da lugar a fenómenos de halo. Pueden producir precipitaciones de carácter continuo, típicamente débiles.

\section{Altocumulus (Ac)}

Podemos distinguir principalmente dos formas:

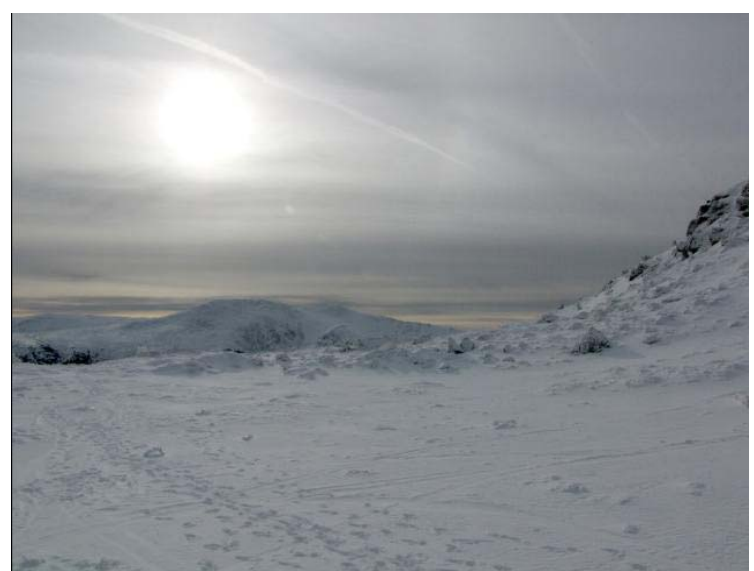

Fig. 16 Altostratus (As)

- Altocumulus lenticularis de aspecto liso y fusiforme. A veces apiladas por encima 0 a sotavento de las cumbres, pareciendo inmóviles. Suelen ir asociadas a vientos moderados o fuertes en la montaña.

- Nubes globosas, blancas y/o grises, que tienen generalmente sombras propias. A veces presentan aspecto fibroso o difuso. La mayoría de los elementos que están dispuestos regularmente y tienen un diámetro entre uno y cinco grados (diámetro entre el meñique y 3 dedos con el brazo
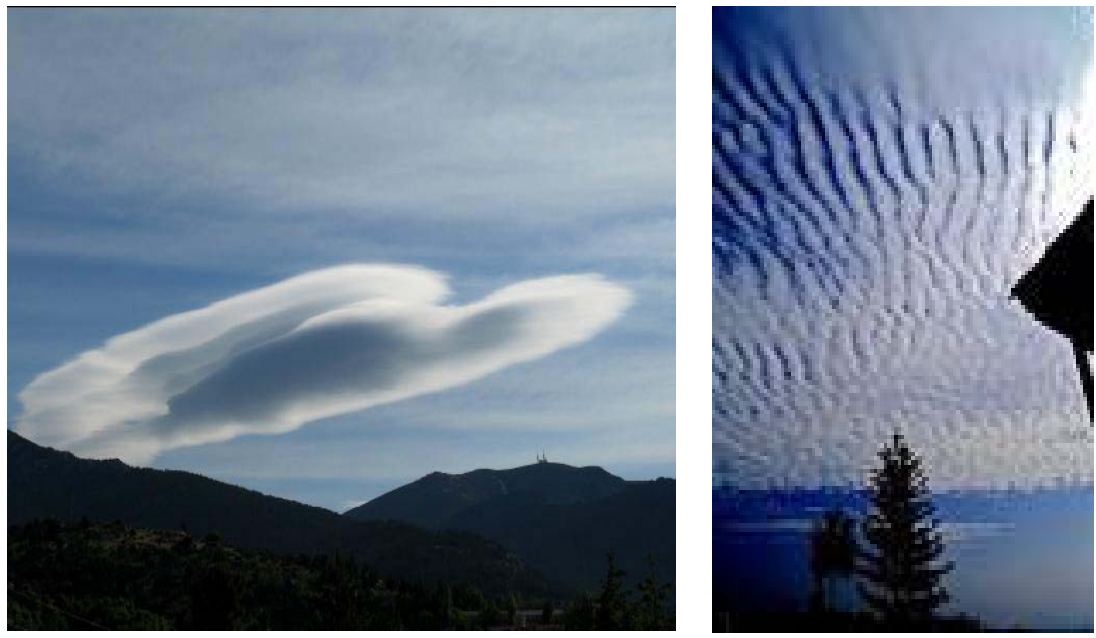

Fig. 17 Altocumulus lenticularis y capa de Altocumulus (Ac). extendido).

\section{Nimbostratus (Ns)}

Capa nubosa gris, frecuentemente sombría, cuyo aspecto resulta velado por las precipitaciones más o menos continuas de lluvia o de nieve, las cuales, en la mayoría de los casos, llegan al suelo. Ocultan completamente el Sol. Por debajo de la capa, existen frecuentemente nubes bajas, desgarradas, soldadas o no con aquella. En montaña el observador se encuentra a menudo dentro de la nube.

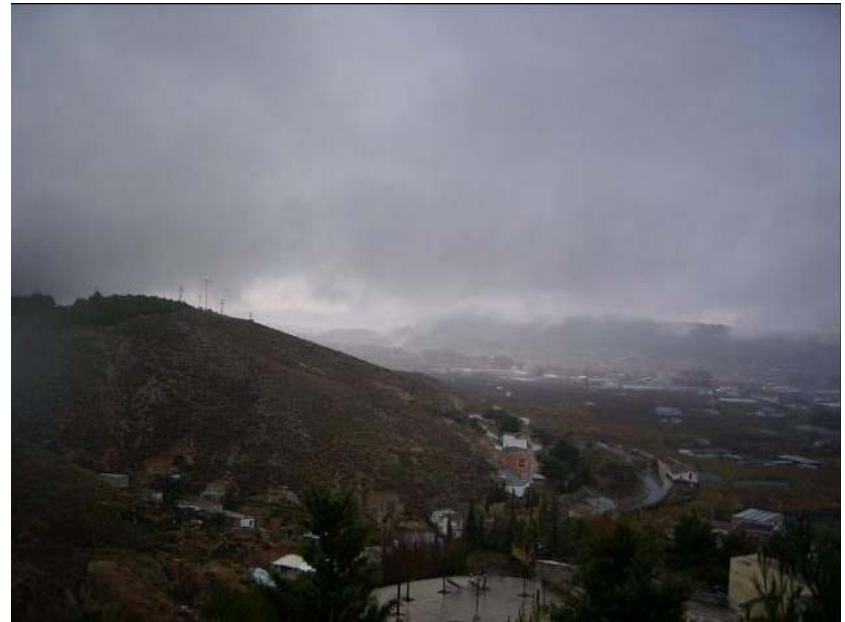

Fig. 18 Nimbostratus (Ns) 


\subsubsection{Nubes bajas}

Sus bases están situadas a alturas inferiores a $3 \mathrm{Km}$. Algunas producen precipitaciones. Hay cuatro géneros:

\section{Cumulus (Cu)}

Nubes aisladas, generalmente densas y de contornos bien definidos, que se desarrollan verticalmente en protuberancias, cúpulas o torres, cuya grumosa parte superior se asemeja a menudo a una coliflor. Las porciones de estas nubes iluminadas por el Sol son casi siempre blancas y brillantes, y su base relativamente oscura, es sensiblemente horizontal. Pueden producir chubascos cuando están fuertemente desarrollados.

\section{Stratocumulus (Sc)}

Banco, manto o capa de nubes grises o blanquecinas o de ambos colores a la vez, que tienen casi siempre partes oscuras compuestas de losas, guijarros o rodillos de aspecto no fibroso, soldados o no. La mayoría de los pequeños elementos están dispuestos regularmente y tienen diámetro aparente superior a los cinco grados (diámetro de cada nube mayor de 3 dedos con el brazo extendido). De poco desarrollo vertical, predominando la extensión horizontal. A veces se agarran a las cimas de las montañas. Son parecidos a los Altocumulus, pero están situados a menor altura. Pueden originar precipitaciones débiles.

\section{Stratus (St)}

Capa nubosa generalmente gris con base bastante uniforme, que puede dar lugar a llovizna. Cuando el Sol es visible a través de la capa, su contorno se distingue netamente. El estrato no produce fenómenos de halo, salvo eventualmente a muy bajas temperaturas. Tienen poco desarrollo vertical y cuando están pegadas al suelo producen la niebla (consideramos que hay niebla cuando la visibilidad se reduce a menos de $1 \mathrm{Km}$ ). Están formados por gotitas de agua. A veces el stratus se presenta en forma de bancos desgarrados.

\section{Cumulonimbus (Cb)}

Nube densa y potente de gran desarrollo vertical (de 8 a $15 \mathrm{Km}$ de espesor), bordes brillantes y base oscura. Una parte al menos de su región superior es generalmente lisa, fibrosa o estriada, y casi siempre aplanada. Esta parte se extiende frecuentemente en forma de yunque o de vasto penacho. Por debajo de la base de esta nube, a menudo muy oscura, existen con frecuencia nubes desgarradas, soldadas o no con ella y precipitaciones. Los $\mathrm{Cb}$ se forman por el desarrollo de cumulus, y nos indican que existe inestabilidad que se puede traducir en tormentas a veces con precipitaciones intensas, granizo y fuertes vientos.

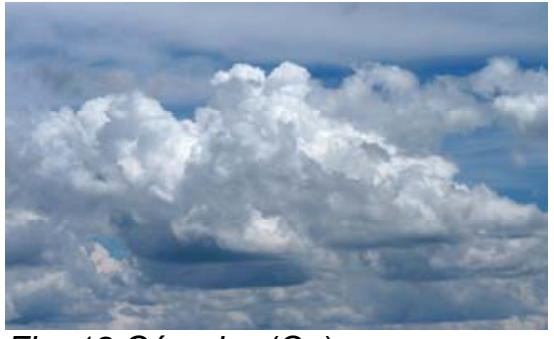

Fig. 19 Cúmulus $(\mathrm{Cu})$

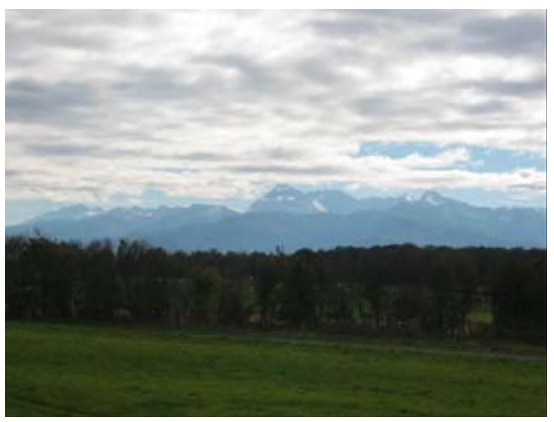

Fig. 20 Stratocumulus(Sc)

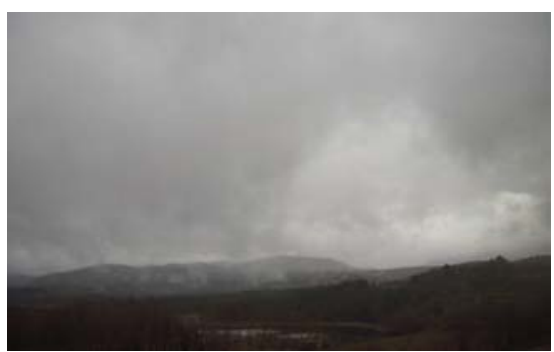

Fig. 21 Stratus (St)

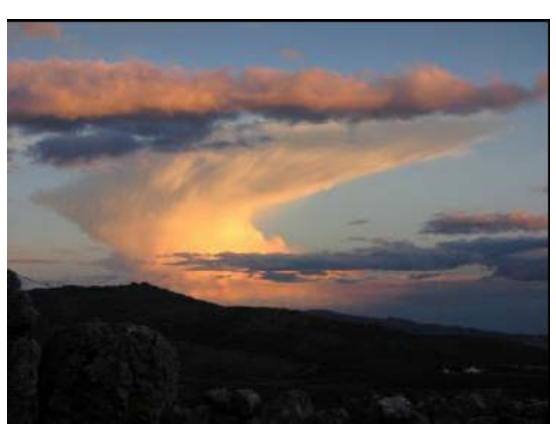

Fig. 22 Cumulonimbus (Cb) 


\section{Observaciones en el jardín meteorológico}

La parcela o jardín meteorológico es una porción de terreno llano, de suelo natural y representativo del entorno, donde se toman medidas meteorológicas. En el caso de observatorios especiales, como los de las redes de alta montaña, a menudo los instrumentos se ubican sobre plataformas a cierta altura sobre el terreno, para limitar la posibilidad de que los instrumentos de medida queden enterrados en el manto nivoso.

Algunos instrumentos, para que cumplan su misión, deben protegerse de la radiación y de las precipitaciones. Por ello se colocan en un abrigo o garita meteorológica, que es básicamente un armario formado por listones que permite la circulación del aire en su interior. Su techo es inclinado para dejar escurrir el agua de lluvia o la nieve, y lleva en su centro una chimenea para activar la circulación del aire. La garita debe tener su puerta orientada hacia el norte y estar pintada de blanco.

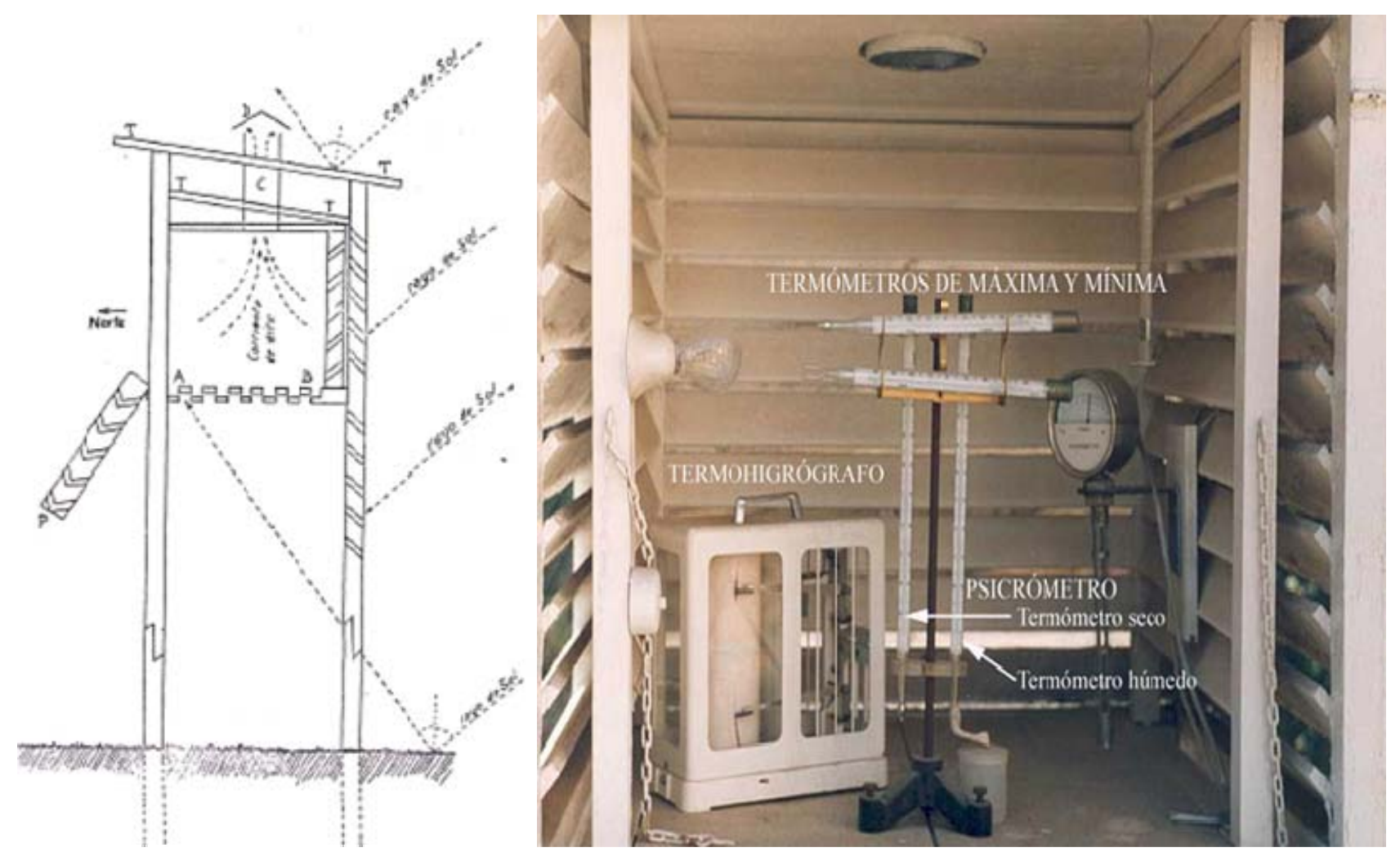

Fig. 23 Esquema de garita meteorológica e interior con instrumentos

Las medidas deben tomarse en general entre 1.25 y 2 metros, por lo que la garita va montada sobre patas de modo que el piso quede a una altura aproximada de 1,20 m. La altura a la que se toman las medidas es importante porque junto al suelo los gradientes verticales de temperatura son a menudo extremadamente grandes. En observatorios donde el manto nivoso estacional hace variar la altitud de la superficie del suelo, pueden utilizarse garitas elevadas en altura o móviles. En la figura 23. Se observa un esquema de garita meteorológica y el interior de una con los instrumentos más habituales.

Típicamente, una garita meteorológica alberga los instrumentos para medir temperatura, humedad y evaporación. La pareja de termómetros ('seco' y 'húmedo') montada verticalmente, conforma un psicrómetro, y se usa para determinar la humedad relativa mediante la diferencia de temperatura entre ambos. 


\subsection{Medidas de Temperatura}

Los termómetros dentro de la garita deben estar suspendidos por medio de soportes apropiados lo más ligeros posible para evitar la propagación del calor por conducción, y las vibraciones producidas por el viento. En general en un observatorio de montaña la garita albergará un termómetro ordinario, los termómetros de máxima y de mínima y un termohigrógrafo. Otro aparato de medida de uso frecuente es el termómetro 'Six-Bellani' o 'Six', que mide también las temperaturas máxima y mínima.

\subsubsection{Temperatura Actual}

Se mide en el momento de la observación, en general con el termómetro ordinario, que consiste en un pequeño recipiente de vidrio, esférico, llamado depósito, prolongado por un tubo capilar muy fino cerrado por su extremo superior; el depósito y parte del tubo están llenos de mercurio. Cuando la temperatura aumenta, el mercurio se dilata y la columna sube por el interior del tubo; lo contrario ocurre cuando la temperatura disminuye. El capilar va sujeto a una escala vitrificada dividida en grados Celsius con divisiones cada $0,2^{\circ} \mathrm{C}$. Este termómetro se coloca dentro de la garita meteorológica en posición vertical, con el bulbo hacia abajo, en el soporte adecuado.

La temperatura actual se mide con una precisión de $0,1^{\circ} \mathrm{C}$, por lo que hay que aproximar la lectura a la décima de grado, aunque no esté marcada en la escala.

Naturalmente, la temperatura actual será igual o superior a la mínima e igual o menor que la máxima.

\subsubsection{Temperatura Máxima}

En el caso de las observaciones NIVOMET, se toma a las 08 UTC y corresponde con la temperatura más alta alcanzada en las últimas 24 horas. El valor debe medirse con una aproximación de $0,1^{\circ} \mathrm{C}$.

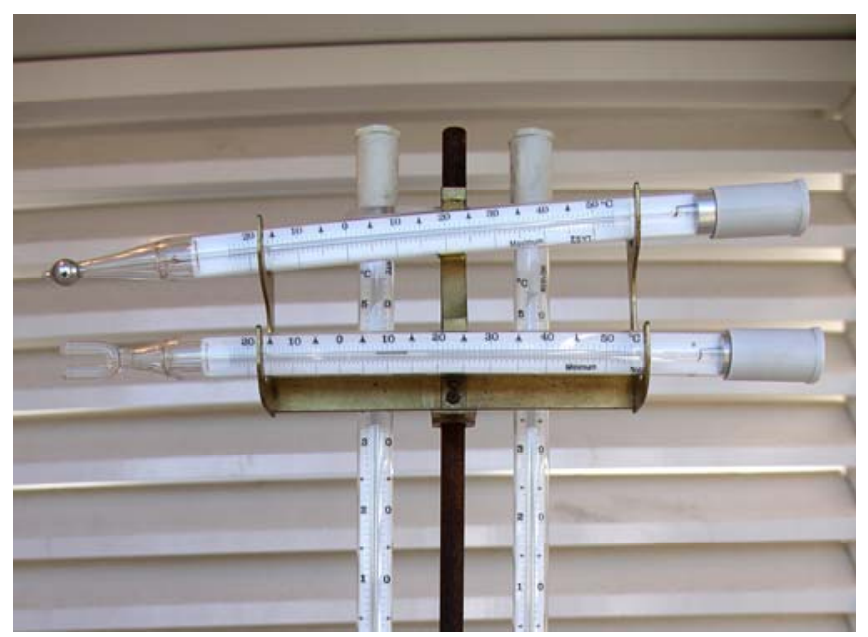

Fig. 24 Termómetros de máxima y mínima
Para su medida se usa en general el termómetro de máxima, que es de tipo clínico, con un estrechamiento junto al depósito de mercurio. Al subir la temperatura, la dilatación del mercurio del depósito vence la resistencia opuesta por el estrechamiento y el mercurio en su extremo opuesto va señalando temperaturas cada vez más altas. Cuando la temperatura baja, y la masa de mercurio se contrae, la columna de mercurio se rompe por el estrechamiento y su extremo libre queda señalando la temperatura máxima. Este termómetro se coloca dentro de la garita en posición casi horizontal, con el depósito un poco más bajo que el otro extremo, generalmente en el mismo soporte del termómetro ordinario formando una cruz con él.

A las 08 UTC, tras la lectura, el termómetro se debe "poner en estación", es decir, se debe poner a punto para la realización de la siguiente medida. Esto consiste en hacer bajar la columna de mercurio hasta que marque la temperatura actual (décima más, décima menos). Para ello se saca del soporte y se coloca verticalmente, con el bulbo hacia abajo, para que la columna de mercurio llegue al estrechamiento cercano del depósito. Tras esto, agarrándolo firme por la parte contraria al bulbo, se sacude un cuarto de vuelta con el brazo extendido, mejor horizontalmente, de modo que la columna de mercurio esté alineada con el brazo, y el depósito quede hacia el exterior. Casi siempre esto es suficiente para que el mercurio baje hasta indicar la temperatura actual. Si no bajase, se puede tratar 
de enfriar el depósito de mercurio, volviendo después a sacudir el termómetro. Deben evitarse las sacudidas bruscas, que pueden romper el fino capilar de vidrio que contiene el mercurio.

Recordemos que el horario UTC es, en la España peninsular y Baleares, una hora menos de lo que marca nuestro reloj en invierno y dos horas menos en verano. La observación de las 08 UTC se hace en invierno a las 09 horas locales y en verano a las 10 horas locales.

\subsubsection{Temperatura Mínima}

Al igual que la máxima, la mínima se toma a las 08 UTC para el parte NIVOMET, y corresponde a la temperatura más baja alcanzada en las 24 horas precedentes. El valor debe medirse con una aproximación hasta la décima de grado, aunque la división de la escala será en general de $0,5^{\circ} \mathrm{C}$. Para medirla se usa el termómetro de mínima que suele ser de alcohol o de algún otro líquido orgánico, y lleva sumergido en el líquido un índice con alma metálica. Cuando la temperatura desciende, el líquido arrastra el índice, porque éste no puede atravesar el menisco y se ve forzado a seguir su recorrido de retroceso. Cuando la temperatura sube, el líquido pasa fácilmente entre la pared del tubo y el índice, y éste permanece quieto señalando la temperatura mínima por su extremo más alejado del depósito. El termómetro de mínima se coloca horizontalmente en un soporte por debajo del termómetro de máxima y formando una cruz con el termómetro ordinario.

Al hacer la lectura téngase siempre presente que la temperatura mínima viene indicada por el extremo del índice más alejado del depósito, nunca por el más cercano; es decir, que de los dos valores señalados por los dos extremos del índice, la temperatura mínima es la mayor.

Tras la lectura de la temperatura mínima, a las 08 UTC en el caso de la observación NIVOMET, el termómetro se debe poner en estación, es decir, se debe dejar a punto para realizar la siguiente medida. Para ello se inclina el termómetro, con el bulbo hacia arriba, para que el índice se mueva hasta que vea frenada su caída por el menisco del propio líquido. Cuando se coloca de nuevo en el soporte, se debe mantener el extremo del bulbo siempre más alto que el otro extremo, evitando así que el índice se desplace hacia el depósito.

\subsubsection{Mantenimiento de los termómetros}

Uno de los problemas más frecuentes es no darse cuenta de que las columnas tanto de mercurio como la orgánica pueden estar partidas y en consecuencia, la lectura del instrumento es errónea. Un primer intento de eliminarlas consistirá en repetir los movimientos de maniobras centrífugas, tal como se describieron para el termómetro de máxima. Cuando las burbujas, antes en el líquido, pasan a la parte superior, dejan de ser perjudiciales, pero conviene vigilar el instrumento, pues es frecuente que el problema se repita.

Sólo en casos muy rebeldes, con mucha prudencia, para reducir las burbujas de gas se puede calentar el termómetro, acercándolo a un radiador o a un recipiente con agua que empiece a hervir, sin sumergirlo nunca en el agua. Se retirará cuando las burbujas y algo del líquido del termómetro entre en el ensanchamiento o depósito de expansión en que termina el capilar. Como método más eficaz para la eliminación de burbujas se recomienda efectuar suaves sacudidas y calentamientos alternativamente. Para el termómetro de mínima, antes de las sacudidas centrífugas conviene bajar el índice hasta el final, con pequeñas sacudidas si es preciso, para evitar que un choque brusco del índice con el tope pueda romper el capilar. Tras eliminar las burbujas se mantendrá el termómetro vertical una hora por lo menos, de modo que el líquido adherido al tubo pueda discurrir totalmente hacia abajo. 


\subsubsection{Medidas con el termómetro Six-Bellani}

Además de los termómetros de máxima y de mínima, en muchos observatorios se dispone de un termómetro Six-Bellani, que consta, en esencia, de un tubo capilar dos veces curvado en $U$. A ambos extremos del tubo hay dos ensanchamientos, ambos con líquido orgánico que se extiende hasta más o menos la mitad de las dos columnas. El resto del tubo, es decir, la parte inferior en forma de $U$ está relleno de mercurio, cuya misión es empujar dos índices de medida sumergidos en el líquido orgánico.

Hay dos escalas de medida, una descendente (en la que se lee la temperatura mínima) y otra ascendente (en la que se lee la temperatura máxima). En ambas escalas, los extremos de la columna de mercurio deben marcar en todo momento la misma temperatura, o muy aproximada. Esta temperatura es la del momento actual.
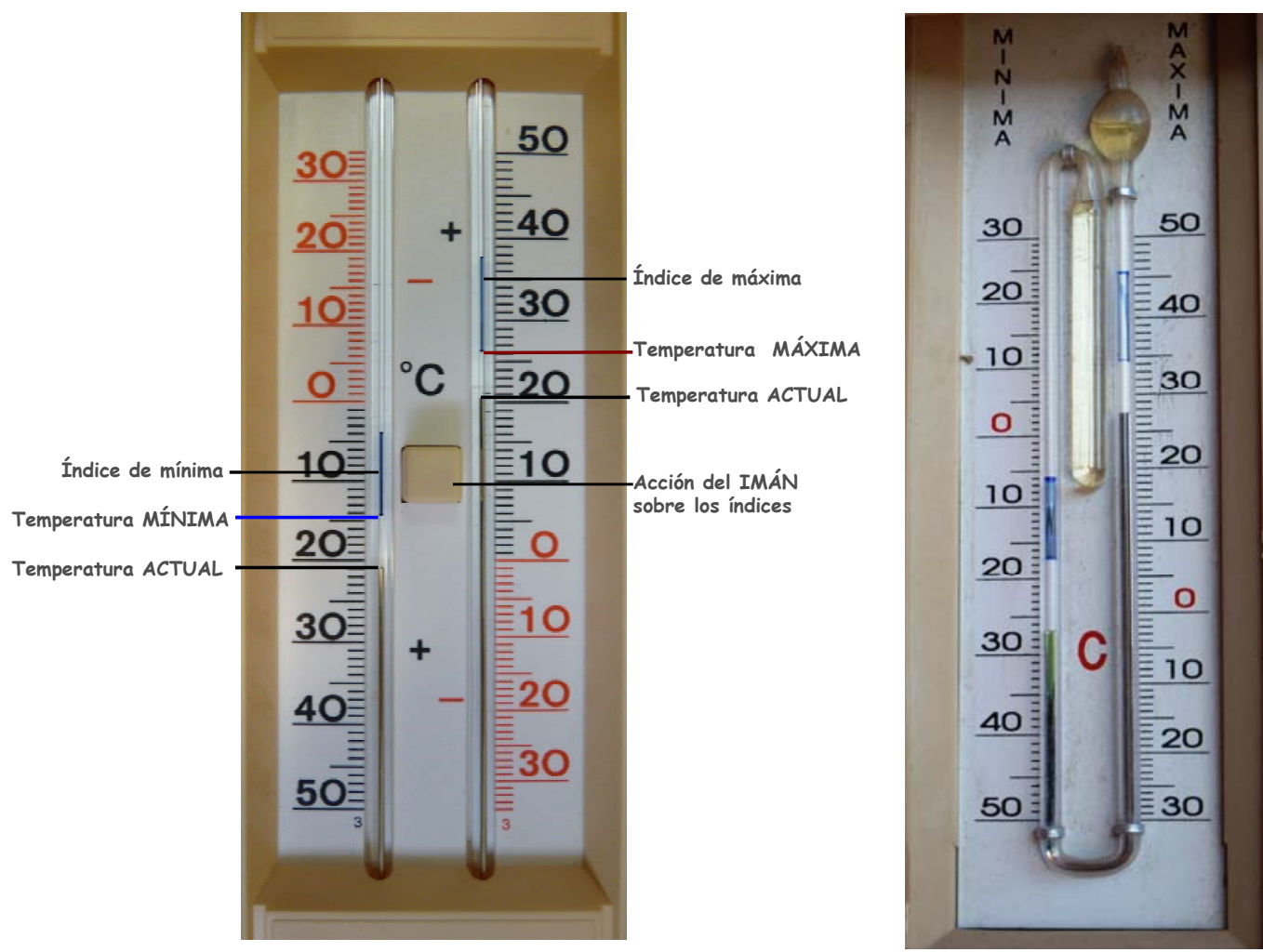

Fig. 25 Termómetro Six-Bellani: detalle de lecturas y estructura

Al subir la temperatura, el mercurio asciende por la columna de la derecha, empujando el índice, cuyo extremo inferior marca la temperatura máxima. Al bajar la temperatura el mercurio asciende por la rama izquierda, empujando el otro índice, cuyo extremo inferior marca la temperatura mínima. Cuando el mercurio retrocede, los índices quedan fijos en el interior del capilar debido a la fuerza que sobre ellos ejerce un imán situado en la parte posterior del termómetro. La lectura de los puntos de la escala coincidentes con los extremos inferiores de los índices dará las respectivas temperaturas máxima y mínima en el período de tiempo considerado.

Para poner el termómetro en estación, tras la observación de las 08 UTC en el caso de la observación NIVOMET, bastará apretar el botón que aleja el imán, dejando libres los índices que bajarán hasta coincidir con el mercurio. Una vez colgado el aparato verticalmente y trasladados los índices hasta ponerlos en contacto con los extremos del mercurio, el termómetro queda en condiciones de observación. 


\subsubsection{Mantenimiento}

Si se fracciona la columna de mercurio, se puede volver a unir dando al conjunto dos o tres sacudidas de arriba abajo. Lo mismo habrá que hacer si se fracciona la columna de alcohol.

Si el índice queda dentro de la columna de mercurio, sacudir el termómetro sujetándolo por la parte inferior del mismo, lo que provoca una fractura de la columna de mercurio y la aparición del índice entre los trozos fracturados. Sacudir el termómetro sujetando éste por la parte superior. Esta operación se repetirá cuantas veces sea necesario, hasta colocar el índice por encima del total de mercurio.

\subsubsection{Medidas con el termohigrógrafo}

Para obtener un registro continuo, tanto de temperatura como de humedad relativa del aire, se dispone del termohigrógrafo (TH), que permite comprobar en qué momento se producen los registros mediante una banda de papel que tiene una escala doble, en grados Celsius y porcentaje de humedad en el eje vertical, y una escala temporal horaria en el eje horizontal. El valor de la temperatura se lee directamente en la mitad superior de la banda de registro, y el de la humedad relativa en la mitad inferior.

Además de para conocer la evolución temporal de la temperatura y la humedad, las medidas del termohigrógrafo nos sirven para contrastar y chequear las del termómetro ordinario. Es normal que exista una pequeña diferencia entre ambas medidas, más o menos

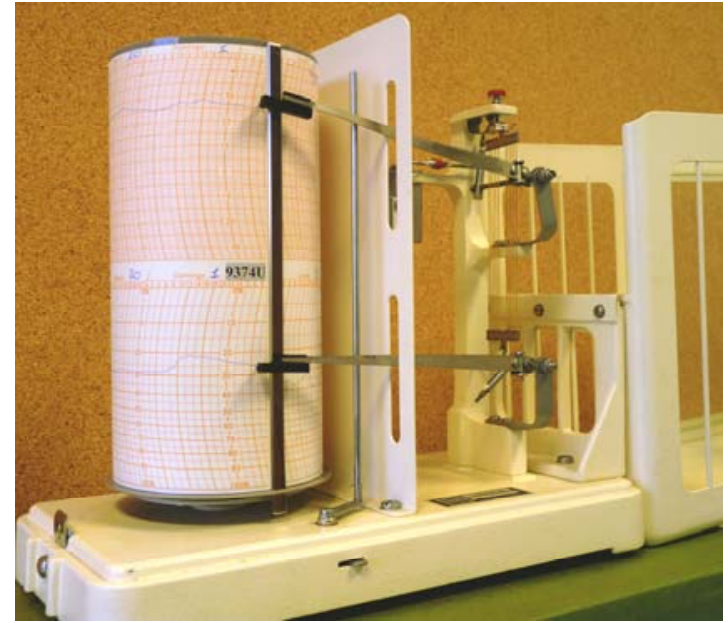

Fig. 26 Termohigrógrafo constante. Cuando esta diferencia cambia significativamente de un día para otro, es síntoma de error o avería. Salvo que se considere que el termómetro ordinario no funciona correctamente, en caso de discrepancia entre las medidas, se tomará como bueno el dato de de éste último.

\subsection{Medida de la Humedad Relativa del aire}

En meteorología es muy importante el concepto de humedad del aire atmosférico, que es el "contenido de vapor de agua en el aire". El vapor de agua es transparente, y siempre está presente en el aire ambiente, pero la cantidad de agua en forma de vapor que puede albergar el aire es limitada. Es mayor o menor según la temperatura sea más o menos alta, pero limitada. Cuando el vapor de agua que contiene el aire sobrepasa el límite, entonces se condensa o congela en forma de diminutas gotitas líquidas o cristales de hielo que forman las nubes y los bancos de niebla.

Existen varios indicadores para expresar la humedad, siendo el más usado el de Humedad Relativa, que es "la relación porcentual entre la cantidad de vapor de agua que tiene el aire y el máximo que podría contener en forma de vapor a una temperatura determinada". Para el confort humano se considera ideal entre el 50 y el $70 \%$.

Hay distintos aparatos para medir la humedad relativa del aire, llamados higrómetros. En los observatorios nivometeorológicos se utiliza el termohigrógrafo, o TH, cuyo elemento sensible es un haz de cabellos que está más o menos tenso según el aire esté más o menos seco.

El valor de la humedad relativa se lee directamente en el registro continuo de la banda de papel semanal, en la parte inferior de la banda. 


\subsubsection{Cambio de la banda de papel del Termohigrógrafo}

El termohigrógrafo es un instrumento de registro semanal. Todos los lunes, tras la observación de las 08 UTC en el caso de los observatorios nivometeorológicos, hay que cambiar la banda de papel y dar cuerda al mecanismo de relojería. Para ello se siguen los siguientes pasos:

- Separar las plumillas de la banda mediante la palanca de separación de brazos.

- Chequear la corrección de las fechas escritas sobre la banda que quitamos y que ponemos. Esto es muy importante, pues un error o un olvido en la fecha harían inútiles las observaciones.

- Al poner la nueva banda, asegurarse de que queda apoyada en la base del tambor en todo su perímetro y bien ajustada al propio tambor, con el solape entre los extremos de la banda bajo la pletina de sujeción.

- Dar cuerda al mecanismo de relojería, hasta el tope, pero sin forzarlo.

- Poner el aparato en hora, girando en última instancia el tambor en sentido contrario al de las agujas del reloj.

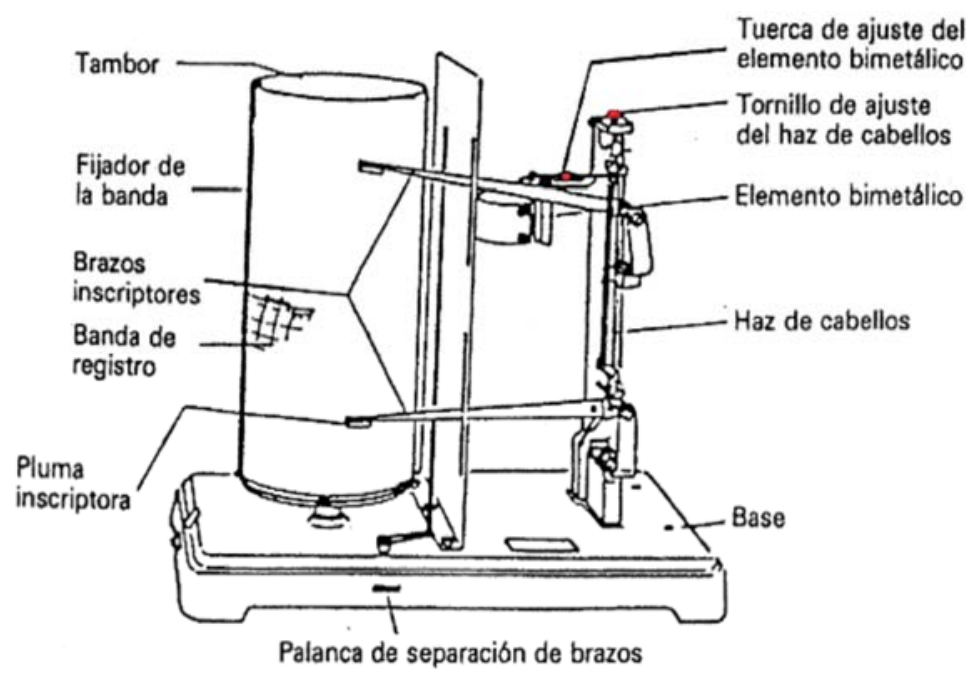

Fig. 27 Elementos del termohigrógrafo

- Tras colocar con cuidado el TH en la garita, acercar las plumillas hasta que apoyen sobre la banda.

\subsubsection{Mantenimiento}

Cuando las plumillas inscriptoras se hayan gastado, quitarlas con cuidado del brazo tras haberlo separado del tambor. Retirar el protector de la punta de las nuevas plumillas y colocarlas en el brazo inscriptor.

Las partes metálicas pulidas del aparato deberán limpiarse del polvo acumulado cada cierto tiempo, con un paño fino de algodón humedecido y con ayuda de un pincel.

El haz de cabellos se limpia pasando cuidadosamente un pincel seco por los cabellos, para quitar las partículas de polvo. Esto es aconsejable hacerlo cada semana. En caso de mayor deterioro, se puede intentar regenerar el haz de cabellos limpiándolo con un paño mojado en agua destilada o, en su defecto, agua de lluvia.

Si el aparato marca mal la temperatura, por ejemplo: siempre marca dos grados menos que el termómetro ordinario, se puede ajustar a la medida correcta con la tuerca de ajuste del elemento bimetálico, en color rojo. Para discrepancias de un grado o menos, mejor no tocarlo.

Lo mismo se puede hacer para la humedad relativa, con el tornillo de ajuste del haz de cabellos, también de color rojo. Para verificar su funcionamiento, recubriendo completamente la rejilla con una bayeta empapada en agua (sin que chorree) el aparato deberá marcar al poco rato entre el 95 y el $100 \%$ de humedad. De no ser así, se podrá corregir la indicación hasta que señale esta medida, sin haber dado lugar a que la bayeta se haya secado demasiado. 


\subsection{Medida de la precipitación}

La precipitación se define como el producto líquido o sólido de la condensación del vapor de agua que cae de las nubes o del aire y se deposita en el suelo. Dicho término comprende la lluvia, el granizo, y la nieve, así como los depósitos como los que puedan dejar las nieblas o neblinas, el rocío, la cencellada blanca y la escarcha.

La cantidad de precipitación es la suma de las precipitaciones líquidas y del equivalente líquido de las precipitaciones sólidas (nieve, granizo, etc....). Sin embargo, debe indicarse en cada observación si se trata de una caída de lluvia, de granizo, de nieve o de una combinación de éstas.

Para su medida se usa el pluviómetro Hellmann (Figura 28) que consta de un vaso cilíndrico cuya boca está formada por un anillo de bronce afilado, un embudo profundo, para que las gotas que han entrado no salgan al rebotar, conduciendo el agua a otro recipiente cilíndrico de boca estrecha por la que penetra el pico del embudo. De este modo, toda el agua recogida se conserva en el frasco interior protegido contra la evaporación por la estrechez de la boca y por el dispositivo de dobles paredes que resulta.

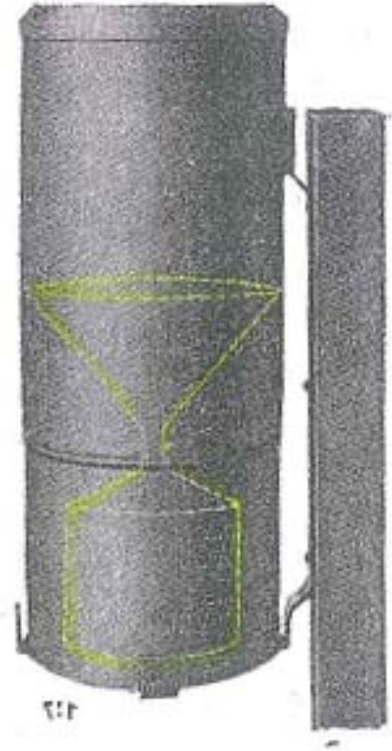

Fig. 28 Pluviómetro Hellmann

La unidad de medida de la precipitación es el litro por metro cuadrado o milímetro de altura de precipitación. Ambas medidas son equivalentes, ya que sobre un suelo perfectamente horizontal sobre el que el agua no se filtrase ni evaporase, una capa de un milímetro de altura y un metro cuadrado de base tiene un volumen de un litro.

$$
\begin{array}{|c|}
1 \text { litro } / 1 \mathrm{~m}^{2}=1 \mathrm{dm}^{3} / 1 \mathrm{~m}^{2}=00^{\prime} 001 \mathrm{~m}^{3} / 1 \mathrm{~m}^{2}=0,001 \mathrm{~m}=1 \mathrm{~mm} \\
1 \mathrm{~mm} \times 1 \mathrm{~m}^{2}=0,001 \mathrm{~m} \times 1 \mathrm{~m}^{2}=0^{\prime} 001 \mathrm{~m}^{3}=1 \mathrm{dm}^{3}=1 \text { litro }
\end{array}
$$

En caso de que la precipitación exceda la capacidad de la garrafilla del pluviómetro, deberemos medir también el agua que quede dentro del armazón metálico del aparato. Las medidas deben expresarse en décimas de milímetro de altura de precipitación, con una aproximación mínima de 2 décimas de milímetro $(0,2 \mathrm{~mm})$, si bien para precipitaciones de más de $10,0 \mathrm{~mm}$. se admite que el error no sobrepase el $2 \%$. La marca superior de la probeta son $10 \mathrm{~mm}\left(10 \mathrm{l} / \mathrm{m}^{2}\right)$.

El agua en la probeta hace un menisco, elevándose su superficie hacia las paredes. La lectura se toma fijándose hasta donde alcanza el fondo del menisco.

Es importante recordar que la probeta que se utiliza para medir la precipitación está especialmente diseñada para ese tipo de pluviómetro, cuya boca mide $200 \mathrm{~cm}^{2}$, una superficie cincuenta veces menor que un metro cuadrado, y está graduada ya directamente en milímetros de altura de precipitación (o lo que es lo mismo litros por metro cuadrado). Si no se dispone de esta probeta, por haberse roto o extraviado, se puede medir el volumen de la precipitación con una probeta estándar (graduada en $\mathrm{cm}^{3}$ ) y hacer la conversión a litros por metro cuadrado multiplicando por 50 , ya que cada $20 \mathrm{~cm}^{3}$ de agua recogidos en un pluviómetro cuya boca tiene $200 \mathrm{~cm}^{2}$ equivale a un litro por metro cuadrado,

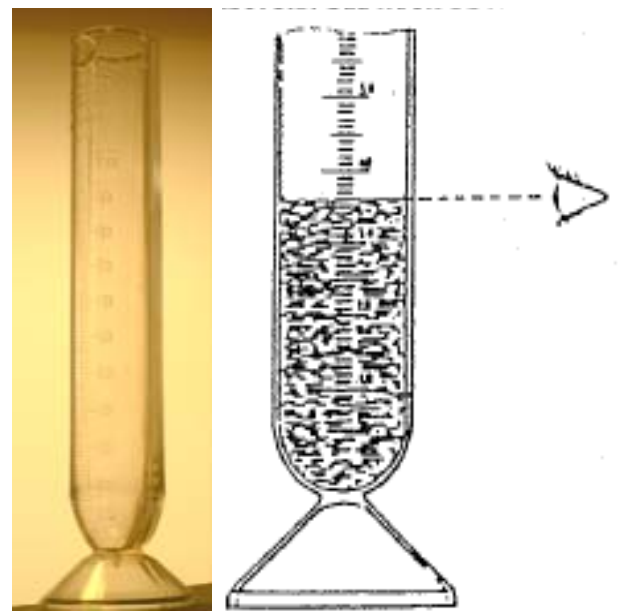

Fig. 29 Probeta del pluviómetro y lectura 
La intensidad de la precipitación es la rapidez con que ésta se acumula en el pluviómetro, y se expresa en $\mathrm{mm} / \mathrm{h}$. Para las nevadas también se puede expresar en términos de velocidad de acumulación de nieve en el suelo, en $\mathrm{cm} / \mathrm{h}$.

Cuando la intensidad se aplica a la calificación de los meteoros, se hace de manera subjetiva. Se habla de intensidad débil, moderada o fuerte, en función de las características observadas. Estas características, sujetas a interpretación, en general no coinciden con otras escalas usadas para valorar la intensidad de precipitación, pues son propias de cada meteoro, diferentes según el tipo de precipitación.

Para la lluvia:

- Intensidad débil: la visibilidad no se reduce o se reduce muy poco. Las gotas caen más bien dispersas, sin provocar apenas salpicaduras, aunque frecuentemente son grandes y es posible distinguir gotas individuales. La velocidad de acumulación de agua en el suelo es pequeña, las superficies secas tardan en mojarse completamente más de dos minutos y no se forman charcos.

- Intensidad moderada: la visibilidad se reduce. Las gotas caen con rapidez suficiente como para provocar pequeñas salpicaduras y formar charcos, siendo difícil distinguir gotas individuales.

- Intensidad fuerte: la visibilidad se reduce mucho. Las gotas caen con fuerza y rebotan en el suelo produciendo salpicaduras en superficies planas que alcanzan varios centímetros, y un ruido sordo y continuo en los tejados.

\section{Para la llovizna}

- Intensidad débil: se aprecia reducción de la visibilidad. Se percibe el contacto de las gotitas con la piel o sobre el parabrisas de los automóviles. Algunas veces puede originar un ligero chorreo sobre las superficies y los tejados.

- Intensidad moderada: la visibilidad queda bastante restringida. El agua corre ligeramente sobre las superficies.

- Intensidad fuerte: la visibilidad se reduce mucho. Las superficies se empapan con rapidez.

Para la nieve:

- Intensidad débil: se aprecia reducción de la visibilidad. Los copos suelen ser pequeños y dispersos, cayendo lentamente. La velocidad de acumulación en el suelo es pequeña, de menos de $0.5 \mathrm{~cm} / \mathrm{h}$.

- Intensidad moderada: la visibilidad queda bastante restringida. Los copos suelen tener un tamaño mediano y caer a velocidad apreciable. En el suelo se acumulan entre $0.5 \mathrm{y} 4 \mathrm{~cm}$ a la hora.

- Intensidad fuerte: la visibilidad queda muy reducida. Los copos, frecuentemente grandes, caen con bastante velocidad y en el suelo la nieve se acumula a un ritmo superior a los $4 \mathrm{~cm}$ a la hora.

Para la observación nivometeorológica, se mide la precipitación caída en las últimas 24 horas, y sólo se toma la medida en la observación de las 08 UTC. En otras observaciones, como la que pueda hacerse para emitir un parte NIVOMET a las 13 UTC, no se medirá la precipitación.

\subsubsection{Coherencia con la estimación del tiempo pasado}

Los distintos elementos que componen una observación deben ser coherentes entre sí. Por ello, cuando ha habido precipitación, el grupo de tiempo presente y pasado de la clave NIVOMET, $7 w w W_{1} W_{2}$, no podrá indicar ausencia de fenómenos; deberá incluir algún meteoro causante de la precipitación, ya sea como tiempo presente (los diez minutos previos a la hora de la observación) o como tiempo pasado, o bien barras (/) indicando desconocimiento del fenómeno. 


\subsection{Medida del espesor total de nieve y del espesor de nieve reciente}

Para conocer la cantidad de nieve caída se utilizan 'jalones'. Un jalón nivométrico no deja de ser una regla colocada verticalmente en el suelo y fijada al terreno permanentemente en un lugar libre de obstáculos, con una superficie apropiada para hacer la medida. La escala graduada que lleva sobre su superficie nos permite ver la altura de nieve caída.

\subsubsection{Espesor total del manto nivoso}

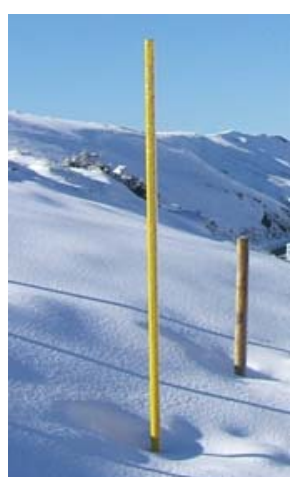

Fig. 30 Jalón nivométrico

El espesor total se mide directamente sobre la escala graduada del jalón nivométrico, y debe expresarse en centímetros enteros, redondeando al valor más cercano.

Al hacer la medida del espesor de nieve, conviene tener cuidado con las cavidades o acumulaciones que se forman alrededor del jalón, debido a la acción del sol o del viento. La forma correcta de medir se detalla en la figura a continuación $n^{\circ} 31$.

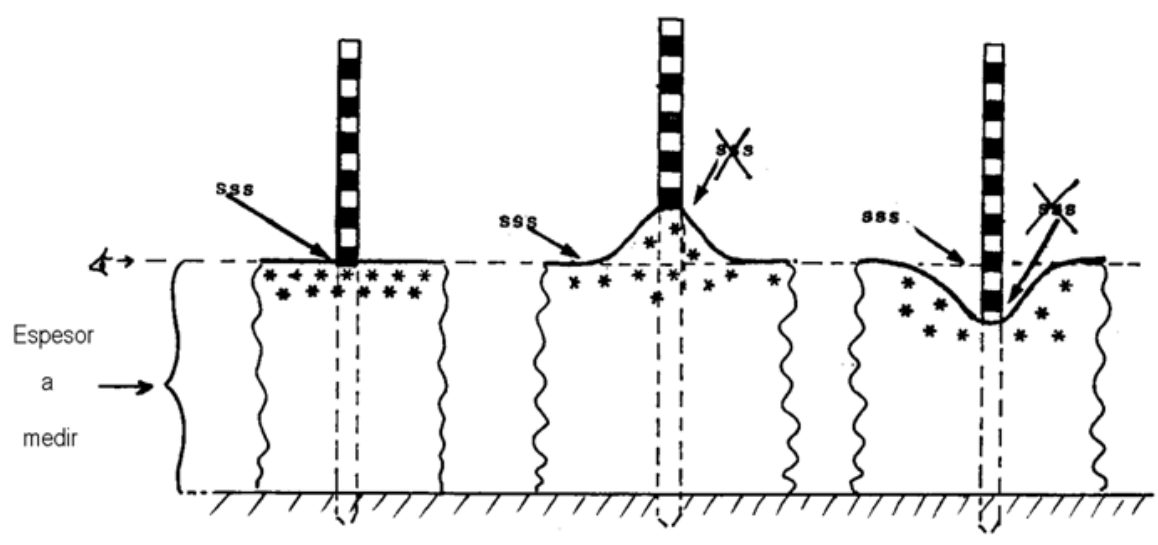

Fig. 31 medida del espesor de nieve

\subsubsection{Espesor de nieve reciente}

Para la nieve reciente se utiliza un jalón especial, el jalón de nieve reciente. Consiste en una vara con una escala graduada en centímetros, unida a una superficie horizontal de $40 \mathrm{~cm}$ de lado y unos milímetros de grosor, plana, de color blanco que refleje la insolación y de un material que repela la humedad.

Este jalón de nieve reciente, es móvil y debe ser limpiado una única vez al día, en la observación de las $08 Z$.

El espesor de nieve reciente se mide directamente en el jalón de la placa de nieve reciente, y se expresa en centímetros enteros, redondeando al valor más cercano.

Cuando el viento es fuerte, puede arrastrar e incluso tirar y levantar del suelo la placa con su escala graduada, de

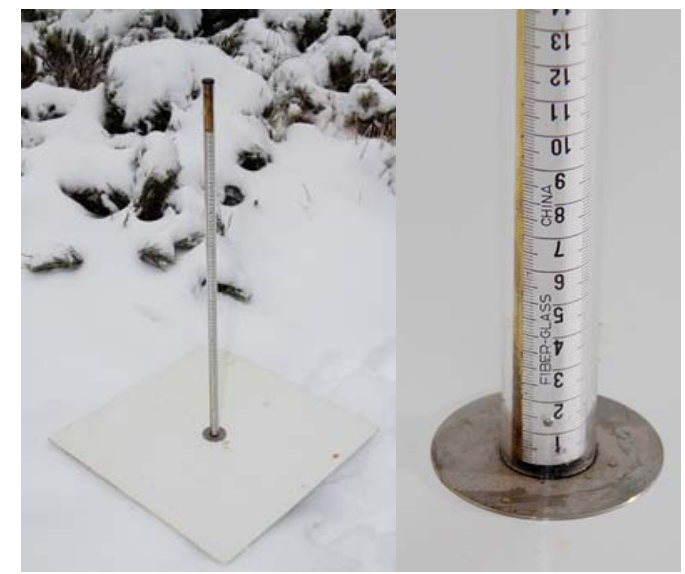

Fig. 32 Jalón y placa de nieve reciente 
manera que no sea posible medir la nieve recién caída en el jalón de nieve reciente. Cuando esto suceda, no estimaremos la cantidad de nieve reciente a partir de las medidas de espesor total en el jalón nivométrico. Esto sería incorrecto, ya que la nieve depositada tiende a comprimirse.

Fuera de la temporada de nieve, cuando no hay manto nivoso estacional, el jalón de nieve reciente debe retirarse del jardín meteorológico, pues el sol deteriora la placa, inutilizándola al curvarla.

\subsection{Transporte de la nieve por el viento}

El transporte de nieve por el viento es un factor muy importante en la estimación del peligro de aludes. Es causa de formación de cornisas, placas de viento, sobreacumulaciones, etc. Su estimación es un problema no resuelto y su medida es compleja y de difícil interpretación. Se usan principalmente dos aparatos de medida, llamados driftrómetro con bolsitas y flowcapt.

Esta observación se refiere al transporte de nieve por el viento en el propio observatorio, no en los alrededores, por lo que deberá ir asociada al meteoro de ventisca en la estación. En los observatorios de AEMET, que no disponen de instrumental de medida, la observación se reducirá a una estimación de la dirección dominante del transporte de nieve, o lo que es lo mismo, la dirección del viento que produce el transporte.

En caso de disponer de instrumental, la medida será diferente según el tipo de aparato, driftrómetro con bolsitas o flowcapt, pero en ambos casos indicará la cantidad de nieve transportada y la dirección del transporte (la dirección del viento que lo produce).

- En el caso del driftrómetro, la cantidad de nieve transportada será la que contenga el saquito que más nieve ha acumulado, e irá expresada en decenas de gramos. La dirección será la dirección de la obertura del saquito que ha recogido una mayor cantidad de nieve.

- En el caso del flowcapt, que es un aparato de registro continuo tanto del flujo de nieve como del viento, la cantidad de nieve transportada será el flujo medio en las últimas 24 horas, expresado en gramos por metro cuadrado y por segundo $\left(\mathrm{g} \cdot \mathrm{m}^{-2} \cdot \mathrm{s}^{-1}\right)$. La dirección será la dirección dominante del viento en las últimas 24 horas.

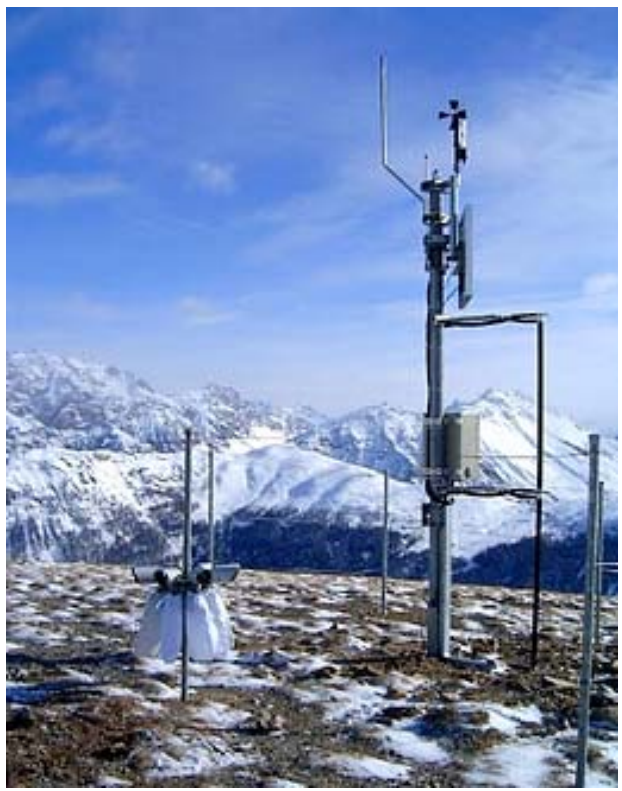

Fig. 33 Driftrómetro y flowcapt 


\section{Observaciones fuera del jardín meteorológico}

Existen una serie de variables, incluidas en la sección 5 de la clave NIVOMET y prácticamente todas ellas con carácter nivológico, que se miden fuera del jardín meteorológico, tras haber realizado las medidas en éste. En este apartado de la guía se va a tratar de explicar cada una de ellas, tanto las que se miden en la zona del observatorio (cerca del jardín) como las que se miden en altitud.

\subsection{Medidas del estado del manto nivoso en la zona del observatorio}

Aunque durante el desplazamiento inicial hacia el jardín meteorológico es muy probable que nos fijemos en el estado de la parte superficial del manto que lo rodea, es en este momento cuando nos toca concretar las características principales de éste. De todos modos, el hecho de haber seguido la evolución de las condiciones meteorológicas y de la parte más superficial del manto desde la última observación, e incluso de los últimos días, debería ayudar al observador a realizar y sobre todo entender mejor el resultado de las distintas mediciones.

Como lugar de medida, lo más adecuado sería una zona cercana al jardín meteorológico, en una zona representativa del entorno del observatorio, evitando las sobreacumulaciones de nieve, y donde la nieve no haya sido pisada o transformada artificialmente.

Se incluyen las siguientes medidas, observando en primer lugar las características más superficiales y a continuación los primeros $10 \mathrm{~cm}$ del manto nivoso:

- Estado de la nieve en superficie.

- Hundimiento del primer tubo de la sonda de golpeo.

- Temperatura de la superficie de la nieve.

- Tipo de granos en superficie.

- Espesor de la costra de rehielo.

- Densidad de la nieve en superficie.

\subsubsection{Estado de la nieve en superficie}

La nieve reciente, una vez depositada en el manto, sufre una serie de transformaciones, debido principalmente a la acción del viento, la gravedad y a la acción termodinámica, dando como resultado los diferentes tipos de granos. En esta observación no se tiene que concretar el tipo de grano presente (se realizará posteriormente), pero desde luego estará relacionada con dicha información.

Pasamos a enumerar y describir brevemente las diferentes posibilidades:

\section{Nieve reciente}

Es nieve que prácticamente no ha evolucionado, bien porque está nevando o ha nevado durante las últimas horas o bien porque la nieve caída anteriormente no ha podido evolucionar, debido en general a un período de intenso frío sin viento apreciable tras una nevada.

Se debe diferenciar entre nieve reciente seca y nieve reciente húmeda. La primera es nieve polvo, muy poco densa (muy ligera) y poco brillante, con la que no se puede hacer bolas, formada principalmente por nieve reciente y partículas reconocibles como tipos de grano integrantes. La segunda, posee una mayor densidad y un aspecto más brillante, se puede hacer bolas y se encuentra formada principalmente por nieve reciente, partículas reconocibles y granos redondos. 


\section{Escarcha en superficie}

Se suele formar en noches suficientemente frías, calmadas y con suficiente vapor de agua en la capa de aire más cercana al manto. Su detección no es siempre sencilla y suele presentar una extensión horizontal irregular en el manto, pero su observación es muy importante desde el punto de vista del análisis de estabilidad del manto nivoso, ya que puede representar una capa frágil en su interior.

\section{Nieve venteada}

Presenta en general buena cohesión, mayor cuanto más intenso haya sido el viento. La existencia de dunas, sastrugis y cornisas suele acompañar a este estado de la nieve en superficie.

Habrá que diferenciar entre nieve venteada que se hunde, formada en general por un grano fino de mayor tamaño y partículas reconocibles, y nieve venteada que no se hunde, de una mayor cohesión, formada en general por un grano fino muy pequeño, como la mostrada en la figura 34 . Dicho hundimiento se define mediante un observador de unos $70 \mathrm{Kg}$ de peso, de pie y sin esquís.

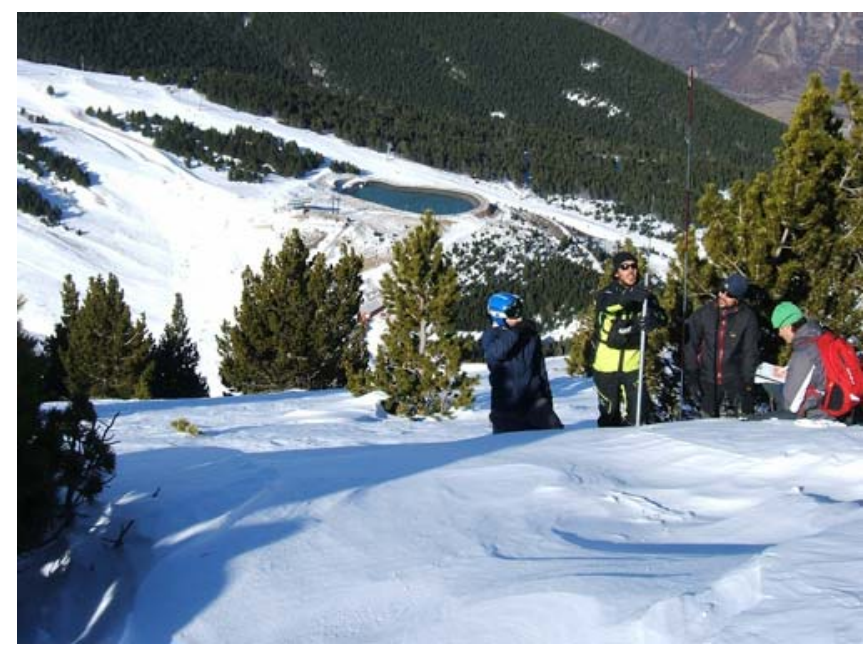

Fig. 34 Manto con grano fino muy cohesionado en superficie

\section{Nieve vieja}

Nieve que ha evolucionado mediante la metamorfosis de fusión hasta su fase terminal, el grano redondo (ver apartado 4.1.4.2.5. de la guía), pero en la que no aparece costra de rehielo. Su aspecto es brillante, debido al contenido de agua líquida, y en ocasiones presenta impurezas que le dan un tono amarronado, debido al largo período de tiempo que ha estado expuesta en la superficie. Se trata de un tipo de nieve con gran capacidad para absorber la radiación solar.

Se debe diferenciar entre nieve vieja húmeda que se hunde (podrida) y nieve vieja húmeda que no se hunde (sin costra), utilizando de nuevo un observador de unos $70 \mathrm{Kg}$ de peso, de pie y sin esquís.

En este sentido, el contenido de agua líquida de la capa de nieve vieja húmeda es el factor clave. Hasta un cierto contenido de agua líquida los granos redondos presentan buena cohesión, soportando bastante bien la sobrecarga a la pisada. Un ejemplo de esto es que, en general, con la nieve vieja húmeda que no se hunde (sin costra) se pueden hacer bolas sin que escurra el agua al apretar. En cambio, con la nieve vieja húmeda que se hunde (podrida), sí que escurre el agua al apretar e incluso hay ocasiones en que no se puede hacer bola debido a la abundancia de agua líquida y ausencia de aire.

\section{Costra de rehielo}

Formada en períodos de fusión diurna y rehielo nocturno superficial. Como es lógico, posee una mayor frecuencia de aparición en cotas bajas y medias que en altas, y en zonas de solana que en umbrías. Es importante diferenciar entre una costra de rehielo que se hunde de una que no se hunde, algo relacionado con su espesor y con la estabilidad del manto. Se utiliza de nuevo un observador de unos $70 \mathrm{Kg}$ de peso, de pie y sin esquís.

\section{Superficie lisa y helada}

Superficie lisa y brillante, en la que los granos han perdido su entidad individual por completo. Se forma, por ejemplo, con intenso frío después de un episodio de lluvia. 


\subsubsection{Hundimiento del primer tubo de la sonda de golpeo}

Con esta medida se pretende analizar la resistencia de la parte superior del manto a la penetración de la sonda de golpeo, midiendo indirectamente la cohesión de dicha capa. El procedimiento a seguir es el siguiente:

- Previamente a la medida hay que dejar el primer tubo de la sonda de golpeo sobre la nieve, para que adquiera una temperatura en equilibrio con esta parte superficial del manto.

- Se pone la punta de la sonda en contacto con la superficie del manto nivoso (ver figura 35).

- Con la sonda en posición totalmente vertical, se deja deslizar libremente entre los dedos.

- Se anota el valor que marca la escala graduada correspondiente al hundimiento de la sonda en la nieve

Como se verá más adelante en la guía, se trata de un método similar al que se utiliza en la primera fase de un sondeo por golpeo, pero en este caso sin varilla en la parte superior del tubo y, por supuesto, sin peso adicional.

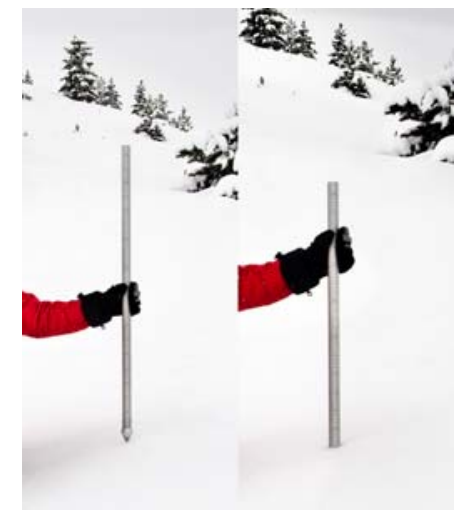

Fig. 35 Hundimiento del primer tubo de la sonda de golpeo

\subsection{Temperatura de la superficie de la nieve}

Una vez se ha estudiado el estado de la superficie del manto, se procede a medir otras variables en los $10 \mathrm{~cm}$ más superficiales de éste.

La primera medida a realizar es la de la temperatura de la superficie de la nieve. Se toma aproximadamente $10 \mathrm{~cm}$ por debajo de la superficie y para efectuar la medida el observador hunde su pie en la nieve no apelmazada. Siguiendo la figura 36, se introduce la sonda del termómetro digital perpendicularmente en la parte frontal de la hendidura en la que no incide el sol y se espera a que se estabilice la medida. Se anota la medida, con una precisión de una décima de grado centígrado.

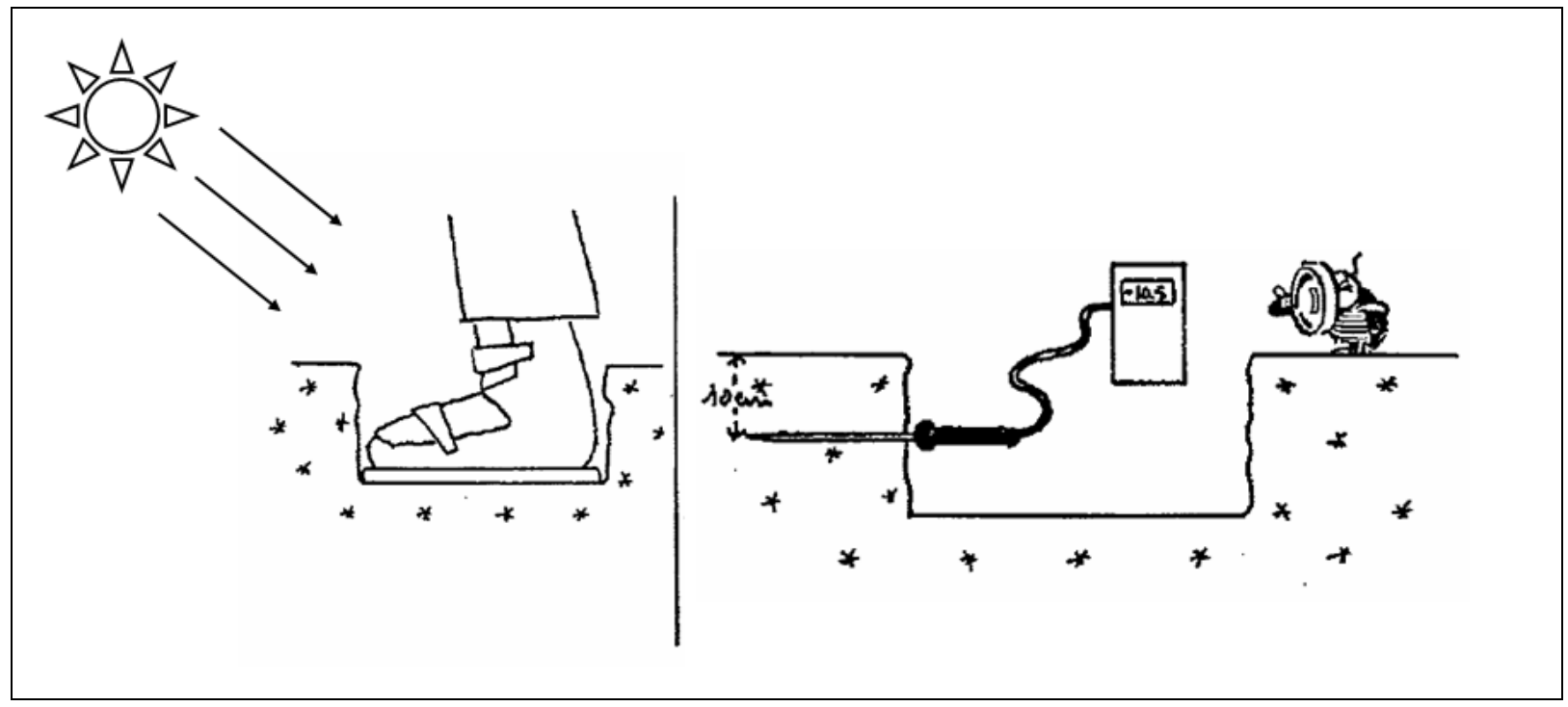

Fig. 36 Medida de la temperatura de la superficie de la nieve (figura adaptada de Météo-France).

Si la parte superficial del manto está muy cohesionada o incluso aparece una costra de rehielo superficial, lo más adecuado para realizar la hendidura será una pala o la propia placa milimetrada. 


\subsection{Tipo de granos en superficie}

Aunque una vez observado el estado del manto en superficie se puede intuir los diferentes tipos de grano existentes, en esta observación habrá que estudiarlos específicamente, empleando para ello la placa milimetrada (o granulométrica) y la lupa. Realizaremos dos tipos de medida:

- El tipo de grano predominante en la superficie

- El tipo de grano predominante entre la superficie y el nivel de $-10 \mathrm{~cm}$

En la primera medida, intentaremos tomar una muestra de granos lo más superficial posible, a poder ser en la parte de la placa en la que se aprecian las cuadrículas que van de 1 a $4 \mathrm{~mm}$, de cara a estimar el diámetro del grano, lo cual nos ayudará en el proceso de decisión. A continuación, se posicionará la lupa encima de la placa y observaremos detenidamente las características de los granos, pero de la forma más rápida posible y con guantes, con el objetivo de no falsear la medida (para no provocar una evolución del grano debido al propio calor del observador). Una buena práctica a la hora de observar encima de la placa sería dar unos pequeños golpes con la lupa a la placa, de tal manera que provoquemos una mayor separación de los granos y podamos individualizar aquellos granos que posean poca cohesión, pero que por otro lado poseen un gran interés. Se realizarán tantas medidas como sean necesarias para estar seguros del tipo de grano existente.

En la segunda medida, procederemos del mismo modo, pero introduciendo la placa a una mayor profundidad, dentro de los $10 \mathrm{~cm}$ del manto por debajo de la superficie. Podríamos aprovechar la pisada realizada para medir la temperatura de la superficie de la nieve, pero como el tiempo transcurrido durante esta medida podría alterar las condiciones propias de la parte frontal liberada, lo más adecuado será realizar una nueva hendidura de unos $10 \mathrm{~cm}$ de profundidad. De nuevo, tomaremos las muestras de la parte frontal que queda a la sombra de los rayos solares incidentes.

Las principales características de cada tipo de grano se encuentran descritas en el apartado de la guía referente al perfil estratigráfico, pero un árbol de decisión que podría ayudar al observador sería el que aparece en la figura 37.

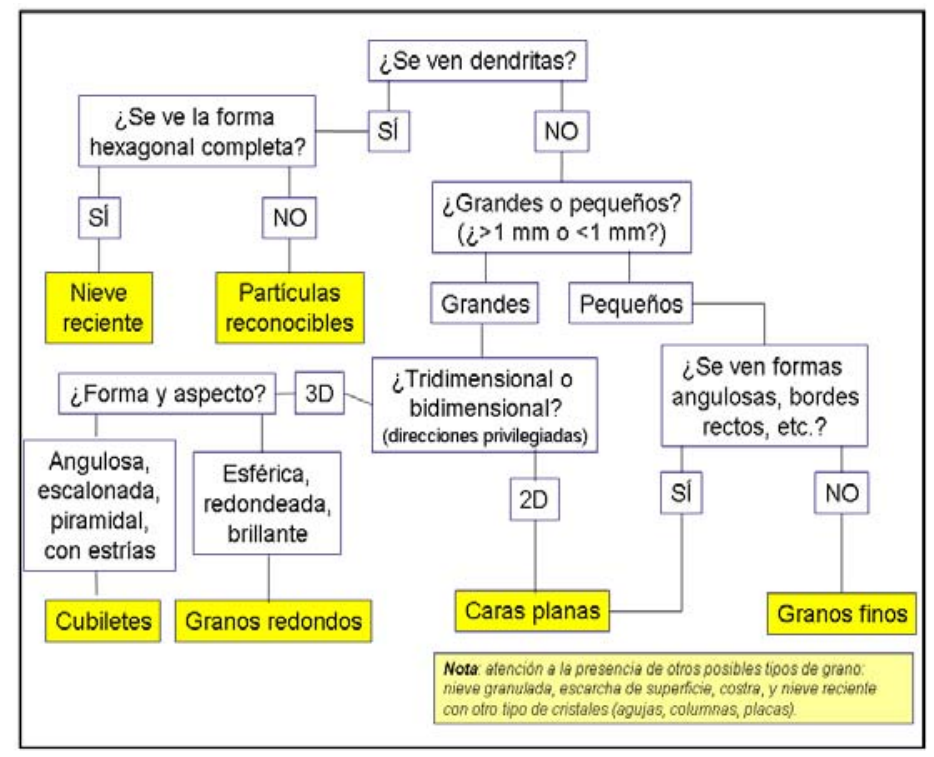

Fig. 37 Árbol de decisión para diferenciar los diferentes

cristales o tipos de grano en el manto nivoso

\subsection{Espesor de la costra de rehielo}

En caso de observar costra de rehielo en la superficie del manto nivoso, habrá que medir su espesor. En ausencia de ésta, habrá que mirar si existe una costra enterrada en los $10 \mathrm{~cm}$ del manto más cercanos a la superficie. Para ello, se puede aprovechar la hendidura realizada en la observación anterior.

Una costra enterrada es bastante fácil de detectar debido al ruido que se produce (cruje) si pasamos el guante o la placa milimetrada por la parte frontal del manto que queda al descubierto, y debido a su aspecto brillante, además de su dureza (no se puede introducir un lápiz).

Una manera de cuantificarla puede ser con la propia escala graduada en $\mathrm{cm}$ del primer tubo de la sonda de golpeo. 


\subsection{Densidad de la nieve en superficie}

El material necesario para realizar esta medida es el siguiente:

- Tubo de densidad: de plástico duro, con un extremo biselado para facilitar la penetración en la nieve. Posee un volumen de 0.5 I (500 cm3), sección de $25 \mathrm{~cm} 2$ y altura de $20 \mathrm{~cm}$.

- Dinamómetro: capaz de medir al menos un peso correspondiente a una masa de $500 \mathrm{~g}$, con una escala que suele estar graduada cada $10 \mathrm{~g}$.

- Placa milimetrada (o granulométrica): también se admite otra herramienta cortante.

- Bolsa de plástico.

Sólo se mide cuando ha nevado más de $5 \mathrm{~cm}$ desde la última observación y cuando, aunque no se haya alcanzado dicha cantidad o no haya nevado desde la última observación, la capa de $10 \mathrm{~cm}$ bajo la superficie es homogénea (un solo estrato). En función de esto, existen dos métodos para medirla:

- Ha nevado más de $\mathbf{5} \mathbf{~ c m}$ desde la última observación (muestreo vertical): aprovechando el espesor de nieve depositado sobre la placa de nieve reciente, se realiza una medida de la densidad de la nieve recién caída, de modo que no interaccione con la nieve preexistente en el manto. El modo de proceder es el siguiente:

o Se coloca el tubo dentro de la bolsa y se pesa su conjunto colgándolo del dinamómetro. Anotar la medida (primera medida del peso).

- Se coloca el tubo de densidad en posición vertical sobre la superficie de la nieve depositada en la placa de nieve reciente, con el extremo biselado en contacto con la nieve. Hundir el tubo de densidad, imprimiéndole un ligero movimiento de rotación, hasta que llegue a la placa de nieve reciente. Anotar la altura de nieve $H$ que registra la varilla graduada de la placa de nieve reciente, la cual se corresponde con la altura del tubo ocupada por nieve.

- En caso de que haya más de $20 \mathrm{~cm}$ sobre la placa de nieve reciente, hundir el tubo hasta llenarlo y cortar por la base del tubo con la placa milimetrada, intentando no comprimir su contenido. En este caso, como es lógico, la altura que se anotará será $20 \mathrm{~cm}$.

- Retirar la nieve que rodea al tubo para posteriormente retirar dicho tubo deslizándolo, en posición vertical, sobre la placa de nieve reciente y finalmente sobre la placa milimetrada.

- Limpiar los pequeños restos de nieve que puedan quedar todavía en la parte exterior del tubo e introducirlo en la bolsa. Pesarlo y anotar la medida (segunda medida del peso).

o Obtener la masa $M$ de la nieve existente en el tubo de medio litro restando las dos medidas del peso.

- Calcular la densidad con la siguiente fórmula, que tiene en cuenta la sección del tubo:

$$
\rho\left(\frac{\mathrm{Kg}}{\mathrm{m}^{3}}\right)=40 \frac{M(\mathrm{~g})}{H(\mathrm{~cm})}
$$

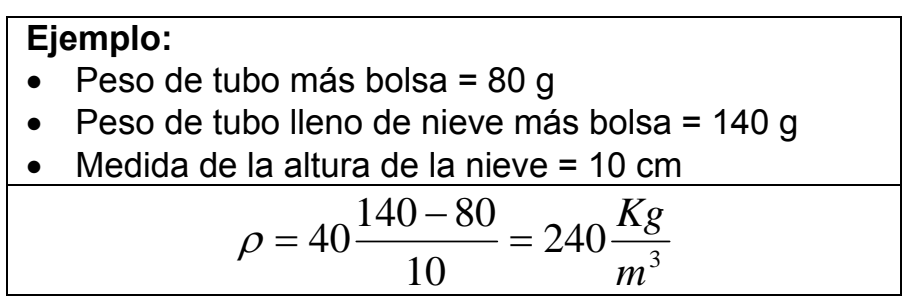

- No ha nevado más de $5 \mathrm{~cm}$ desde la última observación pero la capa de $10 \mathrm{~cm}$ bajo la superficie es homogénea (muestreo horizontal): se procede tal como se describe en el apartado del perfil estratigráfico de la guía, obteniendo la densidad del estrato formado por los $10 \mathrm{~cm}$ más superficiales del manto. 


\subsection{Medidas y estimaciones en altitud}

Se incluyen las siguientes medidas:

- Viento

- Espesor total y espesor de nieve reciente

- Ventisca

\subsubsection{Viento, espesor total y espesor de nieve reciente en altitud}

Estas medidas se toman cuando la estación está equipada con el correspondiente instrumental en altitud: anemómetro, jalón y placa de nieve reciente. El procedimiento para realizar estas medidas se explica en el apartado de medidas dentro del jardín meteorológico de la guía.

\subsubsection{Ventisca en altitud}

Esta medida se realiza siempre, independientemente si se dispone de instrumental en altitud. Aunque se trata de una medida subjetiva, proporciona una información muy relevante de cara a la posible formación de placas de viento en altitud. Es importante no confundirla con la observación de ventisca en la estación y se puede realizar una primera estimación durante las observaciones previas antes de llegar al jardín meteorológico, como ya se ha visto en el correspondiente apartado de la guía.

Para observarla adecuadamente, en primer lugar es necesario orientarse adecuadamente en la estación. Por ejemplo, se puede situar correctamente el Norte geográfico e inducir a partir de éste el resto de direcciones. Es suficiente clasificar la dirección por cuadrantes, según la figura 38.

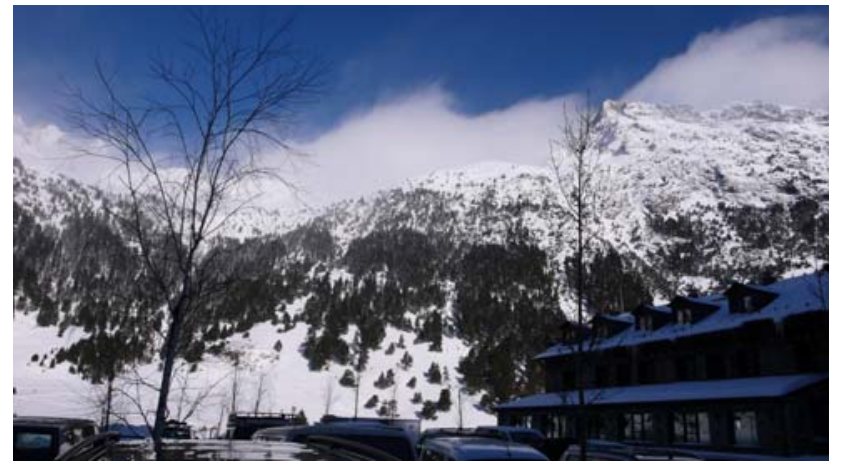

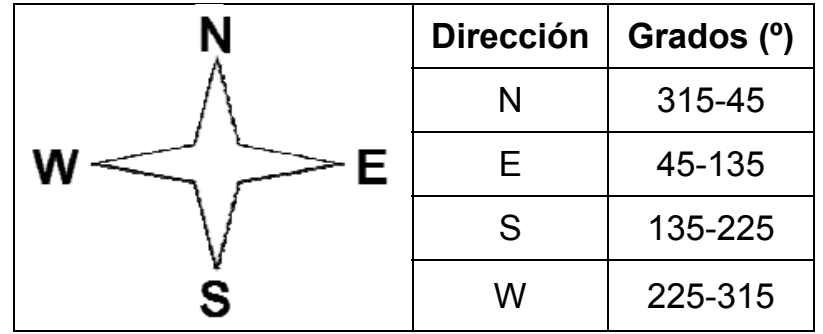

Fig. 38 Rosa de los vientos, con tabla adjunta, para la dirección de las ventiscas en altitud
Fig. 39 Ventisca fuerte del Norte, en la que el observador está orientado hacia esta dirección aproximadamente.
A continuación, observaremos si las cumbres o crestas de las montañas que rodean al observatorio "humean" (ver figura 39). El fenómeno se forma debido al levantamiento y transporte de la nieve por parte del viento mediante un mecanismo llamado de difusión turbulenta, que eleva la nieve movilizable varios metros e incluso en ocasiones centenares de metros. La dirección de la ventisca corresponderá a la dirección del viento que la produce, es decir, la contraria hacia la que se dirige el "humo" o transporte de la nieve. Así, una ventisca del Norte, producirá principalmente un transporte de nieve hacia el Sur, y se apreciará sobre todo en las cumbres y crestas que se vean al mirar hacia el Norte desde el observatorio.

En cuanto a la intensidad de la ventisca, aunque existen escalas que intentan graduar un mayor o menor transporte de la nieve, como por ejemplo la de la EAWS (European Avalanche Warning Services), la cual se basa en el espesor de nieve sobreacumulado, no existe una norma concreta que ayude al observador a la hora de calificar entre ventisca moderada o fuerte sin desplazarse hasta la zona en altitud. En todo caso, cuanta mayor dimensión vertical tenga la ventisca mayor será la intensidad de ésta.

En la observación de la ventisca en altitud es importante no confundirla con nubosidad a sotavento de las cimas, tipo nubes bandera. 


\subsection{Observación de aludes y estimación del nivel de peligro local}

La observación de los aludes, tanto espontáneos como provocados y tanto en el tiempo presente como en el pasado, proporciona en el marco de las tareas operativas del observador nivometeorológico, una valiosa información de aplicación en diversos campos de la nivometeorología. Algunos de ellos son:

- Conjuntamente con otras observaciones proporciona información acerca de la estabilidad del manto nivoso. Complementariamente, la no observación de aludes es también un indicador de la estabilidad del manto nivoso.

- Aporta información respecto a las áreas más favorables al desencadenamiento de aludes y a los caminos y zonas de detención asociados, es decir, en el campo de la predicción espacial.

- La información sobre aludes es esencial en las tareas de prevención activa y pasiva, especialmente en la evaluación de la efectividad de tales acciones, y en la verificación de modelos numéricos de predicción de aludes.

- Y también su observación aporta conocimiento sobre el fenómeno en si.

La observación de aludes no se debe restringir a aquellas zonas directamente visibles desde el emplazamiento del jardín meteorológico sino que también deben considerarse aquellos aludes que tanto el observador como eventualmente otras personas de su confianza hayan observado en el entorno del observatorio a lo largo de sus desplazamientos.

Siguiendo el orden presente en la clave NIVOMET, los elementos a observar son:

Para los aludes de desencadenamiento espontáneo (grupo propio en la clave NIVOMET):

\subsubsection{Número de aludes}

Se trata de anotar según la clave correspondiente todos los aludes observados desde la última observación (en el caso de la observación de las 13 UTC, desde las 08 UTC). En el caso de observarse solamente coladas se cifrará 0 (cero) en el lugar correspondiente.

\subsubsection{Tamaño de los aludes}

Para la determinación del tamaño de los aludes podrá hacerse uso de la tabla propuesta por la EAWS y el cifrado estará vinculado tanto al grupo mayoritario como a la presencia de aludes de mayores dimensiones. Si solamente se observan coladas se cifrará 0 (cero) en el lugar correspondiente. En el caso de aludes grandes se tendrán en cuenta las trayectorias recorridas de forma que, si por lo menos una recorre un camino inhabitual se cifrará 7 en el lugar correspondiente, independientemente del número de aludes de todas las dimensiones. El cifrado requiere, por lo tanto, el conocimiento de la distribución espacial de los aludes grandes en el entorno del observatorio.

El tamaño de los aludes, clasificado en una escala de 1 a 5 , se puede establecer en función de tres criterios distintos pero complementarios. El primero de ellos tiene en cuenta la zona de llegada, distinguiendo fundamentalmente según se trate de ladera o fondo de valle y está en directa relación con la longitud de la trayectoria recorrida por el alud y el volumen de nieve movilizado (tercer criterio).

A su vez, estos dos criterios están asociados a unos determinados daños potenciales sobre las personas $u$ otros elementos y sobre el entorno. El rango de efectos de los aludes va desde aquellos relativamente inofensivos, aunque capaces de tirar al suelo a una persona (purgas o coladas) a los aludes muy grandes, capaces de modificar substancialmente el paisaje y producir un desastre. 
Nuevamente es necesario referenciar la longitud de un alud a los aludes habituales y los extremos de una zona, para lo cual es conveniente disponer de una base de datos de aludes de la zona.

\begin{tabular}{|c|c|c|c|c|}
\hline Tamaño & Nombre & $\begin{array}{l}\text { Clasificación según la zona de } \\
\text { Ilegada }\end{array}$ & $\begin{array}{c}\text { Clasificación según el daño } \\
\text { potencial }\end{array}$ & $\begin{array}{l}\text { Clasificación } \\
\text { cuantitativa }\end{array}$ \\
\hline $\begin{array}{c}\text { Tamaño } \\
1\end{array}$ & $\begin{array}{l}\text { Purga } \\
\text { o } \\
\text { colada }\end{array}$ & \begin{tabular}{||l} 
Acumulación de nieve sin peligro de \\
enterrar pero con peligro de caída.
\end{tabular} & $\begin{array}{l}\text { Relativamente inofensivo para } \\
\text { las personas. }\end{array}$ & \begin{tabular}{|l} 
Longitud $<50 \mathrm{~m}$ \\
Volumen $<100 \mathrm{~m}^{3}$
\end{tabular} \\
\hline \begin{tabular}{|c|} 
Tamaño \\
$\mathbf{2}$
\end{tabular} & $\begin{array}{c}\text { Alud } \\
\text { pequeño }\end{array}$ & El alud se para en la pendiente. & $\begin{array}{l}\text { Puede enterrar, herir o matar a } \\
\text { una persona. }\end{array}$ & \begin{tabular}{|l|} 
Longitud $<100 \mathrm{~m}$ \\
Volumen $<1.000 \mathrm{~m}^{3}$ \\
\end{tabular} \\
\hline $\begin{array}{c}\text { Tamaño } \\
\mathbf{3}\end{array}$ & $\begin{array}{l}\text { Alud } \\
\text { mediano }\end{array}$ & \begin{tabular}{|l} 
El alud alcanza el final de la \\
pendiente.
\end{tabular} & \begin{tabular}{|l} 
Puede enterrar o destruir un \\
coche, causar daños a un \\
camión, destruir un edificio \\
pequeño o romper un número \\
pequeño de árboles.
\end{tabular} & $\mid$\begin{tabular}{|l|}
$\mid$ Longitud $<1.000 \mathrm{~m}$ \\
Volumen
\end{tabular} \\
\hline $\begin{array}{c}\text { Tamaño } \\
\mathbf{4}\end{array}$ & $\begin{array}{l}\text { Alud } \\
\text { grande }\end{array}$ & \begin{tabular}{|l} 
El alud atraviesa zonas planas \\
$($ considerablemente por debajo de \\
$30^{\circ}$ ) una distancia $>50 \mathrm{~m}$ y puede \\
llegar al fondo de valle.
\end{tabular} & \begin{tabular}{|l|l|} 
Puede enterrar y destruir un \\
vagón de tren, un camión \\
grande, varios edificios o una \\
parte de bosque.
\end{tabular} & $\mid$\begin{tabular}{|l|}
$\mid$ Longitud $\sim 1-2 \mathrm{Km}$ \\
Volumen $<100.000 \mathrm{~m}^{3}$
\end{tabular} \\
\hline $\begin{array}{c}\text { Tamaño } \\
5\end{array}$ & $\begin{array}{l}\text { Alud muy } \\
\text { grande }\end{array}$ & $\begin{array}{l}\text { Llega al fondo de valle. Alud más } \\
\text { grande conocido. }\end{array}$ & $\begin{array}{|lll|}\text { Puede modificar el } & \text { paisaje. } \\
\text { Posibilidad de } & \text { daños } \\
\text { desastrosos. } & & \end{array}$ & \begin{tabular}{|l|} 
Longitud $\sim 3 \mathrm{Km}$ \\
Volumen $>100.000 \mathrm{~m}^{3}$
\end{tabular} \\
\hline
\end{tabular}

\subsubsection{Tipo de alud}

La clasificación del tipo de alud se hará tanto según el tipo de nieve movilizado (grado de humedad, edad, dureza) como de la forma de salida (puntual, lineal) y de su profundidad (superficial, de fondo). Se considerará también la presencia de grietas en el manto nivoso aunque no haya habido movilización masiva y rápida del mismo.

La distinción entre alud de placa dura y friable se hará habitualmente a partir del tipo de depósito aparecido: bloques angulosos en el primer tipo y similar al de los aludes de nieve polvo en el segundo. La forma de salida también será relativamente fácil de observar a distancia y también si se trata de un alud de fondo o superficial. En cuanto al grado de humedad de la nieve movilizada, salvo que se haga una inspección in situ, deberá inferirse a partir de otros datos como hora del día, época del año, exposición de la ladera, temperatura, y estado de la nieve en el jardín meteorológico. Normalmente, se hace referencia al contenido de agua líquida en la zona de salida, asumiendo que en la zona de llegada puede ser distinto.

\subsubsection{Altitud de la zona de salida}

Para una determinación rápida es útil conocer las altitudes de los puntos más significativos entorno al observatorio y también puede ayudar el uso de una cartografía adecuada. Como en los demás apartados, en el caso de observarse varios aludes se cifrarán los valores mayoritarios.

\subsubsection{Orientación de la zona de salida}

Se cifrará la orientación dominante según las 8 direcciones principales, y en el caso de que ésta no exista se cifrará un 9 . Siempre se hará referencia a la orientación en la zona de salida aunque a priori es posible que la orientación varíe a lo largo de la trayectoria de un alud. 
Para los aludes de desencadenamiento provocado (grupo propio en la clave NIVOMET):

\subsubsection{Tipo de desencadenamiento}

Se valorará la eficacia de los métodos de desencadenamiento artificiales usados, considerándolos positivos o negativos según si han provocado aludes o no. También se cifrarán los desencadenamientos accidentales, es decir, no voluntarios, asociados a sobrecargas debidas al paso de personas, máquinas, etc. Se cifrará su valor en función de las distintas combinaciones que se produzcan entre ambos factores.

\subsubsection{Tipo de alud}

Igual que para los aludes espontáneos.

\subsubsection{Altitud de la zona de salida}

Igual que para los aludes espontáneos.

\subsubsection{Exposición de la zona de salida}

Igual que para los aludes espontáneos.

\subsubsection{Estimación del nivel de peligro local}

La estimación del peligro de desencadenamiento de aludes se basará en la Escala Europea de Peligro de Aludes, establecida en 5 niveles (Ver página siguiente)

La estimación tendrá validez en el entorno del observatorio en sentido amplio, incluyendo sus principales accesos, no a una escala regional ni tampoco a la escala de una ladera en concreto. Como referencia, dado que la superficie mínima a la que se aplica la Escala Europea de Peligro de Aludes son $100 \mathrm{Km}^{2}$, la estimación debe hacerse para el terreno hasta unos 6-10 Km de distancia (en línea recta) alrededor del observatorio, o una zona más o menos cuadrada de $10 \times 10 \mathrm{Km}$ centrada en el observatorio.

Se trata de una valoración en el momento de realizar la observación y elaborar el parte NIVOMET. Por lo tanto, se fundamentará en los datos recogidos en la observación meteorológica, y en las condiciones presentes y observadas en los días previos del manto nivoso, no en su evolución futura, así como en la observación de aludes realizada.

El nivel de peligro cifrado en el NIVOMET debe ser, pues, siempre coherente sobre todo con las observaciones de las últimas 24 horas; nieve caída y/o precipitaciones en forma líquida, temperaturas máxima, mínima y actual, viento, aludes observados, meteoros, nubosidad, etc. Por ejemplo, no deberemos cifrar un nivel de peligro 5 si no hemos detectado o sospechamos fundadamente que hay actividad natural de aludes.

También, la estimación del peligro de desencadenamiento de aludes será resultado de las distintas evaluaciones de la estabilidad del manto nivoso realizadas mediante los diferentes tests, el sondeo por golpeo, el perfil estratigráfico, y de las características básicas de la superficie del manto nivoso. En esta evaluación también tendrán gran relevancia el conocimiento del tiempo pasado, el conocimiento del medio por parte del observador y su experiencia en distintas situaciones nivometeorológicas en el entorno del observatorio.

Como indicadores que ayuden a valorar el nivel de peligro o su evolución, pueden tenerse en cuenta las tablas de las páginas siguientes: 


\begin{tabular}{|c|c|c|c|}
\hline Nivel de peligro & Icono & $\begin{array}{c}\text { Estabilidad del manto } \\
\text { nivoso }\end{array}$ & Probabilidad de desencadenamiento de aludes \\
\hline 5. MUY FUERTE & & $\begin{array}{l}\text { El manto nivoso es, en } \\
\text { general, muy inestable. }\end{array}$ & $\begin{array}{l}\text { Son esperables numerosos aludes grandes, en algunos casos muy grandes, } \\
\text { desencadenados espontáneamente, incluso en laderas sólo moderadamente } \\
\text { inclinadas. }\end{array}$ \\
\hline 4. FUERTE & & $\begin{array}{l}\text { El manto nivoso está } \\
\text { débilmente estabilizado } \\
\text { en la mayoría de laderas } \\
\text { empinadas }\left({ }^{*}\right) \text {. }\end{array}$ & $\begin{array}{l}\text { Es probable el desencadenamiento de aludes, incluso debido a sobrecargas } \\
\text { débiles }\left({ }^{* *}\right) \text {, en muchas laderas empinadas }\left({ }^{*}\right) \text {. } \\
\text { En algunos casos, son esperables numerosos aludes de tamaño medio, y } \\
\text { frecuentemente grande, desencadenados espontáneamente. }\end{array}$ \\
\hline 3. NOTABLE & & $\begin{array}{l}\text { El manto nivoso está } \\
\text { entre moderada y } \\
\text { débilmente estabilizado } \\
\text { en numerosas laderas } \\
\text { empinadas }\left({ }^{*}\right) \text {. }\end{array}$ & $\begin{array}{l}\text { Es posible el desencadenamiento de aludes, incluso debido a sobrecargas } \\
\text { débiles }\left({ }^{* *}\right) \text {, especialmente en las laderas empinadas cuyas características se } \\
\text { describen en el boletín. } \\
\text { En algunos casos, son posibles aludes de dimensiones medias y a veces } \\
\text { grandes, desencadenados espontáneamente. }\end{array}$ \\
\hline 2. LIMITADO & & $\begin{array}{l}\text { El manto nivoso está en } \\
\text { algunas laderas } \\
\text { empinadas solo } \\
\text { moderadamente } \\
\text { estabilizado (*); en el } \\
\text { resto, está, en general, } \\
\text { bien estabilizado. }\end{array}$ & $\begin{array}{l}\text { Es posible el desencadenamiento de aludes, sobre todo por sobrecargas } \\
\text { fuertes, especialmente en aquellas laderas empinadas cuyas características se } \\
\text { describen en el boletín. } \\
\text { No se esperan aludes grandes desencadenados espontáneamente. }\end{array}$ \\
\hline 1. DÉBIL & & $\begin{array}{l}\text { El manto nivoso está, en } \\
\text { general, bien estabilizado. }\end{array}$ & $\begin{array}{l}\text { En general, sólo es posible desencadenar aludes en laderas muy inclinadas o } \\
\text { en terreno especialmente desfavorable }\left({ }^{*}\right) \text { y a causa de sobrecargas fuertes } \\
\left({ }^{* *}\right) \text {. } \\
\text { Espontáneamente sólo pueden desencadenarse coladas o aludes pequeños. }\end{array}$ \\
\hline
\end{tabular}

$\left(^{*}\right)$ Las áreas favorables a los aludes se describen con mayor detalle en los boletines de peligro de aludes (altitud, orientación, tipo de terreno, etc.).

- Terreno poco o moderadamente inclinado: laderas con una inclinación menor de $30^{\circ}$

$>$ Laderas empinadas: laderas con una inclinación mayor de $30^{\circ}$.

Terreno muy inclinado o extremo: laderas de más de $40^{\circ}$ de inclinación y terreno especialmente desfavorable debido a su perfil, la proximidad a las crestas o la escasa rugosidad de la superficie del suelo subyacente.

$\left({ }^{* *}\right)$ Sobrecargas:

$>$ Débil: un único esquiador o surfista, moviéndose con suavidad y sin caerse. Grupo de personas que respetan la distancia de seguridad (mínimo de $10 \mathrm{~m}$ ). Raquetista.

- Fuerte: dos o más esquiadores/surfistas etc. sin respetar la distancia de seguridad. Máquinas pisanieves u otros vehículos que circulen sobre la nieve, explosivos. Ocasionalmente, un único excursionista o escalador.

Fig. 41 Escala Europea de Peligro de Aludes 


\begin{tabular}{|c|c|c|c|c|c|c|c|c|c|}
\hline & \multirow[b]{2}{*}{$\begin{array}{l}\text { PROBABILIDAD DE } \\
\text { DESENGADENAMIENTO } \\
\text { DE ALUDES }\end{array}$} & \multicolumn{8}{|c|}{ PROBABILIDAD DE DESENCADENAMIENTO EN FUNCIÓN DE LA SOBRECARGA O DEL TAMAÑO DE LOS ALUDES } \\
\hline & & $\begin{array}{c}\text { EN GENERAL } \\
\text { SOLO CON } \\
\text { SOBRECARGAS } \\
\text { FUERTES }\end{array}$ & $\begin{array}{l}\text { PRINCIPALMENTE } \\
\text { CON FUERTES } \\
\text { SOBRECARGAS } \\
\text { (PERO TAMBIEN } \\
\text { POSIBLES CON } \\
\text { SOBRECARGAS } \\
\text { DEBILES) }\end{array}$ & $\begin{array}{l}\text { YA POSIBLES } \\
\text { CON } \\
\text { SOBRECARGAS } \\
\text { DEBILES }\end{array}$ & $\begin{array}{l}\text { PROBABLES } \\
\text { CON } \\
\text { SOBRECARGAS } \\
\text { DEBILES }\end{array}$ & \begin{tabular}{|l} 
SON POSIBLES \\
SALIDAS \\
ESPONTANEAS \\
Ó \\
DE ALUDES DE \\
TAMANO \\
PEQUEÑO
\end{tabular} & \begin{tabular}{|l|} 
SON POSIBLES \\
SALIDAS \\
ESPONTANEAS \\
DE ALUDES DE \\
TAMANO MEDIO, \\
EN ALGUNOS \\
CASOS DE \\
TAMANOO \\
GRANDE
\end{tabular} & \begin{tabular}{|c||} 
SON PROBABLES \\
SALIDAS \\
ESPONTANEAS DE \\
MUCHOS ALUDES \\
DE TAMANO \\
MEDIO, EN \\
ALGUNOS CASOS \\
DE TAMANOO \\
GRANDE
\end{tabular} & \begin{tabular}{|l} 
SON PROBABLES \\
SALIDAS \\
ESPONTANEAS \\
DE NUMEROSOS \\
ALUDES DE \\
TAMAÑO \\
GRANDE
\end{tabular} \\
\hline 듬 & $\begin{array}{l}\text { ALUDES } \\
\text { EN ESCASAS LADERAS } \\
\text { (ESPECIFIICABLES EN EL L } \\
\text { BOLETIN DE ALUDES *) }\end{array}$ & & & & & & & & \\
\hline 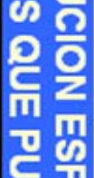 & $\begin{array}{c}\text { ALUDES } \\
\text { EN ALGUNAS LADERAS } \\
\text { EMPINADAS } \\
\text { (ESPECIFICABLES EN EL } \\
\text { BOLETIN DE ALUDES }{ }^{*} \text { ) }\end{array}$ & & & & & & & & \\
\hline 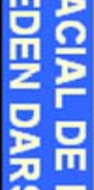 & $\begin{array}{c}\text { ALUDES } \\
\text { EN MUCHAS LADERAS } \\
\text { EMPINADAS } \\
\text { (ESPECIFICABLES EN EL } \\
\text { BOLETIN DE ALUDES *) }\end{array}$ & & & & - & & & & \\
\hline 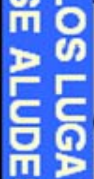 & $\begin{array}{c}\text { ALUDES } \\
\text { EN MUCHAS LADERAS } \\
\text { EMPINADAS } \\
\text { (NO ESPECIFICABLES EN } \\
\text { BOLETIN DE ALUDES *) }\end{array}$ & & & 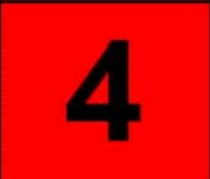 & 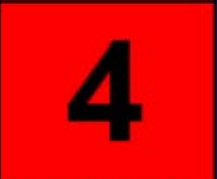 & & & 2 & 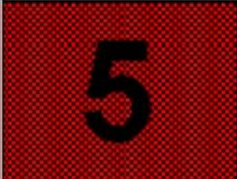 \\
\hline 岂 & $\begin{array}{c}\text { ALUDES } \\
\text { TAMBIEN EN LADERAS } \\
\text { MODERADAMENTE } \\
\text { EMPINADAS }\end{array}$ & & & & s. & & & 일 & , s \\
\hline Esp & ecificables en térmnos d & (10 & yore & & & & & exposició & ve. \\
\hline Casilla & s en blanco indican nivel & gro & onsider & & & & & Versión $\mathrm{E}$ & AWS 2011-0: \\
\hline
\end{tabular}

Fig. 42 Matriz para la estimación del peligro de aludes (fuente: EAWS) 


\begin{tabular}{|c|c|c|c|}
\hline \multicolumn{4}{|c|}{ INDICADORES PREVIOS DEL PELIGRO POTENCIAL DE ALUDES } \\
\hline Indicador & Mayor peligro de aludes & Peligro indeterminado & Menor peligro de aludes \\
\hline Clima & Continental & Intermedio de montaña (entre marítimo y continental) & Marítimo \\
\hline Terreno avalanchoso del entorno del obs. & \begin{tabular}{|l|} 
Pendientes entre $35^{\circ}$ y $40^{\circ}$ \\
\end{tabular} & Pendientes entre $25^{\circ}$ y $30^{\circ}$ o entre $40^{\circ}$ y $60^{\circ}$ & Pendientes menores que $25^{\circ}$ o mayores que $60^{\circ}$ \\
\hline \multicolumn{4}{|c|}{ INDICADORES NIVOLÓGICOS DEL PELIGRO DE ALUDES } \\
\hline Aludes recientes ${ }^{* *}$ & En las últimas 24 horas & Entre las últimas 24 y 48 horas & Hace más de 48 horas o sin aludes \\
\hline Descripción del manto ** & En general, poco profundo, poco denso y poco consolidado & No se conoce o es variable & En general, profundo, denso y consolidado \\
\hline Estabilidad del manto ** & Inestable & No se conoce o lo que se sabe es poco concluyente & Estable \\
\hline Superficie de la nieve ** & Dura, pulverulenta o fría & Se desconoce o no es uniforme & Blanda, consistente o con temperatura cercana a $0^{\circ} \mathrm{C}$ \\
\hline Historial meteorológico & En general, frío y seco & No se conoce o la meteorología ha sido cambiante & En general, relativamente templado y húmedo \\
\hline
\end{tabular}

\section{INDICADORES METEOROLÓGICOS DEL PELIGRO DE ALUDES}

\section{PRECIPITACIONES}

Cantidad de nieve reciente**

Intensidad de la nevada**

Equivalente en agua líquida de la nevada*

Densidad de la nieve reciente ${ }^{* \star}$

Lluvia**

Tendencia del episodio meteorológico

\section{Aumento del peligro de aludes}

$30 \mathrm{~cm}$ o más en 24 horas

Menos de $30 \mathrm{~cm}$ en 24 horas

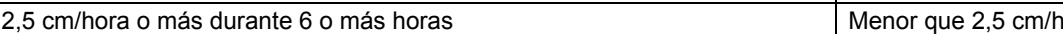

\begin{tabular}{l|l}
$25 \mathrm{~mm}$ o más en 24 horas & Menos de $25 \mathrm{~mm}$ en 24 horas
\end{tabular}

\begin{tabular}{l|l} 
Más de $15 \mathrm{~cm}$ de nieve con densidad igual o superior a $90 \mathrm{Kg} / \mathrm{m} 3$ & Menos de $30 \mathrm{~cm}$ de nieve con densidad igual o inferior a $60 \mathrm{Kg} / \mathrm{m} 3$
\end{tabular}

\begin{tabular}{l|l} 
Presente en algún momento & Ausente
\end{tabular}

\begin{tabular}{l|l} 
Empezó con carácter frío, evolucionando a cálida & Ausente \\
\hline
\end{tabular}

(De $927 \mathrm{~m} / \mathrm{s}$

De 9 a $27 \mathrm{~m} / \mathrm{s}$

Superior a $27 \mathrm{~m} / \mathrm{s}$ con nieve de densidad mayor a $100 \mathrm{Kg} / \mathrm{m} 3$

Entre 7 y $9 \mathrm{~m} / \mathrm{s}$ con nieve de densidad menor a $50 \mathrm{Kg} / \mathrm{m} 3$

Menor que $9 \mathrm{~m} / \mathrm{s}$ o mayor que $27 \mathrm{~m} / \mathrm{s}$

Sostenida

Variable

\section{Aumento superior a $8^{\circ} \mathrm{C}$ en 12 horas, próximas o superiores a $0^{\circ} \mathrm{C}$}

Por encima de las cotas de desencadenamiento de aludes

Por encima de $0{ }^{\circ} \mathrm{C}$ a las cotas de desencadenamiento durante más de $24 \mathrm{~h}$

- Muy bajas $\left(<-10^{\circ} \mathrm{C}\right)$ durante mucho tiempo

. Poco espesor de manto $(<1 \mathrm{~m})$ y temperaturas muy bajas $\left(<-10^{\circ} \mathrm{C}\right)$

Cielo despejado con temperatura menor que $-10^{\circ} \mathrm{C}$

$y$ vientos de $5 \mathrm{~m} / \mathrm{s}$ o menos

Cielo despejado o nubes poco espesas con temperaturas relativamente

suaves y altos ángulos de incidencia del sol, esp. sobre laderas de solana
Suben menos de $8^{\circ} \mathrm{C}$ en 12 horas, siempre bien por debajo de $0^{\circ} \mathrm{C}$

Se mantienen entre $-4^{\circ} \mathrm{C}$ y $-10^{\circ} \mathrm{C}$

Por debajo de las cotas de desencadenamiento de aludes

Por encima de $0^{\circ}$ a las cotas de desencadenamiento durante 12 y $24 \mathrm{~h}$ Entre $-4{ }^{\circ} \mathrm{C}$ y $-10^{\circ} \mathrm{C}$

Nuboso o muy nuboso

Despejado con temperaturas relativamente suaves

Intervalos nubosos con viento mayor que $5 \mathrm{~m} / \mathrm{s}$

Cubierto
Cobertura nubosa diurna*

erreno y observatorios nivometeorológicos: tests de estabilidad, sondeos por golpeo y perfiles estratigráficos, observaciones meteorológicas.

Fig. 43 Guía para la estimación del nivel de peligro local de aludes a partir de las observaciones nivometeorológicas

CUADRO ADAPTADO DE PROGRAMA COMET Traducción AEMET D.T en Aragón 


\begin{tabular}{|c|c|c|c|c|}
\hline Test & $\begin{array}{c}\text { Rutschblock } \\
\text { RB }\end{array}$ & $\begin{array}{c}\text { Compresión } \\
\text { CT }\end{array}$ & $\begin{array}{c}\text { Stuffblock } \\
\text { SB }\end{array}$ & $\begin{array}{c}\text { Pala } \\
\text { ST }\end{array}$ \\
\hline $\begin{array}{c}\text { Más inestable } \\
\begin{array}{c}\text { Marginalmente } \\
\text { estable }\end{array}\end{array}$ & RB4-5 & CT $\leq 12$ & SB $\leq 20$ & ST $\leq$ E \\
\hline Más estable & RB6-7 & CT $\geq 25$ & SB $30-40$ & STM - H \\
\hline
\end{tabular}

Fig. 44 Tabla simplificada de correlación entre test de estabilidad del manto nivoso Moore, 2006)

- Inestable indica que en laderas similares a la ladera testada (incluyendo orientación y pendiente) es probable que un esquiador pueda desencadenar un alud. Mejor pasar por ese tipo de laderas en otra ocasión o en otra zona.

- Marginalmente estable indica condiciones poco claras (es posible que los esquiadores desencadenen aludes al esquiar sobre laderas similares y se aconseja recabar más información sobre la estabilidad del manto; se recomienda ser conservador en la elección de la ruta).

- Más estable indica un potencial de desencadenamiento de aludes bajo (no insignificante) en laderas similares a la ladera testada.

\begin{tabular}{|l|l|}
\hline \multicolumn{2}{|c|}{ Test de la columna extendida ECT } \\
\hline INESTABILIDAD & ECTPV, ECTP\#\# (especialmente con ruptura y propagación en el mismo golpe) \\
\hline ESTABILIDAD & ECTN\#\# \\
\hline NO CONCLUYENTE & ECTX \\
\hline
\end{tabular}




\subsection{CIFRADO DE LAS OBSERVACIONES. LA CLAVE NIVOMET}

Las observaciones que se realizan para elaborar el parte NIVOMET se cifran según una determinada clave siguiendo un orden preciso. La clave NIVOMET tiene partes coincidentes con la clave de cifrado meteorológico SYNOP y otros aspectos exclusivos de carácter nivológico. Es de origen francés y está reconocida como clave regional por la OMM para la transmisión de información nivometeorológica. En este apartado de la guía de observación se describe paso a paso este cifrado.

La clave NIVOMET es un sistema de cifrado que se utiliza en España y Francia para la transmisión de las observaciones nivometeorológicas a través del Sistema Mundial de Telecomunicaciones Meteorológicas.

La clave NIVOMET es una adaptación de otra clave análoga, la clave SYNOP, de uso común en el intercambio de datos de observación meteorológica. Con ella se reduce cada observación a un conjunto breve de caracteres alfanuméricos, todos referentes a la misma hora, facilitando enormemente la transmisión de información. En cada parte NIVOMET se detalla la hora de la observación, el observatorio, y todos los valores que se han medido o estimado en forma de grupos de 5 números. Hay también grupos de 3 números, 333 y 555, que sirven para identificar partes concretas (llamadas secciones) dentro del conjunto.

Un parte NIVOMET tiene el siguiente formato:

\section{AAXX YYGGi $\mathrm{w}_{\mathrm{w}}$}

IIIII $i_{R} i_{x} h / l$ Nddff $1 S_{N} T T T$ 29UUU $7 w w W W_{2} W_{N_{H}} C_{L} C_{M} C_{H} 9 G G g$ $333\left(1 S_{N} T_{x} T_{x} T_{x}\right)\left(2 S_{N} T_{N} T_{N} T_{N}\right)$ 4/sss $\left(7 R_{24} R_{24} R_{24} R_{24}\right)$ 907tt 931s's' $555 \quad 7 I_{Z} Z_{x} Z_{x} Z_{x} \quad 8 I_{T} d_{T} q_{T} q_{T} \quad 1 S_{N} T_{S} T_{S} T_{S} \quad E_{N} P_{S} P_{S} N_{v} C_{N} L_{1}{ }_{1} L_{2}{ }_{2} L^{\prime}{ }_{3} L^{\prime}{ }_{4} L^{\prime}{ }_{5} \quad L_{6} L_{7} L_{8} L_{9} L_{5}$ (2ddff ssss's') $\left(4 F_{1} F_{2} E_{c} E_{c}\right) \quad\left(5 I M_{v} M_{v} M_{v}\right)$

Los grupos que van entre paréntesis son aquellos que son opcionales, en el sentido de que se utilizan en unas ocasiones sí y en otras no, dependiendo de si a la hora de la observación se toman esos valores o no. Por ejemplo, la precipitación en las 24 horas precedentes, que se codifica en el grupo $\left(\mathbf{7} \mathbf{R}_{\mathbf{2 4}} \mathbf{R}_{\mathbf{2 4}} \mathbf{R}_{\mathbf{2 4}} \mathbf{R}_{\mathbf{2 4}}\right)$, sólo se mide a las 08 UTC, por lo que si se hace una observación a las 13 UTC éste grupo no figurará en el parte NIVOMET.

Un ejemplo de parte NIVOMET es el correspondiente a la observación de las 08 UTC del día 6 de octubre de 2010 en el Refugio de Panticosa-Casa de Piedra. Muchos de los valores son barras $(/)$ por corresponder a una fecha en la que no había nieve:

08922 219// 100001009629057700008000290800

$33310226200524 / 000700009076893100$

555 7IIII 8IIII 1/III IIIII IIIII IIIII 2IIII IIII/ 4IIII 5IIII=

\subsubsection{Secciones, grupos y cifrado de las observaciones}

Cada uno de los renglones, denominados 'sección' en la clave, identifica un tipo de información. En el caso del NIVOMET se utilizan las secciones $\mathbf{0}, \mathbf{1}, \mathbf{3}$ y $\mathbf{4}$ (la sección 2 se utiliza en otros partes meteorológicos para información de oleaje). Así: 


\section{SECCIONES DE LA CLAVE NIVOMET}

\begin{tabular}{|c|c|}
\hline Sección 0 & AAXX YYGGi ${ }_{w}$ \\
\hline Sección 1 & Iliii $i_{R} i_{x} h / l \quad N d d f f \quad 1 S_{n}$ TTT 29UUU $7 w w W_{1} W_{2} \quad 8 N_{h} C_{L} C_{M} C_{H} \quad 9 G g g g$ \\
\hline Sección 3 & $\left(1 S_{n} T_{x} T_{x} T_{x}\right) \quad\left(2 S_{n} T_{n} T_{n} T_{n}\right) \quad 4 / s s s\left(7 R_{24} R_{24} R_{24} R_{24}\right) \quad 907 t t \quad 931 s^{\prime} s^{\prime}$ \\
\hline Sección 5 & $\begin{array}{l}7 \mid z Z_{x} Z_{x} Z_{x} \quad 8 I_{t} d_{t} q_{t} q_{t} \quad 1 S_{n} T_{s} T_{s} T_{s} \quad E_{n}^{\prime} P_{s} P_{s} N_{v} C_{n} \quad L^{\prime}{ }_{1} L^{\prime}{ }_{2} L^{\prime}{ }_{3} L^{\prime}{ }_{4} L^{\prime}{ }_{5} \quad L_{6} L_{7} L_{8} L_{9} L_{5} \\
\left.\text { (2ddff ssss's') (4F } F_{1} F_{2} e_{c} e_{c}\right) \quad\left(5 I M_{v} M_{v} M_{v}\right)\end{array}$ \\
\hline
\end{tabular}

La sección cero identifica el tipo de parte y la hora, la sección uno contiene las observaciones meteorológicas en el momento de la observación, la sección tres los valores de conjunto de las 24 horas precedentes y la sección cinco las observaciones propias del manto nivoso.

\subsubsection{Sección 0: AAXX YYGGi}

\section{AAXX Es un grupo fijo, identifica que el parte contiene información de superficie}

YY: Día del mes.

GG: Hora UTC.

El grupo YYGGi ${ }_{w}$ lleva el día del mes y la hora en que se ha realizado la observación, y un número para identificar las unidades de medida del viento, que en el caso de los NIVOMET es siempre en metros por segundo.

Los partes NIVOMET, por ser reportes diarios, no llevan el año ni el mes.

$\mathbf{i}_{\mathbf{w}}=1$ (siempre), indicando que la velocidad se expresa en $\mathrm{m} / \mathrm{s}$.

\subsubsection{Sección 1: Iliii $i_{R} i_{x} h / /$ Nddff 1SnTTT 29UUU 7wwW $W_{2} \quad 8 N_{h} C_{L} C_{M} C_{H} \quad 9 G G g g$}

Esta sección incluye fundamentalmente información meteorológica.

\section{Grupo Iliii}

Es el indicativo sinóptico de la estación. Cada observatorio (o estación) se identifica a nivel mundial por un indicativo. En el caso de la España peninsular y Baleares, todos los indicativos comienzan por 08. Es por lo tanto fijo y siempre el mismo para cada observatorio. Consta de dos partes:

II: Indicativo del país. En el caso de España es el 08.

iii: Indicativo de la estación. 


\section{Grupo $i_{R} i_{x} h / l$}

$\mathbf{I}_{\mathbf{R}}$ : Indicador de la inclusión u omisión de los datos de precipitaciones

Dependiendo de la hora de la observación, se reportan (o no) precipitaciones, eso se refleja en el parte con este indicador. En los partes de las 08 horas va la precipitación y en los de las 13 horas no.

$\mathbf{i}_{\mathbf{R}}=2$ en los NIVOMET de las 08 UTC

$\mathbf{i}_{\mathrm{R}}=4$ en los NIVOMET de las 13 UTC

$\mathbf{i}_{\mathbf{x}}$ : Indicador del modo de explotación de la estación e inclusión u omisión del tiempo presente

$\mathbf{i}_{\mathbf{X}}=1$ siempre: en los partes NIVOMET siempre se cifra el tiempo presente.

h: Altura de la base de las nubes más bajas observadas por encima de la estación.

La estimación de esta variable se realiza en metros. Su cifrado se realiza según la siguiente tabla:

\begin{tabular}{|c|l|}
\hline Cifrado & \multicolumn{1}{c|}{ Descripción } \\
\hline $\mathbf{0}$ & Menos de $50 \mathrm{~m}$. \\
\hline $\mathbf{1}$ & Entre 50 y $100 \mathrm{~m}$. excluido \\
\hline $\mathbf{2}$ & Entre 100 y $200 \mathrm{~m}$. \\
\hline $\mathbf{3}$ & Entre 200 y $300 \mathrm{~m}$. \\
\hline $\mathbf{4}$ & Entre 300 y $600 \mathrm{~m}$. \\
\hline $\mathbf{5}$ & Entre 600 y $1000 \mathrm{~m}$. \\
\hline $\mathbf{6}$ & Entre 1000 y $1500 \mathrm{~m}$. \\
\hline $\mathbf{7}$ & " " \\
\hline $\mathbf{8}$ & Entre 1500 y $2000 \mathrm{~m}$. \\
\hline $\mathbf{9}$ & " 2500 m. o más o sin nubes. \\
\hline $\boldsymbol{I}$ & $\begin{array}{l}\text { Altura de la base de las nubes desconocida o bases de las nubes a un nivel } \\
\text { inferior y cimas a un nivel superior al de la estación }\end{array}$ \\
\hline
\end{tabular}

La altura $\mathbf{h}$ de la clave de cifrado se refiere a la distancia vertical al suelo del observatorio, no en la vertical de cada nube. No debemos tampoco confundir altura con la altitud, que es la distancia vertical respecto al nivel del mar. Para referirnos a puntos de la superficie del terreno hablamos de altitud, ya que sobre el terreno la altura es cero. Para objetos situados por encima de la superficie (como las nubes en la atmósfera) altitud y altura sólo son coincidentes cuando se observan desde un lugar a nivel del mar.

\section{Ejemplo:}

Si en un observatorio a 1900 metros de altitud observamos el cielo completamente cubierto de cirros, un estrato que tapa parte de una montaña a partir de 2300 metros, y un mar de nubes en la parte baja del valle, por debajo de la altitud del observatorio, la altura que debemos cifrar es la del estrato, que será de 400 metros, por lo que cifraremos $h=4$. Las nubes por debajo del nivel del observatorio se cifran en un grupo aparte, y no se tienen en cuenta aquí.

\section{Grupo Nddff}

Grupo de nubosidad y viento.

$\mathbf{N}$ : Fracción de cielo cubierto de nubes cuya base está por encima de la estación expresada en octavas partes de la bóveda celeste. 
Es una medida de la nubosidad total y su cifrado se realiza según la siguiente tabla:

\begin{tabular}{|c|l|}
\hline Cifrado & \multicolumn{1}{|c|}{ Descripción } \\
\hline $\mathbf{0}$ & Cielo completamente despejado \\
\hline $\mathbf{1}$ & $1 / 8$ de cielo cubierto \\
\hline $\mathbf{2}$ & $2 / 8$ de cielo cubierto \\
\hline $\mathbf{3}$ & $3 / 8$ de cielo cubierto \\
\hline $\mathbf{4}$ & $4 / 8$ de cielo cubierto \\
\hline $\mathbf{5}$ & $5 / 8$ de cielo cubierto \\
\hline $\mathbf{6}$ & $6 / 8$ de cielo cubierto \\
\hline $\mathbf{7}$ & $7 / 8$ de cielo cubierto \\
\hline $\mathbf{8}$ & 8/8 Todo el cielo cubierto (completamente) \\
\hline $\mathbf{9}$ & $\begin{array}{l}\text { No se puede estimar la nubosidad porque el cielo está oculto por niebla, } \\
\text { ventisca, etc. }\end{array}$ \\
\hline
\end{tabular}

Los casos de $\mathbf{N}=0$ y $\mathbf{N}=8$ son algo especiales. Sólo cifraremos despejado cuando no haya absolutamente nada de nubosidad (por encima del observatorio, por debajo puede haber) y sólo cifraremos cielo cubierto cuando no se vea absolutamente nada de cielo sin nubes.

Como las nubes se distribuyen en distintas capas, tapándose frecuentemente unas a otras, la nubosidad total no es en general la suma de las nubosidades de las distintas capas. Para valorar el total cuando hay mucha nubosidad (5, 6, 7 octavos), suele resultar más práctico 'agrupar' mentalmente los trozos de cielo despejado.

\section{Ejemplo:}

Un cielo cubierto de altostratos salvo por un pequeño 'agujero' de menos de un octavo en la parte del este que permite ver el cielo azul, y por la parte oeste 4/8 de estratocúmulos y $2 / 8$ de estratos al norte: se cifra la nubosidad total como $\mathbf{N}=7$

dd: Dirección del viento en decenas de grados.

Se consideran solamente las 8 direcciones principales, referidas al norte geográfico. Su cifrado se realiza según la siguiente tabla:

\begin{tabular}{|c|l|}
\hline Cifrado & \multicolumn{1}{|c|}{ Dirección } \\
\hline $\mathbf{0 0}$ & Viento en calma \\
\hline $\mathbf{0 4}$ & Viento del Nordeste. \\
\hline $\mathbf{0 9}$ & Viento del Este. \\
\hline $\mathbf{1 3}$ & Viento del Sudeste. \\
\hline $\mathbf{1 8}$ & Viento del Sur. \\
\hline $\mathbf{2 2}$ & Viento del Sudoeste. \\
\hline $\mathbf{2 7}$ & Viento del Oeste. \\
\hline $\mathbf{3 1}$ & Viento del Noroeste. \\
\hline $\mathbf{3 6}$ & Viento del Norte. \\
\hline $\mathbf{9 9}$ & Viento de dirección variable en el momento de la observación. \\
\hline
\end{tabular}

\section{ff: Velocidad del viento}

La fuerza o velocidad del viento se indica en metros por segundo. Si se dispone de anemómetro, y si este aparato da la medida en nudos, se debe dividir esa medida por 2 para obtener la cifra en metros por segundo. Si la estación no dispone de anemómetro, para poder dar una aproximación de la velocidad del viento se puede seguir el código siguiente, derivado de la escala Beaufort: 


\begin{tabular}{|c|l|}
\hline $\begin{array}{c}\text { Cifrado } \\
(\mathrm{m} / \mathrm{s})\end{array}$ & \multicolumn{1}{c|}{ Descripción } \\
\hline $\mathbf{0 0}$ & Calma, no hay viento, el humo se eleva verticalmente. \\
\hline $\mathbf{0 2}$ & Las banderas y las hojas de los árboles se mueven. \\
\hline $\mathbf{0 7}$ & Las banderas ondean y, las ramas más finas se mueven. \\
\hline $\mathbf{1 4}$ & Las ramas gruesas se agitan, los hilos telefónicos silban, el uso del paraguas se hace difícil. \\
\hline $\mathbf{2 0}$ & Cuesta andar contra el viento, el viento rompe las ramas más débiles. \\
\hline $\mathbf{3 0}$ & Temporal, daños importantes. \\
\hline
\end{tabular}

La medida del viento, como la de la mayoría de las variables que reportamos en el NIVOMET, se refiere al 'momento de la observación' entendiendo como tal los diez minutos que anteceden a hora del parte. Además, en el caso del viento, el valor a cifrar es el valor promedio de los diez minutos, por lo que debemos tratar de no tomar las rachas más fuertes como indicador.

\section{Ejemplo:}

Durante la noche ha soplado mucho viento durante unas horas, se ha oído y hay ramas rotas.

En el momento de la observación, -los diez minutos antes de las 08 UTC-, de camino a la garita y durante la toma de medidas, se nota algo de viento: se mueven las hojas de los árboles pero no las ramas, salvo durante unos breves momentos, que duran menos de un minuto, en los que se han movido las ramas finas de los árboles.

El viento es flojo, se cifra $\mathbf{f f}=02$

\section{Grupo $1 S_{n}$ TTT}

Grupo de la temperatura actual del aire.

$\mathbf{S}_{\mathrm{n}}$ : Indicador del signo de la temperatura. $\mathbf{S}_{\mathrm{n}}$ : 0 para temperatura positiva o cero grados. $\mathbf{S}_{\mathrm{n}}: 1$ para temperatura negativa.

TTT: Temperatura del aire expresada en décimas de grado centígrado.

\begin{tabular}{|l|}
\hline Ejemplos: \\
una temperatura de $-7,5^{\circ} \mathrm{C}$ se cifra 11075 \\
una temperatura de $38^{\circ} \mathrm{C}$ se cifra 10380 \\
\hline
\end{tabular}

Recordemos: la temperatura actual no puede ser inferior a la mínima ni superior a la máxima.

\section{Grupo 29UUU}

Grupo de la humedad atmosférica.

UUU: Humedad relativa del aire expresada en \%

\section{Grupo $7 w w W_{1} W_{2}$}

Grupo de tiempo presente y pasado.

ww: Tiempo presente en el momento de la observación.

Su cifrado se realiza según la tabla a continuación. Si en el momento de la observación se están produciendo dos tipos de fenómenos simultáneamente, en ww se cifrará el que tenga el número más alto: 


\begin{tabular}{|l|l|}
\hline $\begin{array}{c}\text { Cifrado } \\
\text { ww }\end{array}$ & \multicolumn{1}{c|}{ Descripción } \\
\hline $\mathbf{0 0}$ & $\begin{array}{l}\text { No se da en la estación ninguno de los fenómenos siguientes: niebla, lluvia, nieve o } \\
\text { tormenta }\end{array}$ \\
\hline $\mathbf{4 4}$ & Niebla y cielo visible \\
\hline $\mathbf{4 5}$ & Niebla y cielo invisible \\
\hline $\mathbf{4 8}$ & Niebla depositando cencellada y cielo visible \\
\hline $\mathbf{4 9}$ & Niebla depositando cencellada y cielo invisible \\
\hline $\mathbf{1 6}$ & Se ve llover pero no llueve en la estación \\
\hline $\mathbf{6 0}$ & Lluvia intermitente \\
\hline $\mathbf{6 1}$ & Lluvia débil continua (sin interrupción desde el comienzo) \\
\hline $\mathbf{6 3}$ & Lluvia moderada \\
\hline $\mathbf{6 5}$ & Lluvia fuerte \\
\hline $\mathbf{6 7}$ & Lluvia engelante (que se congela al tocar el suelo) \\
\hline $\mathbf{6 9}$ & Lluvia y nieve mezcladas \\
\hline $\mathbf{8 1}$ & Chubascos de lluvia \\
\hline $\mathbf{1 6}$ & Nieva a la vista, pero no en la estación \\
\hline $\mathbf{3 6}$ & Ventisca en la estación \\
\hline $\mathbf{7 0}$ & Nevada débil, intermitente \\
\hline $\mathbf{7 1}$ & Nevada débil continua (sin interrupción desde el comienzo) \\
\hline $\mathbf{7 3}$ & Nevada moderada \\
\hline $\mathbf{7 5}$ & Nevada fuerte \\
\hline $\mathbf{8 4}$ & Chubascos de aguanieve \\
\hline $\mathbf{8 6}$ & Chubascos de nieve \\
\hline $\mathbf{8 8}$ & Chubascos de granizo o nieve granulada \\
\hline $\mathbf{1 7}$ & Truenos sin precipitación en la estación \\
\hline $\mathbf{9 5}$ & Tormenta con lluvia o nieve en la estación \\
\hline $\mathbf{9 6}$ & Tormenta con cellisca o granizada en la estación \\
\hline
\end{tabular}

$\mathbf{W}_{1} \mathbf{W}_{2}$ : Tiempo pasado desde la última observación.

El cifrado se realizará siguiendo la siguiente tabla:

\begin{tabular}{|c|l|}
\hline Cifrado & \multicolumn{1}{|c|}{ Descripción } \\
\hline $\mathbf{0}$ & Ningún fenómeno significativo \\
\hline $\mathbf{3}$ & Ha habido ventisca en la estación \\
\hline $\mathbf{4}$ & Ha habido niebla en la estación \\
\hline $\mathbf{6}$ & Ha habido lluvia, Ilovizna, etc.(precipitación en forma líquida) \\
\hline $\mathbf{7}$ & Ha habido nieve, granizada, etc.(precipitación en forma sólida) \\
\hline $\mathbf{9}$ & Ha habido tormenta \\
\hline $\boldsymbol{I}$ & No se ha podido realizar la observación de tiempo pasado \\
\hline
\end{tabular}

Las cifras de la clave $\mathbf{W}_{\mathbf{1}}$ y $\mathbf{W}_{\mathbf{2}}$ deben describir lo más fielmente posible las condiciones meteorológicas habidas antes de la observación. Si ha habido dos tipos de tiempo desde la última observación $\mathbf{W}_{\mathbf{1}}$ debe ser la cifra más alta de las dos. Si hay 3 ó más fenómenos, por ejemplo si hay tormenta (9), lluvia (6) y granizo (7), debemos cifrar los dos de mayor número: $\mathbf{W}_{\mathbf{1}} \mathbf{W}_{\mathbf{2}}=97$ (y no 96 ). Si ha habido un solo fenómeno significativo se cifra dos veces el mismo número de la clave $\mathbf{W}_{\mathbf{1}}=\mathbf{W}_{\mathbf{2}}$.

Si se desconoce totalmente el tiempo pasado se transmite $\mathbf{W}_{1} \mathbf{W}_{2}=/ /$ y si sólo se conoce una parte del tiempo pasado se cifra $\mathbf{W}_{1}$ y para $\mathbf{W}_{2}$ se pone /. 


\section{Grupo $8 \mathrm{~N}_{\mathrm{h}} \mathrm{C}_{\mathrm{L}} \mathrm{C}_{\mathrm{M}} \mathrm{C}_{\mathrm{H}}$}

Grupo de nubes.

$\mathbf{N}_{\mathrm{h}}$ : Nubosidad en octavos de la capa de nubes más bajas por encima de la estación que formen parte del piso bajo $\left(C_{L}\right)$ o bien, si no hay nubes bajas, que formen parte del piso medio $\left(C_{M}\right)$, sin sumar las de ambas capas. La nubosidad baja $\left(\mathbf{N}_{\mathbf{h}}\right)$ siempre será menor o igual que la nubosidad total $(\mathbf{N})$.

El cifrado se realizará siguiendo la siguiente tabla:

\begin{tabular}{|c|l|}
\hline Cifrado & \multicolumn{1}{|c|}{ Descripción } \\
\hline $\mathbf{0}$ & Ninguna nube o únicamente nubes del tipo $\mathrm{C}_{\mathrm{H}}$ (nubes altas) \\
\hline $\mathbf{1}$ a $\mathbf{8}$ & Fracción del cielo cubierto en octavos \\
\hline $\mathbf{9}$ & Cielo invisible por niebla o ventisca \\
\hline
\end{tabular}

$\mathrm{C}_{\mathrm{L}}$ : Nubes bajas

Se indicará en este índice el género de nube baja predominante y se cifrará según la siguiente tabla:

\begin{tabular}{|c|c|l|}
\hline $\begin{array}{c}\text { Cifrado } \\
\mathbf{0}\end{array}$ & Sin nubes bajas & \multicolumn{1}{c|}{ Descripción } \\
\hline $\mathbf{2}$ & $\begin{array}{c}\text { Cu } \\
\text { (cumulus) }\end{array}$ & $\begin{array}{l}\text { Nubes con bases planas y horizontales que se desarrollan verticalmente } \\
\text { en forma de protuberancias o de coliflores. }\end{array}$ \\
\hline $\mathbf{5}$ & $\begin{array}{c}\text { Sc } \\
\text { (stratocumulus) }\end{array}$ & $\begin{array}{l}\text { Bancos o capas de nubes grises o blanquecinas, agarrados } \\
\text { generalmente a la cima de las montañas. Las bases pueden ser } \\
\text { indefinidas o netas y generalmente horizontales. }\end{array}$ \\
\hline $\mathbf{6}$ & $\begin{array}{c}\mathbf{S t} \\
\text { (stratus) }\end{array}$ & $\begin{array}{l}\text { Capa de nubes, con frecuencia continuas, a veces en forma de bancos } \\
\text { deshilachados agarrados a las laderas de los macizos y a poca altura por } \\
\text { encima del observador. }\end{array}$ \\
\hline $\mathbf{9}$ & $\begin{array}{c}\text { Cb } \\
\text { (cumulonimbus) }\end{array}$ & $\begin{array}{l}\text { Nube densa y potente, de dimensión vertical considerable, con forma de } \\
\text { montaña o de torre. Estas nubes, cuya base es muy oscura, pueden dar } \\
\text { lugar a tormentas y a precipitaciones generalmente fuertes en formas de } \\
\text { lluvia, nieve, cellisca o granizo, acompañadas a veces de bruscas } \\
\text { ráfagas de viento. }\end{array}$ \\
\hline$I$ & Cielo invisible. & $\begin{array}{l}\text { Hay niebla en la estación, la reducida visibilidad impide estimar la } \\
\text { nubosidad. }\end{array}$ \\
\hline
\end{tabular}

$\mathbf{C}_{\mathrm{M}}$ : Nubes medias

Se indicará en este índice el género de nube media predominante o combinación de ellas y se cifrará según la siguiente tabla:

\begin{tabular}{|c|l|l|}
\hline Cifrado & & Descripción \\
\hline $\mathbf{0}$ & Sin nubes medias & Capa grisácea generalmente con base uniforme, que permite entrever \\
\hline $\mathbf{1}$ & As (altostratus) & $\begin{array}{l}\text { Capa de nubes muy oscura, que oculta siempre el Sol y da lugar a } \\
\text { precipitaciones de lluvia o nieve, más o menos continuas. El } \\
\text { observador situado en la montaña se encuentra a menudo dentro de } \\
\text { la nube. }\end{array}$ \\
\hline $\mathbf{2}$ & Ns (nimbostratus) \\
\hline $\mathbf{4}$ & $\begin{array}{l}\text { Ac (altocumulus) } \\
\text { lenticularis) }\end{array}$ & $\begin{array}{l}\text { Bancos o capas de nubes blancas o grises, que generalmente no se } \\
\text { agarran al relieve. }\end{array}$ \\
\hline $\mathbf{7}$ & $\begin{array}{l}\text { Ac As (altocumulus } \\
\text { altoestratus) }\end{array}$ & $\begin{array}{l}\text { Nube aislada en forma de lenteja o de almendra, con los bordes más } \\
\text { delgados, en general por encima de las cimas. }\end{array}$ \\
\hline $\boldsymbol{D}$ & $\begin{array}{l}\text { Nos o más capas de altocúmulos a diferentes alturas o presencia } \\
\text { simultánea de altocúmulos y altoestratos. }\end{array}$ \\
\hline & \multicolumn{2}{|l}{} \\
\hline
\end{tabular}


$\mathbf{C}_{\mathrm{H}}$ : Nubes altas

Se indicará en este índice el género de nube alta predominante y se cifrará según la siguiente tabla:

\begin{tabular}{|c|l|l|}
\hline Cifrado & & Descripción \\
\hline $\mathbf{0}$ & Sin nubes altas & \\
\hline $\mathbf{2}$ & $\mathbf{C i}$ (cirrus) & $\begin{array}{l}\text { Nubes en filamentos más o menos enmarañados y nunca } \\
\text { agarrados al relieve. }\end{array}$ \\
\hline $\mathbf{7}$ & Cs (cirrostratus) & $\begin{array}{l}\text { Velo lechoso más o menos transparente que da lugar al } \\
\text { fenómeno de halo. }\end{array}$ \\
\hline $\mathbf{9}$ & Cc (cirrocumulus) & $\begin{array}{l}\text { Bancos formados por bolas pequeñas, tipo copos, cuyo } \\
\text { diámetro aparente no excede del grosor de un dedo meñique. }\end{array}$ \\
\hline $\boldsymbol{I}$ & Nubes altas invisibles & \\
\hline
\end{tabular}

Para valorar el diámetro aparente de los elementos que componen nubes como los altocúmulos y cirrocúmulos, se suele tomar como referencia el diámetro aparente que subtiende un dedo meñique (que viene a ser un grado) cuando tenemos el brazo extendido. Es decir, probamos a tapar el elemento nuboso con un dedo teniendo el brazo extendido, y si lo tapa son cirrocúmulos. El sol y la luna tienen un diámetro aparente de medio grado. Los altocúmulos tienen un diámetro aparente superior al de un dedo, en general para taparlos hace falta el puño.

\section{Grupo 9GGgg}

Grupo de hora de la observación.

GGgg: Hora real UTC de la observación, en horas y minutos.

Se considera hora de la observación la de la toma de la temperatura del aire.

\subsubsection{Sección 3: $333\left(1 S_{n} T_{x} T_{x} T_{x} 2 S_{n} T_{n} T_{n} T_{n}\right)$ 4/sss $\left(7 R_{24} R_{24} R_{24} R_{24}\right) 907 t$ tt 931s's'}

Esta sección incluye información meteorológica y nivológica.

\section{Grupo $1 S_{n} T_{x} T_{x} T_{x}$}

Grupo de la temperatura máxima del aire en las últimas 24 horas.

$\mathbf{S}_{\mathrm{n}}$ : Indicador del signo de la temperatura. $\mathbf{S}_{\mathrm{n}}:=0$ para temperatura positiva o cero grados. $\mathrm{S}_{\mathrm{n}}:=1$ para temperatura negativa.

$\mathbf{T}_{\mathbf{x}} \mathbf{T}_{\mathbf{x}} \mathbf{T}_{\mathbf{x}}$ : Temperatura máxima del aire expresada en décimas de grado centígrado.

Siempre es conveniente chequear que la temperatura máxima no es inferior a la temperatura actual. Este grupo se transmite en la observación de las 08 UTC, y se omite en la de las 13 UTC.

\section{Grupo $2 S_{n} T_{n} T_{n} T_{n}$}

Grupo de la temperatura mínima del aire en las últimas 24 horas.

$\mathbf{S}_{\mathbf{n}}$ : Indicador del signo de la temperatura. $\mathbf{S}_{\mathbf{n}}=0$ para temperatura positiva o cero grados. $\mathbf{S}_{\mathbf{n}}=1$ para temperatura negativa.

$\mathbf{T}_{\mathrm{n}} \mathbf{T}_{\mathrm{n}} \mathbf{T}_{\mathrm{n}}$ : Temperatura mínima del aire expresada en décimas de grado centígrado.

Siempre conviene comprobar que la temperatura mínima no es superior a la temperatura actual. Este grupo se transmite en la observación de las 08 UTC, y se omite en la de las 13 UTC. 


\section{Grupo 4/sss}

Grupo de espesor total de nieve en el suelo.

sss: Espesor total de la nieve en centímetros.

Cuando en pleno invierno la nieve es reciente y el espesor disminuye mucho, se deberá frecuentemente a que la nieve ha sido transportada por el viento. En ese caso deberemos cifrar ventisca en tiempo pasado.

\section{Grupo $\mathbf{7} \mathbf{R}_{\mathbf{2 4}} \mathbf{R}_{\mathbf{2 4}} \mathbf{R}_{\mathbf{2 4}} \mathbf{R}_{\mathbf{2 4}}$}

Grupo de la precipitación registrada en las últimas 24 horas.

$\mathbf{R}_{\mathbf{2 4}} \mathbf{R}_{\mathbf{2 4}} \mathbf{R}_{\mathbf{2 4}} \mathbf{R}_{\mathbf{2 4}}$ : Cantidad de precipitación recogida expresada en décimas de milímetro.

Este grupo se transmite en la observación de las 08 UTC, y se omite en la de las 13 UTC.

\section{Grupo 907tt}

tt : Duración del periodo de referencia para la medida del espesor de la nieve reciente.

$\mathbf{t t}=68$ (más de $18 \mathrm{~h}$ ) en la observación matinal, $\mathrm{tt}=50(5 \mathrm{~h})$ en la observación de después del mediodía.

\section{Grupo 931s's'}

Grupo de espesor de la nieve reciente.

s's': Espesor de nieve caída en la estación sobre la placa de nieve reciente expresada en centímetros.

Si el espesor esta comprendido entre 0 y $1 \mathrm{~cm}$ se debe cifrar $\mathbf{s}^{\prime} \mathbf{s}^{\prime}=01$

Si el espesor sobrepasa 1 metro se cifra $\mathbf{s}^{\prime} \mathbf{s}^{\prime}=99$, y la altura total se consigna y transmite al final del parte NIVOMET, tras el último grupo de números, en lenguaje claro.

Nota: La placa de nieve reciente se limpia sólo una vez al día, después de la observación de las 08 UTC. Este grupo se transmite en las observaciones de las 08 UTC y de las 13 UTC.

\section{Ejemplos:}

En un observatorio donde se hace NIVOMET a las 08 UTC y a las 13 UTC, se lee en el jalón de nieve reciente $10 \mathrm{~cm}$ a las 13 UTC, y $17 \mathrm{~cm}$ a las 08 UTC del día siguiente. En el NIVOMET de las 13 UTC se cifra s's' = 10 y en el NIVOMET de las 08 UTC del día siguiente se cifra s's' $=17$.

En un observatorio donde se hace NIVOMET a las 08 UTC y a las 13 UTC, se leen $15 \mathrm{~cm}$ en el jalón de nieve reciente a las 13 UTC, y $3 \mathrm{~cm}$ a las 08 UTC del día siguiente. En el NIVOMET de las 13 UTC se cifra s's'=15 y en el NIVOMET de las 08 UTC del día siguiente se cifra s's' $=03$.

En el observatorio del Refugio de Panticosa-Casa de Piedra ha caído una nevada que ha acumulado $136 \mathrm{~cm}$, el NIVOMET podría ser: 


\subsubsection{Sección 5: $555 \quad 7 \mathrm{I}_{\mathrm{z}} \mathrm{Z}_{\mathrm{x}} \mathrm{Z}_{\mathrm{x}} \mathrm{Z}_{\mathrm{x}} \quad 8 \mathrm{I}_{\mathrm{t}} \mathrm{d}_{\mathrm{t}} \mathrm{q}_{\mathrm{t}} \mathrm{q}_{\mathrm{t}} \quad \mathbf{1 S}_{\mathrm{n}} \mathrm{T}_{\mathrm{s}} \mathrm{T}_{\mathrm{s}} \mathrm{T}_{\mathrm{s}} \quad \mathrm{E}_{n}{ }_{n} \mathrm{P}_{\mathrm{s}} \mathrm{P}_{\mathrm{s}} \mathrm{N}_{\mathrm{v}} \mathrm{C}_{\mathrm{n}} \quad \mathrm{L}_{1}{ }_{1} \mathrm{~L}^{\prime}{ }_{2} \mathrm{~L}^{\prime}{ }_{3} \mathrm{~L}_{4}{ }_{4} \mathrm{~L}_{5}$ $L_{6} L_{7} L_{8} L_{9} L_{5}$ (2ddff ssss's') $\left(4 F_{1} F_{2} e_{c} e_{c}\right)\left(5 I M_{v} M_{v} M_{v}\right)$}

Esta sección incluye fundamentalmente información nivológica.

\section{Grupo $7 I_{z} Z_{x} Z_{x} Z_{x}$}

Grupo de la altitud del límite lluvia-nieve, entendiendo por tal la altitud por encima de la cual sólo cae (o no cae) nieve, pero no lluvia. Informa sobre hasta qué altura se ha humidificado el manto por efecto de la precipitación.

$\mathrm{I}_{\mathbf{z}}$ : Indicador de la altitud máxima del límite lluvia-nieve.

Según el grado de precisión con el que pueda estimarse dicha altitud este indicador tomará los valores definidos en la siguiente tabla:

\begin{tabular}{|c|l|}
\hline Cifrado & \multicolumn{1}{|c|}{ Descripción } \\
\hline $\mathbf{0}$ & $\begin{array}{l}\text { La altitud máxima del límite lluvia-nieve es igual al valor } \mathbf{Z}_{\mathbf{x}} \mathbf{Z}_{\mathbf{x}} \mathbf{Z}_{\mathbf{x}} \\
\text { Desde la última observación, la lluvia ha subido (temporalmente) justo a esa } \\
\text { altitud. }\end{array}$ \\
\hline $\mathbf{1}$ & $\begin{array}{l}\text { La altitud máxima del límite lluvia-nieve es superior al valor } \mathbf{Z}_{\mathbf{x}} \mathbf{Z}_{\mathbf{x}} \mathbf{Z}_{\mathbf{x}} \\
\text { Desde la última observación, ha llovido siempre a esa altitud. }\end{array}$ \\
\hline $\mathbf{2}$ & $\begin{array}{l}\text { La altitud máxima del límite lluvia-nieve es inferior al valor } \mathbf{Z}_{\mathbf{x}} \mathbf{Z}_{\mathbf{x}} \mathbf{Z}_{\mathbf{x}} \\
\text { Desde la última observación, siempre ha nevado (no ha llovido en ningún } \\
\text { momento) a esa altitud. }\end{array}$ \\
\hline$I$ & Altitud del límite lluvia-nieve desconocido o sin precipitaciones. \\
\hline
\end{tabular}

$\mathbf{Z}_{\mathbf{x}} \mathbf{Z}_{\mathbf{x}} \mathbf{Z}_{\mathbf{x}}$ : Altitud máxima del límite lluvia-nieve después de la última observación, en decámetros.

Si no ha habido precipitaciones se indica III.

\section{Grupo $8 \mathrm{I}_{\mathrm{t}} \mathrm{d}_{\mathrm{t}} \mathbf{q}_{\mathrm{t}} \mathbf{q}_{\mathrm{t}}$}

Grupo de transporte de nieve por el viento

$I_{t}$ : Indicador del tipo de sensor de medida de transporte de nieve por el viento.

Este indicador se cifrará según la siguiente tabla a la derecha:

\begin{tabular}{|c|l|}
\hline Cifrado & \multicolumn{1}{|c|}{ Tipo de captura } \\
\hline $\mathbf{1}$ & Driftómetro con bolsitas \\
\hline $\mathbf{2}$ & Flowcapt \\
\hline$I$ & Sin medida \\
\hline
\end{tabular}

$\mathbf{d}_{\mathrm{t}}$ : Dirección dominante del transporte de nieve durante las pasadas $24 \mathrm{~h}$.

Hace referencia a la dirección del viento dominante que produce transporte de nieve.

Según el tipo de dispositivo usado será, para el driftrómetro, dirección de la abertura de la bolsita donde se ha recogido la mayor cantidad de nieve; para el flowcapt, dirección dominante en $24 \mathrm{~h}$.

Nota: la dirección de la ventisca de nieve es la del viento que la produce.

Se cifrará según la tabla a la derecha:

\begin{tabular}{|c|l|}
\hline Cifrado & \multicolumn{1}{|c|}{ Dirección } \\
\hline $\mathbf{0}$ & No hay transporte de nieve \\
\hline $\mathbf{1}$ & Noreste \\
\hline $\mathbf{2}$ & Este \\
\hline $\mathbf{3}$ & Sureste \\
\hline $\mathbf{4}$ & Sur \\
\hline $\mathbf{5}$ & Suroeste \\
\hline $\mathbf{6}$ & Oeste \\
\hline $\mathbf{7}$ & Noroeste \\
\hline $\mathbf{8}$ & Norte \\
\hline $\mathbf{9}$ & Varias direcciones \\
\hline $\mathbf{l}$ & Desconocido \\
\hline
\end{tabular}


$\mathbf{q}_{\mathrm{t}} \mathbf{q}_{\mathrm{t}}:$ Cantidad de nieve transportada.

Las unidades dependerán del dispositivo usado.

Para el driftómetro: en decenas de gramos, cantidad máxima de nieve recogida en un saquito.

Para el flowcapt: en $\mathrm{g} / \mathrm{m}^{2} \mathrm{~s}$, flujo medio en $24 \mathrm{~h}$. Para una medida mayor de $99 \mathrm{~g} / \mathrm{m}^{2} \mathrm{~s}, \mathrm{q}_{\mathrm{t}} \mathrm{q}_{\mathrm{t}}=99$.

Este grupo es para estimar el transporte de nieve por el viento en el propio observatorio. Aunque en los observatorios de la red de alta montaña de AEMET no se dispone de aparatos de medida para el transporte de la nieve por el viento, por lo que en general se tendrá $\mathrm{I}_{\mathrm{t}}=/$ y $\mathbf{q}_{\mathrm{t}} \mathbf{q}_{\mathrm{t}}=/ /$. Sí se puede estimar la dirección del transporte $\mathbf{d}_{\mathbf{t}}$ en el caso de que haya habido ventisca en la estación.

\section{Grupo $1 S_{n} T_{s} T_{s} T_{s}$}

Grupo de la temperatura de la superficie de la nieve (tomada a unos $10 \mathrm{~cm}$ de profundidad)

$\mathbf{S}_{\mathrm{n}}$ : Indicador del signo de la temperatura. $\mathrm{S}_{\mathrm{n}}$ : 0 para cero grados (la temperatura de la superficie de la nieve no puede ser superior a este valor). $S_{n}: 1$ para temperatura negativa.

$\mathbf{T}_{\mathbf{s}} \mathbf{T}_{\mathbf{s}} \mathbf{T}_{\mathbf{s}}$ : Temperatura de la superficie de la nieve expresada en décimas de grado centígrado.

Si al medir se obtienen temperaturas positivas (que serán en todo caso muy cercanas a los cero grados si el termómetro utilizado mide bien), el valor se redondeará a cero grados.

\section{Grupo $E_{n}^{\prime} P_{s} P_{s} N_{v} C_{n}$}

Grupo de estado y medidas en la nieve, nubes en el valle y ventisca.

E'n: Estado de la nieve.

El estado de la superficie de la nieve se cifrará según la siguiente tabla:

\begin{tabular}{|c|l|}
\hline Cifrado & \multicolumn{1}{|c|}{ Estado de la nieve } \\
\hline $\mathbf{0}$ & Nieve reciente seca \\
\hline $\mathbf{1}$ & Nieve reciente seca con escarcha de superficie \\
\hline $\mathbf{2}$ & Nieve reciente húmeda \\
\hline $\mathbf{3}$ & Nieve venteada que se hunde \\
\hline $\mathbf{4}$ & Nieve venteada que no se hunde \\
\hline $\mathbf{5}$ & Nieve vieja húmeda que se hunde (podrida) \\
\hline $\mathbf{6}$ & Nieve vieja húmeda que no se hunde (sin costra) \\
\hline $\mathbf{7}$ & Costra de rehielo que se hunde \\
\hline $\mathbf{8}$ & Costra de rehielo que no se hunde \\
\hline $\mathbf{9}$ & Superficie lisa y helada \\
\hline $\mathbf{l}$ & No hay nieve o no se realiza la observación \\
\hline
\end{tabular}

Los términos «se hunde» y «no se hunde» se refieren a un observador de peso medio $(70 \mathrm{Kg})$ de pie y sin esquís.

$\mathbf{P}_{\mathbf{s}} \mathbf{P}_{\mathbf{s}}$ : Profundidad de penetración del primer tubo de la sonda de golpeo en centímetros.

Si el hundimiento es superior a $99 \mathrm{~cm}, \mathbf{P}_{\mathbf{s}} \mathbf{P}_{\mathbf{s}}=99$ y al final del mensaje se expresa en lenguaje claro la profundidad real del hundimiento.

$\mathbf{N}_{\mathbf{v}}$ : Nubes en el valle.

Este indicador hace referencia a nubes cuyas cimas están por debajo del nivel de la estación. Se cifrará según la tabla a continuación: 


\begin{tabular}{|c|ll|}
\hline Cifrado & \multicolumn{2}{|c|}{ Altitud de la cima de las nubes } \\
\hline $\mathbf{0}$ & Sin nubes en el valle & \\
\hline $\mathbf{1}$ & Nubes aisladas & Inferior a $1000 \mathrm{~m}$ \\
\hline $\mathbf{2}$ & Nubes aisladas & Entre 1000 y $1500 \mathrm{~m}$ \\
\hline $\mathbf{3}$ & Nubes aisladas & Superior a $1500 \mathrm{~m}$ \\
\hline $\mathbf{4}$ & Mar de nubes parcial & Inferior a $1000 \mathrm{~m}$ \\
\hline $\mathbf{5}$ & Mar de nubes parcial & Entre 1000 y $1500 \mathrm{~m}$ \\
\hline $\mathbf{6}$ & Mar de nubes parcial & Superior a $1500 \mathrm{~m}$ \\
\hline $\mathbf{7}$ & Mar de nubes completo & Inferior a $1000 \mathrm{~m}$ \\
\hline $\mathbf{8}$ & Mar de nubes completo & Entre 1000 y $1500 \mathrm{~m}$ \\
\hline $\mathbf{9}$ & Mar de nubes completo & Superior a $1500 \mathrm{~m}$ \\
\hline $\mathbf{I}$ & Observación imposible & Estación con niebla \\
\hline
\end{tabular}

$\mathbf{C}_{\mathrm{n}}$ : Ventisca en altitud.

Se cifrará según la tabla siguiente en función de lo observado desde la estación:

\begin{tabular}{|c|l|}
\hline Cifrado & \multicolumn{1}{|c|}{ Dirección y fuerza } \\
\hline $\mathbf{0}$ & No hay ventisca \\
\hline $\mathbf{1}$ & Ventisca en tiempo pasado pero no en el momento de la observación \\
\hline $\mathbf{2}$ & Ventisca moderada del Este \\
\hline $\mathbf{3}$ & Ventisca moderada del Sur \\
\hline $\mathbf{4}$ & Ventisca moderada del Oeste \\
\hline $\mathbf{5}$ & Ventisca moderada del Norte \\
\hline $\mathbf{6}$ & Ventisca fuerte del Este \\
\hline $\mathbf{7}$ & Ventisca fuerte del Sur \\
\hline $\mathbf{8}$ & Ventisca fuerte del Oeste \\
\hline $\mathbf{9}$ & Ventisca fuerte del Norte \\
\hline $\mathbf{l}$ & Observación imposible (nubes o niebla) \\
\hline
\end{tabular}

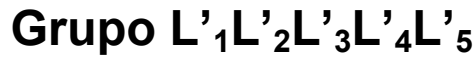

Grupo de aludes con salidas espontáneas.

Aludes observados desde la última observación, en general serán los de las últimas 24 horas Aludes vistos directamente por el observador o reportados por otras personas, que hayan tenido lugar en las proximidades de la estación. Por 'proximidades' se considera las zonas hasta unos 6-10 Km en línea recta. No se incluirán los aludes caídos en los días previos.

$L_{1}{ }_{1}$ : Número de aludes observados.

Se cifrará según la siguiente tabla:

\begin{tabular}{|c|l|}
\hline Cifrado & \multicolumn{1}{|c|}{ Número de aludes observados } \\
\hline $\mathbf{0}$ & Nada a destacar. Sin aludes, sólo se pueden observar coladas superficiales. \\
\hline $\mathbf{1}$ & Un alud \\
\hline $\mathbf{2}$ & Dos aludes observados \\
\hline $\mathbf{3}$ & Tres aludes observados \\
\hline $\mathbf{4}$ & Cuatro aludes observados \\
\hline $\mathbf{5}$ & Cinco aludes observados \\
\hline $\mathbf{6}$ & Seis a diez aludes \\
\hline $\mathbf{7}$ & Once a veinte aludes observados \\
\hline $\mathbf{8}$ & Veintiún a treinta aludes observados \\
\hline $\mathbf{9}$ & Mas de treinta aludes observados \\
\hline $\mathbf{l}$ & Se desconoce (observación imposible) \\
\hline
\end{tabular}


L'2: Tamaño de los aludes.

Se cifrará de acuerdo con la escala europea de tamaños de aludes y según la siguiente tabla:

\begin{tabular}{|c|l|}
\hline Cifrado & \multicolumn{1}{c|}{ Tamaño de los aludes } \\
\hline $\mathbf{0}$ & Nada a destacar. Sin aludes, sólo se pueden observar coladas superficiales. \\
\hline $\mathbf{1}$ & Pequeño(s) \\
\hline $\mathbf{2}$ & Sobre todo pequeños raramente (1 o 2) medianos \\
\hline $\mathbf{3}$ & Sobre todo medianos (no hay grandes) \\
\hline $\mathbf{4}$ & Sobre todo pequeños y rara vez grandes \\
\hline $\mathbf{5}$ & Sobre todo medianos y rara vez grandes \\
\hline $\mathbf{6}$ & Sobre todo grande(s) \\
\hline $\mathbf{7}$ & Por lo menos un alud grande con una trayectoria inusual \\
\hline $\boldsymbol{l}$ & Se desconoce (observación imposible) \\
\hline
\end{tabular}

$L^{\prime}{ }_{3}:$ Tipo de aludes.

Se cifrará según la siguiente tabla:

\begin{tabular}{|c|l|}
\hline Cifrado & \multicolumn{1}{|c|}{ Tipo de aludes } \\
\hline $\mathbf{0}$ & Nada a destacar. Ni aludes, ni coladas superficiales, ni grietas \\
\hline $\mathbf{1}$ & Ningún alud, sólo grieta(s) en el manto nivoso \\
\hline $\mathbf{2}$ & Coladas, secas o húmedas \\
\hline $\mathbf{3}$ & Alud(es) de nieve reciente, seca, salida puntual \\
\hline $\mathbf{4}$ & Alud(es) de nieve reciente, húmeda, salida puntual \\
\hline $\mathbf{5}$ & Alud(es) de placa friable (salida lineal, nieve seca, depósitos más bien finos) \\
\hline $\mathbf{6}$ & Alud(es) de placa dura superficial (salida lineal, nieve seca, depósitos en bloques) \\
\hline $\mathbf{7}$ & Alud(es) de superficie de nieve vieja húmeda o mojada \\
\hline $\mathbf{8}$ & Alud(es) de placa de fondo de nieve seca (salida lineal) \\
\hline $\mathbf{9}$ & Alud(es) de fondo de nieve vieja húmeda o mojada (salida puntual o lineal) \\
\hline $\mathbf{I}$ & Se desconoce \\
\hline
\end{tabular}

L' 4 : Altitud de la zona de salida de los aludes.

Se cifrará según la siguiente tabla:

\begin{tabular}{|c|l|}
\hline Cifrado & \multicolumn{1}{|c|}{ Altitud de la zona de salida del alud } \\
\hline $\mathbf{0}$ & Nada a destacar. \\
\hline $\mathbf{1}$ & Inferior a $1500 \mathrm{~m}$ \\
\hline $\mathbf{2}$ & Entre 1500 y $1750 \mathrm{~m}$ \\
\hline $\mathbf{3}$ & Entre 1750 y $2000 \mathrm{~m}$ \\
\hline $\mathbf{4}$ & Salidas a varias altitudes pero principalmente por debajo de $2000 \mathrm{~m}$ \\
\hline $\mathbf{5}$ & Entre 2000 y $2250 \mathrm{~m}$ \\
\hline $\mathbf{6}$ & Entre 2250 y $2500 \mathrm{~m}$ \\
\hline $\mathbf{7}$ & Entre 2500 y $3000 \mathrm{~m}$ \\
\hline $\mathbf{8}$ & Superior a $3000 \mathrm{~m}$ \\
\hline $\mathbf{9}$ & Salidas a varias altitudes pero principalmente por encima de $3000 \mathrm{~m}$ \\
\hline $\mathbf{l}$ & Se desconoce \\
\hline
\end{tabular}


L's: Orientación (exposición) de la zona de salida de los aludes.

Se cifrará según la siguiente tabla:

\begin{tabular}{|c|l|}
\hline Cifrado & \multicolumn{1}{|c|}{ Orientación de la zona de salida } \\
\hline $\mathbf{0}$ & Nada a destacar \\
\hline $\mathbf{1}$ & La mayoría en orientación Nordeste \\
\hline $\mathbf{2}$ & La mayoría en orientación Este \\
\hline $\mathbf{3}$ & La mayoría en orientación Sudeste \\
\hline $\mathbf{4}$ & La mayoría en orientación Sur \\
\hline $\mathbf{5}$ & La mayoría en orientación Suroeste \\
\hline $\mathbf{6}$ & La mayoría en orientación Oeste \\
\hline $\mathbf{7}$ & La mayoría en orientación Noroeste \\
\hline $\mathbf{8}$ & La mayoría en orientación Norte \\
\hline $\mathbf{9}$ & Sin orientación dominante \\
\hline $\mathbf{l}$ & Se desconoce \\
\hline
\end{tabular}

\section{Grupo $L_{6} L_{7} L_{8} L_{9} L_{5}$}

Grupo de aludes con desencadenamientos provocados.

Aludes observados desde la última observación. El desencadenamiento del alud puede estar provocado accidentalmente, al paso de un esquiador, por ejemplo, o bien artificialmente mediante explosivos. Aludes vistos directamente por el observador o reportados en las proximidades de la estación.

$\mathrm{L}_{6}$ : Tipos de desencadenamiento.

Se cifrará según la siguiente tabla:

\begin{tabular}{|c|l|}
\hline Cifrado & \multicolumn{1}{|c|}{ Tipo de desencadenamiento que provocó el alud } \\
\hline $\mathbf{0}$ & Nada a destacar. Ningún disparo, ningún alud \\
\hline $\mathbf{1}$ & No hay alud (todos los disparos con resultados negativos) \\
\hline $\mathbf{2}$ & $\begin{array}{l}\text { Desencadenamiento artificial positivo (la mayoría de los disparos negativos, algunos } \\
\text { disparos positivos) }\end{array}$ \\
\hline $\mathbf{3}$ & $\begin{array}{l}\text { Desencadenamiento artificial positivo (la mayoría de los disparos positivos, algunos } \\
\text { disparos negativos) }\end{array}$ \\
\hline $\mathbf{4}$ & Un desencadenamiento accidental (ningún disparo o disparos negativos) \\
\hline $\mathbf{5}$ & Un desencadenamiento accidental (al menos un disparo positivo) \\
\hline $\mathbf{6}$ & Varios desencadenamientos accidentales (ningún disparo o disparos negativos) \\
\hline $\mathbf{7}$ & Varios desencadenamientos accidentales (al menos un disparo positivo) \\
\hline $\mathbf{I}$ & Se desconoce (observación imposible) \\
\hline
\end{tabular}

$\mathbf{L}_{7}$ : Tipos de aludes.

Se cifrará con la misma tabla que para $\mathrm{L}_{3}$ :

\begin{tabular}{|c|l|}
\hline Cifrado & \multicolumn{1}{c|}{ Tipo de aludes } \\
\hline $\mathbf{0}$ & Nada a destacar. Ni aludes, ni coladas superficiales, ni grietas \\
\hline $\mathbf{1}$ & Ningún alud, sólo grieta(s) en el manto nivoso \\
\hline $\mathbf{2}$ & Coladas, secas o húmedas \\
\hline $\mathbf{3}$ & Alud(es) de nieve reciente, seca, salida puntual \\
\hline $\mathbf{4}$ & Alud(es) de nieve reciente, húmeda, salida puntual \\
\hline $\mathbf{5}$ & Alud(es) de placa friable (salida lineal, nieve seca, depósitos más bien finos) \\
\hline $\mathbf{6}$ & Alud(es) de placa dura superficial (salida lineal, nieve seca, depósitos en bloques) \\
\hline $\mathbf{7}$ & Alud(es) de superficie de nieve vieja húmeda o mojada \\
\hline $\mathbf{8}$ & Alud(es) de placa de fondo de nieve seca (salida lineal) \\
\hline $\mathbf{9}$ & Alud(es) de fondo de nieve vieja húmeda o mojada (salida puntual o lineal) \\
\hline $\boldsymbol{I}$ & Se desconoce \\
\hline
\end{tabular}


$\mathrm{L}_{8}$ : Altitud de la zona de salida de los aludes.

Se cifrará con la misma tabla que para L'4:

\begin{tabular}{|c|l|}
\hline Cifrado & \multicolumn{1}{|c|}{ Altitud de salida del alud } \\
\hline $\mathbf{0}$ & Nada a destacar. \\
\hline $\mathbf{1}$ & Inferior a $1500 \mathrm{~m}$ \\
\hline $\mathbf{2}$ & Entre 1500 y $1750 \mathrm{~m}$ \\
\hline $\mathbf{3}$ & Entre 1750 y $2000 \mathrm{~m}$ \\
\hline $\mathbf{4}$ & Salidas a varias altitudes pero principalmente por debajo de $2000 \mathrm{~m}$ \\
\hline $\mathbf{5}$ & Entre 2000 y $2250 \mathrm{~m}$ \\
\hline $\mathbf{6}$ & Entre 2250 y $2500 \mathrm{~m}$ \\
\hline $\mathbf{7}$ & Entre 2500 y $3000 \mathrm{~m}$ \\
\hline $\mathbf{8}$ & Superior a $3000 \mathrm{~m}$ \\
\hline $\mathbf{9}$ & Salidas a varias altitudes pero principalmente por encima de $3000 \mathrm{~m}$ \\
\hline $\mathbf{I}$ & Se desconoce \\
\hline
\end{tabular}

$\mathrm{L}_{9}$ : Orientación de la zona de salida de los aludes.

Se cifrará con la misma tabla que para $L^{\prime}{ }_{5}$ :

\begin{tabular}{|c|l|}
\hline Cifrado & \multicolumn{1}{|c|}{ Exposición del alud } \\
\hline $\mathbf{0}$ & Nada a destacar \\
\hline $\mathbf{1}$ & La mayoría en orientación Nordeste \\
\hline $\mathbf{2}$ & La mayoría en orientación Este \\
\hline $\mathbf{3}$ & La mayoría en orientación Sudeste \\
\hline $\mathbf{4}$ & La mayoría en orientación Sur \\
\hline $\mathbf{5}$ & La mayoría en orientación Suroeste \\
\hline $\mathbf{6}$ & La mayoría en orientación Oeste \\
\hline $\mathbf{7}$ & La mayoría en orientación Noroeste \\
\hline $\mathbf{8}$ & La mayoría en orientación Norte \\
\hline $\mathbf{9}$ & Sin orientación dominante \\
\hline $\mathbf{l}$ & Se desconoce \\
\hline
\end{tabular}

$\mathrm{L}_{5}$ : Estimación del nivel de peligro local en la Escala Europea de Peligro de Aludes.

Para su estimación se hará uso de la Escala Europea de Peligro de Aludes. El cifrado resumido se presenta en la siguiente tabla:

\begin{tabular}{|c|c|}
\hline Cifrado & Nivel de peligro \\
\hline $\mathbf{1}$ & DÉBIL \\
\hline $\mathbf{2}$ & LIMITADO \\
\hline $\mathbf{3}$ & NOTABLE \\
\hline $\mathbf{4}$ & FUERTE \\
\hline $\mathbf{5}$ & MUY FUERTE \\
\hline $\boldsymbol{I}$ & DESCONOCIDO \\
\hline
\end{tabular}

\section{Grupos 2ddff y ssss's'}

Grupos de viento y nieve en altitud.

Estos dos grupos están previstos para cifrar los datos de viento y de nieve en altitud cuando la estación meteorológica esté equipada de anemómetro, jalón y placa de nieve reciente en una localización situada a una altitud significativamente mayor a la que se realizan el resto de las observaciones. Si no se dispone de tal información estos grupos se omiten. 
dd: Dirección del viento expresada en decenas de grado. Se cifrará según la siguiente tabla:

\begin{tabular}{|c|l|}
\hline Cifrado & \multicolumn{1}{|c|}{ Descripción } \\
\hline 00 & Viento en calma \\
\hline 04 & Viento del Nordeste \\
\hline 09 & Viento del Este \\
\hline 13 & Viento del Sudeste \\
\hline 18 & Viento del Sur \\
\hline 22 & Viento del Suroeste \\
\hline 27 & Viento del Oeste \\
\hline 31 & Viento del Noroeste \\
\hline 36 & Viento del Norte \\
\hline 99 & Dirección de viento variable \\
\hline
\end{tabular}

ff: Velocidad del viento.

La fuerza o velocidad del viento se indica en metros por segundo. Si el anemómetro da la medida en nudos, se debe dividir ésta por 2 para obtener la cifra en metros por segundo.

sss: Espesor total de la nieve en centímetros.

s's': Espesor de nieve caída en la estación sobre la placa de nieve reciente expresada en centímetros.

Si el espesor esta comprendido entre 0 y $1 \mathrm{~cm}$ se debe cifrar $\mathbf{s}^{\prime} \mathbf{s}^{\prime}=\mathbf{0 1}$

Si el espesor sobrepasa 1 metro se cifra $\mathbf{s}^{\prime} \mathbf{s}^{\prime}=\mathbf{9 9}$, y la altura total se consigna y transmite al final de la clave en lenguaje claro.

Este grupo se transmite en las observaciones de las 08 UTC y de las 13 UTC

\section{Grupo $4 F_{1} F_{2} e_{c} e_{c}$}

Grupo del tipo de granos de superficie y espesor del rehielo.

$\mathbf{F}_{1} \mathbf{F}_{2}$ : Tipo de granos de nieve en superficie.

Se cifrará según la siguiente tabla:

\begin{tabular}{|c|l|}
\hline Cifrado & \multicolumn{1}{|c|}{ Descripción } \\
\hline $\mathbf{1}$ & Nieve reciente \\
\hline $\mathbf{2}$ & Partículas reconocibles \\
\hline $\mathbf{3}$ & Granos finos \\
\hline $\mathbf{4}$ & Granos de caras planas \\
\hline $\mathbf{5}$ & Cubiletes \\
\hline $\mathbf{6}$ & Granos redondos \\
\hline $\mathbf{7}$ & Costras \\
\hline $\mathbf{8}$ & Escarcha \\
\hline $\mathbf{9}$ & Nieve granulada \\
\hline $\mathbf{I}$ & Desconocido \\
\hline
\end{tabular}

$\mathbf{F}_{1}$ Indica el tipo de gránulos predominante en la superficie de la nieve.

$\mathbf{F}_{2}$ Indica el tipo de gránulos predominante entre la superficie de la nieve y el nivel $-10 \mathrm{~cm}$. 
$\mathbf{e}_{c} \mathbf{e}_{c}:$ Espesor de la costra de rehielo en centímetros.

Se cifrará el espesor de la costra de rehielo de superficie o a falta de la misma, de la costra de rehielo que se presente en los primeros $10 \mathrm{~cm}$ bajo la superficie.

Si no hay costra de rehielo, $\mathbf{e}_{c} \mathbf{e}_{\mathrm{c}}=\mathbf{0 0}$

Si el espesor de la costra de rehielo es desconocido, $\mathbf{e}_{c} \mathbf{e}_{c}=/ /$

Si el espesor de la costra de rehielo es menor de $1 \mathrm{~cm}, \mathbf{e}_{c} \mathbf{e}_{c}=01$

\section{Grupo $5 I M_{v} M_{v} M_{v}$}

Grupo de la homogeneidad y la densidad de la nieve en superficie.

I: Indicador de la homogeneidad de la capa en los primeros 10 centímetros bajo la superficie de la nieve.

Se cifrará según la siguiente tabla:

\begin{tabular}{|c|l|}
\hline Cifrado & \multicolumn{1}{c|}{ Descripción } \\
\hline $\mathbf{0}$ & $\begin{array}{l}\text { Ha nevado más de } 5 \text { centímetros desde la última observación (s's' } \geq 5 \mathrm{~cm}) \\
\text { Toma de muestra vertical sobre la placa de nieve reciente. }\end{array}$ \\
\hline $\mathbf{1}$ & $\begin{array}{l}\text { No ha nevado, o ha nevado menos de } 5 \mathrm{~cm}, \text { y la capa de } 10 \mathrm{~cm} \text { bajo la superficie es } \\
\text { homogénea (un solo estrato). Toma de muestra horizontal entre la superficie y el nivel a } 10 \\
\text { cm de profundidad. }\end{array}$ \\
\hline $\mathbf{2}$ & $\begin{array}{l}\text { No ha nevado, o ha nevado menos de } 5 \mathrm{~cm}, \text { y la capa de } 10 \mathrm{~cm} \text { bajo la superficie está } \\
\text { formada por varios estratos de naturaleza diferente. No se mide la densidad. }\end{array}$ \\
\hline
\end{tabular}

$\mathbf{M}_{\mathbf{v}} \mathbf{M}_{\mathbf{v}} \mathbf{M}_{\mathrm{v}}$ : Densidad de la nieve en $\mathrm{Kg} / \mathrm{m}^{3}$.

La medida de la densidad se hará con nieve de los 10 primeros centímetros,

Si no se realiza la medida, se cifrará III. 
4 Observaciones del manto nivoso en terreno representativo cercano a la estación: sondeo por golpeo y perfil estratigráfico, test de estabilidad

En este apartado describiremos un conjunto estándar de procedimientos técnicos que tienen por objeto conocer las características o propiedades del manto nivoso a lo largo de todo su espesor. EI espesor del manto nivoso es la distancia vertical entre el terreno sobre el que descansa y la superficie en contacto con el aire.

Lo más habitual es que el manto nivoso sea heterogéneo, es decir, que esté formado por varias capas con propiedades y características distintas. Cada capa corresponde aproximadamente al depósito de un episodio de nevadas, y el orden en el que se superponen, empezando por la más profunda, corresponde al orden en el que estos episodios se han sucedido en el tiempo. No obstante, las transformaciones que sufre la nieve depositada pueden producir la desaparición de algunas capas o la fusión de capas contiguas, de manera que la correspondencia original entre capas y episodios de nevadas puede no ser exacta.

\subsection{Sondeo por golpeo y perfil estratigráfico del manto nivoso}

Los procedimientos que vamos a describir se agrupan en dos partes claramente diferenciadas que podrían realizarse de manera independiente. Sin embargo, es preferible realizarlas juntas a fin de que los datos extraídos de una y otra se complementen. Las etapas son:

- Sondeo por golpeo: consiste en la toma de medidas de resistencia a la penetración a lo largo de todo el espesor del manto nivoso. Se realiza desde la superficie del manto con la ayuda de una sonda de golpeo. Estos datos nos permiten conocer, en cada nivel del manto, la fuerza de oposición de la nieve a la penetración de la sonda, que es una medida indirecta de la fuerza de cohesión entre los granos.

- Perfil estratigráfico o cata de nieve: consiste en la toma detallada de datos de las distintas capas o estratos que componen el manto nivoso. Se toman datos de temperatura, tipo y tamaño de los cristales de nieve, dureza, humedad y densidad

Si no se dispone de los instrumentos o del tiempo suficiente para realizar las medidas de resistencia, puede realizarse simplemente una cata de nieve, pues la información que aporta es por si misma valiosa para la predicción del peligro de aludes.

\subsubsection{Criterios de elección del emplazamiento}

Debido a las irregularidades propias de los terrenos montañosos y a las diferentes orientaciones de las laderas, la acumulación de la nieve y su transformación por efecto del viento y de la temperatura pueden variar mucho de un lugar a otro. Por este motivo es enormemente importante elegir lugares representativos para realizar los sondeos.

No resultarán de utilidad medidas en lugares como cimas venteadas, hondonadas donde haya sobreacumulaciones o zonas de depósito de aludes. Es muy conveniente también conocer las características del terreno subyacente, evitando zonas con arbustos, rocas distribuidas de manera irregular, etc. 
Un lugar es representativo cuando sus características son parecidas a las de las zonas donde sospechamos pueda haber peligro de aludes. No es necesario ni conveniente realizar el sondeo en lugares peligrosos, pero sí conviene que elijamos para hacerlo lugares con una orientación, un grado de concavidad o convexidad y una altitud semejante a la de las zonas peligrosas. Si no existen lugares semejantes no peligrosos, nos permitiremos rebajar la pendiente y la altitud.

Asimismo, el emplazamiento elegido deberá estar fuera del paso de personas o máquinas, y convenientemente señalizado. En los lugares en los que se prevea que se realizarán varios sondeos a lo largo de la temporada se señalizará una parcela lo suficientemente grande para éstos, empezando a realizar los sondeos desde la zona más baja hacia la más alta.

\subsubsection{Datos topográficos, meteorológicos y temporales}

Una vez elegido el lugar donde vamos a hacer el sondeo, es preciso tomar nota de los siguientes datos:

- Lugar, altitud y orientación (exposición) de la ladera:

- El lugar debe ser indicado preferentemente mediante las coordenadas de longitud y latitud. Si se carece de GPS, se puede indicar el topónimo del lugar (ej. Laguna de Peñalara).

o La altitud se expresa en metros sobre el nivel del mar.

- La orientación de la ladera es la dirección hacia la que miraría una persona colocada de espaldas a la ladera. Se aproxima a las ocho direcciones principales: N, NE, E, SE, S, SW, W y NW. La orientación se determina con la brújula.

- Temperatura actual y tiempo presente

o La temperatura actual es la temperatura del aire en el momento de empezar el sondeo. Se toma con el mismo termómetro utilizado para el manto nivoso, manteniéndolo en lo posible a un metro y medio de altura, alejado del cuerpo y sin que le dé el sol, haciéndole sombra con algo.

o El tiempo presente se refiere al estado del cielo (despejado, nuboso, cubierto) y a la presencia de meteoros (niebla, lluvia, nieve, granizo, ventisca, etc.). Si se cifra por ejemplo "nevando", no es necesario añadir que está cubierto.

- Fecha y hora en la que se inicia el sondeo.

\begin{tabular}{|c|c|c|}
\hline ESTACIÓN:... & ALTITUD:................ & SONDFO POR GOIPFO \\
\hline LUGAR DE MEDIDA: & EXPOSICIÓN:.......... & \\
\hline $\mathrm{x}:$ & INCLINACIÓN: .... & \\
\hline${ }^{\text {GPS }}$ & Ta DEL AIRE:... & \\
\hline FECHA: & TIEMPO PRESENTE:... & \\
\hline HORA LOCAL:.... & OBSERVADOR:...... & \\
\hline
\end{tabular}

Fig. 45 cabecera del impreso de recogida de datos de un sondeo por golpeo 


\subsubsection{Sondeo por golpeo}

\subsubsection{Sondeo previo del espesor total del manto con la sonda fina}

Antes de iniciar el sondeo por golpeo debe medirse el espesor total del manto con una sonda fina. Es conveniente medir el espesor en varios puntos próximos, asegurándonos así de que el lugar del sondeo es representativo del espesor medio del emplazamiento, descartando sitios inadecuados como aquellos que ocultan rocas aisladas, cauces de agua o matorrales. Este espesor total nos servirá luego de referencia para saber cuándo la sonda alcanzará el suelo y nos indica cuántos tubos de la sonda por golpeo vamos a necesitar.

Los tubos no se ensamblan todos desde un principio, sino de uno en uno, cuando vemos que al tubo anterior sólo le faltan $20 \mathrm{~cm}$ para quedar enterrado en la nieve. La sonda fina puede también aportar cierta información acerca del número y profundidad de las capas más significativas y de la existencia de costras de rehielo. No obstante, esta información sólo debe usarse de forma orientativa, pues es demasiado imprecisa.

\subsubsection{Ubicación de los observadores}

Durante el sondeo por golpeo, los observadores que lo realizan no deben modificar con sus pisadas el sector del manto de nieve de donde se extraen los datos. Para ello se colocarán en la pendiente por debajo del punto donde han clavado la sonda. Lo ideal es que haya al menos dos personas para realizar el sondeo. Una encargada de lanzar el peso y la otra dedicada a apuntar los datos y a medir el hundimiento de la sonda. Una de las manos del sondeador se utilizará solamente para mantener el tubo vertical, pero en ningún caso debe frenar su penetración en la nieve.

\subsubsection{Sonda de golpeo y hoja de anotación para medidas de resistencia}

Una sonda de golpeo es un tubo (o un ensamblaje de tubos) graduado en centímetros terminado en punta, unido a una varilla graduada también en centímetros. El mecanismo utilizado para controlar el hundimiento $(x)$ es un peso $(P)$ que golpea el extremo superior del tubo al caer deslizándose por la varilla (ver segunda foto en el cuadro a continuación). La varilla también está graduada, de modo que es posible elegir la altura (h) desde la que se deja caer el peso y, por tanto, la fuerza que en cada caso impacta sobre el tubo.

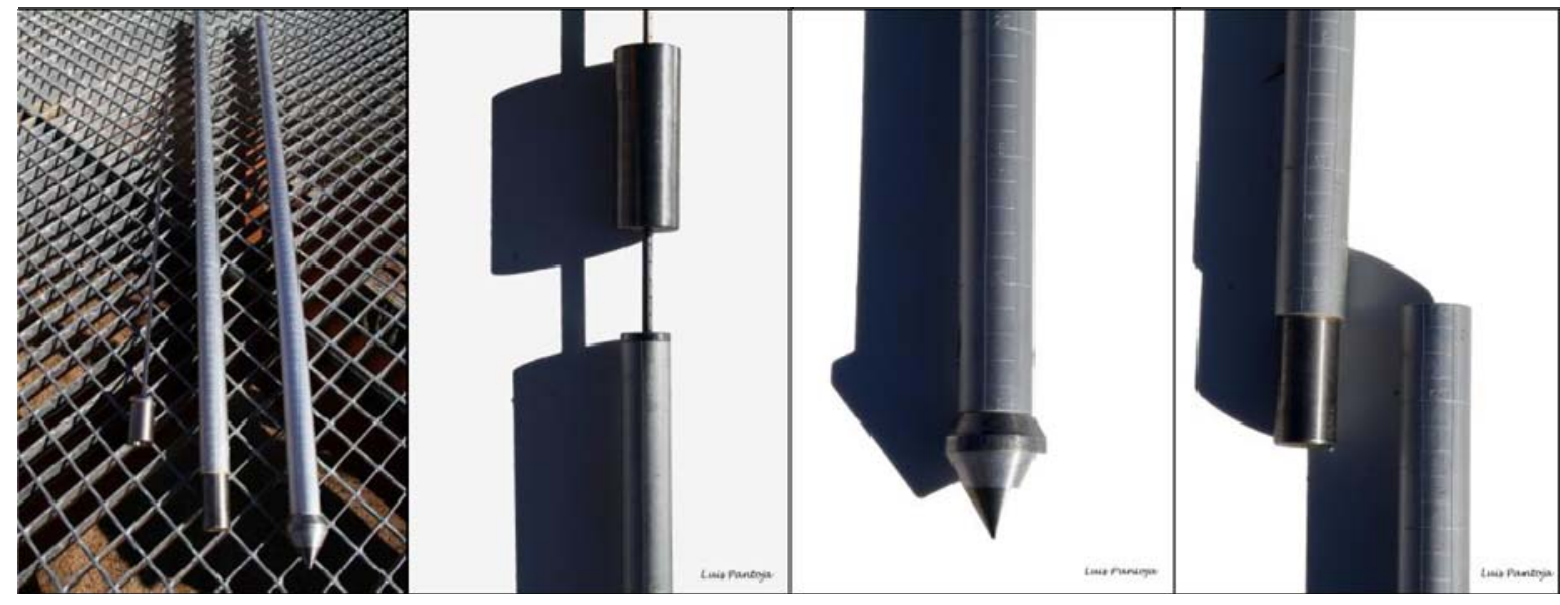

Fig. 46 Sonda de golpeo desmontada y sus distintas piezas: peso en la guía y tubos. 


\subsubsection{Desarrollo del sondeo}

El procedimiento del sondeo consiste en una sucesión de pasos análogos que van marcando el progresivo hundimiento de la sonda. La toma de datos debe señalar claramente la enumeración de los pasos.

Cada paso se caracteriza por el número $\mathrm{n}$ de veces que hemos tenido que lanzar el peso $\mathbf{P}$ desde una altura $\mathbf{h}$ para que el ensamblaje de tubos con peso q se haya hundido hasta la profundidad $\mathbf{x}$.

Los datos que caracterizan los sucesivos pasos son los que luego servirán para calcular la resistencia de las distintas capas de nieve en función de su profundidad. Estos datos se apuntan en una tabla, en la que las filas corresponden a los pasos sucesivos y las columnas a las variables $\mathbf{q}, \mathbf{P}, \mathrm{n}, \mathbf{h}, \mathbf{x}, \mathrm{d}, \mathrm{R}$ y $\mathrm{H}$.

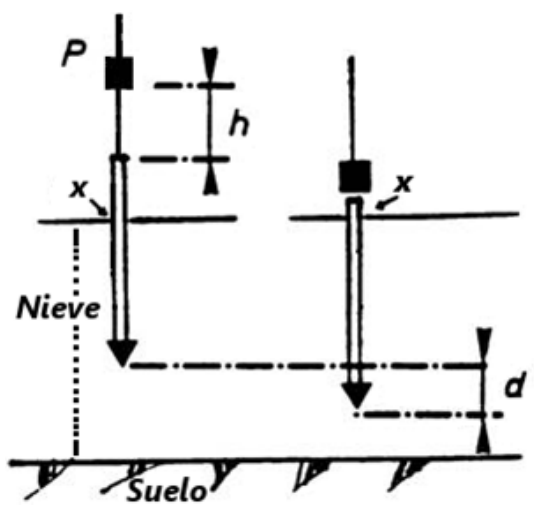

Fig. 47 Procedimiento para el sondeo por golpeo. Fuente: Météo France

Mientras hacemos el sondeo basta con anotar las primeras cinco variables: $\mathbf{q}, \mathbf{P}, \mathbf{n}, \mathbf{h}, \mathbf{x}$ (casillas sombreadas en la tabla siguiente). Las otras tres variables ( $d, R, H)$ se pueden calcular posteriormente, en un lugar cubierto, a partir de las primeras.

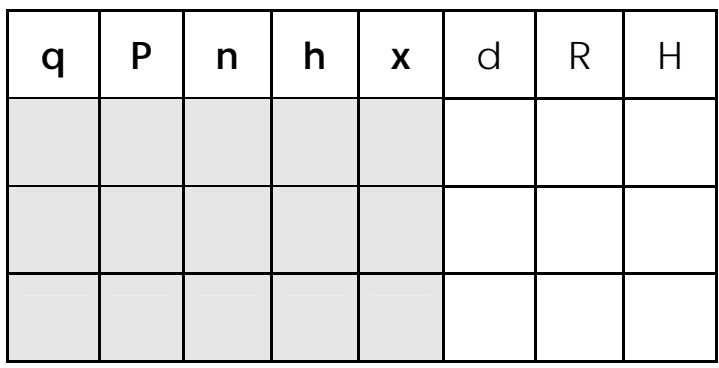

Fig. 48 Tabla para la anotación de los datos del sondeo por golpeo

\begin{tabular}{|c|c|}
\hline$q$ & $\begin{array}{l}\text { Número de tubos empleados (puesto que, tanto el primer tubo junto con la varilla como el resto de } \\
\text { los tubos pesan } 1 \mathrm{Kg} \text {, el peso de los tubos en kilos es igual al número de tubos empleados). }\end{array}$ \\
\hline $\mathbf{P}$ & Peso lanzado. Su valor es constante y suele ser igual a $1 \mathrm{Kg}$. \\
\hline $\mathbf{n}$ & Número de golpes con el peso móvil en cada serie de lanzamientos desde una misma altura $\mathbf{h}$. \\
\hline h & Altura en cm desde la que se deja caer el peso móvil en cada serie de golpes. \\
\hline $\mathbf{x}$ & Profundidad que tras cada serie de $\mathbf{n}$ golpes va alcanzando el extremo de la sonda de golpeo. \\
\hline d & $\begin{array}{l}\text { Espesor atravesado por la sonda tras cada serie de } \mathbf{n} \text { golpes. Se calcula a partir del valor de } x \text {. } \\
\text { Para el paso i-ésimo, } d_{i}=x_{i}-x_{i}-1 \text {. Para el primer paso, } d_{1}=x_{1} \text {. }\end{array}$ \\
\hline $\mathbf{R}$ & Resistencia. Se calcula en cada paso mediante la fórmula: $R=\frac{P \times n \times h}{d}+q+P$ \\
\hline H & $\begin{array}{l}\text { Altura a la que ha llegado la sonda medida desde el nivel del terreno. En el i-ésimo paso, } H_{i}=H_{t}- \\
x_{i} \text {, donde } H_{t}=\text { espesor total del manto de nieve. }\end{array}$ \\
\hline
\end{tabular}

Fig. 49 Significado de las letras en el impreso de recogida de datos de un sondeo por golpeo 
Nótese que la fórmula de la resistencia sólo es válida cuando $\mathbf{d} \neq 0$. El caso $\mathbf{d}=0$ sólo ocurre cuando la sonda no penetra nada, debido a que la altura $\mathbf{h}$ desde la que hemos lanzado el peso es insuficiente. Cuando suceda esto, daremos por nulo ese paso y probaremos con una altura mayor. Aunque el paso queda anulado, apuntamos sus datos en la fila correspondiente, pues a veces puede corresponder a una capa de hielo de grosor despreciable que no conviene obviar. No obstante, dicha fila no entrará a formar parte de la enumeración de los pasos con los que se calcula el perfil de resistencias. Es decir, a efectos del cálculo de $\mathbf{R}$, la consideraremos inexistente.

Lo ideal es que la sonda vaya penetrando poco a poco en la nieve, de manera que la variable $\mathbf{x}$ aumente $1 \mathrm{~cm}$ en cada golpe. El observador puede controlar el descenso de la sonda eligiendo la altura $\mathbf{h}$ desde la que lanza el peso. Siempre debe empezar con alturas pequeñas $(5 \mathrm{o} 10 \mathrm{~cm})$ que sólo aumentará si comprueba que la sonda no se hunde o lo hace con demasiada lentitud, es decir si necesita más de uno o dos golpes para descender $1 \mathrm{~cm}$. La razón por la que conviene hundir poco a poco la sonda es evitar que alguna discontinuidad o capa débil nos pase desapercibida.

Los tubos de la sonda pesan y, por tanto, también contribuyen al hundimiento de ésta en la nieve, sobre todo en la capa más superficial. Con el fin de medir dicha contribución, cada vez que incorporamos un tubo al sondeo deberemos intercalar dos pasos especiales, que se distinguen porque no hay en ellos lanzamiento de peso, es decir, $\mathbf{n}=0$ y $\mathbf{h}=0$.

\section{Primer paso especial: hundimiento del tubo de la sonda}

Medimos la profundidad $\mathbf{x}$ a la que baja la sonda con sólo colocar el primer tubo al que se ha ensamblado previamente la varilla. El tubo se sujeta entre el pulgar y el índice haciendo que permanezca vertical, de forma que la punta quede en contacto con la superficie de la nieve sin ejercer ninguna presión. Después, aflojando la presión de los dedos, se deja penetrar el tubo dentro de la nieve, exclusivamente por su propio peso. En este paso $\mathbf{q}=1$ y $\mathbf{P}=\mathbf{n}=\mathbf{h}=0$.

- Si el tubo penetra en la nieve (por ejemplo $10 \mathrm{~cm}$ ):

Se lee, sobre la escala grabada en el tubo, la graduación más próxima a la superficie de la nieve, redondeando al centímetro, y se anota el valor en el impreso (en la primera fila, en la columna "x").

\begin{tabular}{|c|c|c|c|c|c|c|c|}
\hline$q$ & $P$ & $n$ & $h$ & $x$ & $d$ & $R$ & $H$ \\
\hline 1 & 0 & 0 & 0 & 10 & & & \\
\hline & & & & & & & \\
\hline
\end{tabular}

- Si el tubo no ha penetrado en la nieve:

Anotaremos en la columna " $x$ " el valor 0 .

\begin{tabular}{|l|l|l|l|l|l|l|l|}
\hline $\mathbf{q}$ & $\mathbf{P}$ & $\mathbf{n}$ & $\mathbf{h}$ & $\mathbf{x}$ & $\mathrm{d}$ & $\mathrm{R}$ & $\mathrm{H}$ \\
\hline $\mathbf{1}$ & $\mathbf{0}$ & $\mathbf{0}$ & $\mathbf{0}$ & $\mathbf{0}$ & & & \\
\hline & & & & & & & \\
\hline
\end{tabular}

\section{Segundo paso especial: hundimiento al colocar el peso}

Medimos la profundidad $\mathrm{x}$ a la que baja la sonda al colocar el peso en reposo sobre el tubo anterior. Para ello sujetamos mientras ponemos el peso, y soltamos después de haber colocado, sin golpear, el peso en la base de la varilla. En este paso $\mathbf{q}=1, \mathbf{P}=1$ y $\mathbf{n}=\mathbf{h}=0$.

- Si el tubo baja, penetrando más en la nieve:

Leer la graduación más próxima a la superficie de la nieve y anotar en la segunda fila del impreso, columna "x", el hundimiento del tubo (en este ejemplo se hunde 5 centímetros más de lo que se había hundido previamente).

\begin{tabular}{|l|l|l|l|l|l|l|l|}
\hline $\mathbf{q}$ & $\mathbf{P}$ & $\mathbf{n}$ & $\mathbf{h}$ & $\mathbf{x}$ & $\mathrm{d}$ & $\mathrm{R}$ & $\mathrm{H}$ \\
\hline 1 & 0 & 0 & 0 & 10 & & & \\
\hline 1 & 1 & $\mathbf{0}$ & $\mathbf{0}$ & $\mathbf{1 5}$ & & & \\
\hline
\end{tabular}


- Si el tubo no penetra en la nieve.

En este caso el hundimiento total "x" será el mismo leído en el paso precedente (en nuestro ejemplo $10 \mathrm{~cm}$ ).

\begin{tabular}{|l|l|l|l|l|l|l|l|}
\hline $\mathbf{q}$ & $\mathbf{P}$ & $\mathbf{n}$ & $\mathbf{h}$ & $\mathbf{x}$ & $\mathrm{d}$ & $\mathrm{R}$ & $\mathrm{H}$ \\
\hline 1 & 0 & 0 & 0 & 10 & & & \\
\hline $\mathbf{1}$ & $\mathbf{1}$ & $\mathbf{0}$ & $\mathbf{0}$ & $\mathbf{1 0}$ & & & \\
\hline
\end{tabular}

Tras estos dos pasos especiales, continuamos procediendo a soltar el peso, inicialmente desde $10 \mathrm{~cm}$ y a anotar tanto la altura en la columna " $h$ " como la profundidad a la que se va hundiendo el tubo de la sonda, en la columna "x". Si la sonda se hunde por ejemplo $7 \mathrm{~cm}$ con el primer golpe quedaría como en la tabla a la derecha:

\begin{tabular}{|c|c|c|c|c|c|c|c|}
\hline $\mathbf{q}$ & $\mathbf{P}$ & $\mathbf{n}$ & $\mathbf{h}$ & $\mathbf{x}$ & $\mathrm{d}$ & $\mathrm{R}$ & $\mathrm{H}$ \\
\hline 1 & 0 & 0 & 0 & 10 & & & \\
\hline 1 & 1 & 0 & 0 & 15 & & & \\
\hline $\mathbf{1}$ & $\mathbf{1}$ & $\mathbf{1}$ & $\mathbf{1 0}$ & $\mathbf{2 2}$ & & & \\
\hline
\end{tabular}

En cualquier caso, la enumeración de los pasos con los que se calculará el perfil de resistencias empezará con el primer paso en el que $\mathbf{x}$ sea no nulo.

Dos son las reglas que deben guiar el proceso del sondeo:

1. Procurar, en la medida de lo posible, que en cada paso la sonda se hunda $1 \mathrm{~cm}$.

Teniendo en cuenta que cada paso se caracteriza por unos valores de $\mathbf{h}, \mathbf{n}$ y $\mathbf{x}$, se debe intentar que $\mathbf{x}_{\mathbf{i}}-\mathbf{x}_{\mathbf{i}-1}=\mathbf{d}_{\mathbf{i}}=1$. ( $\mathbf{x}_{\mathbf{i}}$ es la profundidad alcanzada en el i-ésimo paso)

2. Aproximar siempre los valores de la variable $\mathbf{x}$ que se anotan en la hoja a centímetros enteros.

El hundimiento de la sonda se puede controlar a través de la altura $\mathbf{h}$ desde la que deja caer el peso, y a través del número $\mathbf{n}$ de veces que deja caer el peso desde una altura determinada.

\section{Transición desde una capa homogénea a otra con distinta resistencia}

El observador nota la transición desde una capa homogénea a otra más o menos resistente porque el hundimiento regular de la sonda queda interrumpido. Es decir, después de haber realizado $\mathbf{n}$ golpes desde una altura $\mathbf{h}$ en los que la $\mathbf{x}$ ha ido aumentando regularmente, al seguir golpeando desde la misma altura $\mathbf{h}$, el ritmo de descenso varía. A continuación estudiamos los casos más significativos.

\section{- Transición de una capa homogénea a otra de mayor resistencia}

Cuando en una serie de golpes desde una misma altura $\mathbf{h}$, en los que la sonda va penetrando más o menos lo mismo en cada golpe, en el caso ideal un centímetro, notamos que en un golpe la sonda penetra menos, esto significa que hemos llegado a una capa más dura. La estrategia más conveniente a seguir depende de lo próximo que esté el valor del hundimiento a un número entero. Lo vemos a través de ejemplos:

Desde una profundidad de $\mathbf{x}=15 \mathrm{~cm}$, en una serie de golpes la sonda ha penetrado $3 \mathrm{~cm}$ en tres golpes desde una altura $\mathbf{h}=10 \mathrm{~cm}$. Una capa hasta ahora homogénea. Llevamos $\mathbf{n}=3 \mathrm{y} \mathbf{x}=18$.

a. En el cuarto golpe desde $\mathbf{h}=10$, en lugar de hundirse la sonda $1 \mathrm{~cm}$, se hunde sólo $0,2 \mathrm{~cm}$. Entonces, anotamos por separado los golpes previos y aproximamos a cero el hundimiento provocado por el último golpe (ponemos la misma $\mathbf{x}$ ). Aunque anotado, este último golpe no contará para el cálculo de $\mathbf{R}$. Incrementamos la altura en la siguiente serie de golpes, a $15 \mathrm{~cm}$ por ejemplo.

\begin{tabular}{|c|c|c|c|c|c|c|c|}
\hline $\mathbf{q}$ & $\mathbf{P}$ & $\mathbf{n}$ & $\mathbf{h}$ & $\mathbf{x}$ & $\mathbf{d}$ & $\mathbf{R}$ & $\mathrm{H}$ \\
\hline$\ldots$ & $\ldots$ & $\ldots$ & $\ldots$ & 15 & & & \\
\hline 1 & 1 & 3 & 10 & 18 & & & \\
\hline 1 & 1 & 1 & 10 & 18 & & & \\
\hline$\ldots$ & $\ldots$ & $\ldots$ & 15 & $\ldots$ & & & \\
\hline
\end{tabular}


b. En el cuarto golpe desde la misma altura, $\mathbf{h}=10$, la sonda se hunde $0,5 \mathrm{~cm}$.

En este caso, lo más conveniente es dar uno o dos golpes más hasta que la profundidad alcanzada sea un número entero de centímetros, preferentemente 1. Anotamos los golpes que llevábamos previamente como una serie, y los siguientes como otra. Si dimos, por ejemplo, 2 golpes en total hasta llegar al centímetro entero, para esta última serie tendremos

\begin{tabular}{|c|c|c|c|c|c|c|c|}
\hline $\mathbf{q}$ & $\mathbf{P}$ & $\mathbf{n}$ & $\mathbf{h}$ & $\mathbf{x}$ & $\mathbf{d}$ & $\mathbf{R}$ & $\mathrm{H}$ \\
\hline$\ldots$ & $\ldots$ & $\ldots$ & $\ldots$ & 15 & & & \\
\hline 1 & 1 & 3 & 10 & 18 & & & \\
\hline 1 & 1 & 2 & 10 & 19 & & & \\
\hline$\ldots$ & $\ldots$ & $\ldots$ & & & & & \\
\hline
\end{tabular}
$\mathbf{n}=2, \mathbf{h}=10, \mathrm{y} \mathbf{x}=19$

$\rightarrow$ Luego, si creemos que la capa dura encontrada es relativamente gruesa, aumentaremos la altura en el quinto paso, por ejemplo a $15 \mathrm{~cm}$.

\begin{tabular}{|c|c|c|c|c|c|c|c|}
\hline $\mathbf{q}$ & $\mathbf{P}$ & $\mathbf{n}$ & $\mathbf{h}$ & $\mathbf{x}$ & $\mathbf{d}$ & $\mathrm{R}$ & $\mathrm{H}$ \\
\hline$\ldots$ & $\ldots$ & $\ldots$ & $\ldots$ & 15 & & & \\
\hline 1 & 1 & 3 & 10 & 18 & & & \\
\hline 1 & 1 & 2 & 10 & 19 & & & \\
\hline 1 & 1 & $\ldots$ & 15 & & & & \\
\hline$\ldots$ & $\ldots$ & $\ldots$ & $\ldots$ & $\cdots$ & & & \\
\hline
\end{tabular}

$\rightarrow$ Pero si pensamos que la capa dura encontrada es fina, en la siguiente serie de golpes mantendremos la altura $\mathbf{h}=10 \mathrm{y}$ jugaremos con el número de golpes.

\begin{tabular}{|c|c|c|c|c|c|c|c|}
\hline $\mathbf{q}$ & $\mathbf{P}$ & $\mathbf{n}$ & $\mathbf{h}$ & $\mathbf{x}$ & $\mathbf{d}$ & $\mathbf{R}$ & $\mathrm{H}$ \\
\hline$\ldots$ & $\ldots$ & $\ldots$ & $\ldots$ & 15 & & & \\
\hline 1 & 1 & 3 & 10 & 18 & & & \\
\hline 1 & 1 & 2 & 10 & 19 & & & \\
\hline 1 & 1 & $\ldots$ & 10 & $\ldots$ & & & \\
\hline$\ldots$ & $\ldots$ & $\ldots$ & $\ldots$ & $\ldots$ & & & \\
\hline
\end{tabular}

c. En el cuarto golpe, al soltar el peso desde la misma altura, $\mathbf{h}=10$, la sonda se hunde $0,7 \mathrm{~cm}$.

Entonces, aproximamos la profundidad alcanzada al siguiente centímetro entero, $\quad \mathbf{x}=19$ en nuestro ejemplo, y unimos este cuarto golpe a los tres precedentes, anotando una serie de cuatro golpes idénticos. La siguiente serie de golpes la efectuaremos desde una altura mayor, por ejemplo,

\begin{tabular}{|c|c|c|c|c|c|c|c|}
\hline $\mathbf{q}$ & $\mathbf{P}$ & $\mathbf{n}$ & $\mathbf{h}$ & $\mathbf{x}$ & $\mathbf{d}$ & $\mathbf{R}$ & $\mathrm{H}$ \\
\hline$\ldots$ & $\ldots$ & $\ldots$ & $\ldots$ & 15 & & & \\
\hline 1 & 1 & 4 & 10 & 19 & & & \\
\hline 1 & 1 & $\ldots$ & 15 & $\ldots$ & & & \\
\hline$\ldots$ & $\ldots$ & $\ldots$ & $\ldots$ & $\ldots$ & & & \\
\hline
\end{tabular}
desde $\mathbf{h}=15 \mathrm{~cm}$. 


\section{- Transición de una capa homogénea a otra menos resistente:}

Cuando en una serie de golpes desde una misma altura $\mathbf{h}$, en los que la sonda va penetrando más o menos lo mismo en cada golpe, en el caso ideal un centímetro, notamos que en un golpe la sonda penetra más, esto significa que hemos llegado a una capa de menor resistencia. En este caso, el último golpe se computa separado de los precedentes. Se pasa a lanzar el peso desde una altura menor. Lo vemos a través de un ejemplo:

Desde una profundidad de $\mathbf{x}=15 \mathrm{~cm}$, en una serie de golpes la sonda ha penetrado $3 \mathrm{~cm}$ en tres golpes desde una altura $\mathbf{h}=10 \mathrm{~cm}$. Una capa hasta ahora homogénea. Llevamos $\mathbf{n}=3 \mathrm{y} \mathbf{x}=18$.

En el cuarto golpe, al soltar el peso desde la misma altura, $\mathbf{h}=10$, en vez de hundirse la sonda $1 \mathrm{~cm}$ se hunde $3 \mathrm{~cm}$.

Entonces, separamos el cuarto golpe de la serie anterior. Anotamos en una línea los tres primeros golpes, para los que $\mathbf{n}=3, \mathbf{h}=10$ y $\mathbf{x}=18$, y en la línea siguiente el último golpe, para el que $\mathbf{n}=1, \mathbf{h}=10$ y $\mathbf{x}=21$.

Para la siguiente serie de golpes, disminuiremos la altura desde la que se lanza el peso, por ejemplo, a $5 \mathrm{~cm}$.

\begin{tabular}{|c|c|c|c|c|c|c|c|}
\hline $\mathbf{q}$ & $\mathbf{P}$ & $\mathbf{n}$ & $\mathbf{h}$ & $\mathbf{x}$ & $\mathbf{d}$ & $\mathbf{R}$ & $\mathrm{H}$ \\
\hline$\ldots$ & $\ldots$ & $\ldots$ & $\ldots$ & 15 & & & \\
\hline 1 & 1 & 3 & 10 & 18 & & & \\
\hline 1 & 1 & 1 & 10 & 21 & & & \\
\hline 1 & 1 & $\ldots$ & 5 & $\ldots$ & & & \\
\hline$\ldots$ & $\ldots$ & $\ldots$ & $\ldots$ & $\ldots$ & & & \\
\hline
\end{tabular}

\section{Manto nivoso de espesor superior a 1 metro}

Al alcanzar el hundimiento de la sonda la graduación $80 \mathrm{~cm}$ del primer tubo, sin esperar más, manteniéndolo firmemente con una mano, se desmonta la varilla, se ajusta el segundo tubo a su parte superior, y se vuelve a montar la varilla ya lastrada con el peso móvil.

En este proceso, se repite la anotación conforme los dos pasos especiales que se realizaron al empezar el sondeo. Es decir, si al colocar el colocar el segundo tubo se produce un hundimiento, lo anotaremos con $\mathbf{P}=0, \mathbf{n}=0$ y $\mathbf{h}=0$, y si se produce un hundimiento al colocar la varilla junto con el peso, lo anotaremos con $\mathbf{P}=1, \mathbf{n}=0$ y $\mathbf{h}=0$. En ambos casos ahora ya con $\mathbf{q}=2$.

\section{Contacto con el suelo}

El sondeo termina cuando la punta de la sonda entra en contacto con el suelo. Sabemos que la punta de la sonda ha llegado al suelo porque aunque aumentemos al máximo la altura desde la que se suelta el peso, ya no baja más. La profundidad total a la que ha bajado la sonda debe coincidir con la medida inicial realizada con la sonda fina. 


\subsubsection{Perfil estratigráfico o cata de nieve}

Consiste en la toma de los datos más relevantes de cada una de las diferentes capas que podamos detectar en el manto nivoso, ahora sobre un corte total del mismo abierto con una pala. Estos datos servirán para trazar el perfil estratigráfico del manto, una información fundamental para estimar su estabilidad. Los datos recogidos en la cata son:

- Temperatura

- Tipo y diámetro de los granos de nieve

- Densidad

- Dureza

- Humedad

\subsubsection{Perfil de temperaturas}

Las medidas se toman con el termómetro de nieve, que es como los de cocina. Su elemento sensible es una varilla metálica, terminada en punta para facilitar su inserción en la nieve.

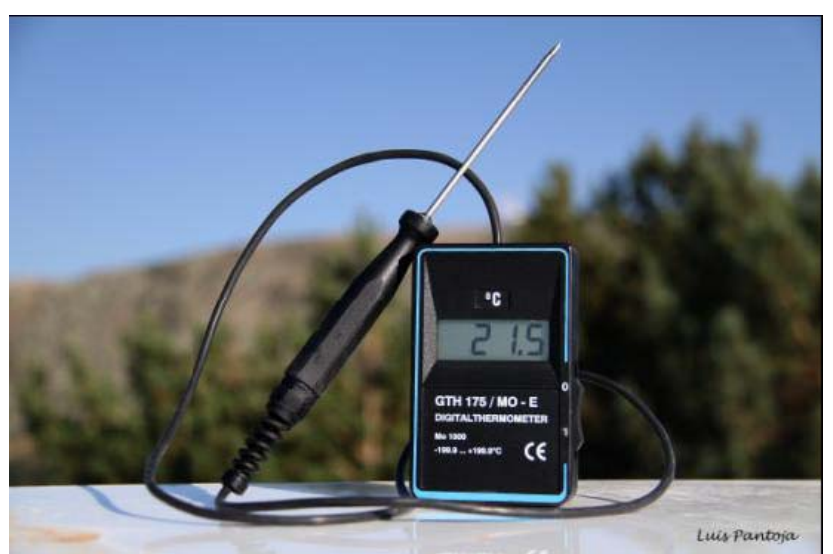

Fig. 50 Termómetro de nieve.

El perfil de temperaturas expresa la variación de la temperatura de la nieve en función de la altura. Se obtiene tomando datos de temperatura al menos cada $10 \mathrm{~cm}$ en el primer metro de profundidad, pero si se detectan espesores donde varía muy bruscamente, se intercalarán en ellos más medidas a fin de precisar mejor esa variación.

A estos datos se debe siempre añadir la temperatura sobre la superficie de la nieve, que se mide colocando el termómetro sobre dicha superficie, haciéndole sombra con la pala u otro objeto.

La primera medida dentro del corte se hace a la altura del múltiplo de $10 \mathrm{~cm}$ más próximo a la superficie (por ejemplo, si la altura total del manto nivoso es $137 \mathrm{~cm}$, la primera medida se toma a 130 $\mathrm{cm}$ del suelo). Si el espesor del manto es mayor de $150 \mathrm{~cm}$, la temperatura se puede medir cada 20 $\mathrm{cm}$ a partir del primer metro de profundidad. La temperatura dentro del corte se mide introduciendo el termómetro en la pared nivosa al nivel elegido, esperando al menos 30 segundos a que el valor se estabilice. Para facilitar esto, es útil mantener el sensor del termómetro dentro de la nieve. Evidentemente, nunca puede superar los $0^{\circ} \mathrm{C}$. Si en algún momento se miden temperaturas de la nieve superiores a cero grados (que puede suceder, por tener la nieve sales disueltas o por error del termómetro), anotaremos cero grados.

Con el fin de que la radiación solar no altere los datos, la temperatura debe medirse lo primero, nada más abrir el corte. Si el día es muy soleado y el manto muy grueso, conviene abrir el corte poco a poco, de 50 en $50 \mathrm{~cm}$, tomando en cada tramo los datos de temperatura correspondientes.

La nieve es un buen aislante. Esto significa que cuando las temperaturas del aire son inferiores a $0^{\circ} \mathrm{C}$, los terrenos cubiertos de nieve pierden menos calor que los que no lo están. Por esta razón, lo normal es que la temperatura de la nieve en la base del manto sea más alta que la de las capas superiores, y que durante el día sólo la temperatura de la superficie del manto nivoso se aproxime a la temperatura del aire, quedando el interior del manto a más baja temperatura.

Durante la noche, la temperatura de la superficie del manto puede llegar a ser muy inferior a la del aire, debido a que la nieve pierde calor por radiación.

\begin{tabular}{|c|c|}
\hline $\begin{array}{c}\mathbf{H} \\
\mathbf{C m}\end{array}$ & $\begin{array}{c}\mathbf{T} \\
{ }^{\circ} \mathbf{C}\end{array}$ \\
\hline 130 & -4.5 \\
\hline 120 & -5.0 \\
\hline 110 & -5.2 \\
\hline & \\
$\cdots$ & $\cdots$ \\
\hline 10 & -0.5 \\
\hline 0 & 0.0 \\
\hline
\end{tabular}




\subsubsection{Análisis de las capas del manto nivoso}

La detección de las capas que configuran el manto nivoso se realiza con la vista y, fundamentalmente, con el tacto, siempre con los guantes puestos. Haciendo descender un dedo (o la placa milimetrada) a lo largo de todo el corte, es posible distinguir discontinuidades en el grado dureza, en la densidad o en la textura. Muchas veces también es posible distinguir a simple vista franjas de nieve con diferentes tonalidades de blanco. Dichas tonalidades corresponden, normalmente, a distintos tipos o tamaños de grano.

Los observadores deben marcar con alguna señal visible - como por ejemplo, un palillo pinchado todos los niveles en los que aprecien, con la vista o con el tacto, un cambio cualitativo en la nieve. El espesor entre dos de estos niveles constituye una capa del perfil estratigráfico.

La sucesión de las discontinuidades y los espesores de las capas deben ser adecuadamente registrados en una hoja, donde el observador anotará los niveles superior e inferior de cada capa, en orden descendente. Evidentemente, el nivel superior de una capa coincide con el nivel inferior de la que tiene encima. A la derecha de cada capa así registrada se irán anotando los resultados de medir o valorar el resto de sus propiedades. Estas propiedades, que completan la caracterización de cada capa del perfil estratigráfico, son:

\subsection{Tipo y tamaño de los granos}

Los granos o cristales del manto nivoso se identifican, con la ayuda de una lupa, por su aspecto y por su diámetro (medido en décimas de $\mathrm{mm}$ ). Con este fin nos servimos de la placa milimetrada o granulométrica de nieve, en la que hay dibujos esquemáticos de los diferentes tipos de grano y rejillas de distintas dimensiones.

En cada capa puede haber más de un tipo de grano. Siempre anotarán los símbolos de los dos tipos predominantes, poniendo en primer lugar el más abundante. Si sólo hay un tipo de grano, se pondrá su símbolo por duplicado.
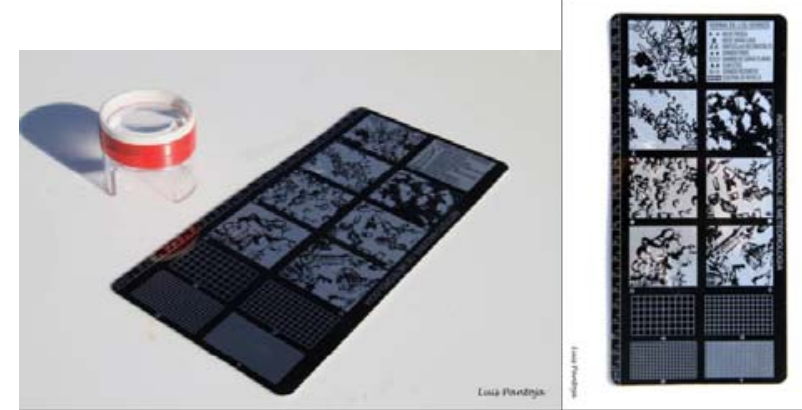

Fig. 51 Placa de nieve milimetrada o granulométrica y lupa

La clasificación de los cristales de nieve de la International Association of Cryospheric Sciences (IACS) es muy detallada, y a menudo los granos presentan características mixtas entre unos tipos y otros. En la práctica, trataremos de encuadrar las formas que encontremos en un conjunto reducido de tipos, asignándoles el tipo más parecido. Los principales tipos de grano y sus símbolos son:

\begin{tabular}{|l|c|c|}
\hline Tipo de grano o cristal & Símbolo (IACS) & Código y color (IACS) \\
\hline Nieve reciente & + & PP \\
\hline Nieve granulada & $\star$ & PPgp \\
\hline Partículas reconocibles & $/$ & DF \\
\hline Granos finos & $\bullet$ & RG \\
\hline Granos de caras planas & $\square$ & FC \\
\hline Cubiletes & $\wedge$ & DH \\
\hline Granos redondos & $\circ$ & MF \\
\hline Costra de rehielo & O & MFar \\
\hline Capa de hielo & - & IF \\
\hline Escarcha & V & SH \\
\hline
\end{tabular}


- Nieve reciente $(+)$ : Está formada por cristales de copos recién caídos. Procede de nevadas acaecidas en atmósferas no turbulentas. Sus cristales tienen forma de estrellas, plaquetas, agujas, columnas, prismas hexagonales, etc.

Su cohesión es por 'trabazón', dejando entre sí muchos huecos de aire, lo que la hace poco compacta, con baja densidad.

El diámetro típico de estos cristales es de 1 a $3 \mathrm{~mm}$.

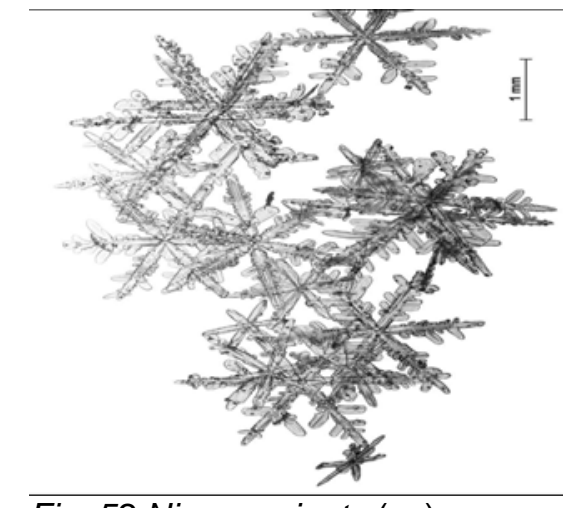

Fig. 52 Nieve reciente $(+)$

- Nieve granulada ( $\Delta$ ): Está formada por pequeños granos parecidos a los del corcho blanco de embalar.

Es una forma especial de la nieve reciente, que procede de nevadas en atmósfera turbulenta, donde gotitas de agua subfundida se congelan sobre los cristales de hielo, en un proceso de escarchado por contacto o 'riming'.

Su cohesión no es buena, por lo que, enterrada en el manto, puede constituir una capa de débil cohesión.

Su diámetro puede alcanzar $5 \mathrm{~mm}$.

- Partículas reconocibles $(/)$ (ó también: $\boldsymbol{\lambda}$ ): Son trozos de cristales de nieve reciente, seca en general, que han sido fragmentados por el viento o parcialmente redondeados por metamorfosis destructiva.

Los fragmentos van perdiendo la cohesión de trabazón y ganando cohesión por 'sinterización', un proceso que los une mediante pequeños puentes de hielo entre los granos. La nieve de partículas reconocibles es más densa y apelmazada que la nieve reciente, con menor contenido de aire.

Su diámetro característico es de alrededor de 1 ó $2 \mathrm{~mm}$.

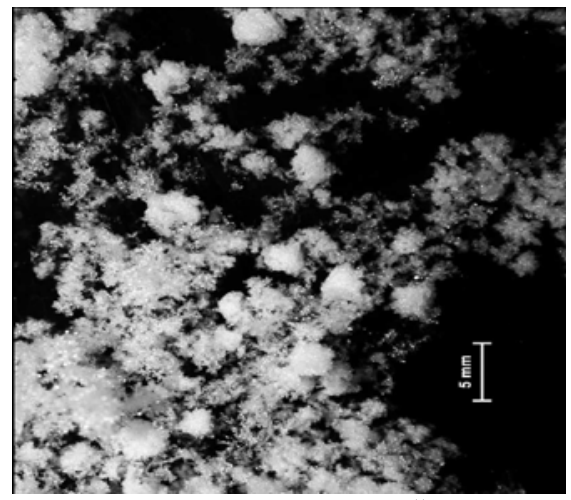

Fig. 53 Nieve granulada $(\nexists$ )

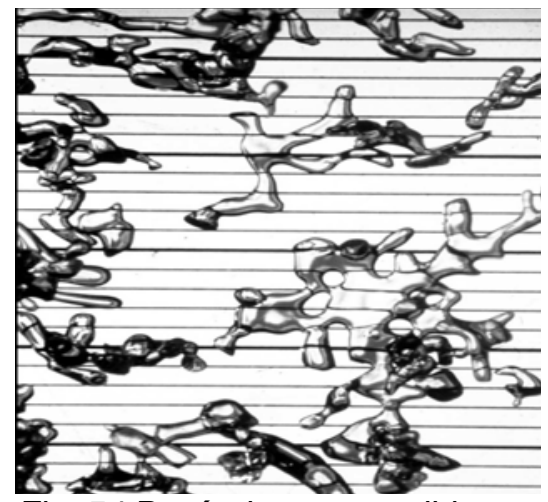

Fig. 54 Partículas reconocibles

$(/$ ó $\lambda)$

- Granos finos $(\bullet)$ : Son pequeños granos redondeados, resultado de la metamorfosis destructiva que suponen la acción del viento y el metamorfismo de gradiente débil (procesos de cambio de estado entre hielo y vapor de agua en medio térmicamente homogéneo).

La cohesión entre los cristales es por sinterización (puentes de hielo entre los cristales) y en ocasiones pueden formar conglomerados.

Su diámetro característico (no confundir el grano individual con los conglomerados de granos) es de 0.2 a $0.5 \mathrm{~mm}$.

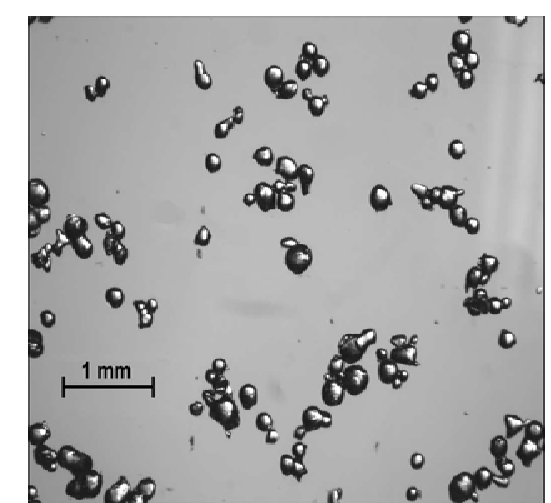

Fig. 55 Granos finos $(\bullet)$ 
- Granos de caras planas ( $\square$ ): Son granos que exhiben formas angulosas y caras planas.

Estas formas limitan la formación de puentes de hielo o de agua entre los granos, dando lugar a nieve de baja cohesión.

El orden de magnitud de los diámetros es de 0.5 a 3 $\mathrm{mm}$, predominando los menores de $1 \mathrm{~mm}$.

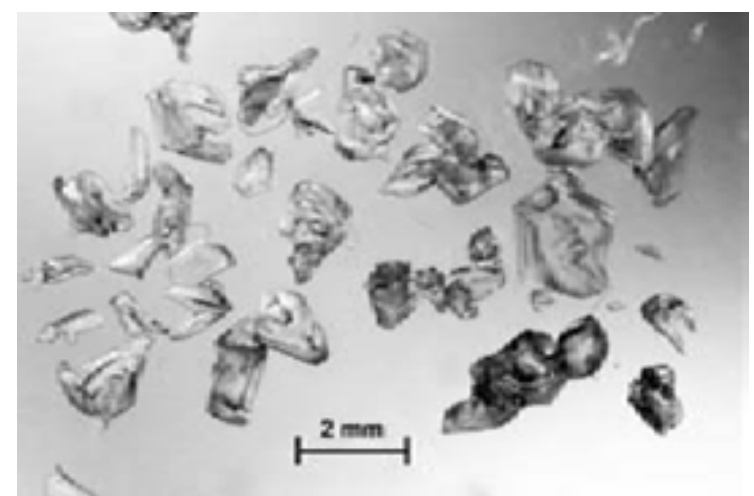

Fig. 56 Granos de caras planas ( ( )

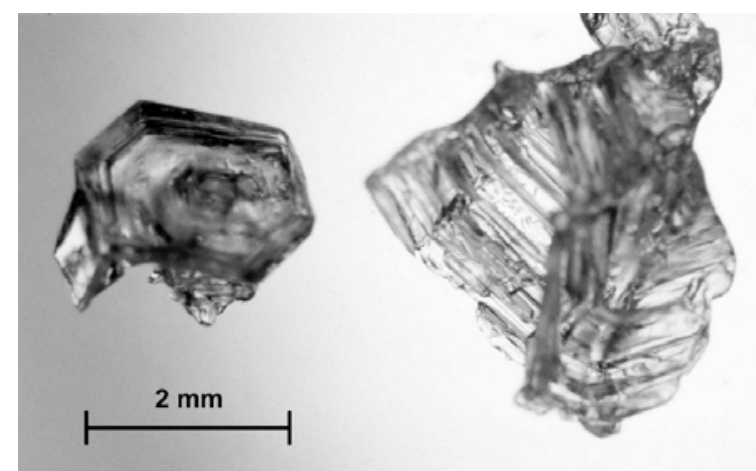

Fig. 57 Cubiletes $(\wedge)$

- Cubiletes $(\wedge)$ : son cristales grandes, que presentan estrías, frecuentemente tienen forma de pirámides escalonadas.

Se forman por difusión del vapor entre granos debida a gradientes fuertes de temperatura dentro del manto.

Su forma limita la cohesión entre los granos, que es pequeña, lo que los hace componentes típicos de las capas de débil cohesión que pueden aparecer en el manto nivoso.

Su diámetro varía típicamente de 2 a $5 \mathrm{~mm}$.

- Escarcha de superficie ( $V$ ): cristales de hielo, con forma de laminillas, de aspecto parecido a pequeñas plumas transparentes.

Se forma por la condensación sólida del vapor de agua sobre la superficie de nieve fría, en general en noches frías $y$ despejadas, sin viento y con suficiente humedad.

Cuando estas plumas quedan enterradas en un manto frío, constituyen capas de débil cohesión y pueden persistir largos periodos como planos de ruptura y deslizamiento.

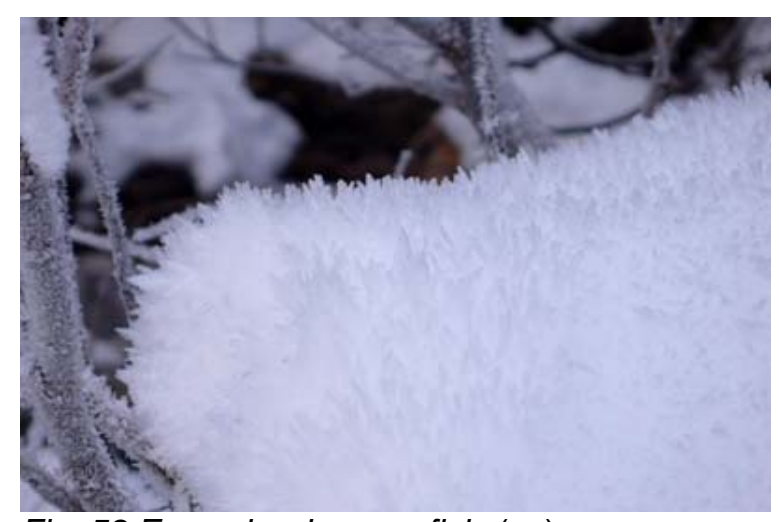

Fig. 58 Escarcha de superficie ( $\vee$ )

Puede medir varios $\mathrm{cm}$. 
- Granos redondos ( 0 ): tienen forma esférica, y son relativamente grandes, formando conglomerados Aparecen en zonas del manto donde la temperatura es o ha sido de $0{ }^{\circ} \mathrm{C}$, por la presencia de agua líquida entre las superficies de los granos, lo que les da un aspecto brillante.

Su cohesión, de capilaridad, es buena cuando el contenido de agua líquida es pequeño (régimen pendular), pero disminuye fuertemente cuando el contenido de agua líquida es grande (nieve empapada, régimen funicular).

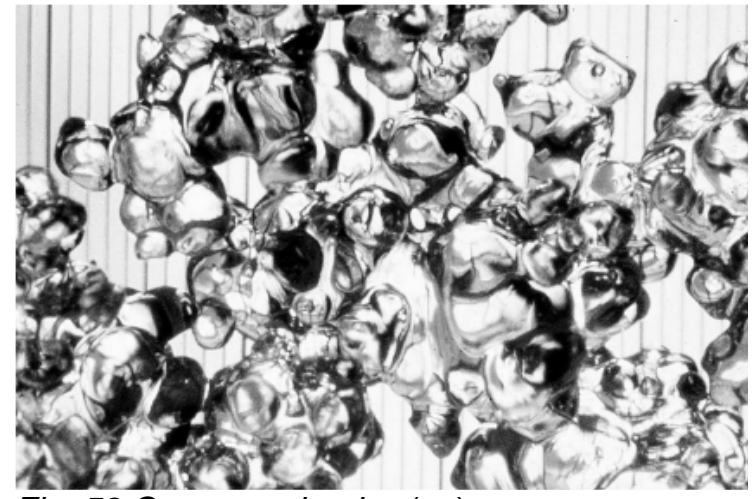

Fig. 59 Granos redondos ( o )

Su diámetro puede variar de 0.5 a $3 \mathrm{~mm}$.

- Costra de rehielo (@O), @D, ...): es el resultado de la congelación de una capa superficial de nieve mezclada con agua líquida.

En ella se reconocen los granos recongelados tras haberse humedecido por fusión o por la lluvia.

Su resistencia aumenta con el número de ciclos de rehielo sufridos.

Pueden aparecer en la superficie del manto o en su interior, tras ser recubiertas por una nevada, constituyendo entonces 'capas de hielo'.

Su espesor es muy variable, generalmente en torno a $1 \mathrm{~cm}$, aunque en casos de intensos ciclos de fusión-congelación puede llegar a ser de 15 ó $20 \mathrm{~cm}$.

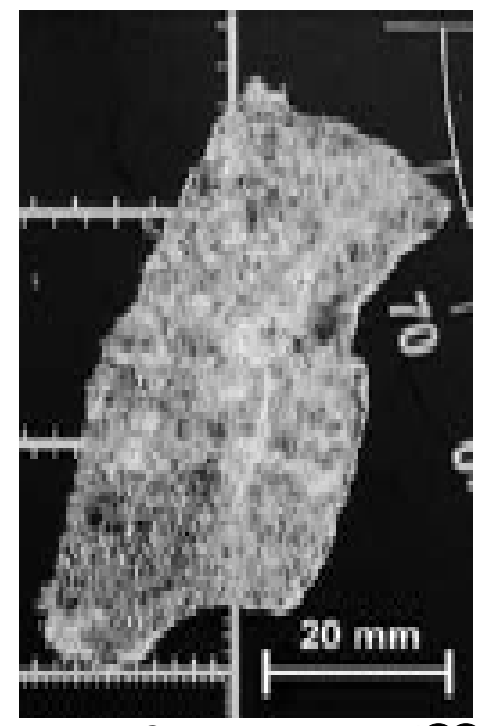

Fig. 60 Costra de rehielo (@)

- Capa de hielo (-): su aparición en el interior del manto se debe a la congelación de agua que percola dentro de la nieve fría, procedente de la lluvia o de la fusión en superficie. Son muy poco porosas.

En las capas de hielo no se reconocen en general granos individuales o partículas.

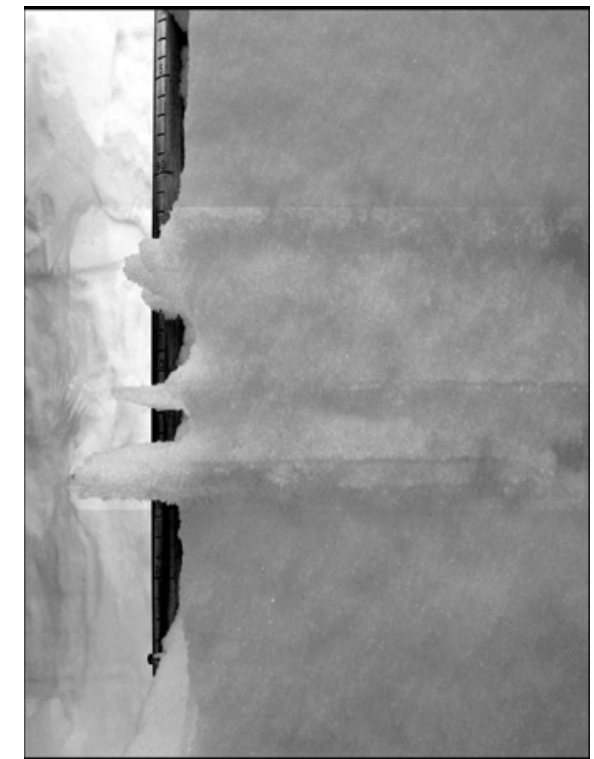

Fig. 61 Capa de hielo ( - ) 


\subsection{Dureza}

Se valora aproximadamente, en función del tipo de objeto que podemos hacer penetrar en la nieve sin aplicar demasiada fuerza: un puño enguantado, cuatro dedos juntos de una mano enguantada extendida, un solo dedo, un lápiz y un cuchillo. Sólo se admiten valores ordinales, que van de 1 a 6 .

\begin{tabular}{|l|l|l|c|c|}
\hline & Dureza & \multicolumn{1}{|c|}{ Penetra: } & Código & Símbolo \\
\hline $\mathbf{1}$ & Muy blanda & Puño (Fist) & F & \\
\hline $\mathbf{2}$ & Blanda & 4 dedos (4Fingers) con la mano extendida, no penetra un puño & 4F & $/$ \\
\hline $\mathbf{3}$ & Media & 1 dedo (1Finger), no penetran 4 dedos con la mano extendida & $\mathbf{1 F}$ & X \\
\hline $\mathbf{4}$ & Dura & Lápiz (Pencil), no penetra un dedo & P & / \\
\hline $\mathbf{5}$ & Muy dura & Cuchillo (Knife), no penetra un lápiz & K & I \\
\hline $\mathbf{6}$ & Hielo & Imposible (Ice), no penetra un cuchillo & I & - \\
\hline
\end{tabular}

Cada grado de dureza tiene asignado, aparte del número, un código y un símbolo ya reconocidos en general internacionalmente. En la medida de lo posible, junto con los números, utilizaremos los símbolos y códigos internacionales, procedentes estos últimos de la nomenclatura en inglés.

\subsection{Humedad}

La nieve puede contener agua en sus tres estados: sólido, líquido y gaseoso. La humedad de la nieve se refiere a su contenido en agua líquida. Llamamos "nieve seca" a la que sólo contiene hielo y vapor de agua. Por el contrario, llamamos "nieve húmeda" a la que también contiene agua líquida.

Siempre que la nieve contenga agua líquida, su temperatura será de $0^{\circ} \mathrm{C}$ (o casi, la temperatura de la nieve húmeda puede ser ligeramente diferente de $0^{\circ} \mathrm{C}$, debido a que no está compuesta de agua pura). Con temperaturas inferiores a $-1^{\circ} \mathrm{C}$ la nieve se considerará seca y no será necesario hacer esta prueba.

En una cata, la humedad se valora de forma aproximada en función de la maleabilidad de la nieve y su capacidad para mojar el guante o escurrir agua. Éste índice de humedad sólo admite valores ordinales, del 1 a 5.

\begin{tabular}{|c|c|c|c|c|}
\hline $\begin{array}{l}\text { Índice de } \\
\text { humedad }\end{array}$ & Humedad & Descripción & Código & Símbolo \\
\hline 1 & $\begin{array}{l}\text { Seca } \\
\text { (Dry) }\end{array}$ & $\begin{array}{l}\text { Granos sueltos. No permite hacer bolas. } \\
\text { Normalmente, su temperatura es inferior a } 0^{\circ} \mathrm{C} \text {. }\end{array}$ & D & \\
\hline 2 & $\begin{array}{l}\text { Poco } \\
\text { húmeda } \\
\text { (Moist) }\end{array}$ & $\begin{array}{l}\text { Se puede hacer bolas, pero no moja el guante. Con } \\
\text { una lupa de } 10 \text { aumentos es todavía imposible } \\
\text { distinguir agua. } T=0^{\circ} \mathrm{C} \text {. }\end{array}$ & M & | \\
\hline 3 & $\begin{array}{l}\text { Húmeda } \\
\text { (Wet) }\end{array}$ & $\begin{array}{l}\text { Se puede hacer bolas que mojan el guante, pero al } \\
\text { apretarlas no escurren agua. Con una lupa de } 10 \\
\text { aumentos ya es posible ver agua entre los granos. } \\
\mathrm{T}=0^{\circ} \mathrm{C} \text {. }\end{array}$ & $\mathbf{W}$ & II \\
\hline 4 & $\begin{array}{l}\text { Mojada } \\
\text { (Very wet) }\end{array}$ & $\begin{array}{l}\text { Se puede hacer bolas que, al apretarlas, escurren } \\
\text { agua. Todavía contiene algo de aire. } \mathrm{T}=0^{\circ} \mathrm{C} \text {. }\end{array}$ & V & III \\
\hline 5 & $\begin{array}{l}\text { Muy mojada } \\
\text { (Soaked) }\end{array}$ & $\begin{array}{l}\text { Al manipularla chorrea agua. Casi no contiene aire. } \\
\mathrm{T}=0^{\circ} \mathrm{C} \text {. (Régimen funicular) }\end{array}$ & $\mathbf{S}$ & IIII \\
\hline
\end{tabular}

Respecto a los códigos y símbolos, para la humedad también usaremos de preferencia los estándares internacionales, procedentes de la nomenclatura en inglés. 


\subsection{Densidad}

La densidad se mide de manera usual, dividiendo la masa de una cierta porción de nieve por el volumen que ocupa. Para ello se utiliza un tubo o cilindro hueco de $1 / 2$ litro de capacidad, que se llena de nieve y se pesa con un dinamómetro dentro de una bolsa de plástico.

El tubo se llena de nieve hincándolo y hundiéndolo en el lugar del corte del manto donde se sitúa la capa. Una vez lleno, se extrae con cuidado y se coloca en la bolsa de plástico para pesarlo.

La densidad, en $\mathrm{Kg} / \mathrm{m}^{3}$ ó $\mathrm{g} / \mathrm{dm}^{3}$, será: 2 x (peso del tubo lleno - peso del tubo vacío).

Se hará una medida en cada estrato cuyo espesor sea igual o superior a $10 \mathrm{~cm}$. Se harán dos medidas en los estratos de espesor igual o superior a $30 \mathrm{~cm}$ (una en la parte superior y otra en la parte inferior).

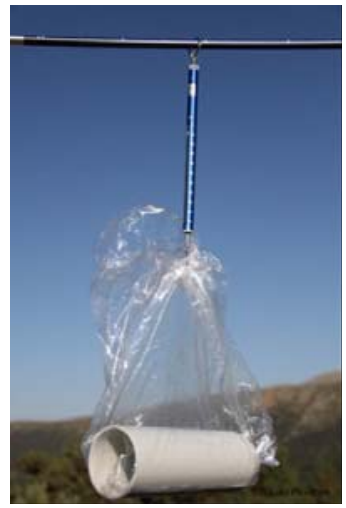

Fig. 62 Tubo y dinamómetro

Cada tipo de grano admite un rango amplio de densidades, pero no puede sobrepasar ciertos límites sin transformarse en un tipo distinto o derretirse.

\begin{tabular}{|l|c|}
\hline \multicolumn{1}{|c|}{ TIPO DE NIEVE } & DENSIDAD $(\mathrm{Kg} / \mathrm{m} 3)$ \\
\hline Nieve reciente muy ligera & $<50$ \\
\hline Nieve reciente & $\sim 150$ \\
\hline Partículas reconocibles & $150-300$ \\
\hline Granos finos & $250-450$ \\
\hline Granos de caras planas & $250-400$ \\
\hline Granos redondos (nieve húmeda a mojada) & $300-500$ \\
\hline Cubiletes & $150-300$ \\
\hline Hielo & $800-900$ \\
\hline
\end{tabular}

Fig. 63 Densidades típicas de los distintos tipos de nieve (EAWS)

Las distintas propiedades de la nieve están relacionadas entre sí. Sus relaciones son, sin embargo, complejas, pues dependen en buena medida de la historia del manto nivoso. Ésta es una de las razones por las que es aconsejable hacer un seguimiento de la evolución de dicho manto a lo largo de toda la temporada invernal.

\subsection{Evolución de la nieve en el manto nivoso}

Las formas en las que originalmente aparece la nieve sobre la superficie del suelo son varias: nieve reciente, nieve granulada, escarcha de superficie y costra de rehielo.

La nieve granulada $(*)$, la escarcha de superficie $(V)$ y la costra de rehielo $(\mathcal{C}, \boldsymbol{0})$ no evolucionan a ritmo apreciable, por lo que, una vez sepultadas, pueden permanecer meses en el interior del manto nivoso sin apenas transformarse. La nieve granulada y la escarcha de superficie forman capas de baja cohesión y, consecuentemente, débiles. Las costras de rehielo, sin embargo, son capas generalmente finas con una resistencia muy alta. La presencia de estos tres tipos es relevante para el desencadenamiento de aludes, pues posteriormente, una vez enterrados en el manto pueden actuar como planos de ruptura (la nieve granulada y la escarcha de superficie) o superficies de deslizamiento (la costra de rehielo) entre capas.

A diferencia de los tipos anteriores, la nieve reciente $(+)$ experimenta transformaciones apreciables bajo el efecto de distintas causas. A pesar de que los procesos de transformación del manto originados a partir de la nieve reciente pueden tener desarrollos diversos (evolucionando a diferentes tipos de grano), todos tienen el mismo resultado final: nieve de grano redondo ( 0 ) o de primavera. 
La nieve de grano redondo es nieve húmeda o mojada; por consiguiente, si permanece en contacto con aire muy frío, sus espesores más superficiales se transforman en costras de rehielo. Esta situación es muy frecuente al final de la temporada invernal, cuando el calor del día produce un incremento del contenido de agua líquida en el manto y el frío posterior de la noche congela la superficie de la nieve mojada. En cualquier otra circunstancia, la única evolución posible para la nieve de grano redondo es la fusión total, que tiene lugar con el deshielo primaveral.

Por su parte, las capas de nieve reciente $(+)$, las de nieve de partículas reconocibles $(/)$-ó $(\boldsymbol{\lambda})$-, de granos finos $(\bullet)$, de caras planas $(\square)$ y de cubiletes $(\Lambda)$, están formadas por agua en los estados sólido y gaseoso (nieve seca). Los cambios de estado de sólido a gas (sublimación) y de gas a sólido (sublimación inversa o condensación sólida) constituyen uno de los mecanismos fundamentales de su transformación.

Los factores implicados en la evolución de la nieve se clasifican en dos grandes grupos: factores mecánicos y factores termodinámicos.

Los factores mecánicos son fundamentalmente el viento, que afecta a la nieve de la superficie, y la presión producida por el peso de la nieve acumulada encima. Su efecto transformador se produce en unas horas o, como máximo, en unos pocos días. Más lentamente, también tienen efecto mecánico sobre el manto nivoso los movimientos de reptación, que lo deforman y someten a tensiones, pudiendo también eventualmente ser causa de desencadenamiento de aludes.

El viento rompe los cristales de la nieve reciente $(+)$ y apelmaza los trozos resultantes, formando, en un primer momento, partículas reconocibles $(/)$-ó $(\boldsymbol{\lambda})-\mathrm{y}$, si el viento se prolonga, una mezcla de partículas reconocibles y granos finos de dimensiones reducidas $(/, \bullet)$. El desmenuzamiento y apelmazamiento de las partículas y granos favorece la formación de puentes de contacto helado entre los granos (sinterización) e incrementa la densidad. La capa así endurecida forma cornisas rígidas sobre el lado de sotavento de cumbres o rocas, así como las llamadas "placas de viento", dos tipos de estructura frecuentemente implicados en desprendimientos y avalanchas. Las placas de viento son capas superficiales endurecidas por el viento, generalmente de poco espesor, que pueden tener debajo capas de nieve con débil cohesión constituyendo lo que se denominan "estructuras de placa". Son peligrosas porque pueden producir, en quienes andan sobre la nieve, una falsa impresión de estabilidad.

A medida que una capa queda sepultada por la nieve que cae sobre ella, la presión aprieta los granos unos junto a otros, eliminando aire y aumentando la densidad.

Los factores termodinámicos son, fundamentalmente, los procesos de sublimación directa e inversa entre los granos sólidos y el vapor de agua presente en el aire que llena sus resquicios. Estos procesos, por los que las moléculas de agua pasan desde el aire a la superficie de los granos y de ésta al aire, afectan sobre todo a las formas y al tamaño de los granos, y dependen del gradiente de temperatura.

Los cambios producidos por los factores termodinámicos, si bien en condiciones muy favorables pueden producirse con rapidez, pudiendo bastar una sola noche en los casos más extremos, son en general lentos, necesitando algunos de ellos periodos de hasta 3 semanas. 
El gradiente de temperatura no es otra cosa que la rapidez con la que varía la temperatura en función de la profundidad, y se mide en grados Celsius por $\mathrm{cm}$.

Por lo general, la temperatura de la nieve en contacto con el suelo es de aproximadamente $0{ }^{\circ} \mathrm{C}$, y disminuye en el interior del manto, aproximándose a la del aire en la superficie. Esto sucede porque la nieve es un buen aislante. Su poder aislante aumenta con la proporción de aire que contiene. Por tanto, cuanto más aire tiene la nieve seca menos densidad - mayor es la posibilidad de que presente gradientes importantes de temperatura.

En aquellos espesores del manto nivoso donde la temperatura es casi constante, es decir, en los que varía menos de $0,05^{\circ} \mathrm{C} / \mathrm{cm}$ ó $5^{\circ} \mathrm{C} / \mathrm{m}$, los granos tienden a redondearse, resultando, por tanto, un predominio de granos finos.

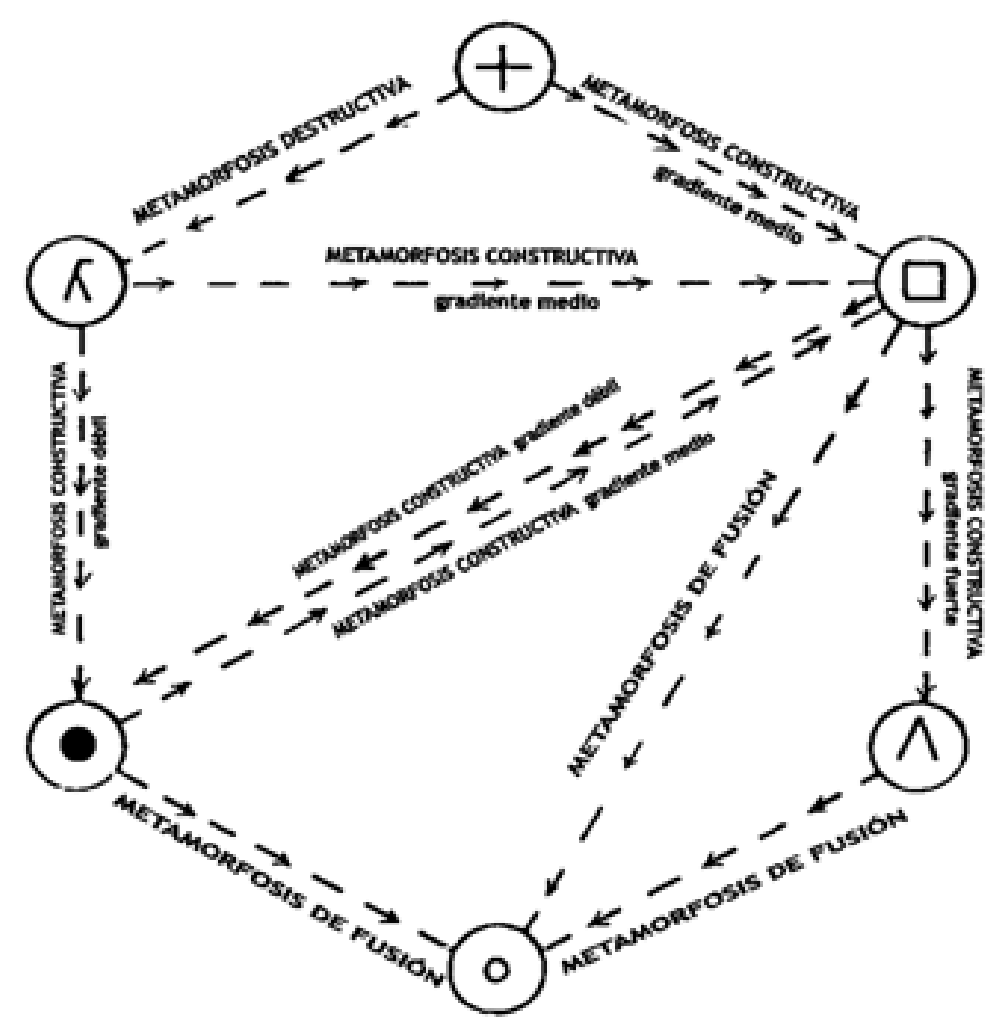

Fig. 64 Esquema de la metamorfosis de la nieve en el manto nivoso (CEN - Météo France)

En aquellos espesores donde la temperatura varía de forma apreciable, los granos tienden a adoptar formas angulosas con superficies planas. Si la densidad es baja, es decir, si hay bastante aire en la nieve, los granos también ven favorecida su tendencia a crecer.

Cuando la variación de temperatura en el manto está comprendida entre 0,05 y $0,20^{\circ} \mathrm{C} / \mathrm{cm}$ o lo que es lo mismo, entre 5 y $20^{\circ} \mathrm{C} / \mathrm{m}$ (gradiente medio), se forman granos de caras planas ( $\square$ ), cuyos diámetros pueden llegar a medir $3 \mathrm{~mm}$. Cuando la variación sobrepasa los $0,20^{\circ} \mathrm{C} / \mathrm{cm}$ ó $20^{\circ} \mathrm{C} / \mathrm{m}$ (gradiente fuerte), se forman los granos en forma de pirámide escalonada llamados cubiletes $(\wedge)$, capaces a veces de alcanzar los $5 \mathrm{~mm}$. Las capas de caras planas y sobre todo de cubiletes tienen muy poca cohesión, por lo que pueden actuar como superficies de fractura para la nieve que las cubre, contribuyendo a que aumente el peligro de aludes.

Los granos de caras planas tienen la capacidad de reconvertirse en grano fino si el gradiente de temperatura disminuye, pero para los cubiletes no hay posibilidad de reconversión. Las capas de cubiletes pueden permanecer meses enterradas en el manto nivoso, con el potencial peligro que esto supone.

La única evolución posible de los cubiletes es la que finalmente afecta a todos los tipos de nieve cuando, por efecto del deshielo, se humedecen y se convierten en nieve húmeda, mojada o muy mojada, de grano redondo. Las evoluciones posibles de los granos en el manto nivoso se sintetizan en la figura 64. 


\subsubsection{Cálculos y elaboración del informe del sondeo}

Una vez tomados todos los datos, los observadores deben tapar el agujero realizado en la nieve y pueden retirarse a un lugar cubierto para calcular los datos de resistencia, analizar el perfil estratigráfico y elaborar el informe.

\subsection{Cálculos y gráfica de resistencia}

Los datos tomados en el sondeo por golpeo sirven para calcular y representar la resistencia de la nieve en cada capa del manto, es decir, la resistencia a la penetración de la sonda en función de la altura medida desde el terreno: $\mathbf{R}(\mathbf{H})$.

El siguiente paso es calcular los valores de ambas variables.

Para la resistencia, cuya fórmula es $R=\frac{P \times n \times h}{d}+q+P$, ya tenemos anotados $\mathbf{q}, \mathbf{P}, \mathbf{n}$ y $\mathbf{h}$, pero nos faltan los de $\mathbf{d}$, que es el hundimiento de la sonda cada $\mathbf{n}$ golpes. Cada valor correspondiente a un tramo de resistencia homogénea.

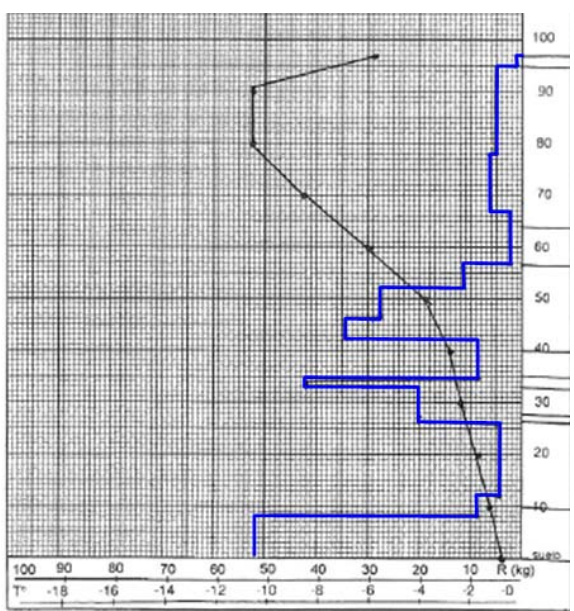

Fig. 65 Gráfica de resistencias (azul)

Para cada fila, se obtiene el valor de la columna d efectuando la diferencia entre el valor de la columna $\mathbf{x}$ de esa fila y el valor de la columna $\mathbf{x}$ de la fila precedente. El primer valor de $\mathbf{d}$ es igual que el primer valor de $\mathbf{x}, \mathbf{y}$ en el caso general, para la i-ésima fila: $\mathbf{d}_{\mathbf{i}}=\mathbf{x}_{\mathbf{i}}-\mathbf{x}_{\mathbf{i}-1}$

Seguidamente, calcularemos los valores de la columna $\mathbf{H}$, de alturas respecto del suelo del límite superior de cada estrato de resistencia homogénea y espesor $\mathbf{d}$.

\begin{tabular}{|l|l|l|l|l|l|l|l|}
\hline $\mathrm{q}$ & $\mathrm{p}$ & $\mathrm{n}$ & $\mathrm{h}$ & $\mathrm{x}$ & $\mathrm{d}$ & $\mathrm{R}$ & $\mathrm{H}$ \\
\hline 1 & 0 & 0 & 0 & 2 & 2 & 1 & 97 \\
\hline 1 & 1 & 0 & 0 & 2 & 0 & & 95 \\
\hline 1 & 1 & 5 & 5 & 10 & 8 & 5 & 95 \\
\hline 1 & 1 & 10 & 3 & 19 & 9 & 5 & 87 \\
\hline 1 & 1 & 10 & 3 & 25 & 6 & 7 & 78 \\
\hline 1 & 1 & 3 & 5 & 30 & 5 & 5 & 72 \\
\hline 1 & 1 & 1 & 5 & 40 & 10 & 2 & 67 \\
\hline 1 & 1 & 7 & 5 & 44 & 4 & 10 & 57 \\
\hline 1 & 1 & 15 & 10 & 50 & 6 & 27 & 53 \\
\hline 1 & 1 & 8 & 20 & 55 & 5 & 34 & 47 \\
\hline 1 & 1 & 5 & 10 & 63 & 8 & 8 & 42 \\
\hline 1 & 1 & 4 & 10 & 64 & 1 & 42 & 34 \\
\hline 1 & 1 & 3 & 40 & 71 & 7 & 19 & 33 \\
\hline 1 & 1 & 2 & 10 & 85 & 14 & 3 & 26 \\
\hline 1 & 1 & 5 & 5 & 89 & 4 & 8 & 12 \\
\hline 1 & 1 & 10 & 40 & 97 & 8 & 52 & 8 \\
\hline & & & & & & & \\
\hline
\end{tabular}

Fig. 66 Datos para el perfil de resistencias
Para ello, comenzaremos por la última línea del impreso. En esta última línea, $\mathbf{H}$ será evidentemente igual a $\mathbf{d}$. En las otras líneas, $\mathbf{H}$ será la suma del valor de $\mathbf{H}$ de la línea inferior y del valor de $\mathbf{d}$ de la línea considerada.

Por tanto, se calcula $\mathbf{H}$ de línea en línea partiendo de la última hasta la primera. En el caso general, para la i-ésima fila: $\mathbf{H}_{\mathbf{i}}=\mathbf{H}_{\mathrm{i}+1} \mathbf{+} \mathbf{d}_{\mathrm{i}}$.

El cálculo de los valores de la columna $\mathbf{H}$ nos ayudará también a chequear la corrección de los cálculos: el último valor de $\mathbf{x}$ y el primero de $\mathbf{H}$, ambos correspondientes al espesor total del manto, deben ser iguales.

Por último, calcularemos la resistencia a la penetración, utilizando la fórmula de la figura 67 , que es la que aparece encuadrada en el impreso de toma de datos del sondeo por golpeo ${ }^{1}$.
1 : La fórmula del impreso está simplificada, por asumir que siempre $Q=$ peso de un tubo $=1 \mathrm{Kg}$. Si se utilizasen sondas de golpeo cuyos tubos no pesasen $1 \mathrm{Kg}$, deberá tenerse en cuenta al calcular la resistencia, usando la fórmula completa, donde $Q=$ peso de un tubo
$R=\frac{P \times n \times h}{d}+Q \times q+P$ 
Para la aplicación de la fórmula debemos recordar que

$\mathbf{P}=$ peso móvil $=1 \mathrm{Kg}$.

$$
R=\frac{P \times n \times h}{d}+q+P
$$

Fig. 67 Fórmula para el cálculo de la resistencia.

Las resistencias calculadas para cada hundimiento $\mathbf{d}$ consecutivo a $\mathbf{n}$ golpes se anotan en la columna R. Recordemos que cuando $\mathbf{d}=0$ (estrato nulo, por tanto inexistente) no hay que calcular la resistencia. Dejaremos la casilla en blanco o la rellenaremos con una $\mathrm{x}$.

En la práctica, se multiplica el número de golpes $\mathbf{n}$ por la altura de caída $\mathbf{h}$ en $\mathrm{cm}, \mathrm{y}$ se divide el resultado por el hundimiento $\mathrm{d}$, también en $\mathrm{cm}$. Se añade a este resultado el peso de la masa móvil, que es $1 \mathrm{Kg}, y$ el peso del tubo o tubos $(1,2$ ó $3 \mathrm{Kg}$ ). $\mathbf{R}$ se expresa en $\mathrm{Kg}$ redondeando, por defecto, a enteros.

\section{Ejemplo de cálculo:}

\begin{tabular}{|c|c|c|c|c|c|c|c|c|}
\hline $\mathbf{q}$ & $\mathbf{P}$ & $\mathbf{n}$ & $\mathbf{h}$ & $\mathbf{x}$ & $\mathbf{d}$ & $\mathbf{R}$ & $\mathbf{H}$ & CÁLCULO DE LA RESISTENCIA \\
\hline $\mathbf{1}$ & $\mathbf{0}$ & $\mathbf{0}$ & $\mathbf{0}$ & $\mathbf{2}$ & $\mathbf{2}$ & $\mathbf{1}$ & $\mathbf{9 7}$ & $\mathrm{R}=\frac{0 \times 0}{2}+1+0=1 \mathrm{Kg}$ \\
\hline $\mathbf{1}$ & $\mathbf{1}$ & $\mathbf{0}$ & $\mathbf{0}$ & 2 & $\mathbf{0}$ & & 95 & No se calcula \\
\hline $\mathbf{1}$ & $\mathbf{1}$ & $\mathbf{5}$ & $\mathbf{5}$ & 10 & $\mathbf{8}$ & $\mathbf{5}$ & 95 & $\mathrm{R}=\frac{5 \times 5}{8}+1+1=3.1+2=5.1 \cong 5 \mathrm{Kg}$ \\
\hline $\mathbf{1}$ & $\mathbf{1}$ & $\mathbf{1 0}$ & $\mathbf{3}$ & 19 & $\mathbf{9}$ & $\mathbf{5}$ & $\mathbf{8 7}$ & $\mathrm{R}=\frac{10 \times 3}{9}+1+1=3.3+2=5.3 \cong 5 \mathrm{Kg}$ \\
\hline $\mathbf{1}$ & $\mathbf{1}$ & $\mathbf{1 0}$ & $\mathbf{3}$ & $\mathbf{2 5}$ & $\mathbf{6}$ & $\mathbf{7}$ & $\mathbf{7 8}$ & $\mathrm{R}=\frac{10 \times 3}{6}+1+1=5.0+2=7 \mathrm{Kg}$ \\
\hline & & & & & & & &
\end{tabular}

Con objeto de que la gráfica refleje de forma intuitiva lo que ocurre dentro del manto, se representa $\mathbf{H}$ en el eje vertical o de ordenadas. Cada milímetro en el papel equivale a un $\mathrm{cm}$ en la realidad. $\mathbf{R}$ se representa en el eje horizontal o de abscisas, y cada milímetro en el gráfico equivale a un $\mathrm{Kg}$.

\begin{tabular}{|c|c|c|c|c|c|c|c|}
\hline $\mathbf{q}$ & $\mathbf{P}$ & $\mathbf{n}$ & $\mathbf{h}$ & $\mathbf{x}$ & $\mathbf{d}$ & $\mathbf{R}$ & $\mathbf{H}$ \\
\hline 1 & 0 & 0 & 0 & 2 & 2 & 1 & 97 \\
\hline 1 & 1 & 0 & 0 & 2 & 0 & 0 & 95 \\
\hline 1 & 1 & 5 & 5 & 10 & 8 & 5 & 95 \\
\hline 1 & 1 & 10 & 3 & 19 & 9 & 5 & 87 \\
\hline 1 & 1 & 10 & 3 & 25 & 6 & 7 & 78 \\
\hline 1 & 1 & 3 & 5 & 30 & 5 & 5 & 72 \\
\hline 1 & 1 & 1 & 5 & 40 & 10 & 2 & 67 \\
\hline 1 & 1 & 7 & 5 & 44 & 4 & 10 & 57 \\
\hline 1 & 1 & 15 & 10 & 50 & 6 & 27 & 53 \\
\hline 1 & 1 & 8 & 20 & 55 & 5 & 34 & 47 \\
\hline 1 & 1 & 5 & 10 & 63 & 8 & 8 & 42 \\
\hline 1 & 1 & 4 & 10 & 64 & 1 & 42 & 34 \\
\hline 1 & 1 & 3 & 40 & 71 & 7 & 19 & 33 \\
\hline 1 & 1 & 2 & 10 & 85 & 14 & 3 & 26 \\
\hline 1 & 1 & 5 & 5 & 89 & 4 & $\mathbf{8}$ & $\mathbf{1 2}$ \\
\hline 1 & 1 & 10 & 40 & 97 & 8 & $\mathbf{5 2}$ & $\mathbf{8}$ \\
\hline
\end{tabular}

Para el trazado, comenzaremos por la base, por la última línea de la tabla de datos

1. Tomando los valores de la última fila, se dibuja una línea vertical desde la base (suelo), con abscisa igual a $\mathbf{R}$ (52 $\mathrm{Kg}$ en el ejemplo) hasta la altura igual a $\mathbf{H}$ (8 $\mathrm{cm}$ en el ejemplo), es la línea que va del número 1 al número 2 en la figura 68 .

2. Tomando los valores de la fila inmediatamente superior, desde el punto alcanzado anteriormente, se traza una línea horizontal hasta el nuevo punto de abscisa $\mathbf{R}$ (8 $\mathrm{Kg}$ en este caso). Desde esta última posición, se dibuja una nueva recta vertical hasta la altura $\mathbf{H}(12 \mathrm{~cm})$. En la figura 68 es la línea que va del número 3 al número 4.

3. Se continúa como en el paso 2 , de línea en línea hasta llegar a la primera fila de datos. 


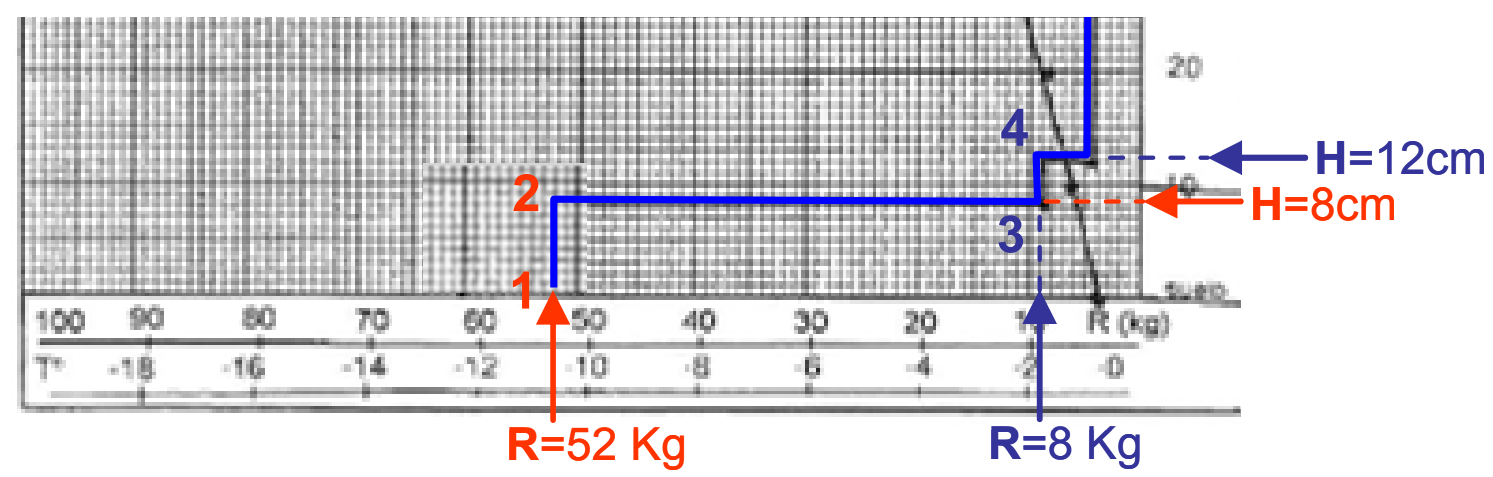

Fig. 68 Trazado del perfil de resistencia

El valor $\mathbf{R}_{\mathbf{i}}$ de la resistencia en el paso $\mathbf{i}$, se adjudica a todo el espesor de nieve comprendido entre $\mathbf{x}_{\mathbf{i}}$ y $\mathbf{x}_{\mathbf{i}-1}$, o lo que es lo mismo, entre $\mathbf{H}_{\mathbf{i}+1}$ y $\mathbf{H}_{\mathbf{i}}$.

Consecuentemente, la gráfica que expresa la resistencia del manto de nieve en función de la profundidad será una gráfica escalonada.

\subsection{Gráfica de temperaturas}

A partir de los datos de temperatura tomados en el corte del manto nivoso podemos construir la gráfica $\mathbf{T}(\mathbf{H})$, de la temperatura en función de la altura.
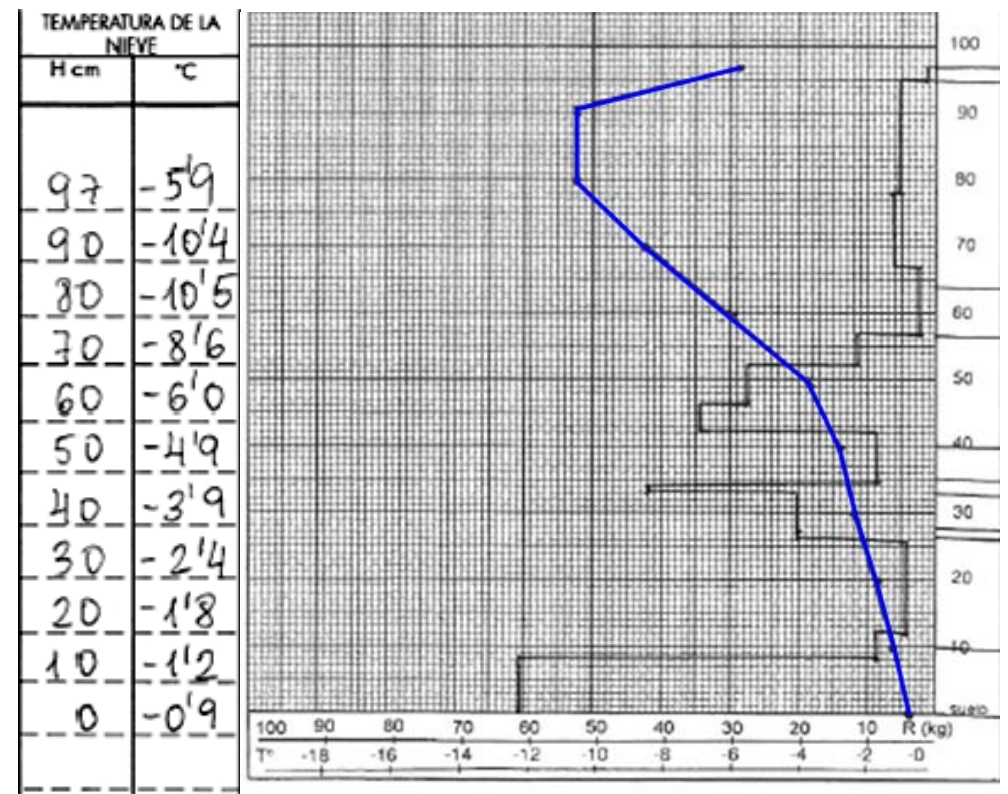

Las unidades utilizadas son grados Celsius $\left({ }^{\circ} \mathrm{C}\right)$ para la temperatura y centímetros $(\mathrm{cm})$ para la altura.

De forma análoga a la gráfica de resistencias, la gráfica de temperaturas también se representa asignando el eje vertical al parámetro $\mathrm{H}$ (altura), y el eje horizontal a las temperaturas.

Dado que la nieve tiene una temperatura menor $\mathrm{o}$ igual que $0{ }^{\circ} \mathrm{C}$, la gráfica de temperaturas quedará siempre a la izquierda del eje vertical.

Fig. 69 Datos y gráfica del perfil de Temperatura

\subsection{Tabla del perfil estratigráfico}

La tabla del perfil estratigráfico es una tabla donde se anotan de forma ordenada todas las características del manto detectadas en la cata. 
El eje vertical de la tabla representa la altura, y a cada una de las propiedades de la nieve evaluadas en la cata le corresponde una columna.

Las capas del manto aparecen representadas en el orden de su superposición real, por las franjas comprendidas entre las alturas de sus niveles superior e inferior. Las propiedades de cada capa se anotan sobre la franja, en las columnas correspondientes.

En la columna $\mathrm{H}$ se anotan los niveles superior e inferior de cada capa. Obviamente, el nivel superior de una capa coincide con el nivel inferior de la capa que
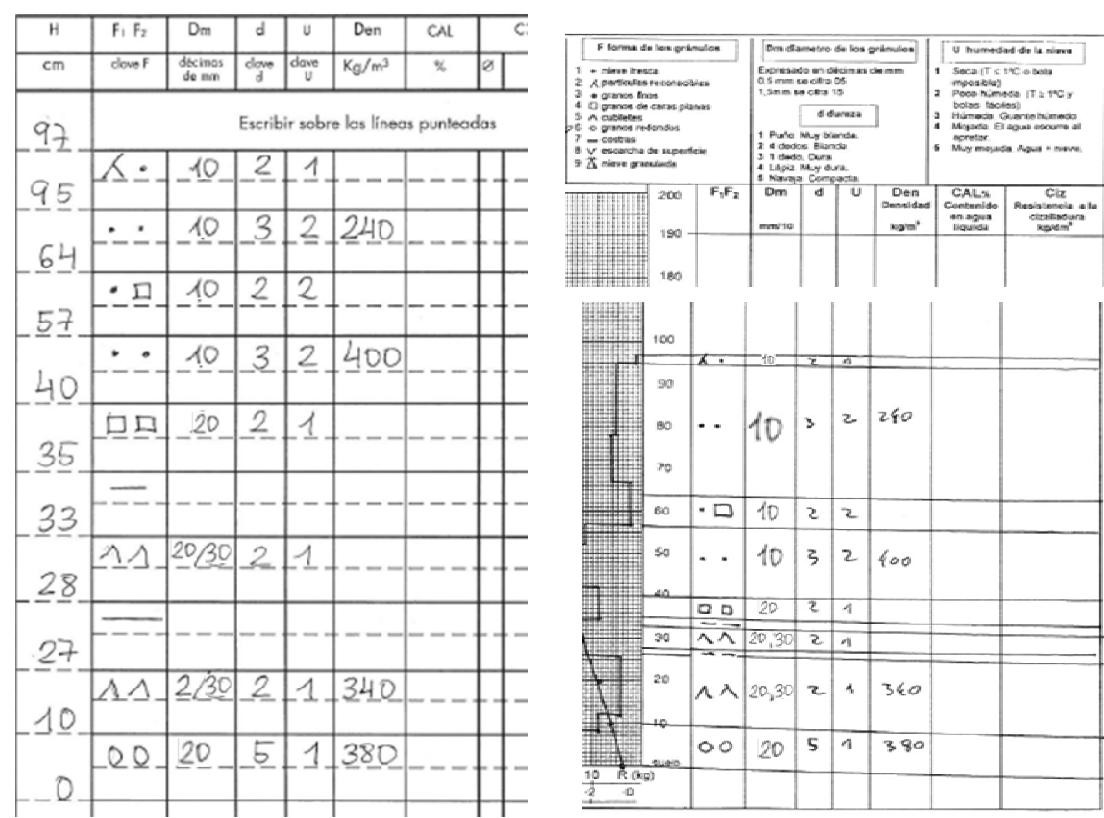

Fig. 70 Datos y representación de un perfil estratigráfico tiene encima.

\subsection{Análisis e informe}

El análisis de los datos del sondeo y de la cata tiene por objeto conocer la estructura del manto nivoso en capas diferenciadas, determinar el orden de superposición de las mismas, y valorar la resistencia o debilidad de cada capa y de la estructura total. El informe elaborado por los observadores ha de ser fundamentalmente descriptivo. En todos los casos debería incluir los siguientes datos:

- Enumeración ordenada de las capas diferenciadas por su resistencia y dureza, destacando las capas frágiles o de resistencia inferior a $4 \mathrm{Kg}$.

- Espesor de cada capa

- Tipos de grano de cada capa, destacando aquellas de baja cohesión como las de nieve granulada, de caras planas y cubiletes.

- Situación de las costras de rehielo y escarcha de superficie sepultada, si las hubiera.

- Descripción del comportamiento de la temperatura, destacando los intervalos en los que presenta un gradiente moderado o fuerte (variación rápida con la altura) y el nivel a partir del cual el manto adquiere el valor constante de $0^{\circ} \mathrm{C}$.

Una vez dibujadas las gráficas y representado el perfil estratigráfico, cada estrato de resistencia constante o casi constante en la gráfica de resistencias debería coincidir, en el caso ideal, con una de las capas registradas en la tabla del perfil estratigráfico. En la realidad esto no siempre es así, pues tanto el sondeo por golpeo como la detección de las capas mediante la vista y el tacto son procedimientos inexactos que con frecuencia pasan por alto algunas discontinuidades. No obstante, si el sondeo está bien realizado, deberá haber una cierta correspondencia entre ambos registros.

Con la ayuda de la composición de gráfica y perfil, buscaremos estructuras potencialmente peligrosas como las de placa, evaluaremos el grado de cercanía a la fusión, etc.

En general, trataremos de asociar la diferente resistencia de los estratos a la penetración de la sonda, así como las distintas temperaturas y gradientes de temperatura, con la presencia de distintos tipos de grano y las distintas durezas, densidades y humedades. Todas estas características serán consecuencia de las condiciones ambientales reinantes, tanto en el momento de la precipitación como a lo largo de la estancia de los granos en el interior del manto nivoso. 


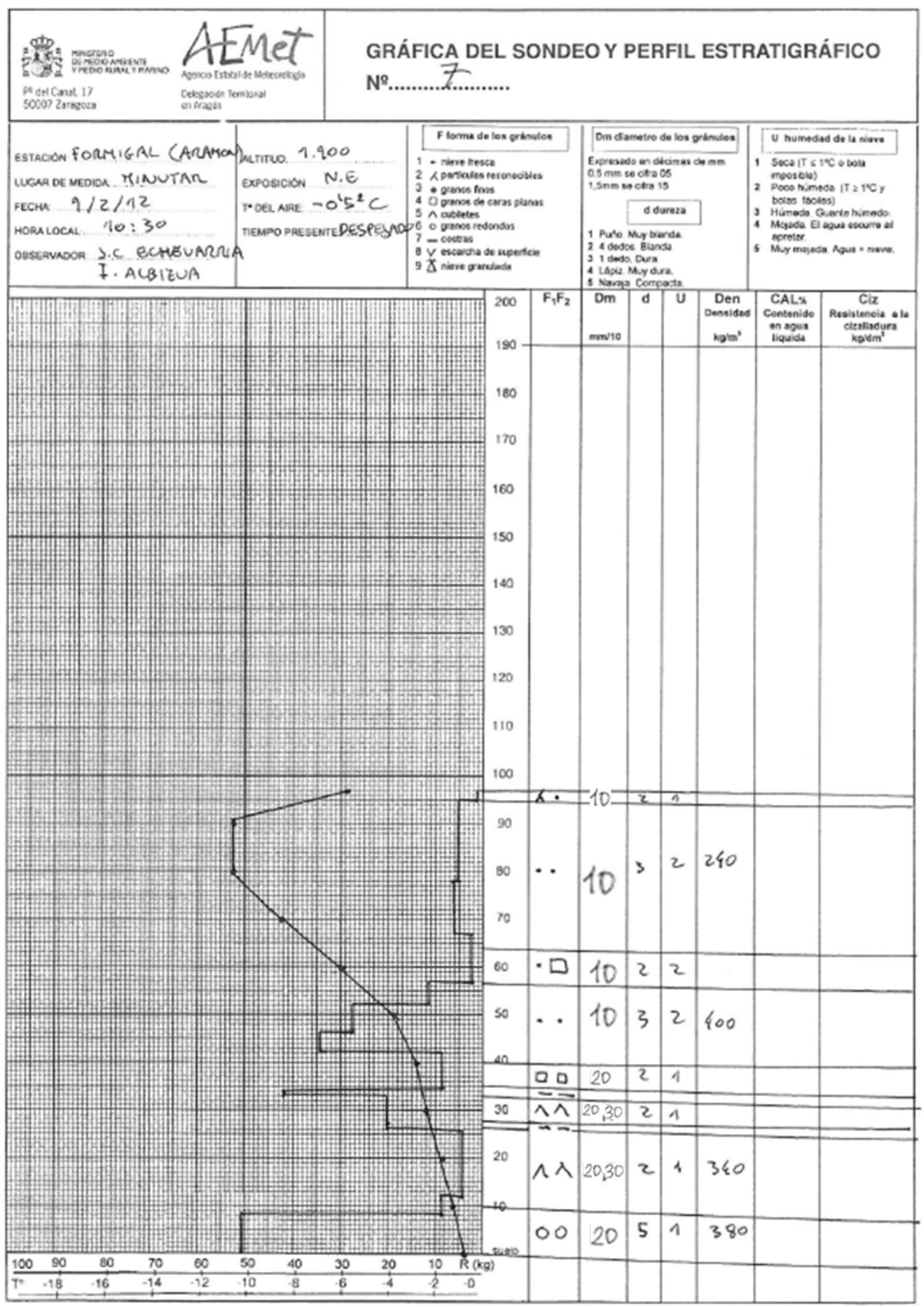

Fig. 71 Gráficas de resistencia y temperatura y perfil estratigráfico (Formigal Minutar) 


\subsection{Test de estabilidad}

\subsubsection{Estabilidad del manto nivoso}

Dentro del manto nivoso, cada estrato está sometido a dos tipos de fuerzas opuestas: las fuerzas de tracción (peso del manto nivoso) que lo empuja ladera abajo, y las fuerzas de resistencia (anclajes al suelo, cohesión de la nieve y rozamiento de los granos) que lo fijan a la pendiente. Mientras estas últimas son mayores, el manto nivoso permanece en equilibrio. Pero si las fuerzas de tracción aumentan (paso de personas, caída de más nieve, caída de cornisas) o las de resistencia disminuyen (metamorfosis del manto nivoso) este equilibrio se puede romper y desencadenarse un alud.

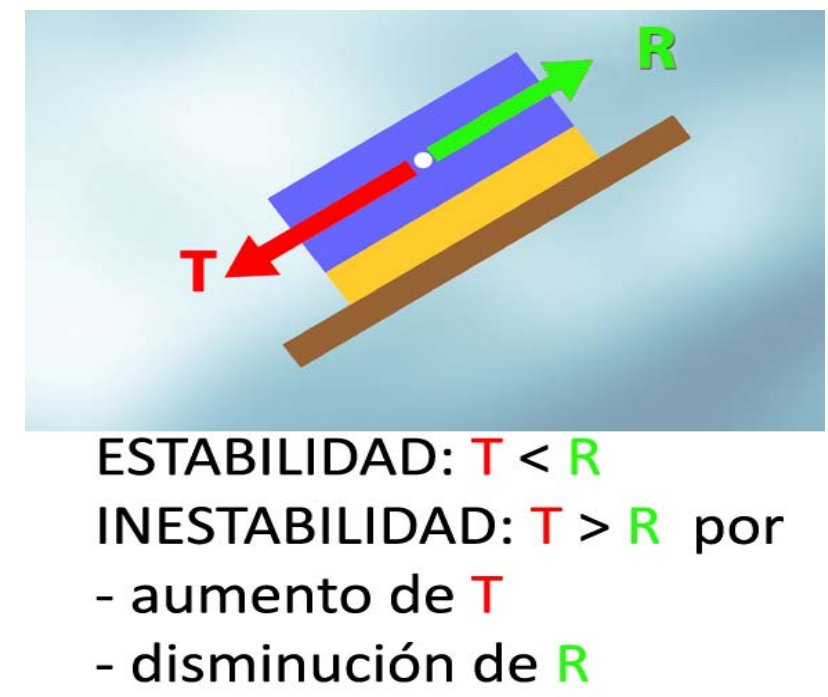

Fig. 72 Fuerzas en el interior del manto nivoso

El concepto de inestabilidad puede resultar confuso. Si el manto está en reposo (que es lo que hace la mayor parte del tiempo) es porque hay estabilidad. Así, la estabilidad está definida como la probabilidad de que no se desencadenen aludes.

Con el término inestabilidad nos referimos a cómo de precaria es la estabilidad, es decir, a cómo de cerca estamos de las condiciones de ruptura, y también, a veces, menos apropiadamente, a cuánta energía puede liberarse si el manto se pone en movimiento.

Para evaluar la estabilidad del manto nivoso, debemos estudiar por separado:

- La resistencia lateral: es la fortaleza de la cohesión entre los granos de cada capa. Como ejemplo de resistencia lateral débil podemos imaginarnos una capa de nieve granulada que al acumularse en pendientes inclinadas, acaba por deslizar espontáneamente al no cohesionar entre sí. El sondeo por golpeo nos informa sobre la resistencia lateral de los estratos del manto nivoso.

- La resistencia basal: es la intensidad de la ligadura entre capas; es decir, qué esfuerzo puede soportar una capa antes de deslizar sobre la que está debajo. Es independiente de la dureza de la capa en cuestión. Imaginemos una capa compacta de nieve venteada (con una resistencia lateral fuerte) pero asentada sobre una capa frágil: la estabilidad será escasa debido a una resistencia muy débil de la base sobre la que se asienta. Los diferentes test de estabilidad nos sirven para determinar el grado de inestabilidad de una estructura de placa. 

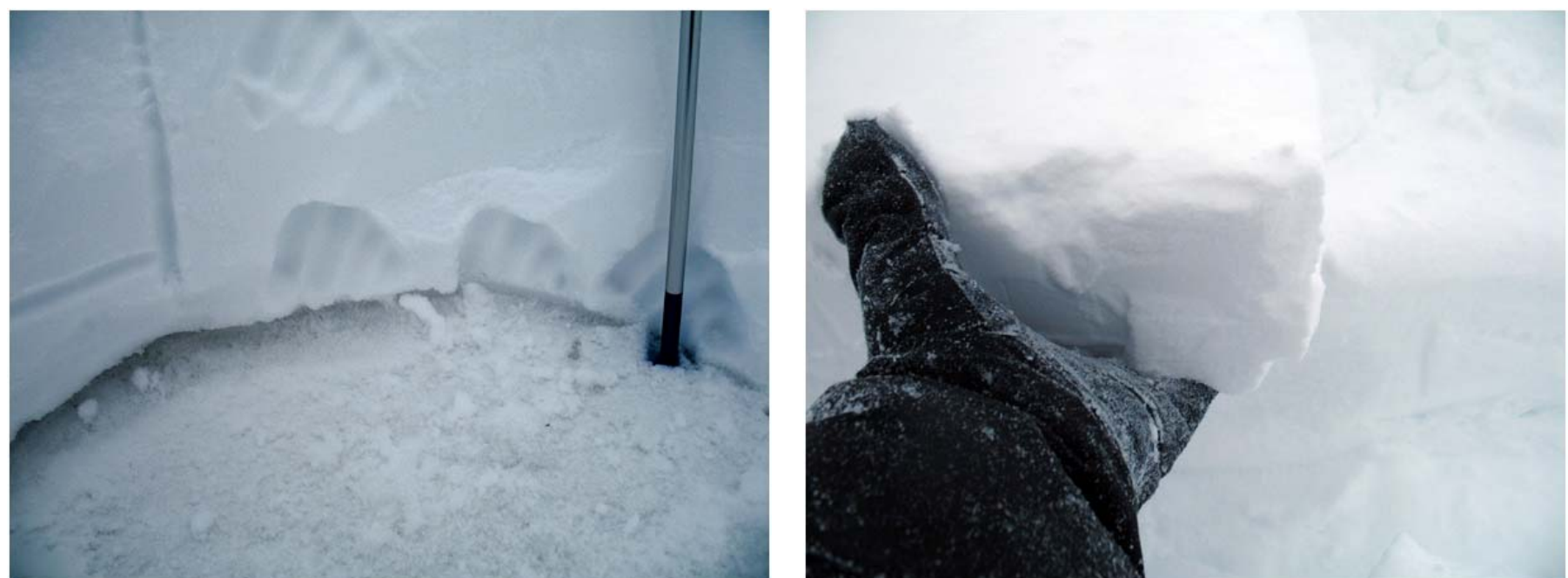

Fig. 73 Placa de nieve: resistencia lateral fuerte (izda), y manto asentado sobre capa de nieve granulada: resistencia basal débil (dcha)

Para determinar la estabilidad del manto nivoso, evaluaremos su resistencia lateral independientemente de la basal. No obstante, las conclusiones deben tomarse como indicativas, ya que frecuentemente, sus resultados no son extrapolables al resto de las laderas debido a las irregularidades locales del manto nivoso.

Los tests de estabilidad son una colección de métodos prácticos, relativamente rápidos y fáciles de hacer, que nos proporcionan una idea de los esfuerzos que un manto nivoso seco puede soportar antes de producirse el desencadenamiento de un alud. Es importante no olvidar que los tests de estabilidad no son aplicables a la nieve húmeda. La interpretación de sus resultados es muy útil para la toma de decisiones sobre el terreno y para la estimación del nivel de peligro local.

El objetivo es detectar la posibilidad de desencadenamiento de aludes de placa, en nieve seca, que son los más directamente relacionados con la sobrecarga que puede soportar el manto. Estos aludes son también los más difíciles de anticipar por quien transita sobre la nieve, puesto que las capas con débil cohesión que los facilitan son subyacentes en el manto. También son los que más accidentes causan a esquiadores y montañeros.

Para que se desencadene un alud de placa, el manto nivoso debe estar constituido por al menos una capa frágil o de débil cohesión enterrada, que ceda al paso del esquiador, y de una capa más o menos dura encima, de la cual se fragmente un trozo y se deslice ladera abajo. Este tipo de apilamiento, llamado estructura de placa, es el que vamos a intentar detectar. Hay que tener en cuenta que la capa débil puede ser de un espesor muy pequeño, a veces menor que un centímetro y por tanto muy difícil de detectar.

\subsubsection{Elección del emplazamiento y principios básicos de los tests}

Es muy importante una elección correcta del emplazamiento. Lo más interesante sería testar una zona de desencadenamiento, pero no podremos hacer los tests en lugares así por ser peligroso. Recordemos que siempre debemos aplicar las medidas básicas de seguridad en la nieve. Por eso se debe elegir una 'pendiente test', más pequeña o segura (sin peligro por encima o por debajo del lugar) pero con la misma orientación y altitud que la ladera a evaluar. Por ejemplo, para obtener información tras un episodio de ventisca, buscaremos para realizar los tests un lugar seguro en una ladera pequeña con una sobrecarga de nieve venteada similar a la de las demás laderas, en un lugar sin trazas de esquiadores ni restos de aludes previos. 
Sobre la pendiente, el sitio ideal tendrá una inclinación de al menos $30^{\circ}$, aunque con inclinaciones de 25 a $30^{\circ}$ ya se considera que se obtiene información útil. La distribución de la nieve deberá ser relativamente uniforme, con un espesor igual o en todo caso algo menor al de su entorno. Estará lejos de crestas o collados para evitar las perturbaciones del viento, y también separado de árboles, a una distancia igual o mayor a la altura de los propios árboles.

Una vez hecha la elección del emplazamiento se debe tener en cuenta que todos los tests de estabilidad consisten básicamente en aislar un bloque de nieve del resto del manto y someterlo a una carga para tratar de provocar su ruptura y deslizamiento. El proceso, en general, es como sigue:

- Se despeja la parte delantera de nieve (lo que viene bien también para hacer un perfil estratigráfico rápido y detectar capas frágiles). El frente del corte debe estar mirando ladera abajo.

- Se aísla total o parcialmente, según los casos, el bloque de nieve, usando una pala y una sierra de nieve. A falta de sierra se puede usar un esquí o un cordino.

o Dimensiones usuales del bloque: $30 \times 30 \mathrm{~cm}, 90 \times 30 \mathrm{~cm}$ ó $30 \times 100 \mathrm{~cm}$, sobre una altura máxima de $120 \mathrm{~cm}$., ya que los esfuerzos y sobrecargas sobre el manto nivoso difícilmente penetran más de un metro. Los $30 \mathrm{~cm}$ de ancho o de fondo corresponden a las dimensiones usuales de la pala de nieve. Si la pala es de mayor tamaño, las dimensiones del bloque deben ajustarse a las de la pala.

- Se presta atención a cualquier signo de ruptura mientras se aísla el bloque. En ocasiones éste se hunde (colapso de capa débil) y se queda en el mismo sitio. Si esto sucede, se le dará la puntuación de muy fácil (ver más adelante la forma de puntuar cada test) y se evaluará la ruptura: su posición en el manto, la calidad de la superficie de deslizamiento, el tipo de granos en la capa débil.

- Si no hay colapso durante el proceso de aislar el bloque, se procede a intentar provocar la ruptura de las capas débiles aplicando esfuerzos o cargas cada vez mayores sobre el bloque. Cuando éstas se produzcan, se evalúan: posición, calidad, tipo de grano. Si no se producen rupturas, se calificará el test con la máxima puntuación, o como imposible.

\subsubsection{Calidad de la superficie de ruptura}

A la hora de evaluar mediante tests de estabilidad la posibilidad de que parte del manto nivoso se ponga en movimiento, deslizando sobre el manto subyacente, resulta de gran interés añadir a la información sobre la carga que soporta el manto, la información sobre la calidad de la fractura resultante, que además puede ser fácilmente incluida en los resultados de los propios tests.

Asignar una calidad a las superficies de fractura es algo que en general viene dado por la experiencia. Se han descrito principalmente dos sistemas para evaluar la calidad de las superficies de fractura en el manto nivoso, viniendo a ser similares. La tabla mostrada a continuación describe las tres posibilidades principales que pueden presentarse al fracturar un bloque de manto nivoso.

\begin{tabular}{|c|c|}
\hline Calidad & Descripción \\
\hline & $\begin{array}{l}\text { Fractura lisa, plana, limpia, que afecta a todo el bloque testado y suele desplazarse } \\
\text { rápidamente. Algo de rugosidad puede aparecer en capas débiles gruesas debido } \\
\text { al rozamiento del bloque que colapsa al deslizar, pero la fractura inicial es lisa. }\end{array}$ \\
\hline $\mathbf{Q} 2$ & $\begin{array}{l}\text { Fractura algo rugosa. La placa no desliza tan rápido como en Q1. La superficie } \\
\text { puede tener algunas irregularidades pero no tantas como Q3. La fractura afecta a } \\
\text { todo el bloque, pero en general éste no cae. }\end{array}$ \\
\hline 0 & $\begin{array}{l}\text { Fractura rugosa, desigual, no plana o en varios planos. En general la fractura no } \\
\text { afecta a todo el bloque testado, que se mueve poco o incluso no se mueve, } \\
\text { aunque la pendiente sea superior a } 35^{\circ} \text {. }\end{array}$ \\
\hline
\end{tabular}


Cuando se identifiquen superficies de fractura, se les asignará un tipo de calidad y se cifrará en los resultados de los test junto con el tipo y tamaño de los granos presentes en la superficie de fractura.

\subsubsection{Cifrado del resultado de los test de estabilidad}

La comunicación de los resultados obtenidos, es diferente para cada test (ver las tablas de cifrado), pero mantiene bastantes elementos comunes, lo que permite el uso de un formato más o menos unificado.

En los últimos años se viene generalizando el uso de un estándar para la comunicación de resultados de los test de estabilidad. Se emplean las letras de las siglas identificativos de los test y de la escala de puntuación en inglés. A este estándar trataremos de ceñirnos.

El cifrado consiste en encadenar, usando abreviaturas y símbolos, la información de la puntuación del test (que incluye las siglas del test y el código de puntuación propiamente dicho), la calidad de la fractura, la profundidad, el tipo y tamaño de los granos que componen la capa débil y la información complementaria que se considere necesaria en cada momento. Puede sintetizarse como sigue:

Puntuación-test Calidad-fractura @ $\downarrow$ Profundidad Tipo-grano Diámetro mm Información-adicional

o bien, expresado con abreviaturas y símbolos:

\section{TTT\#\#Qn@ $\downarrow z Z z F D_{m} m m$ Infos}

Donde el significado es el que se describe en la tabla a continuación:

\begin{tabular}{|c|c|}
\hline Símbolo & Descripción \\
\hline TTT\#\# & $\begin{array}{l}\text { Puntuación del test. Se compone de las siglas del test y su puntuación. Para cada test se } \\
\text { usa una puntuación específica, recogida en la tabla. } \\
\text { TTT: Siglas en inglés que identifican el test, pueden ser } 2 \text { ó } 3 \text { caracteres (ST, CT, ECT, } \\
\text { RB, etc.). } \\
\text { \#\#: Sigla del código de puntuación, en inglés, o número de golpes necesarios para producir } \\
\text { una fractura; en letra o cifra. Puede ser sólo carácter (\#). }\end{array}$ \\
\hline Qn & Calidad de la rotura (Q1, Q2 ó Q3). \\
\hline$@$ & Símbolo fijo, significando "a". \\
\hline$\downarrow$ & $\begin{array}{l}\text { Símbolo indicando que el número siguiente (zzz) es profundidad, desde la superficie del } \\
\text { manto. Si el número siguiente (zzz) fuese distancia desde la superficie del terreno, se } \\
\text { usaría una flecha hacia arriba }(\uparrow) \text {. }\end{array}$ \\
\hline ZZZ & $\begin{array}{l}\text { Profundidad (o altura sobre el terreno) en centímetros de la rotura medida desde la } \\
\text { superficie del manto. Si es menos de un metro, se usarán sólo dos cifras (zz). }\end{array}$ \\
\hline $\mathbf{F}$ & $\begin{array}{l}\text { Tipo de grano predominante en la capa débil. Se usará el símbolo de la clasificación } \\
\text { internacional de nieve en el suelo de la IACS }(\square, \vee, \mathbf{\sim}, \wedge \text {, etc., ver tabla). También se } \\
\text { puede dar en lenguaje claro. }\end{array}$ \\
\hline $\mathrm{D}_{\mathrm{m}} \mathrm{mm}$ & $\begin{array}{l}\text { Diámetro del grano predominante en la capa débil, incluyendo la unidad de medida, que en } \\
\text { general será el milímetro. Pueden usarse decimales (por ejemplo: 0'8 mm) }\end{array}$ \\
\hline Infos & $\begin{array}{l}\text { Cuando es necesario, se añade en lenguaje claro más información: inclinación, si ha } \\
\text { deslizado todo el bloque, sólo parte o sólo un borde (en el test Rutschblock), si se ha } \\
\text { profundizado menos de } 120 \mathrm{~cm} \text {, etc. }\end{array}$ \\
\hline
\end{tabular}


Frecuentemente, y esto es lo más productivo y aconsejable, los tests de estabilidad se llevan a cabo junto con un perfil estratigráfico o un sondeo por golpeo. Esto permite hacer los tests con vistas a evaluar las capas más sospechosas o interesantes que hayamos encontrado en el perfil. Los resultados pueden anotarse, cifrados, junto con el resto de la información de cada capa, en el mismo gráfico que se hace para el sondeo o el que podamos haber hecho para un perfil.

En caso de comunicar resultados de tests de estabilidad junto con los de un sondeo o perfil, la información imprescindible de la fecha y hora y del lugar, orientación, inclinación y meteorología, será la misma que la reportada para el perfil. Si no es así, en todo caso nos aseguraremos de que los resultados que comunicamos contengan siempre fecha, lugar, etc.

Ejemplos de cifrado de resultados de test de estabilidad:

\begin{tabular}{|c|c|}
\hline Cifrado & Significado \\
\hline 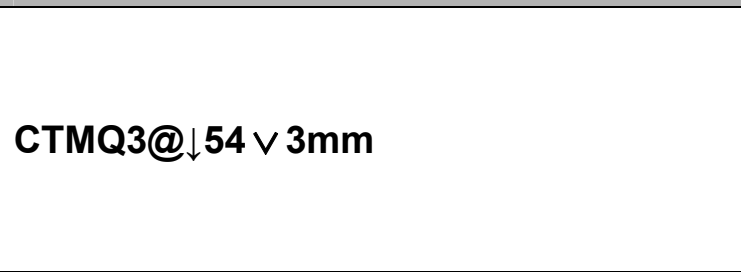 & $\begin{array}{l}\text { Test de compresión (CT) con puntuación } \mathbf{M} \text { (moderate, } \\
\text { media, es decir, entre los golpes } 11 \text { y } 20 \text {, articulando } \\
\text { desde el codo). La ruptura es de calidad } \mathbf{3} \text { (desigual, no } \\
\text { plana y rugosa), a } \mathbf{5 4} \mathbf{~ c m} \text { de profundidad, y está formada } \\
\text { por escarcha enterrada en el manto, de un tamaño de } 3 \\
\mathbf{m m} \text {. }\end{array}$ \\
\hline STEQ1@ $\downarrow 28 \square 1,5$ & $\begin{array}{l}\text { Test de la pala (ST) en el que la puntuación ha sido E } \\
\text { (easy, fácil, es decir, al tirar de la pala con poca fuerza). } \\
\text { La superficie de ruptura es de calidad } 1 \text { (plana y lisa, con } \\
\text { deslizamiento rápido), la capa débil está formada por } \\
\text { granos de caras planas de } 1,5 \mathrm{~mm} \text { de tamaño y a } 28 \mathrm{~cm} \\
\text { de profundidad. }\end{array}$ \\
\hline ECTN8Q3@ $\downarrow 26 \wedge 2,5 \mathrm{~mm}$ Pendiente 30 & $\begin{array}{l}\text { Test de la columna extendida (ECT) realizado en una } \\
\text { pendiente de } 30^{\circ} \text {, en el que se ha producido una fractura } \\
\text { en el golpe número } 8 \text { (golpes articulados desde la } \\
\text { muñeca), que no se ha propagado ni en el golpe } \\
\text { número } 8 \text { ni en el golpe número } 9 \text {. La fractura es de } \\
\text { calidad } 3 \text { (no plana, con una superficie desigual y rugosa) } \\
\text { y se ha producido en una capa de cubiletes de } 2,5 \mathrm{~mm} \\
\text { de diámetro, a } 26 \mathrm{~cm} \text { de profundidad. }\end{array}$ \\
\hline ECTP14Q1@ $\downarrow 35 * 3 \mathrm{~mm}$ Pendiente 35 & $\begin{array}{l}\text { Test de la columna extendida (ECT) realizado en una } \\
\text { pendiente de } 35^{\circ} \text {, en el que se ha producido una fractura } \\
\text { de calidad } 1 \text {, (plana y con superficie lisa) sobre una capa } \\
\text { de nieve granulada con granos de } 3 \mathrm{~mm} \text { de grosor a } 35 \\
\mathrm{~cm} \text { de profundidad. La fractura se inicia en el golpe } \\
\text { número } 14 \text { y se ha propagado a lo largo de toda la } \\
\text { columna en el golpe } 14 \text { ó el } 15 \text {. }\end{array}$ \\
\hline $\begin{array}{l}\text { RB6Q2@54 } \downarrow \square 2 \mathrm{~mm} \\
\text { Cede el borde del bloque Pendiente } 35^{\circ}\end{array}$ & $\begin{array}{l}\text { Test Rutschblock (RB) en una pendiente de } \mathbf{3 5}^{\circ} \text { de } \\
\text { inclinación. El bloque ha cedido en el paso } \mathbf{6} \text {, tras } \\
\text { sucesivos saltos sin esquís, pero parcialmente, deslizando } \\
\text { sólo un borde del bloque. La fractura producida en el } \\
\text { manto nivoso está a } \mathbf{5 4} \mathbf{c m} \text { de profundidad, es de calidad } \\
\mathbf{2} \text {, con superficie rugosa y relativamente plana, con granos } \\
\text { de caras planas de } \mathbf{2 m m} \text { de diámetro. }\end{array}$ \\
\hline
\end{tabular}




\subsubsection{Principales test de estabilidad}

Existen muchos test de estabilidad, algunos como el Rutschblock son ya muy veteranos, aunque algo laboriosos, y otros son más inmediatos pero aportan menos información, como el del bastón. En todo caso, siempre que se disponga de un mínimo de tiempo, por ejemplo durante una travesía, y se pase por una 'pendiente test', pequeña y segura pero con las características de orientación, venteo, etc. que nos interesen, es buena idea gastar algunos minutos haciendo los tests más rápidos.

Identificaremos los tests por su nombre y por sus siglas en inglés, conforme a la siguiente tabla:

\begin{tabular}{|l|c|l|}
\hline \multicolumn{1}{|c|}{ Nombre del test } & Siglas & \multicolumn{1}{|c|}{ Nombre en inglés } \\
\hline Test de la Pala (test noruego o de Faarlund) & ST & Shovel shear Test \\
\hline Test por compresión & CT & Compression Test \\
\hline Test de la columna extendida & ECT & Extended Column Test \\
\hline Test del bloque deslizante & RB & Rutschblock test \\
\hline Test de la propagación de la sierra & PST & Propagation Saw Test \\
\hline Test de la pendiente con esquís & SC & Slope Cut Testing \\
\hline Test del peso & SB & Stuffblock Test \\
\hline Test de la cuña deslizante & & Rutschkiel test \\
\hline Test del bastón & & Ski Pole Test \\
\hline Test de la pala inclinada & & Shovel Tilt Test \\
\hline
\end{tabular}

Como conjunto, el test de la pala (ST), el test de compresión (CT) y el test de la columna extendida (ECT), pueden llevarse a cabo de forma rápida y progresiva, encadenándolos uno tras otro. Con ellos se recoge información sobre la existencia y ubicación de eventuales capas débiles, sobre cómo de fácil es que se produzca una fractura en las capas débiles, y si ésta es capaz de propagarse por el manto.

Complementando la información obtenida con el conjunto de estos tres tests con otros datos, sobre todo los obtenidos de un perfil estratigráfico, se tiene un marco razonable para hacer una estimación de la estabilidad del manto nivoso, al menos en laderas con características similares a la que testamos.

Cuando se dispone de más tiempo, los tests principales son probablemente el test Rutschblock (RB) y el test de propagación de la sierra (PST). El RB es el más directamente aplicado a dar una estimación de la estabilidad del manto, y es el más estudiado y referenciado. EI PST informa de la capacidad de propagar fracturas independientemente del esfuerzo que pueda sufrir el manto nivoso. Ambos se describen en el apéndice $A$. 


\subsubsection{Test de la Pala -test Noruego o de Faarlund- (ST)}

\section{Objetivo:}

Conocer dónde (a qué profundidad) puede producirse una fractura basal, dando una idea cualitativa de la resistencia de las capas débiles a los esfuerzos de cizalladura. Se usa para identificar capas débiles enterradas y no suele ser útil para valorar capas cercanas a la superficie del manto. Se va sometiendo a cada tramo del manto nivoso a un esfuerzo de cizalladura y se buscan las capas en las que se rompe y sobre las que pueden deslizar las capas superiores.

\section{Procedimiento:}

a. Se aísla un bloque en forma de columna de $30 \times 30 \mathrm{~cm}$, con el frente mirando ladera abajo, cortando primero los laterales. Si se trata de un corte que lleva un rato abierto (por ejemplo por haber hecho un perfil estratigráfico) retranquear previamente el frente de nieve unos $20 \mathrm{~cm}$ para hacer el test en nieve no transformada.

b. Si la capa superficial es muy blanda o de nieve polvo (dureza puño) se puede retirar esa nieve de la superficie.

c. Se corta también por la parte trasera del bloque, pero no toda la parte trasera; el corte se hace como máximo hasta $70 \mathrm{~cm}$ de profundidad, siendo mejor hacerlo hasta la profundidad a la que llegará la hoja de la pala o poco más. Mejor si el corte acaba en una capa de nieve dura. Podemos dejar la sierra en el fondo del corte trasero para ayudar a identificar la profundidad.

d. Se inserta con cuidado la hoja de pala en la parte trasera del bloque y se tira del mango con las dos manos, sin hacer palanca, en dirección paralela a la pendiente y hacia el observador (eje del mango lo más derecho posible).

e. Si la columna rompe por un plano (basal) a una profundidad más arriba del final del corte trasero, se marca en la parte trasera el nivel de ruptura. La atención debe estar puesta en localizar rupturas lisas y planas, que salen fácilmente.

f. Si la columna se rompe a la profundidad del final del corte trasero, o si no se rompe, se quita la nieve desde el final del corte trasero hacia arriba y se repiten los pasos c, $d$ y e en lo que queda de columna de nieve por debajo.

g. Es aconsejable, una vez que se han identificado las capas débiles, repetir el test para corroborar los resultados, tratando de que el borde de la pala quede unos $10-20 \mathrm{~cm}$ por encima del nivel de la capa débil o fractura encontrada.

h. Para cada capa débil encontrada, se anota la profundidad de la rotura, su calidad y el tipo de granos que la componen.

\section{Debemos anotar:}

- Grado de esfuerzo necesitado para provocar la fractura (\#)

- Profundidad de cada capa que fractura (zzz)

- Calidad de cada fractura (Q1, Q2, Q3)

- Tipo y tamaño de los granos en las superficies de fractura

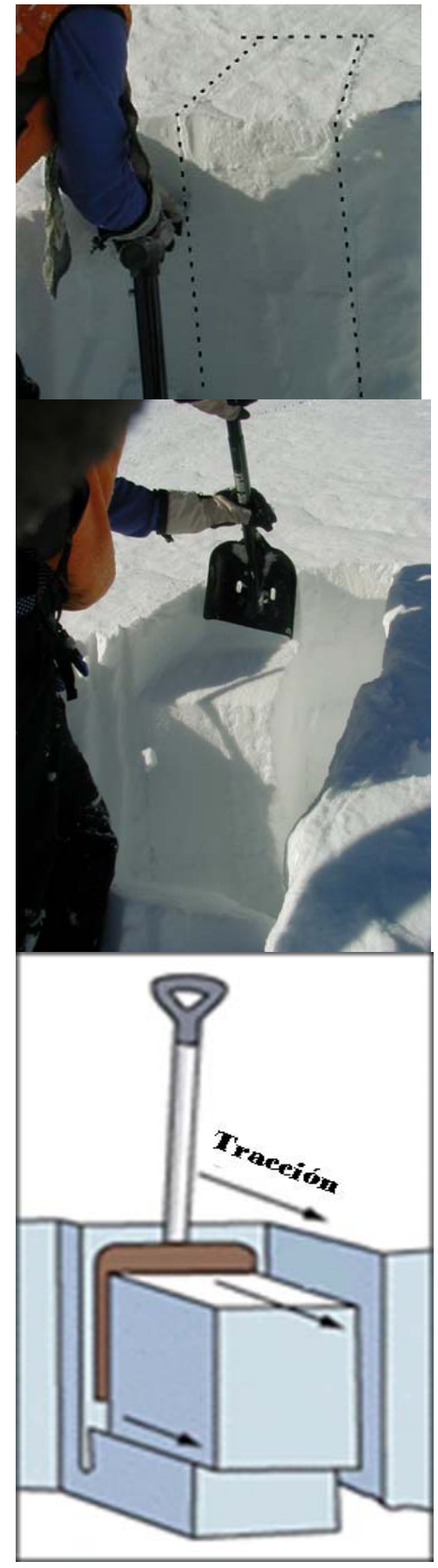

Fig. 74 Test de la Pala. 


\section{Puntuación:}

Para cada capa débil encontrada, se puntúa conforme a cinco categorías, recogidas en la tabla mostrada a continuación:

\begin{tabular}{|c|c|l|l|}
\hline Puntuación & $\#$ & \multicolumn{1}{|c|}{ Término } & \multicolumn{1}{c|}{ Descripción } \\
\hline STV & V & Very easy-Muy Fácil & $\begin{array}{l}\text { Fractura (cae, se desmorona) al aislar el bloque o meter } \\
\text { la pala }\end{array}$ \\
\hline STE & E & Easy - Fácil & Fractura al tirar con poca fuerza \\
\hline STM & M & Moderate - Mediana & Fractura al tirar con una fuerza mediana \\
\hline STH & H & Hard - Difícil & Cae al tirar con un esfuerzo sostenido y considerable \\
\hline STN & N & No shear - Imposible & No hay fractura \\
\hline
\end{tabular}

Algunos autores e instituciones manejan una categoría más STC (Collapse) para distinguir el caso de que el bloque rompa mientras se aísla, antes de introducir la pala.

\section{Cifrado:}

El test de la pala (ST) es un test progresivo, en el que para cada bloque aislado del manto en el que hagamos el test, podemos encontrar más de una capa de fractura. Podremos obtener resultados para varias capas débiles, cada una a distinta profundidad, cediendo a distintos esfuerzos, y con distintos carácter y tipo de grano en la fractura.

Para cada capa de fractura encontrada, o al menos para las más significativas, daremos un resultado.

\section{El formato es: ST\#Qn@ $\downarrow$ ZzzF D $\mathbf{D}_{\mathrm{m}} \mathrm{mm}$ Infos}

\section{Ejemplos:}

STVQ1@ $\downarrow 42 \wedge 3 \mathrm{~mm}$ : fractura V, (Very easy, muy fácil, que se ha producido mientras se aislaba el bloque o al meter la pala), con calidad 1, superficie de deslizamiento plana y suave, situada a $42 \mathbf{c m}$ de la superficie del manto en la que hay cubiletes de $3 \mathrm{~mm}$ de diámetro.

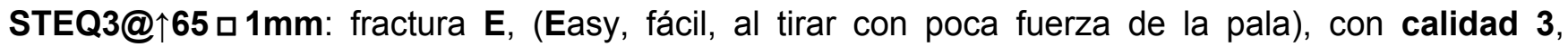
superficie de ruptura no plana, desigual y rugosa, a $65 \mathrm{~cm}$ de la superficie del terreno y compuesta de granos de caras planas de $1 \mathrm{~mm}$ de diámetro.

STN no se ha observado fractura (N, No shear, no fractura). No se han encontrado capas débiles.

STN@ $\ 110 \vee 4 \mathrm{~mm}$ : no se ha observado fractura (N, No shear, no fractura), hay una capa débil a 110 $\mathbf{c m}$ de profundidad, formada por escarcha enterrada de un diámetro de $\mathbf{4} \mathbf{~ m m}$, que no ha fracturado.

\section{Comentarios:}

- No debe olvidarse que el objetivo primordial del test de la pala es identificar dónde hay capas débiles. De hecho, se puede llevar a cabo en terreno llano.

- En lo referente a esfuerzos, es un test subjetivo, que depende de las dimensiones de la hoja y del mango de la pala, de la dureza de la placa y de la fuerza del observador.

- Para interpretar el test en términos de estabilidad se necesita experiencia: la muestra de manto testada es muy reducida, y se necesitan muchos test para hacerse una idea realista de la estabilidad. También, el hecho de ir retirando las capas superiores antes de evaluar cada capa, influye a la hora de evaluar la estabilidad, y se ha descrito que por ello los observadores inexpertos suelen sobreestimar la inestabilidad de la nieve al utilizar sólo este test, ya que el manto suele parecer menos estable de lo que realmente es.

- En nieve reciente, para buscar capas débiles superficiales se recomienda más el test de la pala inclinada o 'Shovel Tilt Test': para ello se coloca la parte superior de la columna $(30-40 \mathrm{~cm})$ sobre la hoja de la pala, se inclina (entre 5 y 15 grados más de la inclinación de la pendiente) y se golpea suavemente por debajo, aumentando la fuerza para observar posibles fracturas. 


\subsubsection{Test de Compresión (CT)}

Origen: Calgary (Canadá), años 70 Duración: 5 minutos.

\section{Objetivo:}

Identificar capas débiles en el interior del manto nivoso y estimar el esfuerzo necesario para que cedan. Es más efectivo para encontrar capas débiles en el primer metro de profundidad, siendo las capas débiles muy superficiales poco significativas. También, informa sobre el potencial de desencadenamiento.

\section{Método:}

a. Se aísla un bloque de $30 \times 30 \mathrm{~cm}$, con el frente mirando ladera abajo, cortando los laterales y la parte trasera. Profundidad máxima de $120 \mathrm{~cm}$. Conviene que al menos uno de los dos laterales esté despejado para observar las fracturas. Si tenemos un corte que lleva un rato abierto (por ejemplo por haber hecho un perfil estratigráfico) retranquear previamente el frente de nieve unos $20 \mathrm{~cm}$ para hacer el test en nieve no transformada.

- Si se producen fracturas durante el proceso de aislar el bloque, se puntúan como V, (Very easy, muy fácil, ver tabla de puntuación más adelante).

b. Se coloca la pala en plano sobre el bloque y se ejercen sucesivamente 3 series de 10 golpes sobre la pala. Las fracturas pueden verse en los laterales de la columna:

- $1^{a}$ serie: 10 golpes con la mano arqueada golpeando con las yemas de los dedos y articulando el movimiento en la muñeca.

- $\mathrm{Si}$, al golpear, la parte superior de la columna desliza o queda muy desigual, impidiendo la transmisión de los golpes hacia abajo; retirar la parte desigual de la columna, nivelar la parte superior y seguir golpeando. Si se produce una fractura sin que el bloque se desplace apenas; no retirarlo.

- $2^{\mathrm{a}}$ serie: 10 golpes con la mano arqueada golpeando con las yemas de los dedos y movimientos del antebrazo a partir del codo.

- $3^{a}$ serie: 10 golpes con la mano abierta o el puño, moviendo todo el brazo desde el hombro. No golpear con una fuerza que pueda dañar la mano.

c. Permaneceremos atentos a la cuenta de golpes y a la columna de manto que testamos, para detectar la fractura en el mismo momento en que se produzca.

\section{Debemos anotar:}

- Número de golpe en el que se produce la fractura (\#)

- Profundidad de la capa que fractura (zzz)

- Calidad de la fractura(Q1, Q2, Q3)

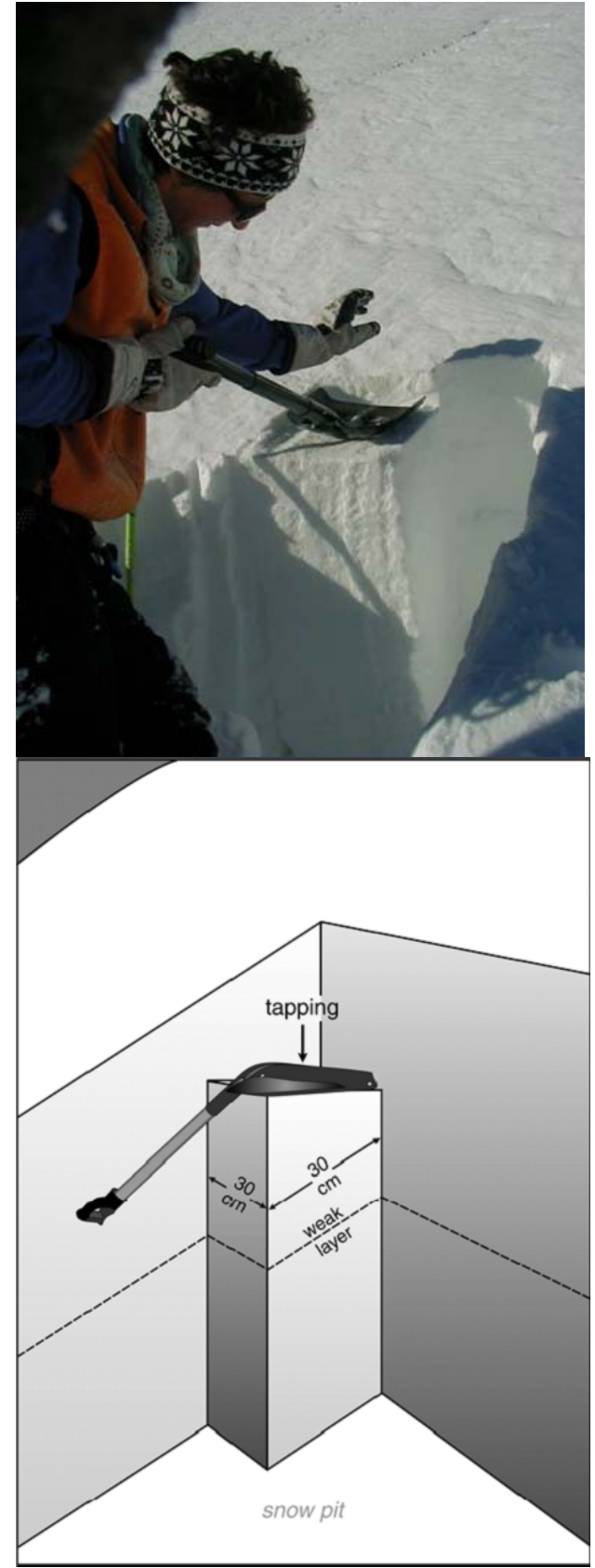

Fig. 75 Test de Compresión.

- Tipo y tamaño de los granos presentes en la superficie de fractura 


\section{Puntuación:}

Se puntúa en 5 niveles, que identifican la facilidad con que rompe la capa débil:

\begin{tabular}{|c|c|l|l|}
\hline Puntuación & $\#$ & \multicolumn{1}{|c|}{ Término } & \multicolumn{1}{c|}{ Descripción } \\
\hline CTV & $\mathbf{V}$ & Very easy - Muy Fácil & Fractura al aislar el bloque \\
\hline CTE & E & Easy - Fácil & Fractura golpes desde la muñeca (CT1 a CT10) \\
\hline CTM & M & Moderate - Mediana & Fractura golpes desde el codo (CT11 a CT20) \\
\hline CTH & H & Hard - Difícil & Fractura golpes desde el hombro (CT21 a CT30) \\
\hline CTN & $\mathbf{N}$ & No shear - Imposible & No hay rotura tras 30 golpes \\
\hline
\end{tabular}

\section{Cifrado:}

En el test de compresión (CT) se busca una única capa débil, la primera que se detecte, evaluando el esfuerzo necesario para que dicha capa ceda, permitiendo el movimiento del bloque de manto que tiene encima. Por ello, para cada bloque aislado en el que practiquemos el test obtendremos un único resultado. En este test se puede añadir también, como información adicional, la profundidad que efectivamente se ha testado, si no han sido los $120 \mathrm{~cm}$ que se toman como estándar.

\section{El formato es CT\#Qn@ $\downarrow$ ZzzFD ${ }_{\text {m }}$ mm Infos}

\section{Ejemplos:}

CTHQ2@ @75 1 1mm: fractura H (Hard, difícil, golpes 21 a 30, articulando desde el hombro) con un corte de calidad 2, con superficie rugosa y más bien plana, en una capa a $75 \mathbf{c m}$ de profundidad compuesta por granos de caras planas de $1 \mathrm{~mm}$.

CTEQ3@ $\downarrow 21 \star 3 \mathrm{~mm}$ Capa $\star 6 \mathrm{~cm}$ espesor: fractura E (Easy, fácil, golpes 1 a 10 , articulando desde la muñeca), con un corte de calidad 3 , con superficie no plana, desigual y rugosa, de una capa a $21 \mathrm{~cm}$ de profundidad compuesta de nieve granulada y de $3 \mathrm{~mm}$ de diámetro. Esta capa tiene un espesor de $6 \mathbf{c m}$.

CTN@ $\downarrow 35 \wedge 2 \mathrm{~mm}$ : no se ha producido fractura. Hay una capa débil identificada previamente (en un perfil estratigráfico por ejemplo), a $35 \mathrm{~cm}$ de la superficie del manto, compuesta por cubiletes de $\mathbf{2} \mathbf{m m}$ de diámetro, pero que no se ha fracturado tras las tres series de golpes.

\section{Comentarios:}

- Se puede hacer la media después de hacer varios tests (si se ha identificado una misma capa frágil).

- Aunque menos que el de la pala, en lo referente a esfuerzos, es un test también subjetivo. Las dimensiones de la pala apenas influyen, pero el esfuerzo trasmitido al manto depende de la dureza de la placa y de la fuerza del observador.

- Los aludes desencadenados por humanos se asocian sobre todo a una ruptura fácil (E: golpes 1 a 10), bastante más que a difícil (H: golpes 21 a 30).

- Calidades de rotura Q1 y Q2 han identificado capas débiles en aludes de placa cercanos más a menudo que roturas irregulares (Q3).

Criterio para estimar la estabilidad de una pendiente determinada con el Test por Compresión (CT):

- Realizar dos CT en dos puntos separados entre sí $1 \mathrm{~m}$.

- Si ambos tests indican inestabilidad (V ó E), la pendiente se considera inestable.

- Si ambos tests indican estabilidad (M, $\mathbf{H}$ ó $\mathbf{N}$ ) u ofrecen resultados diferentes:

- Realizar una segunda serie de dos TC en otro lugar separado unos $10 \mathrm{~m}$ del anterior.

o Si ambos test indican inestabilidad, se considera que la pendiente se considera tiene una estabilidad baja.

o Si los resultados fueran mejores, distintos entre sí o si aparecen otras capas frágiles, la estabilidad de la pendiente sería de relativamente buena a buena. 


\subsubsection{Test de la Columna Extendida (ECT)}

Origen: Colorado (USA), 2006.

Duración: 5 - 10minutos.

Objetivo: identificar fracturas capaces de propagarse a lo largo de una capa débil en un bloque de manto nivoso. Está enfocado a evaluar el potencial de propagación de fracturas en estructuras de placa.

\section{Método:}

a. Se aísla un bloque de $\mathbf{9 0} \times \mathbf{3 0} \mathrm{cm}$ (ancho $\mathrm{x}$ fondo), con el frente mirando ladera abajo, cortando los laterales y la parte trasera. Profundidad máxima de $120 \mathrm{~cm}$. Conviene que al menos uno de los dos laterales esté despejado para observar las fracturas. Si tenemos un corte que lleva un rato abierto (por ejemplo por haber hecho un perfil estratigráfico) retranquear previamente el frente de nieve unos $20 \mathrm{~cm}$ para hacer el test en nieve no transformada.

- Si se producen fracturas durante el proceso de aislar el bloque, se puntúan como $\mathbf{V}$, muy fácil (ver tabla de puntuación más adelante).

b. Se coloca la pala en plano sobre un extremo del bloque y se ejercen sucesivamente 3 series de 10 golpes sobre la pala. Las fracturas pueden verse en los laterales de la columna:

- $1^{a}$ serie: 10 golpes con la mano arqueada golpeando con las yemas de los dedos y articulando el movimiento en la muñeca.

- Si, al golpear, la parte superior de la columna desliza o queda muy desigual, impidiendo la transmisión de los golpes hacia abajo; retirar la parte desigual de la columna, nivelar la parte superior y seguir golpeando. Si se produce una fractura sin que el bloque se desplace apenas; no retirarlo.

- $2^{\text {a }}$ serie: 10 golpes con la mano arqueada golpeando con las yemas de los dedos y movimientos del antebrazo a partir del codo.

- $3^{a}$ serie: 10 golpes con la mano abierta o el puño, moviendo todo el brazo desde el hombro. No golpear con una fuerza que pueda dañar la mano.

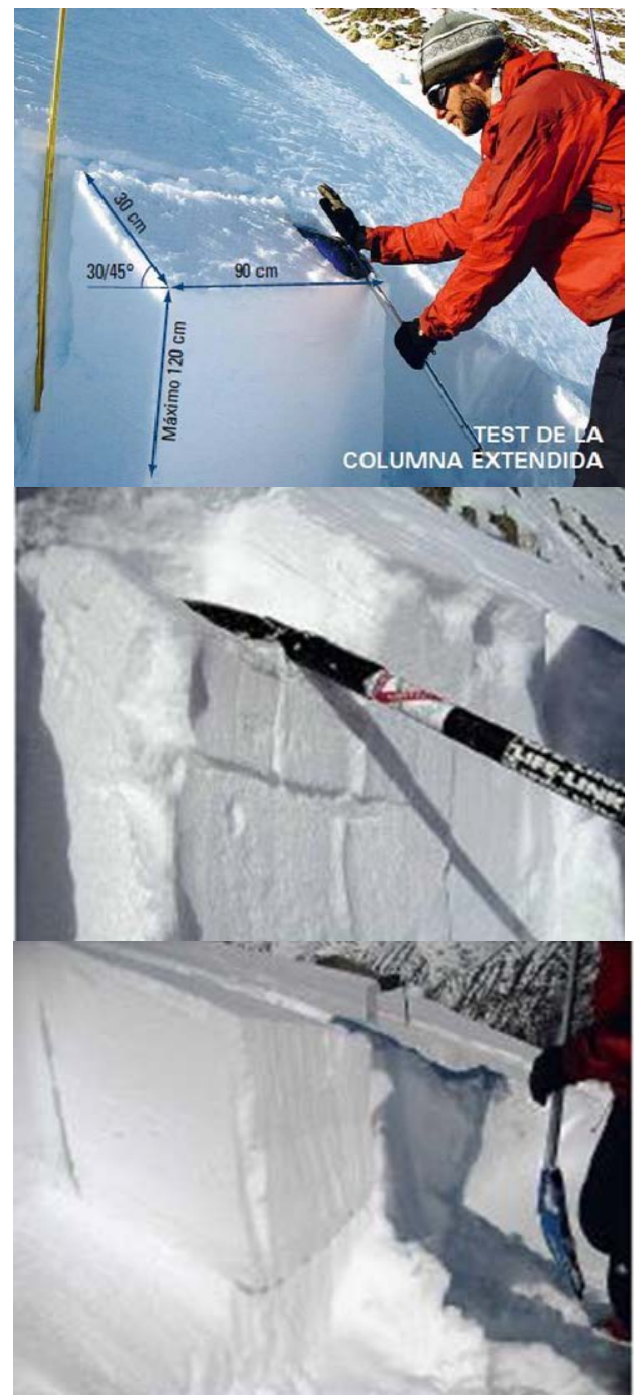

Fig. 76 Test de la Columna Extendida

c. Observar tanto el golpe en que se produce la fractura como si se necesita más de un golpe adicional para que la fractura se propague completamente, hasta el extremo opuesto del bloque. Esto puede pasar en el mismo golpe que la fractura, en un golpe posterior, o no tener lugar.

d. Mientras no haya fractura, se continúa el golpeo hasta completar las 3 series de 10 golpes.

e. Si se observa una fractura pero ésta no se propaga completamente en el mismo golpe en el que inicia o en el golpe siguiente, o se propaga sólo parcialmente, sin alcanzar el extremo opuesto del bloque, se puede dar por finalizado el golpeo.

\section{Debemos anotar:}

- Cuándo se inicia la fractura; el número de golpe en que se produce (\#\#).

- Cuándo se propaga completamente la fractura, alcanzando el extremo opuesto del bloque:

o En el mismo golpe en que se ha iniciado o en el inmediatamente posterior.

- Tras haber dado 2 o más golpes o nunca (no se propaga o lo hace parcialmente).

- Si no se ha producido fractura tras terminar las 3 series de diez golpes. 
- Profundidad de la capa que fractura (zzz)

- Calidad de la rotura (Q1, Q2, Q3)

- Tipo y tamaño de los granos en la superficie de fractura.

Puntuación:

El Test de la Columna Extendida (ECT) se puntúa conforme a la tabla a continuación:

\begin{tabular}{|c|c|l|}
\hline Puntuación & Término & Descripción \\
\hline ECTPV & $\begin{array}{l}\text { Propagación muy } \\
\text { fácil (Very easy) }\end{array}$ & $\begin{array}{l}\text { La fractura se propaga a la totalidad del bloque aislado, a lo largo de la } \\
\text { capa débil, durante el proceso de aislar el bloque }\end{array}$ \\
\hline ECTP\#\# & Propagación & $\begin{array}{l}\text { La fractura se inicia en el golpe \#\# y se propaga a lo largo de toda la } \\
\text { columna, a través de la capa débil, en el golpe \#\# ó en el golpe \#\# + 1 }\end{array}$ \\
\hline ECTN\#\# & No propagación & $\begin{array}{l}\text { La fractura se inicia en el golpe \#\# pero no se propaga a lo largo de la } \\
\text { totalidad de la columna ni en el golpe \#\# ni en el golpe \#\# + 1 }\end{array}$ \\
\hline ECTX & No fractura & No se produce fractura en la capa débil. \\
\hline
\end{tabular}

Cifrado: el resultado del test se consigna: ECT\#\#Qn@ $\downarrow$ zzzF $\mathbf{D}_{\mathrm{m}} \mathrm{mm}$ Infos

\section{Ejemplos:}

ECTP12Q3@35 $\downarrow \wedge 2 \mathrm{~mm}$ : La fractura se ha producido en el golpe 12, en una capa a $35 \mathrm{~cm}$ de profundidad, y se ha propagado en ese mismo golpe o en el siguiente. La capa débil muestra un corte de calidad 3, rugoso, no plano o en varios planos, y está compuesta de cubiletes de $2 \mathbf{m m}$ de diámetro.

ECTN25Q2@48 $\downarrow \square 1 ’ 2 \mathrm{~mm}$ : Se ha producido fractura en el golpe número 25 (golpeo articulando el brazo desde el hombro), en una capa situada a una profundidad de $48 \mathrm{~cm}$, con un corte de calidad 2 , con superficie rugosa, más bien plana, formada por granos de caras planas de 1'2 mm de diámetro, pero la fractura no se ha propagado ni en ese golpe ni en el siguiente.

ECTX: No se ha producido fractura tras terminar la serie de 30 golpes. No hay capas débiles identificadas.

\section{Comentarios:}

- La interpretación de los resultados del ECT es bastante directa:

o Puntuaciones ECTPV y ECTP\#\# sugieren condiciones de inestabilidad, ya que la propensión del manto a propagar fracturas es alta, mientras que por el contrario ECTN\#\# es en general indicativo de estabilidad.

- La puntuación ECTX, sin embargo, no es indicadora necesariamente de estabilidad, ya que indica únicamente que es difícil provocar fracturas en la zona testada, y se desconoce si el manto es propenso o no a propagar eventuales fracturas. Como la fuerza necesaria para provocar una fractura puede ser muy diferente en distintas zonas de una misma ladera, cuando se obtiene ECTX se recomienda recabar más información con otos test (PST, RB).

- Es más fiable cuando indica estabilidad, ya que el número de casos de "falsa estabilidad" (manto inestable cuando el test indica estabilidad) es menor que para muchos otros test. En el lado opuesto, los casos de "falsa inestabilidad" (el test indica inestable pero la ladera se considera estable) son más abundantes, un $18 \%$.

- La dependencia con el observador (la diferencia de fuerza aplicada por distintos observadores) es pequeña. Es más relevante el hecho de que una fractura se propague completamente en el mismo golpe en el que se produce o en el siguiente que el número de golpe en el que ésta se produce. Cuando ruptura y propagación completa suceden en el mismo golpe, se considera un excelente indicador de inestabilidad, independientemente del número de golpe en el que se haya producido la fractura.

- Tiene limitaciones cuando se evalúan debilidades en capas superficiales de nieve blanda (dureza puño, o menor de $4 \mathrm{Kg}$ ), ya que el filo de la pala tiende a cortar estas capas blandas. También se ve reducida su utilidad para capas a más de un metro de profundidad.

- Se considera útil para pendientes débiles. 


\section{APÉNDICES}

\subsection{Apéndice A: Otros test de estabilidad.}

\subsubsection{Test del bastón}

Es un test muy rápido de realizar pero poco preciso, y es solamente válido para las capas más superficiales. Se trata de hacer penetrar el bastón en la nieve cogiéndolo del revés, por la roseta. Éste debería entrar en la nieve ofreciendo cada vez mayor resistencia. Si repentinamente entrase con más facilidad, podría indicar que hemos encontrado una capa más frágil y potencialmente peligrosa, por lo que procederíamos a desenterrarla y estudiarla con mayor detenimiento.

\subsubsection{Test de la pala inclinada (Shovel Tilt Test)}

Se recomienda para identificar capas débiles en nieve reciente cerca de la superficie del manto, hasta unos $40 \mathrm{~cm}$ de profundidad.

Se aísla completamente una columna de manto de las dimensiones de la hoja de la pala, (máxima profundidad 30-40 cm). Se inserta la pala horizontalmente, por debajo de las capas sospechosas, de manera que la parte superior queda encima de la hoja de la pala. Se inclina ésta entre 5 y 15 grados más que la pendiente del manto y se va golpeando por debajo de la hoja, con fuerza creciente, hasta que se produzca una fractura.

El test se puntúa según la fuerza que se haya necesitado para producir la fractura: Easy (fácil), Moderate (moderada) ó Hard (difícil). Si es necesario inclinar la hoja de la pala más de 15 grados, por no producirse fracturas con menos inclinación, se incluye el ángulo de inclinación junto con el resultado del test.

\subsubsection{Tests de la pendiente con esquís}

Son poco fiables y entrañan un riesgo.

- De ladera (Slope Cut testing): atravesamos la parte superior de la ladera asegurados con cuerda y efectuamos cargas progresivas sobre ella. El anclaje de la cuerda debe ser a una roca o árbol, pero no debe ser en la nieve, ya que podríamos desencadenar un alud que nos arrastraría. Esto suele hacerse para chequear la exactitud de los resultados de tests de estabilidad, comprobando si se producen ruidos de colapso (whumpf), de ruptura (crack), un alud de placa o uno de nieve suelta

- Vuelta maría: al dar una vuelta maría, cortamos un triángulo con los esquís y cargamos peso sobre él. Si este triángulo se desmoronase, podría indicar inestabilidad del manto.
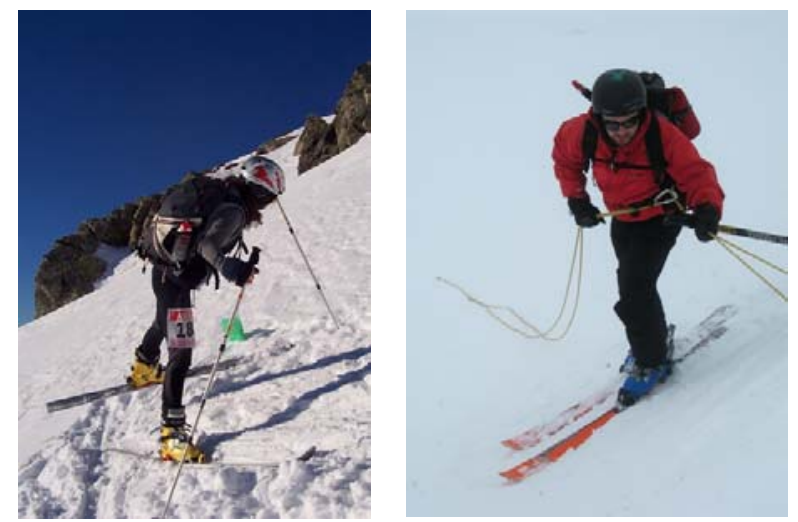

Fig. 77 Test de la pendiente con esquís: de la vuelta maría y de ladera 


\subsubsection{Test Rutschblock o del bloque deslizante (RB)}

Origen: Suiza, años 70

Duración: 15 minutos.

\section{Objetivo:}

Evaluar la posibilidad de que se produzcan aludes de placa, tratando de provocar un mini-alud de placa. Aunque no sirve como indicación única de la estabilidad del manto nivoso en una ladera, es el test más directamente asociado a la valoración de ésta si va complementado con un perfil estratigráfico. Se considera que da una medida semi-cuantitativa de la estabilidad de una pendiente.

\section{Método:}

a. Se aísla un bloque del manto nivoso de $2 \times 1,5 \times 1,5 \mathrm{~m}$ (anchura $\times$ fondo $\mathrm{x}$ profundidad, con el lado largo mirando ladera abajo). El test está calibrado para estas dimensiones, es importante ceñirse a ellas, y para una persona de $80 \mathrm{Kg}$ de peso, incluyendo el equipamiento estándar.

b. Se somete a un proceso de carga en 5 etapas (ver tabla de puntuación más adelante) hasta que se produce (o no) la ruptura.

c. Durante el proceso de carga, estaremos atentos en cada paso a las fracturas, al deslizamiento o a los desmoronamientos que puedan producirse.
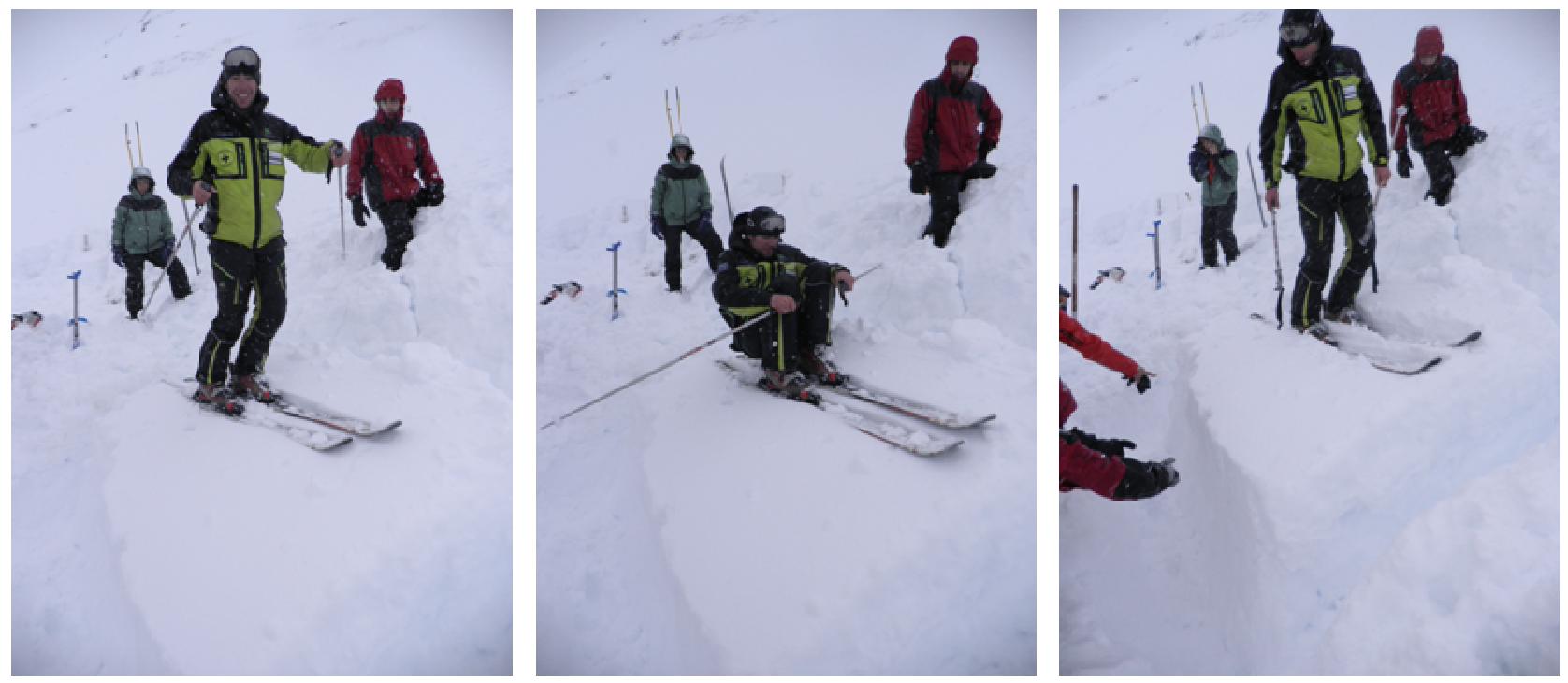

Fig. 78 Test Rutschblock, carga de un bloque

\section{Debemos anotar:}

- Número de paso en el que el bloque desliza (\#).

- Porción del bloque que desliza
o El bloque completo
o Parte del bloque (en general bajo los esquís)
o Sólo un borde (el borde inferior)

- Profundidad de la capa que fractura (zzz)

- Calidad de la rotura $(\mathbf{Q 1}, \mathbf{Q 2}, \mathbf{Q 3 )}$

- Tipo y tamaño de los granos presentes en la superficie de fractura. 


\section{Puntuación:}

Se puntúa de 1 a 7 según se produzca una fractura en el bloque en el paso 1 , el paso $2, \ldots$, el paso 7 .

\begin{tabular}{|c|c|}
\hline Puntuación & Descripción: momento en el que se produce una fractura o deslizamiento \\
\hline RB1 & 1. Durante el proceso de aislar el bloque del resto del manto nivoso \\
\hline RB2 & $\begin{array}{l}\text { 2. Al subirse despacio al bloque por la parte de arriba (a unos } 35 \mathrm{~cm} \text { de distancia } \\
\text { del borde superior) o tras permanecer subido a él con esquís }\end{array}$ \\
\hline RB3 & 3. Tras presionar hacia abajo con una flexión de rodillas, sin saltar \\
\hline RB4 & 4. Tras el primer salto sobre el bloque con los esquís desde una cierta altura \\
\hline RB5 & 5. Tras el segundo o tercer salto con esquís \\
\hline RB6 & $\begin{array}{l}\text { 6. Tras sucesivos saltos sobre el bloque sin esquís (si, por haber una placa friable } \\
\text { o fina, la superficie no aguanta sin hundirse, saltar con los esquís puestos unos } \\
35 \mathrm{~cm} \text { más abajo, hacia la mitad del bloque) }\end{array}$ \\
\hline RB7 & 7. Ninguno de los pasos anteriores produce efecto sobre el bloque (no desliza) \\
\hline
\end{tabular}

\section{Cifrado:}

El resultado del test se consigna: RB\#Qn@ $\downarrow$ ZzzF $\mathbf{D}_{\mathbf{m}} \mathbf{m m}$ Infos

\section{Ejemplos:}

RB5Q2@ $\downarrow 54 \square 2 \mathrm{~mm}$ Cae parte del bloque, pendiente 25': parte del bloque, no todo, ha cedido en el paso 5 (tras el segundo o tercer salto), en una pendiente de $\mathbf{2 5}^{\circ}$, moviéndose sobre una capa de granos de caras planas de $\mathbf{2} \mathbf{m m}$ de diámetro a $\mathbf{5 4} \mathbf{c m}$ de profundidad. La superficie de fractura es de calidad 2 rugosa y más bien plana.

RB7@ $\downarrow 87 \wedge 3 \mathrm{~mm}$ pendiente $35^{\circ}$ : el bloque no ha deslizado en una pendiente de $35^{\circ}$. Hay una capa de cubiletes de $3 \mathrm{~mm}$ de diámetro a $87 \mathrm{~cm}$ de profundidad pero no ha cedido.

RB1Q1@ $\downarrow 75 \vee$ Desliza el bloque completo, pendiente 30': el bloque completo ha cedido en el paso 1 (durante el proceso para aislarlo del resto del manto). Se ha producido una fractura plana y lisa, de calidad 1 en la que había escarcha, enterrada a $75 \mathrm{~cm}$ de profundidad.

\section{Comentarios:}

- Desviaciones de \pm 1 punto en el resultado del test son esperables, debido a la variabilidad espacial natural de la estabilidad en una pendiente. Desviaciones de 2 o más puntos (léase una puntuación de 5 en lugar de 3) son muy improbables si se ha elegido un lugar apropiado para hacer el test.

- El efecto de la inclinación de la ladera sobre el resultado del test no es muy importante, pero existe; la puntuación tiende a incrementarse en un punto por cada $10^{\circ}$ de menos en el ángulo de la pendiente. Por ello, es aconsejable comunicar el ángulo de pendiente junto con el resultado del test (mejor que corregir el resultado puntuando respecto de la inclinación estándar).

- Se detectan fracturas en capas débiles que estén por debajo de la profundidad de penetración de los esquís, no detectándose aquellas que, por ser superficiales, sean cortadas por la penetración de los esquís en el manto. También puede sobreestimarse la estabilidad asociada a capas débiles profundas, bajo placas gruesas y bien consolidadas, ya que en estos casos la resistencia en los bordes de las placas juega un papel más importante.

- En la parte alta de las laderas, suelen obtenerse puntuaciones mayores (mayor estabilidad) y más variables que en las partes central y baja de las pendientes. No obstante, los casos en que la estabilidad es sustancialmente sobreestimada son menos del $10 \%$.

- No va muy bien para nieve reciente, salvo que la penetración de los esquís se quede al menos 10 centímetros por encima de la profundidad de la capa débil.

Puede llevarse a cabo con tabla de nieve (snowboard) en lugar de con esquís, pero deben tenerse en cuenta algunas consideraciones en el modo de efectuar la carga sobre el bloque, ya que la forma de desplazarse con la tabla es diferente que con los esquís. Cuando se realiza con snowboard se denomina 'Boardblock', y su abreviatura es BB. Otra variante, consistente en aislar un bloque de forma triangular en lugar de rectangular (cuña deslizante) se repasa más adelante en este apéndice. 


\subsubsection{Test de Stuffblock o del peso (SB)}

Origen: Montana (USA), años 90.

Duración: 5 -10minutos.

\section{Objetivo:}

Identificar capas débiles y obtener una indicación del potencial de desencadenamiento de aludes al paso de humanos en laderas similares y cercanas. Es más efectivo para encontrar capas débiles cerca de la superficie del manto. Se golpea el manto con un peso conocido que se ha soltado desde una altura conocida, minimizando así la dependencia de los resultados del test con el observador. Las eventuales fracturas pueden verse mejor en el lateral de la columna, y se recomienda hacerlo en terreno con inclinación superior a $25^{\circ}$.

\section{Método:}

a. Separar una columna del manto según el mismo criterio que el test de compresión (CT); de $30 \times 30 \mathrm{~cm}$, con el frente mirando ladera abajo, cortando los laterales y la parte trasera, y profundidad máxima de $120 \mathrm{~cm}$. Colocar la pala sobre ella con el mango hacia arriba (ver fig. 79).

b. Si se produce alguna fractura mientras se aísla el bloque, se calificará como $\mathbf{V}$ (Very easy, muy fácil, ver la tabla de puntuación más abajo).

c. Cargar el bloque con un saco de tela fina relleno de 4,5 $\mathrm{Kg}$ de nieve, sobre la parte plana de la pala. Para ello:

- Primero: se deposita suavemente sobre la hoja de la pala, anotando las fracturas si las hay; en este caso se calificará como E (Easy, fácil)

- Posteriormente: se deja caer desde alturas progresivamente mayores: de $10,20,30 \ldots \mathrm{cm}$. Tras cada golpe, revisar la columna en busca de fracturas y, si se produce alguna, anotar la profundidad del plano de deslizamiento y la altura desde la que se ha soltado el peso.

d. En caso de que se haya producido una fractura, retirar el bloque suelto y continuar el test sobre la superficie de deslizamiento. El grosor del bloque que se retira es un dato a registrar y a tener en cuenta; los resultados para columnas así acortadas no reflejarán ya la resistencia de las capas débiles encontradas más abajo con la misma

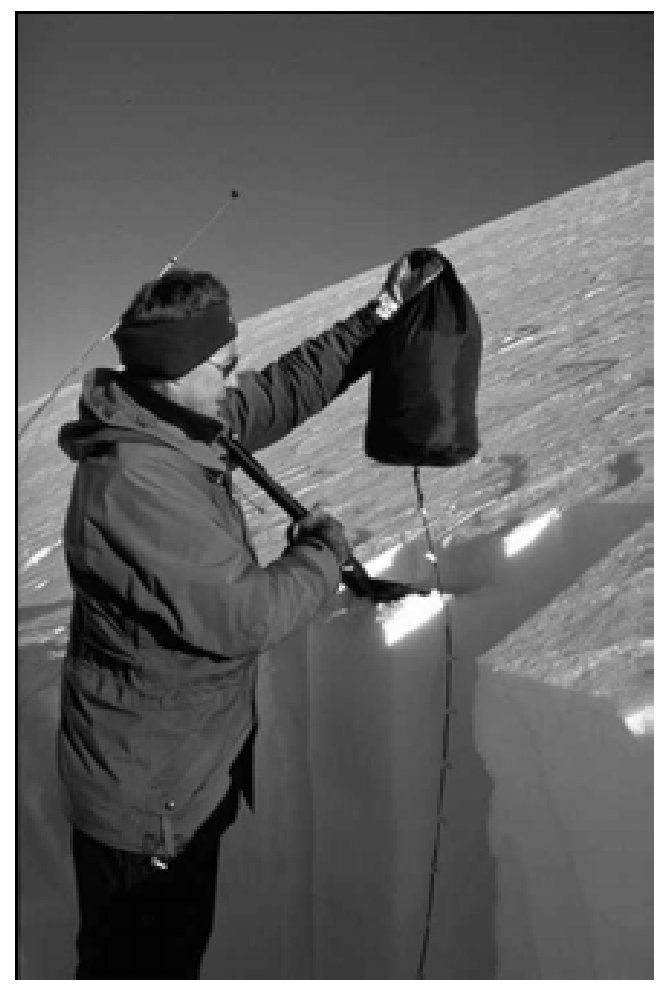

Fig. 79 Test Stuffblock o del peso precisión que la fractura inicial.

e. Se lanza el saco hasta una altura de $70 \mathrm{~cm}$. Si no hay fracturas tras soltar el bloque desde $70 \mathrm{~cm}$, se cifrará SBN.

\section{Debemos anotar:}

- Altura desde la que se ha soltado el saco cuando se ha producido la fractura (hh).

- Profundidad de la capa que fractura (zzz)

- Calidad de la rotura $(\mathbf{Q 1}, \mathbf{Q 2}, \mathbf{Q 3})$

- Tipo y tamaño de los granos presentes en la superficie de fractura.

- Si no se ha aislado el bloque hasta $120 \mathrm{~cm}$ de profundidad, conviene anotar la profundidad hasta la que realmente se ha testado el manto y reportarla junto con el resultado del test. 


\section{Puntuación:}

El test del peso se puntúa conforme a la siguiente taba:

\begin{tabular}{|c|c|c|c|c|}
\hline Puntuación & hh & Término & & Descripción \\
\hline SBV & $\mathbf{V}$ & Very easy - Muy Fácil & \multicolumn{2}{|c|}{ Fractura al aislar el bloque } \\
\hline SBE & $\mathbf{E}$ & Easy - Fácil & \multicolumn{2}{|c|}{ Fractura al colocar el saco suavemente sobre la pala } \\
\hline \multirow{3}{*}{ SBhh } & 10 ó 20 & Easy - Fácil & \multirow{3}{*}{$\begin{array}{l}\text { Fractura } \\
\text { durante } \\
\text { la carga }\end{array}$} & Al soltar el saco desde 10 ó $20 \mathrm{~cm}$. \\
\hline & 30 ó 40 & Moderate - Mediana & & Al soltar el saco desde 30 ó $\mathbf{4 0} \mathrm{cm}$. \\
\hline & 50,60 ó 70 & Hard - Difícil & & Al soltar el saco desde 50,60 ó $70 \mathrm{~cm}$. \\
\hline SBN & $\mathbf{N}$ & No shear - Imposible & \multicolumn{2}{|c|}{ No hay fractura tras haber soltado el saco desde $70 \mathrm{~cm}$. } \\
\hline
\end{tabular}

\section{Cifrado:}

El resultado del test se consigna: SBhhQn@ $\downarrow$ zzzF $\mathbf{D}_{\mathrm{m}} \mathrm{mm}$ Infos

\section{Ejemplos:}

SB40Q2@ $\downarrow 34 \square 1,5 \mathrm{~mm}$ : se ha producido una fractura al soltar el saco desde $40 \mathrm{~cm}$ de altura. La capa que ha fracturado está a $34 \mathrm{~cm}$ de profundidad, compuesta de granos de caras planas de 1,5 $\mathbf{m m}$ de diámetro y la superficie de fractura es de calidad 2 rugosa y más bien plana.

SB20Q1@ $\downarrow 42 \wedge 2 \mathrm{~mm}$ Testado hasta $100 \mathrm{~cm}$, espesor total $180 \mathrm{~cm}$ : se ha producido una fractura de calidad 1, lisa y plana, en una capa con cubiletes de $2 \mathrm{~mm}$ de grosor, a $42 \mathbf{c m}$ de profundidad, al soltar el saco desde una altura de $20 \mathrm{~cm}$. Se ha testado hasta un metro de profundidad sin que salgan más fracturas, y no se han testado los siguientes $80 \mathrm{~cm}$ de manto.

SBN: no se han producido fracturas. Se ha hecho el test hasta $120 \mathrm{~cm}$ de profundidad o hasta la superficie del terreno si el espesor total es menor de $120 \mathrm{~cm}$.

\section{Comentarios:}

- Es útil usar un saco que lleve atada a su base una cuerda graduada cada $10 \mathrm{~cm}$, con nudos por ejemplo.

\subsubsection{Test de la cuña deslizante (Rutschkiel test)}

Es una variación del test del bloque deslizante, pero se corta un bloque triangular, de $3 \mathrm{~m}$ de base por $2 \mathrm{~m}$ de altura, el vértice hacia arriba. El proceso de aislamiento del bloque es más rápido ya que se efectúa colocando una sonda de montaña en el vértice superior y haciendo correr un cordino por ella, a modo de sierra, por los lados laterales. Se procede como en el Rutschblock.

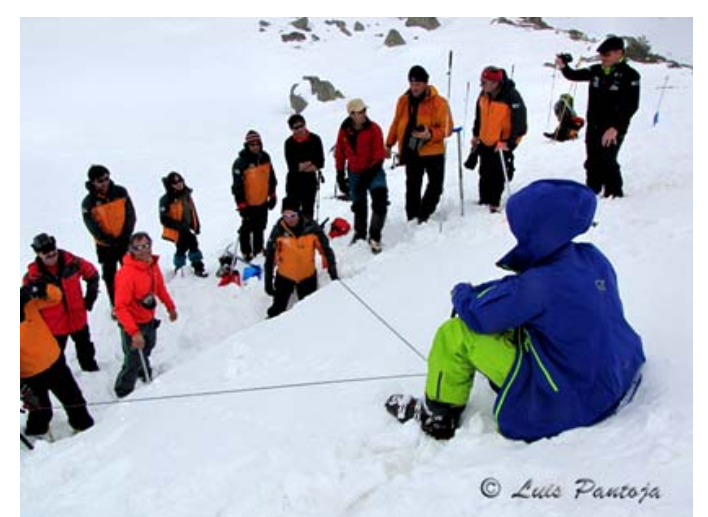

Fig. 80 Corte para el test de cuña deslizante 


\subsubsection{Test de la propagación de la sierra (PST)}

Origen: Canadá, 2005.

Duración: 5 - 10 minutos.

\section{Objetivo:}

Valorar si una capa débil, previamente identificada -típicamente bajo una placa, formando una estructura de placa-, es propensa a propagar una fractura ya iniciada, sin tener en cuenta la carga necesaria para iniciar la fractura.

\section{Método:}

a. Se despeja una pared vertical de la nieve y se identifica la capa débil a testar. Va bien resaltar la capa débil cepillando suavemente con una brocha o el dorso de un guante.

b. Se separa completamente del resto del manto una columna de $30 \mathrm{~cm}$ (frente o ancho) por $100 \mathrm{~cm}$ (lateral ladera arriba o fondo), y profundo hasta la capa frágil o más, dejando un lateral despejado. Si la capa débil está a una profundidad mayor que un metro, la dimensión del corte largo (ladera arriba) deberá ser la misma que la profundidad de la capa débil.

c. Se introduce la parte roma de la sierra en la capa débil por la parte frontal del bloque aislado y se va desplazando pendiente arriba, permaneciendo atentos al momento en que se propaga una fractura por delante de la sierra, a lo largo de la capa débil.

d. Si el corte de la sierra se desvía, saliéndose de la capa débil, el resultado del test no sirve, debe repetirse el proceso.

e. En el punto en que comience la propagación de la fractura por delante de la sierra, se detiene ésta y se mide.
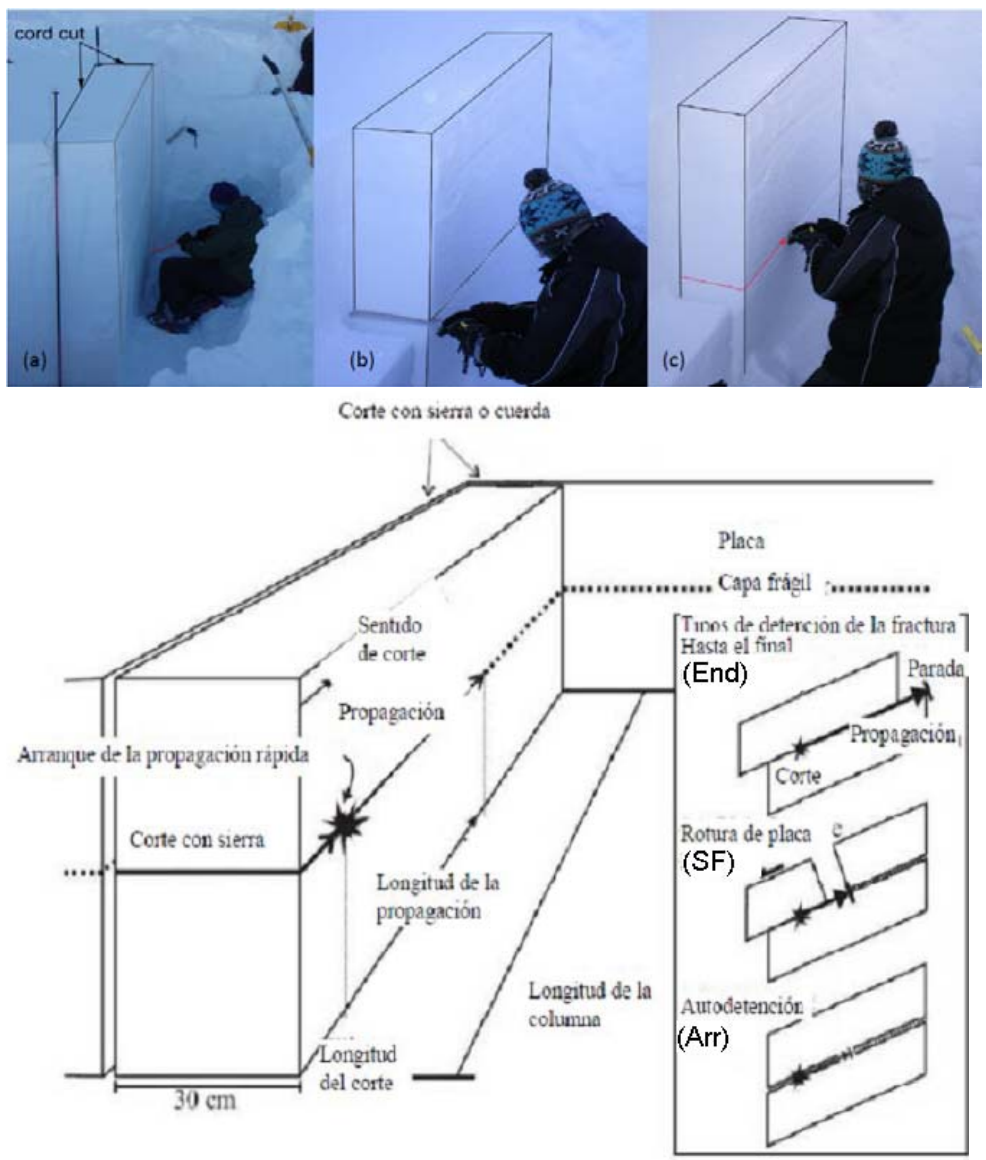

Fig. 81 Procedimiento para el test de propagación de la sierra

\section{Debemos anotar:}

- La distancia recorrida con la sierra hasta el momento de producirse la propagación (x).

- La longitud de la columna (dimensión ladera arriba) que hemos aislado, en general $100 \mathrm{~cm}$ (y).

- La profundidad de la capa débil (zzz).

- Lo que ha sucedido, que puede ser una de las 3 siguientes cosas:

i) La fractura se propaga totalmente, hasta el final del bloque, quedando este separado (End, fin).

ii) La fractura se detiene sin causa aparente antes de alcanzar el final del bloque (Arr, detención).

iii) La fractura se propaga un poco, pero se detiene por romperse la placa por encima del nivel de la capa débil, similar a la corona o línea de fractura de un alud (SF, ruptura de placa). 


\section{Puntuación:}

Las observaciones importantes para interpretar los resultados del test son:

1. ¿Ha habido que cortar más de $50 \mathrm{~cm}$ (más de la mitad del bloque) o menos de $50 \mathrm{~cm}$ (menos de la mitad del bloque) para que la fractura comenzase a propagarse?

2. ¿Se ha propagado la fractura completamente, alcanzando el final del bloque, o se ha detenido dentro del bloque?

Por tanto, debemos valorar:

1. Si $\mathbf{x}>50 \mathrm{~cm}$ (ó $\mathbf{x}>\mathbf{y} / 2$ en el caso de que la dimensión del bloque sea mayor de $100 \mathrm{~cm}$ ).

- $\quad \mathbf{x}$ es la longitud, en $\mathrm{cm}$, del corte con la sierra.

- y es la longitud, en $\mathrm{cm}$, de la columna, $100 \mathrm{~cm}$ o la profundidad de la capa débil, si ésta está a una profundidad superior a un metro.

2. Qué ha sucedido en la propagación de la fractura, conforme a la tabla a continuación:

\begin{tabular}{|c|l|}
\hline Resultado & \multicolumn{1}{c|}{ Descripción } \\
\hline End & La fractura se propaga hasta el final de la columna (Fin) \\
\hline $\begin{array}{c}\text { SF } \\
\text { (Slab Fracture) }\end{array}$ & $\begin{array}{l}\text { La fractura se para por romperse la placa superior a la capa débil (RP, rompe la } \\
\text { placa) }\end{array}$ \\
\hline $\begin{array}{c}\text { Arr } \\
\text { (Arrest) }\end{array}$ & La fractura se detiene antes de llegar al final de la columna. (Par, parada) \\
\hline
\end{tabular}

\section{Cifrado:}

El test de propagación de la sierra se consigna: PST x/y (Resultado) @ $\downarrow z z z$ Infos

\section{Ejemplo:}

PST 40/100 (End)@ $\downarrow 60 \vee$ : la fractura ha comenzado a propagarse a los $40 \mathrm{~cm}$ y ha llegado hasta el final de los $100 \mathrm{~cm}$ totales del bloque. La capa débil testada está a una profundidad de $60 \mathrm{~cm}$ y formada por escarcha enterrada.

\section{Interpretación:}

- Es probable la propagación de una fractura en pendientes similares cercanas: si la propagación comienza antes de llegar a cortar la mitad de la columna $(50 \mathrm{~cm}$ en general) y además se propaga completamente, alcanzando el final del bloque.

- No es probable la propagación de fracturas en capas débiles: en todos los demás casos, incluyendo aquellos en los que se la fractura alcanza el final del bloque pero la propagación ha comenzado tras cortar más de la mitad de la columna.

\section{Comentarios:}

- $\quad$ EI PST no es un test de golpeo; no informa sobre cómo de difícil es producir una fractura en una capa débil, sino sólo qué podría pasar en una capa débil si se produce una fractura.

- Indica más casos de 'falsa estabilidad' que otros tests, especialmente si la capa frágil es poco profunda. Por otro lado, arroja pocos resultados de 'falsa inestabilidad'. Así pues, es más concluyente cuando indica que la estabilidad no es buena (que se propagan las fracturas).

- En general se prueba el comportamiento de capas débiles en los primeros 100-120 cm de profundidad, que es lo que penetran los esfuerzos en el manto. No obstante, el PST se ve poco afectado por la inclinación y por el grosor de la placa sobre la capa débil. Esto permite testar capas débiles en zonas más planas que las zonas de salida de los aludes, también más accesibles y menos peligrosas, aunque en ellas su profundidad sea mayor. Así, se puede tener una idea de la tendencia de las capas débiles a propagar fracturas en otras zonas de menos espesor y mayor inclinación, donde sí que pueden ceder al paso de esquiadores.

- Se requiere experiencia para identificar capas débiles, y no es muy operativo en travesías, pero puede ser interesante para analizar la estabilidad de una ladera especialmente conflictiva para una instalación fija (estación de esquí, vía de comunicación, camino transitado....). 


\subsection{Apéndice B: Referencias de las ilustraciones}

52,53,54,55,56,57,59,60,61: International Classification for Seasonal Snow on the Ground. ICSIUCCS-IACS Working Group on Snow Classification. UNESCO, 2009.

5,31,36,47,64,72,74,75,76: Météo-France.

$1,2,7,8,9,12,13,14,15,16,17,18,20,22,23,24,32,46,50,51,62,77,80$ y portada: Luis Pantoja.

3,19,21,25,26,29,68: Gerardo Sanz.

34,39, 58: Javier Rodríguez Marcos.

30: Samuel Buisán.

35: Víctor Fuenlabrada.

37: Francisco Espejo.

78: AEMET (DTAra).

40, 42: EAWS.

43: The Comet Program.

44: Moore, $\mathrm{M}$.

74: fsavalanche.org.

75: SWAG.

33: Isaw.ch.

11: Unidad didáctica de nubes. FECYT-MEC.

79: The Stuffblock Snow Stability Test Publication Number: 9623-2836-MTDC.

81: ASARC (Univ. Calgary).

27,29: Instrucciones para el uso, instalación y mantenimiento de Aparatos Meteorológicos (INM).

23,28: Manual del observador de Meteorología. Jansá Guardiola, 1968.

\subsection{Apéndice C: Bibliografía}

- Guide to Meteorological Instruments and Methods of Observation. WMO-No. 8. $7^{\text {a }}$ edición. 2008.

- Manual de claves. Claves internacionales. Volumen 1.1 (Anexo II al Reglamento Técnico de la OMM): Parte A - Claves alfanuméricas. OMM-Nº 306. Edición de 2011.

- Manual de claves. Claves regionales y prácticas nacionales de cifrado. Volumen II. OMM-Nº 306. Edición de 2011.

- Guía de prácticas hidrológicas. Volumen II: Gestión de recursos hídricos y aplicación de prácticas hidrológicas. OMM-Nº 168. Sexta edición. 2011.

- Guía del sistema mundial de observación. OMM-Nº 544. Edición de 1989.

- Instrucciones para el uso, instalación y mantenimiento de Aparatos Meteorológicos. Servicio de Publicaciones del MTTC, INM, serie C-46, Madrid 1988

- Unidad didáctica de nubes, Quirantes, J.A. y León, F. FECYT-MEC.

- Fierz, C., Armstrong, R.L., Durand, Y., Etchevers, P., Greene, E., McClung, D.M. Nishimura, K., Satyawali, P.K. and Sokratov, S.A. 2009. The International Classification for Seasonal Snow on the Ground. IHP-VII Technical Documents in Hydrology N83, IACS Contribution N¹, UNESCO-IHP, Paris.

- Retallack, B. J. Compendio de apuntes para la formación del personal meteorológico de la clase IV Volumen II, Meteorología. OMM-Nº 266. Edición de 1991.

- Jansá Guardiola, J. M. Manual del observador de meteorología. $2^{a}$ ed. España. Ministerio del Aire, Subsecretaría de Aviación Civil, Servicio Meteorológico Nacional. 1968.

- E. Pahaut y C. Sergent. La neige: formation et évolution. Traducción del CMT de Aragon, La Rioja y Navarra (INM). Francia. Météo-France. CNRM CEN. Edición de octubre de 1991. Publicación Météo-France.

- C. Sergent, C. Coléou y P. David. Mesures nivométéorologiques. Traducción del CMT de Aragón, La Rioja y Navarra (INM). Francia. Météo-France. CNRM CEN. Edición de 1991. Publicación Météo-France. 
- Y Danielou y E. Pahaut. Les mesures de la densité de la neige. Traducción del CMT de Aragón, La Rioja y Navarra (INM). Francia. Météo-France. CNRM CEN. Edición de 1991. Publicación MétéoFrance.

- C. Sergent. Propriétés physiques de la neige. Traducción del CMT de Aragón, La Rioja y Navarra (INM). Francia. Météo-France. CNRM CEN. 1997. Publicación Météo-France.

- G Guyomarch,y L Mérindol. Transport de la neige pour le vent. Traducción del CMT de Aragón, La Rioja y Navarra (INM). Francia. Météo-France. CNRM CEN. Edición de 1991. Publicación MétéoFrance.

- G Guyomarch. Les avalanches. Traducción del CMT de Aragón, La Rioja y Navarra (INM). Francia. Météo-France. CNRM CEN. 1996. Publicación Météo-France

- Equipo de formación del Centro de Estudios de la Nieve. Normas para la realización de un sondeo por golpeo. Traducción del CMT de Aragón, La Rioja y Navarra (INM). Francia. Météo-France. CNRM CEN. Edición de 1994. Publicación Météo-France.

- Gérald Giraud, Jean-Pierre Navarre, Cécile Coléou. Stabilité-Instabilité du manteau neigeux. Approche statique. Francia. Météo-France CNMR CEN. Publicación Météo-France.

- C Coléou. Les Tests de Stabilité. Francia. Météo-France CNMR CEN. Publicación Météo-France.

- Greene, E., D. Atkins, K. Birkeland, K. Elder, C. Landry, B. Lazar, I. McCammon, M. Moore, D. Sharaf, C. Sternenz, B. Tremper, and K. Williams, 2010. Snow, Weather and Avalanches: Observation Guidelines for Avalanche Programs in the United States. American Avalanche Association, Pagosa Springs, CO, Second Printing Fall 2010.

- COMET PROGRAM. Snowpack and its assesment. Disponible en Web: http://www.meted.ucar.edu/afwa/snowpack.

- Bruce Tremper. Staying Alive in Avalanche Terrain. 2a edición. The mountaineers books. 2008. ISBN: 0898868343

- Tremper, B.: Simple Snow Stability Tests. Disponible en Web: http://www.avalanche.org

- D. McClung, P Schaerer. Avalanchas. Ediciones Desnivel. 1996. ISBN: 84-87746-87-X.

- Werner Munter. 3 X 3 Avalanchas: la gestión del riesgo en los deportes de invierno. Ediciones Desnivel. 2003. ISBN: 978-84-9829-073-8.

- Schweizer, J. and Jamieson, J.B., 2004. Snow stability measurements. Proceedings of the International Seminar on Snow and Avalanche Test Sites, Grenoble, France, 2001. Cemagref editions, Antony (Hauts-de-Seine), France: pp. 317-331.

- Bruce Jamieson. The compression test after 25 years. The Avalanche Review 1999. 18 (1), 10-12.

- Ron Simenhois y Karl W. Birkeland. The Extended Column Test: a field test for fracture initiation and propagation. Proceedings of the 2006 International Snow Science Workshop. Telluride. Colorado.

- Ron Simenhois y Karl Birkeland. An update on the Extended Column Test: New recording standards and additional data analyses. The Avalanche Review 26(2), 2007.

- Ron Simenhois y Karl W. Birkeland. The Extended Column Test: Test effectiveness, spatial variability, and comparison with the Propagation Saw Test. Cold Regions Science and Technology journal, 2009.

- Dave Gauthier y Bruce Jamieson. The Propagation Saw Test (PST). Enviado al Avalanche.ca Journal, Nov. 2007.

- Jürg Schweizer. The Rutschblock Test - Procedure and Application in Switzerland. The Avalanche Review, 2002.

- Mark Moore. Rough Correlations of Common Snowpack Stability Tests. Proceedings of the 2006 International Snow Science Workshop, Telluride, Colorado. 2006.

- Igor Chiambretti. Field observation methods in Italy ECT vs RB stability tests, first results. Presentación en el 16th EAWS Meeting, Grenoble 15th - 17th September 2011.

- Ron F. Johnson y Karl W. Birkeland. Integrating shear quality into stability test results. Proceedings of the 2002 International Snow Science Workshop. Penticton, B C., Canada. 2002. 


\subsection{Apéndice D: Impresos para toma de datos.}

\subsubsection{Hoja de toma de datos para test de estabilidad}

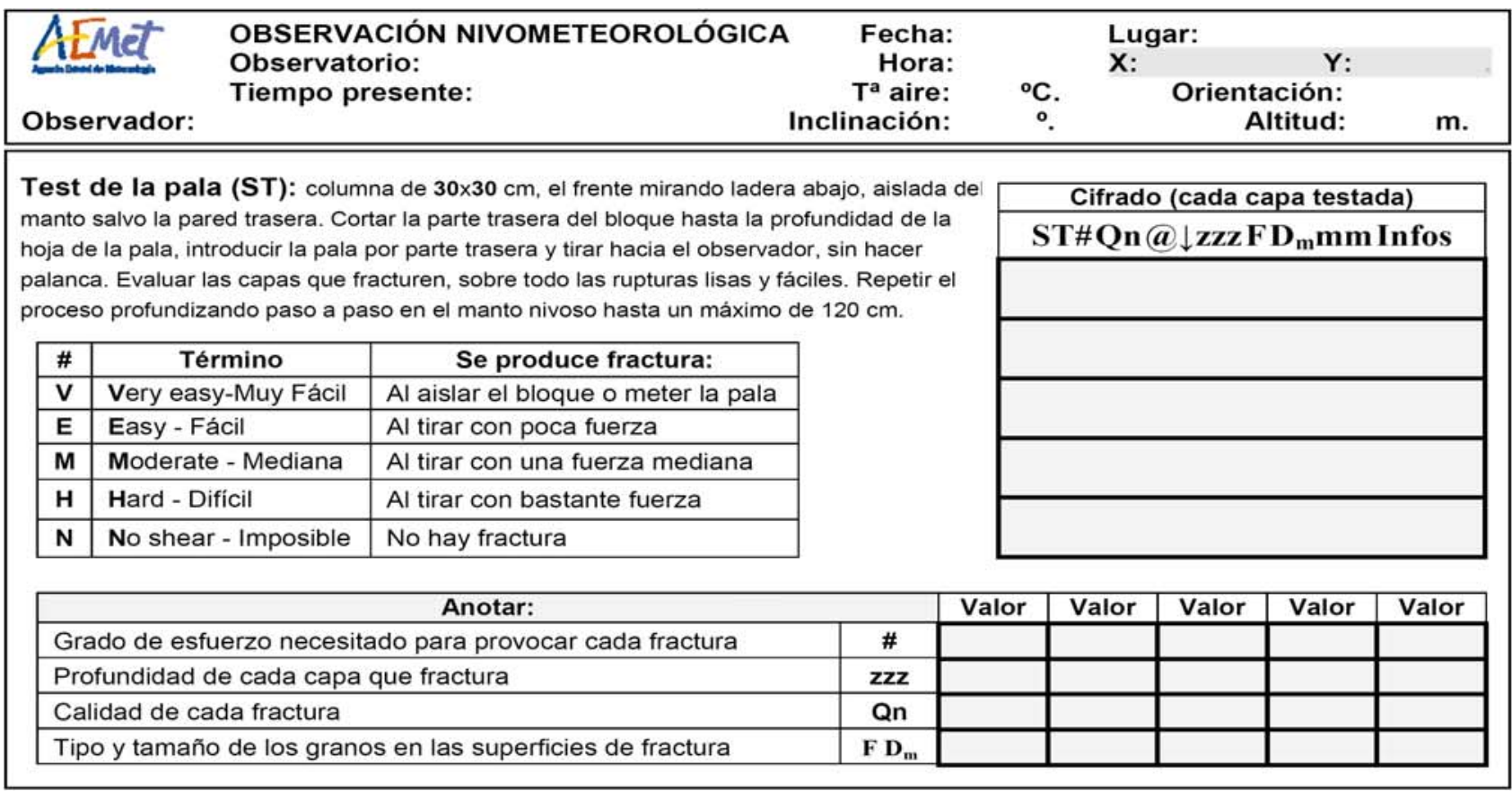

Test de Compresión (CT): columna de $30 \times 30 \times 120 \mathrm{~cm}$ (fondo $\times$ ancho $\times$ profundidad máxima), aislada por los 4 lados, con el frente mirando ladera abajo. Con la hoja de la pala colocada horizontalmente sobre el bloque, realizar 3 series de 10 golpes sobre la pala:

- $1^{a}$ serie: Con las puntas de los dedos moviendo sólo la muñeca

- $2^{a}$ serie: Con los dedos moviendo el antebrazo desde el codo

- $3^{a}$ serie: Con toda la mano moviendo el brazo desde el hombro

\# Término Descripción

V Very easy - Muy Fácil Fractura al aislar el bloque

E Easy-Fácil $\quad$ Fractura golpes desde la muñeca (golpes 1 a 10)

M Moderate-Mediana Fractura golpes desde el codo (golpes 11 a 20)

H Hard - Difícil

N No shear - Imposible

Fractura golpes desde el hombro (golpes 21 a30)

No hay rotura tras 30 golpes

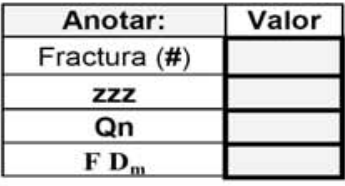

Cifrado
CT\#Qn@ $\downarrow$ zzzF $D_{\mathrm{m}} \mathrm{mm}$ Infos

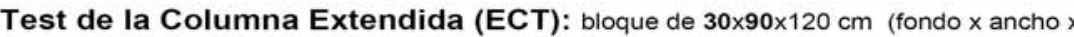
profundidad máx.), aislado por los 4 lados, con el frente (lado ancho) mirando ladera abajo. Con la hoja de la pala colocada horizontalmente sobre un extremo del bloque, realizar 3 series de 10 golpes sobre la pala:

- $\quad 1^{a}$ serie: Con las puntas de los dedos moviendo sólo la muñeca

- $2^{a}$ serie: Con los dedos moviendo el antebrazo desde el codo

- $\quad 3^{a}$ serie: Con toda la mano moviendo el brazo desde el hombro

Atentos al $n^{\circ}$ de golpe en el que se produce la fractura y a si ésta se propaga completamente en ese mismo golpe o en el siguiente.

\begin{tabular}{|l|l|l|}
\hline Puntuación & \multicolumn{1}{|c|}{ Descripción } & \multicolumn{1}{|c|}{ Cifrado } \\
\hline ECTPV & $\begin{array}{l}\text { La fractura se propaga a la totalidad del bloque aislado, a lo largo de } \\
\text { la capa débil, durante el proceso de aislar el bloque }\end{array}$ & ECT\#\# Qn @ $\downarrow$ ZZz F D $\mathbf{m}$ mm Infos \\
\hline ECTP\#\# & $\begin{array}{l}\text { La fractura se inicia en el golpe \#\# y se propaga a lo largo de toda la } \\
\text { columna, a través de la capa débil, en el golpe \#\# ó en el golpe \#\#+1 }\end{array}$ & \\
\hline ECTN\#\# & $\begin{array}{l}\text { La fractura se inicia en el golpe \#\# pero no se propaga a lo largo de la } \\
\text { totalidad de la columna ni en el golpe \#\# ni en el golpe \#\#+1 }\end{array}$ & \\
\hline ECTX & No se produce fractura en la capa débil. \\
\hline
\end{tabular}

\begin{tabular}{|l|l|}
\hline Qn & \multicolumn{1}{|c|}{ CALIDAD DE LA FRACTURA } \\
\hline Q1 & Fractura limpia, plana y con movimiento rápido \\
\hline Q2 & Fractura menos limpia y un poco rugosa \\
\hline Q3 & Fractura irregular, no plana y rugosa \\
\hline
\end{tabular}




\subsubsection{Hoja de toma de datos para perfil estratigráfico}

\begin{tabular}{|c|c|c|c|}
\hline Agencia Estatal de Meteorología & $\begin{array}{l}\text { ESTACIÓN } \\
\text { LUGAR DE MEDIDA: } \\
\text { GPS } \\
\quad r:\end{array}$ & $\begin{array}{l}\text { ALTITUD: } \\
\text { ORIENTACIÓN } \\
\text { INCLINACIÓN: } \\
\text { T'DEL AIRE: } \\
\text { TIEMPO PRESENTE: }\end{array}$ & $\begin{array}{c}\text { PERFIL } \\
\text { ESTRATIGRÁFICO } \\
\text { No }^{0} . \ldots \ldots \ldots \ldots . . . . \\
\end{array}$ \\
\hline $\begin{array}{l}\text { Delegación Territorial en Aragón } \\
\text { Paseo del Canal, } 17 \\
50007 \text { ZARAGOZA }\end{array}$ & $\begin{array}{l}\text { FECHA } \\
\text { HORA LOCAL }\end{array}$ & M & OBSERVADOR: \\
\hline
\end{tabular}

\begin{tabular}{|c|c|c|c|c|c|c|c|c|c|}
\hline \multicolumn{2}{|c|}{$\begin{array}{l}\text { TEMPERATURA DE } \\
\text { LA NIEVE }\end{array}$} & $\mathrm{H}$ & $F_{1} F_{2}$ & $D_{m}$ & d & $\mathrm{U}$ & Den & $\overline{C A L}$ & \multirow{3}{*}{\begin{tabular}{l}
\multicolumn{1}{c}{ H altura en cm } \\
Para la temperatura, indica el nivel \\
donde se ha realizado la medida. \\
Para la estratigrafia, indica los \\
niveles que limitan cada estrato.
\end{tabular}} \\
\hline $\mathrm{H} \mathrm{cm}$ & ${ }^{\circ} \mathrm{C}$ & $\mathrm{cm}$ & clavef & $\begin{array}{c}\text { décimas } \\
\text { demm }\end{array}$ & clave d & Clave U & $\mathrm{kg} / \mathrm{m}^{3}$ & $\%$ & \\
\hline & & & \multicolumn{6}{|c|}{ Escribir sobre las líneas punteadas } & \\
\hline & & & & & & & & & F Tipo de granos o cristales \\
\hline & & & & & & & & & \multirow{9}{*}{$\begin{array}{ll}1 & + \text { Nieve reciente } \\
2 & \text { / Partículas reconocibles } \\
3 & \bullet \text { Granos finos } \\
4 & \square \text { Caras planas } \\
5 & \wedge \text { Cubiletes } \\
6 & \circ \text { Granos redondos } \\
7 & \text { - Costras - Capas de hielo } \\
8 & \vee \text { Escarcha } \\
9 & \star \text { N Nieve granulada } \\
\end{array}$} \\
\hline & & & & & & & & & \\
\hline & & & & & & & & & \\
\hline & & & & & & & & & \\
\hline & & & & & & & & & \\
\hline & & & & & & & & & \\
\hline & & & & & & & & & \\
\hline & & & & & & & & & \\
\hline & & & & & & & & & \\
\hline & & & & & & & & & \multirow{2}{*}{$\mathrm{D}_{\mathrm{m}} \begin{array}{c}\text { Diámetro de los granos o } \\
\text { cristales de nieve }\end{array}$} \\
\hline & & & & & & & & & \\
\hline & & & & & & & & & \multirow{2}{*}{$\begin{array}{c}\text { Expresado en décimas de } \mathrm{mm} \\
0.5 \mathrm{~mm} \text { se cifra } 05\end{array}$} \\
\hline & & & & & & & & & \\
\hline & & & & & & & & & d Dureza \\
\hline & & & & & & & & & \multirow{6}{*}{ 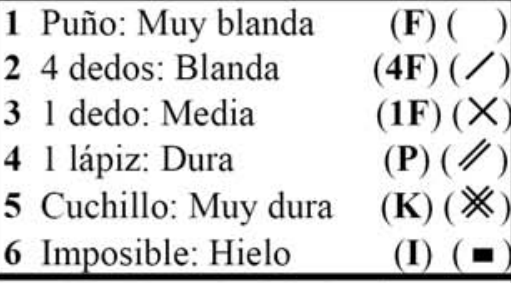 } \\
\hline & & & & & & & & & \\
\hline & & & & & & & & & \\
\hline & & & & & & & & & \\
\hline & & & & & & & & & \\
\hline & & & & & & & & & \\
\hline & & & & & & & & & U Humedad de la nieve \\
\hline & & & & & & & & & \multirow{2}{*}{$\begin{array}{l}1 \text { Seca (Dry) } \\
\left(\mathrm{T} \leq-1^{\circ} \mathrm{C} \text { ó bolas imposibles) }\right.\end{array}$} \\
\hline & & & & & & & & & \\
\hline & & & & & & & & & \multirow{4}{*}{$\begin{array}{ll}2 \text { Poco húmeda (Moist) } & \text { (M) (I) } \\
\text { (hace bola, } \mathrm{T}>-1{ }^{\circ} \mathrm{C} \text { ) } & \\
3 \begin{array}{l}\text { Húmeda (Wet) } \\
\text { (moja el guante) }\end{array} & \text { (W) (II) }\end{array}$} \\
\hline & & & & & & & & & \\
\hline & & & & & & & & & \\
\hline & & & & & & & & & \\
\hline & & & & & & & & & \multirow{2}{*}{$\begin{array}{l}4 \begin{array}{l}\text { Mojada (Very wet) } \\
\text { (escurre agua al apretar) }\end{array} \\
\text { (V) (III) }\end{array}$} \\
\hline & & & & & & & & & \\
\hline & & & & & & & & & \multirow{2}{*}{$\begin{array}{l}5 \text { Muy mojada (Soaked) } \\
\text { (agua +nieve) }\end{array}$} \\
\hline & & & & & & & & & \\
\hline & & & & & & & & & \multirow{4}{*}{\begin{tabular}{l}
\multicolumn{1}{c}{ Den Densidad } \\
Densidad en $\mathrm{kg} / \mathrm{m}^{3}$ \\
Con tubo de muestreo de $0.5 \mathrm{l}:$ \\
Den $=\mathbf{2} \mathbf{x}$ (peso nieve en gramos)
\end{tabular}} \\
\hline & & & & & & & & & \\
\hline & & & & & & & & & \\
\hline & & & & & & & & & \\
\hline & & & & & & & & & \multirow{3}{*}{$\begin{array}{l}\text { CAL } \\
\text { Contenido en agua líquida } \\
\text { (\% en volumen) }\end{array}$} \\
\hline & & & & & & & & & \\
\hline & & & & & & & & & \\
\hline
\end{tabular}




\subsubsection{Hoja de toma de datos para sondeo por golpeo}

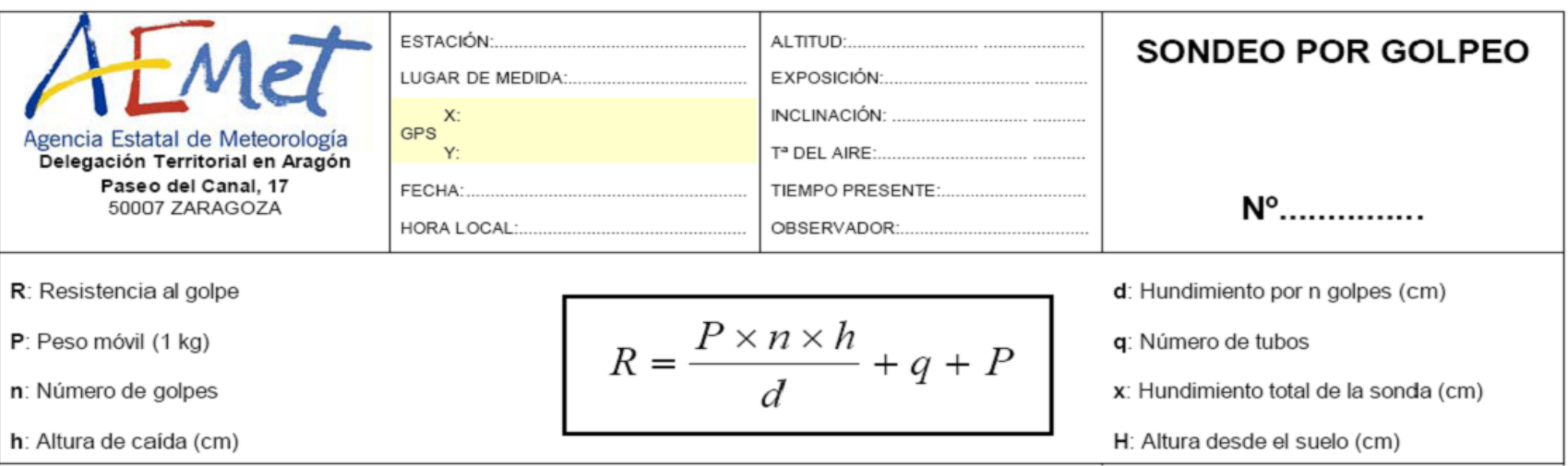

\begin{tabular}{|c|c|c|c|c|c|c|c|c|c|c|c|c|c|c|c|c|c|c|c|c|c|c|c|}
\hline$q$ & $\mathbf{P}$ & $\mathbf{n}$ & h & $\mathbf{x}$ & d & $\mathbf{R}$ & H & $q$ & $P$ & $\mathrm{n}$ & $\mathrm{h}$ & $x$ & $\mathrm{~d}$ & $\mathrm{R}$ & $\mathrm{H}$ & $q$ & $\mathrm{P}$ & $\mathrm{n}$ & $\mathrm{h}$ & $x$ & $d$ & $\mathrm{R}$ & $\mathrm{H}$ \\
\hline & & & & & & & & & & & & & & & & & & & & & & & \\
\hline & & & & & & & & & & & & & & & & & & & & & & & \\
\hline & & & & & & & & & & & & & & & & & & & & & & & \\
\hline & & & & & & & & & & & & & & & & & & & & & & & \\
\hline & & & & & & & & & & & & & & & & & & & & & & & \\
\hline & & & & & & & & & & & & & & & & & & & & & & & \\
\hline & & & & & & & & & & & & & & & & & & & & & & & \\
\hline & & & & & & & & & & & & & & & & & & & & & & & \\
\hline & & & & & & & & & & & & & & & & & & & & & & & \\
\hline & & & & & & & & & & & & & & & & & & & & & & & \\
\hline & & & & & & & & & & & & & & & & & & & & & & & \\
\hline & & & & & & & & & & & & & & & & & & & & & & & \\
\hline & & & & & & & & & & & & & & & & & & & & & & & \\
\hline & & & & & & & & & & & & & & & & & & & & & & & \\
\hline & & & & & & & & & & & & & & & & & & & & & & & \\
\hline & & & & & & & & & & & & & & & & & & & & & & & \\
\hline & & & & & & & & & & & & & & & & & & & & & & & \\
\hline & & & & & & & & & & & & & & & & & & & & & & & \\
\hline & & & & & & & & & & & & & & & & & & & & & & & \\
\hline & & & & & & & & & & & & & & & & & & & & & & & \\
\hline & & & & & & & & & & & & & & & & & & & & & & & \\
\hline & & & & & & & & & & & & & & & & & & & & & & & \\
\hline & & & & & & & & & & & & & & & & & & & & & & & \\
\hline & & & & & & & & & & & & & & & & & & & & & & & \\
\hline & & & & & & & & & & & & & & & & & & & & & & & \\
\hline & & & & & & & & & & & & & & & & & & & & & & & \\
\hline & & & & & & & & & & & & & & & & & & & & & & & \\
\hline & & & & & & & & & & & & & & & & & & & & & & & \\
\hline & & & & & & & & & & & & & & & & & & & & & & & \\
\hline & & & & & & & & & & & & & & & & & & & & & & & \\
\hline & & & & & & & & & & & & & & & & & & & & & & & \\
\hline & & & & & & & & & & & & & & & & & & & & & & & \\
\hline & & & & & & & & & & & & & & & & & & & & & & & \\
\hline & & & & & & & & & & & & & & & & & & & & & & & \\
\hline & & & & & & & & & & & & & & & & & & & & & & & \\
\hline & & & & & & & & & & & & & & & & & & & & & & & \\
\hline
\end{tabular}




\subsubsection{Hoja para gráfico de sondeo y perfil estratigráfico}

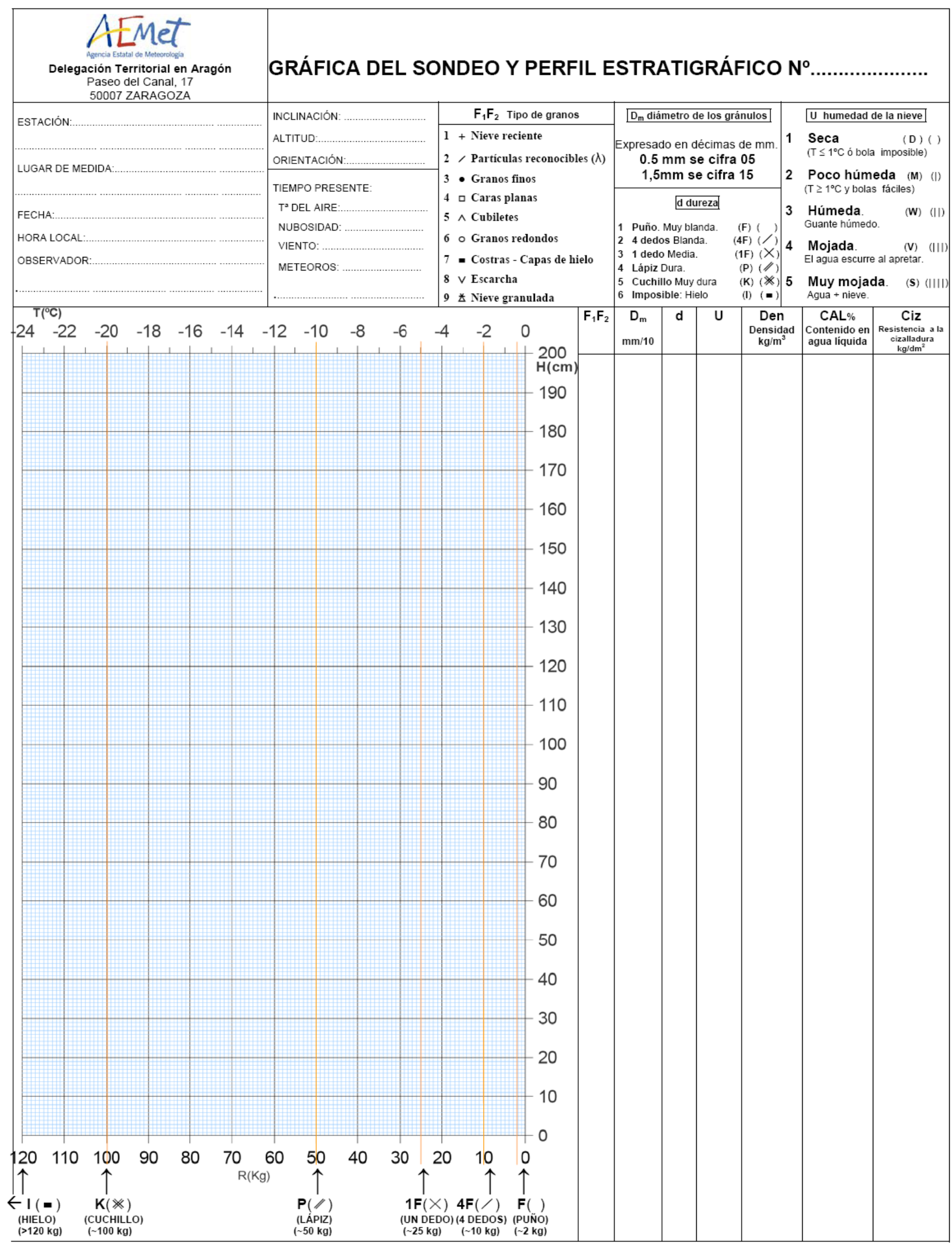

\subsection{Apéndice E: Síntesis de la clave NIVOMET}


08iii

Grupo indicador de la estación nivometeorológica 08: Indicativo fijo para las estaciones de España iii: Indicativo propio de la estación

21h / / ó $41 \mathrm{~h} /$ /

Grupo que informa sobre la altura de las nubes más bajas observadas (h)

La forma 21h / / se utiliza en la observación de mañana (08Z)

La forma $41 \mathrm{~h}$ / / se utiliza en la observación del mediodía (13Z)

h: Altura de la base de las nubes más bajas

h: Altura de la base de las nubes más bajas Observadas por
Cifrado Altura

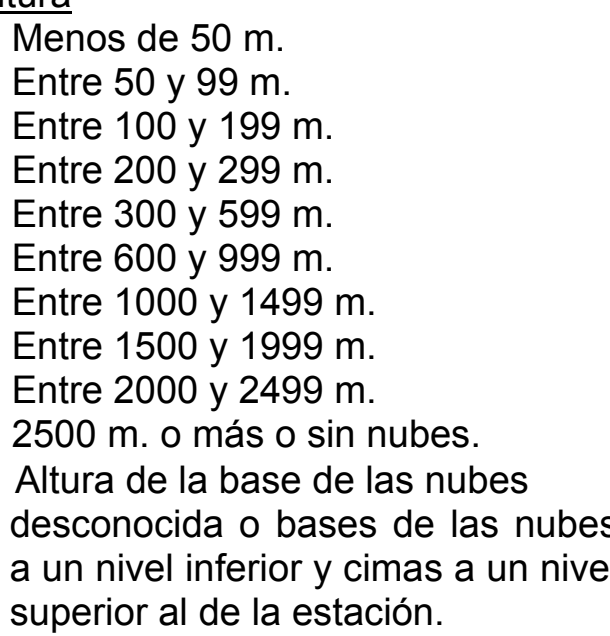$$
\text { superior al de la estación. }
$$

Nddff

Grupo indicador de nubosidad total y viento N: Nubosidad total

Fracción de cielo cubierto de nubes expresado en octavas partes de bóveda celeste

\section{Cifrado Nubosidad}

Cielo completamente despejado

$1 / 8$ de cielo cubierto

$2 / 8$ de cielo cubierto

$3 / 8$ de cielo cubierto

$4 / 8$ de cielo cubierto

$5 / 8$ de cielo cubierto

$6 / 8$ de cielo cubierto

$7 / 8$ de cielo cubierto

Cielo completamente cubierto

nubosidad porque el cielo esta oculto

por niebla, ventisca, etc.

\section{$08 \mathrm{iii}$}

$21 \mathrm{~h} / /$

\section{CLAVE NIVOMET (I)}

\section{$41 \mathrm{~h} / /$}

\section{Nddff $1 S_{n}$ TTT 29UUU 7wwW $W_{2} 8 N_{h} C_{L} C_{M} C_{H} 9 G G g g$}

dd: Dirección de donde viene el viento, en decenas de grado

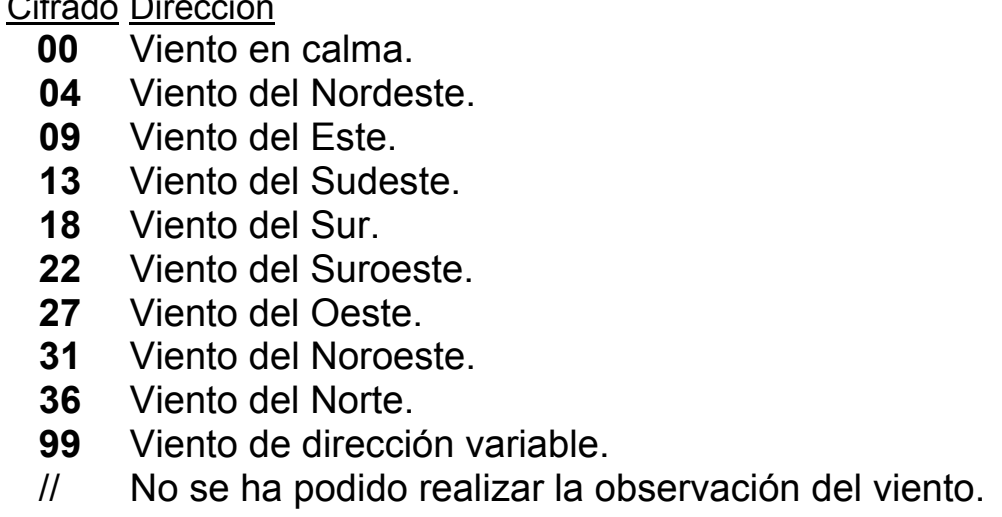

$7 w w W_{1} W_{2}$

Grupo indicador del tiempo presente y pasado en la estación

7: Indice fijo indicador del grupo

ww: Tiempo presente en el momento de la observación

\section{Cifrado Fenómeno(s) observados}

No se da en la estación ninguno de los fenómenos

Niebla

siguientes: niebla, lluvia, nieve o tormenta

44 Niebla y cielo visible

45 Niebla y cielo invisible

48 Niebla depositando cencellada y cielo visible

49 Niebla depositando cencellada y cielo invisible

Lluvia

16 Se ve llover pero no llueve en la estación

60 Lluvia intermitente

61 Lluvia débil continua (sin interrupción desde el

61 comienzo)

63 Lluvia moderada

65 Lluvia fuerte

67 Lluvia engelante (que se congela al tocar el suelo)

69 Lluvia y nieve mezcladas

81 Chubascos de lluvia

16 Nieva a la vista, pero no en la estación

36 Ventisca en la estación

70 Nevada débil, intermitente

71 Nevada débil continua (sin interrupción desde e

71 comienzo)

73 Nevada moderada

84 Chubasco(s) de aguanieve

86 Chubasco(s) de nieve

88 Chubasco(s) de granizo o nieve granulada

14 Las ramas gruesas se agitan, se hace difícil usa Las ramas

20 Cuesta andar contra el viento. El viento rompe algunas ramas.

30 Temporal, daños importantes.

$1 S_{\mathrm{n}} \mathrm{TT}$

Grupo indicador de la temperatura del aire en la garita 1: índice fijo indicador del grupo

Sn: Signo de la temperatura

$\frac{\text { Cifrado }}{\mathbf{0}} \quad \frac{\text { Temperatura }}{\text { Positiva o caro }}$

$1 \quad$ Negativa

TTT: Temperatura del aire expresada en décimas de

29UUU

Grupo indicador de la humedad relativa del aire 29: Índice fijo indicador de grupo

UUU: Humedad relativa del aire expresada en $\%$
17 Truenos sin precipitación en la estación

95 Tormenta con lluvia o nieve en la estación

96 Tormenta con cellisca o granizada en la estación

$\mathbf{W}_{1} \mathbf{W}_{\mathbf{2}}$

Tiempo pasado, fenómenos que hayan ocurrido desde la última observación.

Cifrado Fenómenos observados

Ningún fenómeno significativo

\section{Ventisca}

Niebla

Lluvia, llovizna, etc. (Precipitación en forma líquida)

Nieve, granizo, etc. (Precipitación en forma sólida)

Tormenta

No se ha podido realizar la observación de tiempo pasado

Las cifras de la clave de tiempo pasado deben describir lo mejor posible las condiciones meteorológicas habidas antes de la observación. Si hubo dos fenómenos desde la última observación:

$$
\mathbf{W}_{1} \text { es la cifra más alta de las dos }
$$

$\mathbf{W}_{2}$ es la cifra más baja

Si hubo un solo fenómeno significativo Se cifra dos veces el mismo número de la clave: $w_{1}=w_{2}$
$8 \mathrm{~N}_{\mathrm{h}} \mathrm{C}_{\mathrm{L}} \mathrm{C}_{\mathrm{M}} \mathrm{C}_{\mathrm{H}}$

Grupo indicador de la nubosidad

8: Índice fijo indicador del grupo

$\mathbf{N}_{h}$ : Nubosidad de la capa más baja de nubes bajas o medias

Se cifra en octavos de bóveda celeste y siemp hace referencia al nivel superior a la estación

Cifrado Nubosidad

$0 \quad$ Ninguna nube de tipo bajo o medio

Fracción del cielo cubierto en octavos

9 Cielo invisible por niebla o ventisca

$C_{L}$ : Nubes bajas

Cifrado Tipo de nubes

$0 \quad$ Sin nubes bajas

Cu (Cúmulos)

Sc (Estratocúmulos)

St (Estratos)

$\mathrm{Cb}$ (Cumulonimbos)

Estación con niebla - Cielo invisible

\section{$\mathrm{C}_{\mathrm{M}}$ : Nubes medias}

Cifrado Tipo de nubes

0 Sin nubes medias

As (Altoestratos)

Ns (Nimboestratos)

Ac (Altocúmulos)

Ac lenticulares

Ac y As o dos capas de Ac a

diferentes alturas

Nubes medias no visibles

\section{$\mathrm{C}_{\mathrm{H}}$ : Nubes altas}

Cifrado Tipo de nubes

\section{Sin nubes altas}

Ci (Cirros)

Cs (Cirrostratos)

Cc (Cirrocúmulos)

Nubes altas no visibles

9GGgg

Hora real de la observación

9: Índice fijo indicador de grupo

GGgg: Hora real UTC de la observación en horas (GG) y minutos (gg) 


\section{AEMet \\ CLAVE NIVOMET (II) \\ 333 (1 $\left.\mathrm{S}_{n} T_{x} T_{x} T_{x} 2 S_{n} T_{n} T_{n} T_{n}\right)$ 4/sss (7R $\left.R_{24} R_{24} R_{24} R_{24}\right)$ 907tt 931s's' \\ $5557 I_{z} Z_{x} Z_{x} Z_{x} 8 I_{t} d_{t} q_{t} q_{t} 1 S_{n} T_{s} T_{s} T_{s} E^{\prime}{ }_{n} P_{s} P_{s} N_{v} C_{n} L^{\prime}{ }_{1} L^{\prime}{ }_{2} L^{\prime}{ }_{3} L^{\prime}{ }_{4} L^{\prime}{ }_{5} L_{6} L_{7} L_{8} L_{9} L_{5}$ (2ddff ssss's') (4F $\left.F_{1} F_{2} e_{c} e_{c}\right)\left(5 I M_{v} M_{v} M_{v}\right)$}

333

Grupo fijo y obligatorio indicador de la sección 3 del parte NIVOMET

$1 S_{n} T_{x} T_{x} T_{x}$

Temperatura máxima transmitida sólo en la observación de las 08 UTC

1: Índice fijo indicador del grupo

$\mathbf{S}_{\mathrm{n}}$ : Signo de la temperatura

Cifrado Temperatura

0 Positiva o cero

1 Negativa

$\mathbf{T}_{\mathrm{x}} \mathbf{T}_{\mathbf{x}} \mathbf{T}_{\mathrm{x}}$ : Temperatura máxima en décimas de grado centígrado

$2 S_{n} T_{n} T_{n} T_{n}$

Temperatura mínima, transmitida sólo en la observación de las 08UTC

2: Índice fijo indicador del grupo

$\mathbf{S}_{\mathrm{n}}$ : Signo de la temperatura

$\frac{\text { Cifrado }}{0} \quad \frac{T \text { Temperatura }}{\text { Positiva o cero }}$

$$
\begin{array}{lll}
0 & \text { Positiva o } \\
1 & \text { Negativa }
\end{array}
$$

$T_{n} T_{n} T_{n}$ : Temperatura minima en décimas de grado centígrado 4/sss

Grupo indicador del espesor total de nieve

sss: Espesor total de la nieve en centímetros leído en el jalón nivométrico.

$\mathbf{7 R}_{\mathbf{2 4}} \mathbf{R}_{\mathbf{2 4}} \mathbf{R}_{\mathbf{2 4}} \mathbf{R}_{\mathbf{2 4}}$

Grupo de cantidad de precipitación recogida en las $24 \mathrm{~h}$. anteriores

a la observación.

7: Índice fijo indicador del grupo

$\mathbf{R}_{24} \mathbf{R}_{\mathbf{2}} \mathbf{R}_{\mathbf{2}} \mathbf{R}_{\mathbf{2}}$ Cantidad de precipitación recogida en las últimas $\mathbf{2 4}$ horas expresada en décimas de $\mathrm{mm}$.

Este grupo se debe consignar obligatoriamente en la observación de

la mañana (08 UTC) y se omite en la del mediodía (13 UTC)

907tt

Grupo de duración del periodo de referencia para la medida de la

nieve reciente

907: Índice fijo indicador del grupo

tt: Duración del periodo de referencia para la medida de la nieve reciente

Cifrado Significado

$\begin{array}{ll}\frac{68}{50} & \text { Periodo superior a } 18 \text { h. (Observación de las } 08 \text { UTC) } \\ \mathbf{5 0} & \text { Periodo igual a } 5 \text { h. (Observación de las } 13 \text { UTC) }\end{array}$

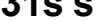

931: Índice fijo, indicador del grupo

s's': Espesor de la nieve reciente expresado en centímetros, leído sobre

el jalón de la placa de nieve reciente:

- En la observación de las 08 UTC es la altura en centímetros enteros de nieve caída en las últimas 24 horas.

- En la observación de las 13 UTC es la altura en centímetros enteros de nieve caída desde las 08 UTC hasta las 13 UTC. Si no hay espesor acumulado, $\mathbf{s}^{\prime} \mathbf{s}$ ' $=00$

$\mathrm{Si}$ el espesor esta comprendido entre 0 y $1 \mathrm{~cm}$., se cifra $\mathbf{s}^{\prime} \mathbf{s}^{\prime}=01$

$\mathrm{Si}$ el espesor es de un metro o más, se cifra s's' $=99$, y la altura total se consigna y transmite al final del parte NIVOMET en lenguaje claro.

Este grupo se consigna tanto en las observaciones de la mañana como de mediodía, aunque en la observación del mediodía se anota y se cifra la lectura pero no se limpia la placa de nieve reciente
555

Grupo fijo y obligatorio indicador de la sección 5 del parte NIVOMET

\section{$7 \mathrm{I}_{\mathrm{z}} \mathrm{Z}_{\mathrm{x}} \mathrm{Z}_{\mathrm{x}} \mathrm{Z}_{\mathrm{x}}$}

Altitud máxima alcanzada por el límite lluvia-nieve

7: Índice fijo indicador del grupo

$\mathrm{I}_{\mathbf{z}}$ : indicador de la altitud máxima del límite lluvia-nieve Cifrado Significado

0 La altitud máxima del limite lluvia-nieve es igual al valor $\mathbf{Z}_{\mathrm{x}} \mathbf{Z}_{\mathbf{x}} \mathbf{Z}_{\mathbf{x}}$

$1 \quad$ La altitud máxima del limite lluvia-nieve es superior al valor $\mathbf{Z}_{\mathbf{x}} \mathbf{Z}_{\mathbf{x}} \mathbf{Z}_{\mathbf{x}}$

La altitud máxima del limite lluvia-nieve es inferior al valor $\mathbf{Z}_{\mathbf{x}} \mathbf{Z}_{\mathbf{x}} \mathbf{Z}_{\mathbf{x}}$ Altitud del límite lluvia-nieve desconocido o sin precipitaciones

$\mathbf{Z}_{\mathrm{x}} \mathbf{Z}_{\mathrm{x}} \mathbf{Z}_{\mathrm{x}}$ : Altitud máxima en decámetros alcanzada por el límite lluvia-nieve desde la última observación

Si no ha habido precipitaciones: $Z_{x} Z_{x} Z_{x}=1 /$

\section{$8 I_{t} d_{t} q_{t} q_{t}$}

ransporte de nieve por el viento

8: Índice fijo indicador del grupo

$\mathrm{I}_{\mathrm{t}}$ : Indicador del tipo de sensor de medida del transporte de nieve

$\frac{\text { Cifrado }}{1} \quad \frac{\text { Tipo de captura }}{\text { Driftrómetro con bolsitas }}$

$2 \quad$ Flowcapt

$\mathbf{d}_{\mathrm{t}}$ : Dirección dominante del transporte en las últimas $24 \mathrm{~h}$ (la del viento).
Cifrado Dirección

$\frac{\text { Cifrado }}{0} \frac{\text { Dirección }}{\text { No hay tran }}$

1 Nordeste.

2 Este.

3 Sureste.

4 Sur.

$\mathbf{5}$ Suroeste.

$5 \quad$ Suroeste

Oeste.

Noroeste.

Norte.

: Cantidad de nieve transportada

Dirección descos

Si no se dispone de sensores de medida: $\mathrm{q}_{\mathrm{t}} \mathrm{q}_{\mathrm{t}}=/ /$

\section{$1 S_{n} T_{s} T_{s} T_{s}$}

Temperatura de la capa superficial de la nieve

1: Índice fijo, indicador de la temperatura

$\mathrm{S}_{\mathrm{n}}$ : Signo de la temperatura

Cifrado $\quad$ Temperatura

$\begin{array}{ll}0 & \text { Cero grados } \\ 1 & \text { Negativa }\end{array}$

$\mathbf{T}_{\mathbf{s}} \mathbf{T}_{\mathbf{s}} \mathbf{T}_{\mathbf{s}}$ : Temperatura de la nieve a $10 \mathrm{~cm}$. de la superficie Se mide en décimas de grado y no puede ser mayor de $0^{\circ} \mathrm{C}$
$E_{n}^{\prime} P_{s} P_{s} N_{v} C_{n}$

Estado de la nieve, nubes en el valle y ventisca en altitud

E'n: Estado de la nieve

$\frac{\text { Cifrado }}{0} \quad$ Estado de la nieve

Nieve reciente seca

1 Nieve reciente seca con escarcha de superficie

$2 \quad$ Nieve reciente húmeda

Nieve venteada que se hunde

Nieve venteada que no se hunde

Nieve vieja húmeda que se hunde (podrida)

Nieve vieja húmeda que no se hunde (sin costra)

Costra de rehielo que se hunde

Costra de rehielo que no se hunde.

Superficie lisa y helada.

No hay nieve o no se realiza la observación.

$\mathbf{P}_{\mathbf{s}} \mathbf{P}_{\mathbf{s}}$ : Hundimiento del primer tubo de la sonda de golpeo en $\mathrm{cm}$. El tubo de la sonda debe apoyarse verticalmente, sin presión, obre la capa de nieve.

Si el hundimiento es superior a $99 \mathrm{~cm}$., se cifra 99 y al final del parte NIVOMET se expresa en lenguaje claro la profundidad real del hundimiento.

En ausencia de nieve, este grupo se cifrara /l.

$\mathbf{N}_{\mathrm{v}}$ : Nubes en el valle

La base de las nubes está por debajo del nivel de la estación.

Cifra Cantidad de nubes

0 Sin nubes en el valle.

1 Nubes aisladas

3 Nubes aisladas

4 Mar de nubes parcial

5 Mar de nubes parcial

6 Mar de nubes parcial

7 Mar de nubes completo

8 Mar de nubes completo

Mar de nubes completo

Observación imposible

Altitud de la cima de las nubes

Inferior a 1000 metros. Entre 1000 y 1500 metros. Superior a 1500 metros. Inferior a 1000 metros. Entre 1000 y 1500 metros. Superior a 1500 metros. Inferior a 1000 metros. Entre 1000 y 1500 metros. Superior a 1500 metros.

Estación con niebla.

$\mathrm{C}_{\mathrm{n}}$ : Ventisca en altitud.

a dirección de la ventisca es la del viento que la produce. Cifrado Dirección y fuerza Cifrado Dirección y fuerza $\frac{\text { Cifrado }}{0} \frac{\text { Dirección y fuerza }}{\text { No hay ventisca en altitud. }} \frac{\text { Cifrado }}{5} \frac{\text { Dirección y fuerza }}{\text { Ventisca moderada de Norte. }}$

Ventisca en tiempo pasado 6 Ventisca fuerte del Este. pero no en el momento de $\quad \mathbf{7}$ Ventisca fuerte del Sur. de la observación

2 Ventisca moderada del Este 8 Ventisca fuerte del Oeste.

3 Ventisca moderada de Sur 9 Ventisca fuerte del Norte.

4 Ventisca moderada del Oeste / Observación imposible (nubes o niebla). 


\section{$5557 \mathrm{I}_{z} Z_{x} Z$}

$L^{\prime} L^{\prime}{ }_{2} L^{\prime}{ }_{3} L_{4}^{\prime} L^{\prime}{ }_{5}$

Grupo de aludes: Salidas espontáneas

$L^{\prime}$ : Número de aludes observados

Cifrado $\frac{\text { Características }}{0}$

Nada a destacar. Sin aludes. Sólo coladas superficiales

Un alud

Dos aludes observados

Tres aludes observados

Cinco aludes observados

De seis a diez aludes observados

De once a veinte aludes observados

De veintiún a treinta aludes observados

Más de treinta aludes observados

Desconocido (observación imposible)

$L^{\prime}$ : Tamaño de los aludes

Cifrado $\frac{\text { Características }}{0}$

Nada a destacar. Sin aludes. Sólo coladas superficiales Pequeños(s)

Sobre todo pequeños, rara vez (1 ó 2) medianos

Sobre todo medianos (no hay grandes)

Sobre todo pequeños y rara vez grandes

Sobre todo grandes

Por lo menos un alud grande con una trayectoria inusual

Se desconoce (observación imposible)

$\mathrm{L}^{\prime}{ }_{3}$ : Tipo de aludes

Cifrado Características

Nada a destacar. Ni aludes, ni coladas superficiales, ni grietas

Ningún alud, sólo grieta(s) en el manto nivoso

Alud(es) de nieve reciente seca, salida puntual

Alud(es) de placa friable (salida lineal, nieve seca, depósitos más bien finos)

bloques)

Alud(es) de superficie de nieve vieja húmeda o mojada

Alud(es) de fondo de nieve vieja húmeda o mojada (salida puntual o lineal) Se desconoce

$L_{4}$ : Altitud de la zona de salida de los aludes

Cifrado Altitud de salida del alud

Nada a destacar

Entre 1500 y $1750 \mathrm{~m}$

Entre 1750 y $2000 \mathrm{~m}$

Salida a diferentes altitudes, pero principalmente por debajo de $2000 \mathrm{~m}$ Entre 2000 y $2250 \mathrm{~m}$

Entre 2250 y $2500 \mathrm{~m}$

Entre 2500 y $3000 \mathrm{~m}$

Superior a $3000 \mathrm{~m}$

Salida a diferentes altitudes, pero principalmente por encima de $3000 \mathrm{~m}$ Se desconoce

$\mathrm{L}^{\prime}{ }_{5}$ Orientación de la zona de salida de los aludes Cifrado Orientación dominante Nordeste (NE) Este (E) Sudeste (SE) Sur (S)

\begin{tabular}{|c|c|}
\hline Cifrado & Orientación dominante \\
\hline & Oeste (W) \\
\hline 7 & $\begin{array}{l}\text { Noroeste (NW) } \\
\text { Norte (N) }\end{array}$ \\
\hline $\begin{array}{l}9 \\
1\end{array}$ & $\begin{array}{l}\text { Sin orientación dominant } \\
\text { Se desconoce }\end{array}$ \\
\hline
\end{tabular}

Suroeste (SW)
$\mathbf{L}_{6} \mathrm{~L}_{7} \mathrm{~L}_{8} \mathrm{~L}_{9} \mathrm{~L}_{5}$

Grupo de aludes: Desencadenamiento provocado

\section{$L_{6}$ : Tipos de desencadenamiento}

Cifrado Características

Nada a destacar. Ningún disparo, ningún alud

1 No hay alud (todos los disparos con resultados negativos)

Desencadenamiento artificial positivo (la mayoría de los disparos

Desencadenamiento attifial positivo (me

(mayoría de los disparos

(ningún disparo o disparos negativos)

Varios disparo positivo)

7 Varios desencadenamientos accidentales (al menos un disparo positivo) Desconocido (observación imposible)

$\mathrm{L}_{7}$ : Tipo de aludes (como $\mathrm{L}_{3}{ }_{3}$ )

Cifrado Caracteristicas

Nada a destacar. Ni aludes, ni coladas superficiales, ni grietas

Ningún alud, sólo grieta(s) en el manto nivoso

Coladas, secas o húmedas

Alud(es) de nieve reciente seca, salida puntual

Alud(es) de placa friable (salida lineal, nieve seca, depósitos más bien finos) Alud(es) de placa dura superficial (salida lineal, nieve seca, depósitos en bloques)

7 Alud(es) de superficie de nieve vieja húmeda o mojada

9 Alud(es) de fondo de nieve vieja húmeda o mojada (salida puntual o lineal) Se desconoce

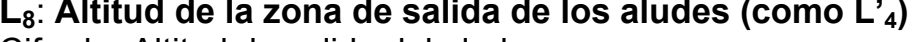

Cifrado Altitud de salida del alud

Nada a destacar

Inferior a $1500 \mathrm{~m}$

Entre 1500 y $1750 \mathrm{~m}$

Entre 1750 y $2000 \mathrm{~m}$

Salida a diferentes altitudes, pero principalmente por debajo de $2000 \mathrm{~m}$

Entre 2000 y $2250 \mathrm{~m}$

Entre 2500 y $3000 \mathrm{~m}$

Superior a $3000 \mathrm{~m}$

Salida a diferentes altitudes, pero principalmente por encima de $3000 \mathrm{~m}$

Se desconoce

$L_{9}$ : Orientación de la zona de salida de los aludes (como $L^{\prime}{ }_{5}$ )

Cifrado Orientación dominante

Nordeste (NE)

Este (E)

Sudeste (SE)

Suroeste (SW)

$L_{5}$ : Estimación del nivel de peligro local en la Escala Europea de Peligro de Aludes.

\begin{tabular}{c} 
Cifrado \\
\hline 1 \\
2 \\
3 \\
4 \\
5 \\
$/$
\end{tabular}

Notable

Fuerte.

Muy fuerte.

Mesconocido (2ddff)

Grupo de viento en altitud. Se cifra si la estación meteorológica está equipada con anemómetro a mayor altitud.

2: Indice fijo indicador del grupo

. Direcion de denten ex decenas de

ff: Velocidad del viento expresada en $\mathrm{m} / \mathrm{s}$. Se cifra como en el grupo Nddff.

(ssss's')

Grupo de datos de innivación en altitud. Se cifra si la estación dispone de jalón nivométrico y placa de nieve reciente a mayor altitud.

equipada de instrumentos en altitud. Si no es así ambos grupos se omiten.

ss: Espesor total $(\mathrm{en} \mathrm{cm})$ de la capa de nieve en el suelo en el lugar

me medida en altud.

enteros.

s's': Espesor, en centímetros, de la nieve reciente caída en altitud.

nieve caída en las últimas 24 horas.

- En la observación de las 13 UTC es la altura en centímetros enteros de nieve caída desde las 08 UTC hasta las 13 UTC.

Si no hay espesor acumulado, $\mathbf{s}^{\prime} \mathbf{s}^{\prime}=00$

$\mathrm{Si}$ el espesor esta comprendido entre 0 y $1 \mathrm{~cm}$., se cifra s's' = 01

Si el espesor es de un metro o más, se cifra s's' = 99, y la altura total se consigna y transmite al final del parte NIVOMET en lenguaje claro.

Este grupo se consigna tanto en las observaciones de la mañana como de mediodia, aunque en la observación del mediodía se anota y se cifra la lectura pero no se limpia la placa de nieve reciente

$\left(4 \mathrm{~F}_{1} \mathrm{~F}_{2} \mathbf{e}_{\mathrm{c}} \mathbf{e}_{\mathrm{c}}\right)$

Caracteristicas de los gránulos de la superficie y espesor del rehielo. 4: Índice fijo indicador de grupo.

$F_{1} F_{2}$ : Tipo de granos de nieve en superficie

$F_{1}$ : tipo de grano predominante en la superficie

$F_{2}$ : tipo de grano predominante entre la superficie y el nivel de $-10 \mathrm{~cm}$.

$\frac{\text { Cifrado }}{1(+)} \frac{\text { Tipo de grano }}{\text { Nieve reciente }} \quad \frac{\text { Cifrado }}{6(0)} \quad \frac{\text { Tipo de grano }}{\text { Granos redondos }}$

2 ( ()) Partículas reconocibles 7 (-) Costras

$3(\bullet)$ Granos finos 8 (v) Escarcha

4 (口) Granos de caras planas 9 ( $(*)$ Nieve granulad
$5(\wedge)$ Cubiletes

Desconocido

$e_{c} e_{c}$ : Espesor de la costra de rehielo en centímetros.

Espesor de la costra de rehielo en la superficie y, en su defecto, de la que se presente en los primeros $10 \mathrm{~cm}$. bajo la superficie.

Si no hay costra de rehielo: $\mathbf{e}_{c} \mathbf{e}_{c}=00$

Si se desconoce el espesor de la costra de rehielo: $\mathbf{e}_{c} \mathbf{e}_{\mathrm{c}}=\|$

Si el espesor de la costra de rehielo es inferior a $1 \mathrm{~cm}: \mathbf{e}_{c} \mathbf{e}_{c}=01$

$\left(5 I M_{v} M_{v} M_{v}\right)$

Homogeneidad y densidad de la nieve en superficie

5: Índice fijo indicador de grupo

I: Indicador de la homogeneidad de la capa

Cifrado $\quad$ Características de la capa

Ha nevado más de $5 \mathrm{~cm}$ desde la última observación. 政

No ha nevado, o ha nevado menos de $5 \mathrm{~cm}$, y la capa de $10 \mathrm{~cm}$ bajo la superficie es homogénea (un solo estrato). Toma de muestra

horizontal entre la superficie y el nivel a $10 \mathrm{~cm}$ de profundidad

No ha nevado, o ha nevado menos de $5 \mathrm{~cm}$, y la capa de $10 \mathrm{~cm}$ bajo la superficie está formada por varios estratos de naturaleza diferente. No se mide la densidad.

Limitado. 